\title{
EFFECT OF COOLING FLOW ON THE OPERATION OF A HOT ROTOR-GAS \\ FOIL BEARING SYSTEM
}

\author{
A Dissertation \\ by \\ KEUN RYU \\ Submitted to the Office of Graduate Studies of \\ Texas A\&M University \\ in partial fulfillment of the requirements for the degree of \\ DOCTOR OF PHILOSOPHY
}

December 2011

Major Subject: Mechanical Engineering 
Effect of Cooling Flow on the Operation of a Hot Rotor-Gas Foil Bearing System Copyright 2011 Keun Ryu 


\title{
EFFECT OF COOLING FLOW ON THE OPERATION OF A HOT ROTOR-GAS \\ FOIL BEARING SYSTEM
}

\author{
A Dissertation \\ by \\ KEUN RYU \\ Submitted to the Office of Graduate Studies of \\ Texas A\&M University \\ in partial fulfillment of the requirements for the degree of \\ DOCTOR OF PHILOSOPHY
}

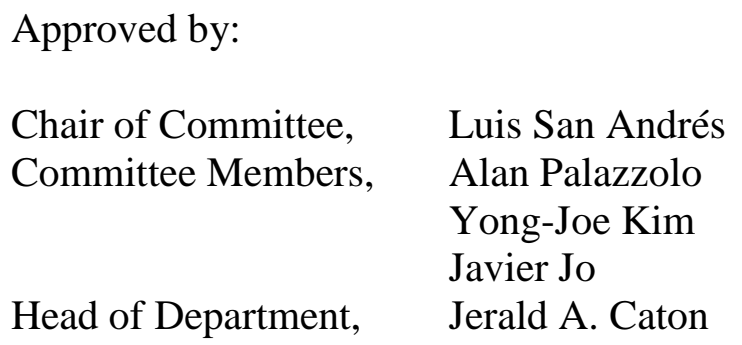

December 2011

Major Subject: Mechanical Engineering 


\author{
ABSTRACT \\ Effect of Cooling Flow on the Operation of a Hot Rotor-Gas Foil Bearing System. \\ (December 2011) \\ Keun Ryu, B.S., Hanyang University, Seoul, Korea; \\ M.S., Hanyang University, Seoul, Korea; \\ M.S., Texas A\&M University \\ Chair of Advisory Committee: Dr. Luis San Andrés
}

Gas foil bearings (GFBs) operating at high temperature rely on thermal management procedures that supply needed cooling flow streams to keep the bearing and rotor from overheating. Poor thermal management not only makes systems inefficient and costly to operate but could also cause bearing seizure and premature system destruction. To date, most of thermal management strategies rely on empirically based "make-and-break" techniques which are often inefficient.

This dissertation presents comprehensive measurements of bearing temperatures and shaft dynamics conducted on a hollow rotor supported on two first generation GFBs. The hollow rotor $(1.36 \mathrm{~kg}, 36.51 \mathrm{~mm}$ OD and $17.9 \mathrm{~mm}$ ID) is heated from inside to reach an outer surface temperature of $120^{\circ} \mathrm{C}$. Experiments are conducted with rotor speeds to $30 \mathrm{krpm}$ and with forced streams of air cooling the bearings and rotor. Air pressurization in an enclosure at the rotor mid span forces cooling air through the test GFBs. The cooling effect of the forced external flows is most distinct when the rotor is 
hottest and operating at the highest speed. The temperature drop per unit cooling flow rate significantly decreases as the cooling flow rate increases. Further measurements at thermal steady state conditions and at constant rotor speeds show that the cooling flows do not affect the amplitude and frequency contents of the rotor motions. Other tests while the rotor decelerates from $30 \mathrm{krpm}$ to rest show that the test system (rigid-mode) critical speeds and modal damping ratio remain nearly invariant for operation with increasing rotor temperatures and with increasing cooling flow rates. Computational model predictions reproduce with accuracy the test data. The work adds to the body of knowledge on GFB performance and operation and provides empirically derived guidance for successful integration of rotor-GFB systems. 


\section{DEDICATION}

This dissertation is dedicated

To my Lord and Savior Jesus Christ, who is rich in mercy and love

To my wife, Dong Yun Lee, for her love and prayers

To my daughters, Arin and (Faith)

To my father and mother, for their love, guidance, and support

To my brother, Hoon, for his love and encouragement

To my home country, Korea 


\section{ACKNOWLEDGEMENTS}

First and foremost, I would like to thank my Lord and Savior Jesus Christ through whom all things are sustained and held together. May He receive all the honor, all glory be His.

I do express my gratitude to my wife, Dong Yun Lee, who has been my advisor and helpmate, giving me two beautiful and lovely daughters.

I am forever indebted to a great many people - too many to mention - many have been mentors and many I have collaborated with.

I thank my advisor, Dr. Luis San Andrés, for giving me the opportunity to join

the Tribology group and pursue a doctorate degree at the TAMU Turbomachinery Laboratory and for providing the environment which made all of this work possible. His encouragement, advice, and guidance are gratefully appreciated. He treated me as his peer and valued my opinions, characteristics that made him invaluable as a mentor.

I thank my committee members, Dr. Alan Palazzolo, Dr. Yong-Joe Kim and Dr. Javier Jo, for their time and effort in offering advice.

The support of NASA NRA on Subsonic Rotary Wing, SSRW2-1.3 Oil-Free Engine Technology (Foil Gas Bearing Modeling). Grant Cooperative Agreement NNX07P98A and the TAMU Turbomachinery Research Consortium are acknowledged. Thanks to the Korea Institute of Science and Technology (KIST) for donating the test foil bearings and rotor. 
I also acknowledge the many contributions of Dr. Tae Ho Kim (currently at KIST) to the success of the TAMU foil bearing project. He was invaluable throughout my time as a graduate student at KIST and TAMU as both my colleague and my mentor.

Thanks to my former fellow lab-mates and colleagues at TAMU Turbolab: Dr. Adolfo Delgado, Thomas Chirathadam, Ash Maruyama, Anthony Breedlove, Sanjeev Seshagiri, Paola Mahecha, Zach Ashton, Arian Vistamehr, Yaying Niu, Jose Baker, Chad Jarrett, Jared Goldsmith, Katherine Janica, Chris Kulhanek, Manish Thorat, and Jason Wilkes, for their friendship and support over the last few years. I also would like to thank Mr. Eddie Denk for his assistance.

I also thank Dr. Yong-Bok Lee and Dr. Chang-Ho Kim, former advisors at KIST, and Prof. Gunhee Jang, former advisor at Hanyang University, for their continuous mentorship and encouragement.

I thank Pastor Young-Sik An for his love and prayers.

Thanks also go to TAMU Judo team members, in particular, Coach Bob Perez, Daniel Gomez, and Dr. Jean-Francois Chamberland.

Finally, I thank my parents and brother, Hoon, for their continuous and unconditional support and love throughout my entire life. 


\section{NOMENCLATURE}

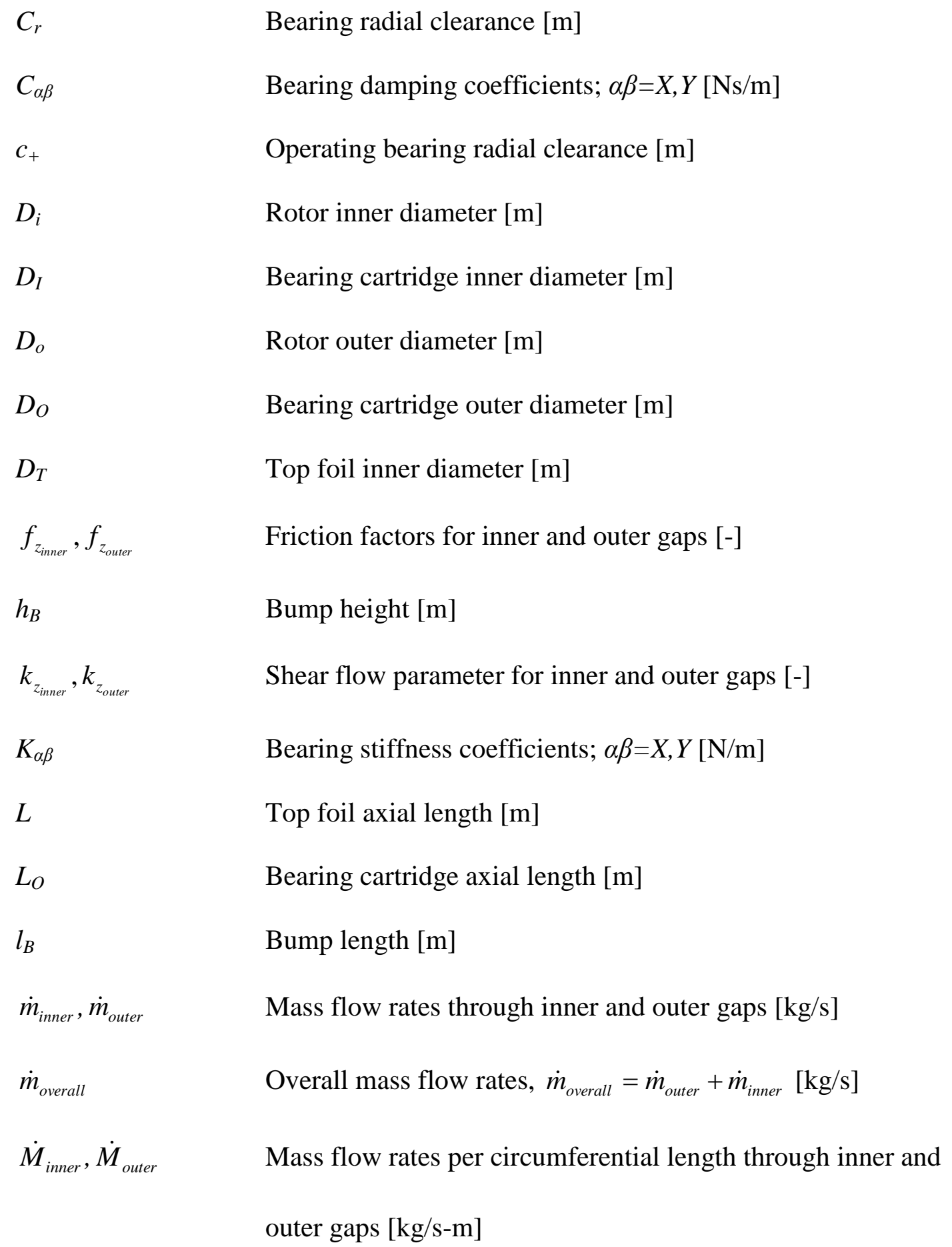




\begin{tabular}{|c|c|}
\hline$N_{B}$ & Number of Bumps [-] \\
\hline$P$ & Gas film pressure $\left[\mathrm{N} / \mathrm{m}^{2}\right]$ \\
\hline$P_{a}$ & Ambient pressure $\left[\mathrm{N} / \mathrm{m}^{2}\right]$ \\
\hline$P_{C o}$ & Outer cooling gas stream entrance pressure $\left[\mathrm{N} / \mathrm{m}^{2}\right]$ \\
\hline$P_{\text {ent }}$ & Entrance gas pressure $\left[\mathrm{N} / \mathrm{m}^{2}\right]$ \\
\hline$P_{\text {exit }}$ & Exit gas pressure $\left[\mathrm{N} / \mathrm{m}^{2}\right]$ \\
\hline$P_{S}$ & Supply gas pressure $\left[\mathrm{N} / \mathrm{m}^{2}\right]$ \\
\hline$Q$ & Volume flow rate $\left[\mathrm{m}^{3} / \mathrm{s}\right]$ \\
\hline$r_{B}$ & Bump arc radius $[\mathrm{m}]$ \\
\hline$R_{c}$ & Ideal gas constant $[\mathrm{J} / \mathrm{kg}-\mathrm{K}]$ \\
\hline $\operatorname{Re}_{a_{\text {inner }}}, \operatorname{Re}_{a_{\text {inner }}}$ & Axial flow Reynolds numbers for inner and outer gaps [-] \\
\hline $\operatorname{Re}_{c_{e n t}}, \operatorname{Re}_{c_{e x i t}}$ & Circumferential flow Reynolds number at entrance and exit \\
\hline & planes [-] \\
\hline$R_{I}$ & Rotor inner diameter $[\mathrm{m}]$ \\
\hline$R_{O}$ & Rotor outer diameter $[\mathrm{m}]$ \\
\hline$s_{0}$ & Bump pitch [degree] \\
\hline$t$ & Time $[\mathrm{s}]$ \\
\hline$T$ & Gas temperature $[\mathrm{K}]$ \\
\hline$T_{1}-T_{4}$ & Free end GFB cartridge outboard temperature $\left[{ }^{\circ} \mathrm{C}\right]$ \\
\hline$T_{5}$ & Free end bearing support housing surface temperature $\left[{ }^{\circ} \mathrm{C}\right]$ \\
\hline$T_{6}-T_{9}$ & Drive end GFB cartridge outboard temperature $\left[{ }^{\circ} \mathrm{C}\right]$ \\
\hline$T_{10}$ & Drive end bearing support housing surface temperature $\left[{ }^{\circ} \mathrm{C}\right]$ \\
\hline
\end{tabular}




\begin{tabular}{|c|c|}
\hline$T_{a m b}$ & Test rig ambient temperature $\left[{ }^{\circ} \mathrm{C}\right]$ \\
\hline$t_{B}$ & Bump foil thickness $[\mathrm{m}]$ \\
\hline$t_{B C}$ & Bearing cartridge wall thickness $[\mathrm{m}]$ \\
\hline$T_{C o}$ & Outer cooling gas stream entrance temperature $\left[{ }^{\circ} \mathrm{C}\right]$ \\
\hline$T_{e}$ & Air temperature inside housing enclosure $\left[{ }^{\circ} \mathrm{C}\right]$ \\
\hline$T_{F o}$ & Top foil back surface temperature $\left[{ }^{\circ} \mathrm{C}\right]$ \\
\hline$T_{h}$ & Cartridge heater temperature $\left[{ }^{\circ} \mathrm{C}\right]$ \\
\hline$T_{h s}$ & Heater reference temperature $\left[{ }^{\circ} \mathrm{C}\right]$ \\
\hline$T_{\text {out }}$ & Exhaust air temperature released into ambient air from FE bearing \\
\hline & {$\left[{ }^{\circ} \mathrm{C}\right]$} \\
\hline $\operatorname{Tr}_{D E}$ & Drive end rotor surface temperature $\left[{ }^{\circ} \mathrm{C}\right]$ \\
\hline $\operatorname{Tr}_{F E}$ & Free end rotor surface temperature $\left[{ }^{\circ} \mathrm{C}\right]$ \\
\hline$t_{T}$ & Top foil thickness $[\mathrm{m}]$ \\
\hline$U$ & Circumferential bulk flow velocity in inner gap [m/s] \\
\hline$u_{c}$ & Mean circumferential flow velocity $[\mathrm{m} / \mathrm{s}]$ \\
\hline$U_{\text {ent }}$ & Entrance circumferential bulk flow velocity in inner gap $[\mathrm{m} / \mathrm{s}]$ \\
\hline$W_{\text {inner }}$ & Axial bulk flow velocity in inner gap [m/s] \\
\hline$W_{\text {outer }}$ & Axial bulk flow velocity in outer gap $[\mathrm{m} / \mathrm{s}]$ \\
\hline$X, Y, Z$ & Inertial Cartesian coordinate system [m] \\
\hline$Z_{c}$ & Compressibility factor [-] \\
\hline$\alpha$ & Inlet flow pre-swirl factor [-] \\
\hline$\alpha_{B}$ & Bump arc angle [degree] \\
\hline
\end{tabular}


$\Omega$

Acronyms

DE

DH

DV

FE

$\mathrm{FH}$

FV

GFB

N.F.

TEHD
Damping ratio

Thermal inlet mixing coefficients

Gas viscosity $\left[\mathrm{Ns} / \mathrm{m}^{2}\right]$

Gas density $\left[\mathrm{kg} / \mathrm{m}^{3}\right]$

Circumferential wall shear stress function $\left[\mathrm{N} / \mathrm{m}^{2}\right]$

Axial wall shear stress function $\left[\mathrm{N} / \mathrm{m}^{2}\right]$

Circumferential coordinate [rad]

Rotor angular velocity [/s]

Drive end bearing

Drive end, horizontal direction

Drive end, vertical direction

Free end bearing

Free end, horizontal direction

Free end, vertical direction

Gas foil bearing

Natural frequency

Thermohydrodynamic 


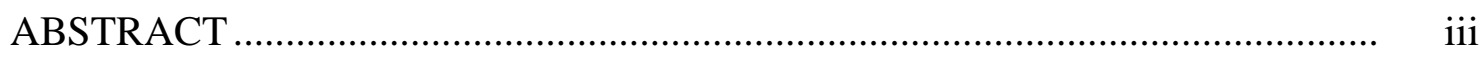

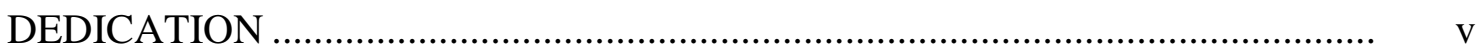

ACKNOWLEDGEMENTS ………....................................................... vi

NOMENCLATURE ........................................................................... viii

TABLE OF CONTENTS .......................................................................... xii

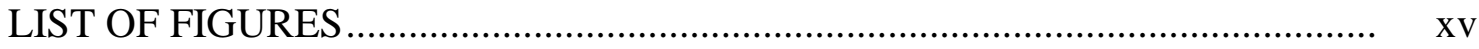

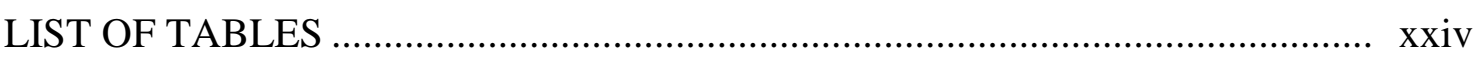

CHAPTER

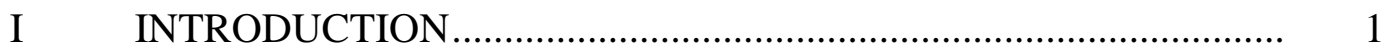

II LITERATURE REVIEW ........................................................

III DESCRIPTION OF TEST ROTOR-BEARING SYSTEM AND INSTRUMENTATION................................................................ 15

3.1 Test Rig .......................................................................... 15

3.2 Dimensions of Test Bearings and Estimation of Bearing Clearances $\quad$................................................................. 24

IV EXPERIMENTAL PROCEDURE ……............................................ 31

V EXPERIMENTAL RESULTS: TEMPERATURE

MEASUREMENTS …………………………………………..... 36

5.1 Temperature Rise of System Components versus Elapsed Time ….......................................................................... 36

5.2 Rotor Surface and Bearing Sleeve Temperatures versus Cooling Flow Rate 
5.3 Rotor and Bearing Sleeve Temperature Rises per Unit Cooling Flow Rate: Cooling Capability of Forced Axial Flow.....

5.4 Temperatures on Bearing Sleeves.....

VI EXPERIMENTAL RESULTS: ROTORDYNAMIC RESPONSE MEASUREMENTS

6.1 Fixed Rotor Speed Operation

6.2 Rotor Deceleration with Constant Speed Ramp Rate

VII PREDICTIONS OF BEARING TEMPERATURES AND

ROTORDYNAMIC RESPONSE AND COMPARISONS TO EXPERIMENTAL DATA

7.1 Prediction of Bearing Temperatures and Comparison to Test Data 73

7.2 Prediction of Rotor Imbalance Responses and Comparison to Test Data

VIII CONCLUSIONS AND RECOMMENDATIONS. 90

REFERENCES.

APPENDIX A MATERIAL PROPERTIES OF INCONEL 718, INCONEL X-750, AND AISI 4140.

APPENDIX B SPECIFICATIONS OF EQUIPMENT AND INSTRUMENTATION

APPENDIX C REPEATABILITY OF RECORDED TEMPERATURES: TEST CASES \#1 AND \#3

APPENDIX D ELECTRIC POWER DELIVERED TO CARTRIDGE HEATER: TEST CASE \#3

APPENDIX E TEMPERATURE RISES OF SYSTEM COMPONENTS

VERSUS ELAPSED TIME: TEST CASES \#1, \#2, \#4, AND \#5 . 109

APPENDIX F COMPLETE EXPERIMENTAL DATA 
APPENDIX G RECORDED COOLING FLOW RATE VERSUS SUPPLY AIR PRESSURE: TEST CASES \#1-\#6.

APPENDIX H TEMPERATURE RISE OF BEARING SLEEVE VERSUS TEMPERATURE RISE OF AIR INSIDE HOUSING ENCLOSURE: TEST CASES \#1AND \#4, \#3 AND \#6

APPENDIX I PREDICTION OF AXIAL AND CIRCUMFERENTIAL FLOW CONDITIONS FOR THE INNER AND OUTER COOLING STREAMS

APPENDIX J ROTORDYNAMIC RESPONSE DURING START-UP: COLD ROTOR CONDITION. TEST CASE \#7.

APPENDIX K NATURAL FREQUENCIES OF TEST ROTOR-BEARING SYSTEM

APPENDIX L ROTOR WHIRL ORBITS: TEST CASES \#7 AND \#9

APPENDIX M COMPLETE INPUT DATA FOR PREDICTION OF FOIL BEARING PERFORMANCE AND PREDICTED TEMPERATURES AND STATIC LOAD PARAMETERS

APPENDIX N PREDICTED TEMPERATURE FIELDS: TEST CASE \#5. $10 \mathrm{KRPM}$

APPENDIX O PREDICTED STIFFNESS AND DAMPING COEFFICIENTS: 


\section{LIST OF FIGURES}

FIGURE

Page

1 Photographs of bump-type 1st generation gas foil bearing for oil-free turbomachinery. Manufacturer: Korea Institute of Science and Technology (KIST).

2 Schematic view of thermocouple locations in a test foil bearing. Reproduced from [23]

3 Schematic views for three methods of foil bearing thermal management using forced cooling air. Taken from Ref. [23]

4 Schematic view of radial foil bearing and its housing in an oil-free turbocharger. Reproduced from [29]

5 Photographs of high temperature GFB rotordynamic test rig. $T_{1}-T_{10}$, $T_{h}, T_{\text {out }}$, and $T_{e}$ represent locations of temperature measurement. A bearing sleeve with an axial slot to route a thermocouple installed at the bearing mid-span also shown (oblique view).....

6 Schematic view (not to scale) for dimensions ( $\mathrm{mm}$ ) of test rotor, cartridge heater, bearing support housing air feed enclosure. Noted locations of thermocouples for feed enclosure air temperature $\left(T_{e}\right)$ and reference to control heater set temperature $\left(T_{h s}\right)$.

7 Cut view (not to scale) of section B-B in Fig. 6 of bearing support housing with dimensions of wall thickness around test bearing. Material of bearing support housing and bearing sleeve: AISI 4140

8 Distance-to-spot ratio of infrared thermometer [35]

9 Air feed enclosure at mid plane of bearing housing (cover removed for photograph) and locations of thermocouples $\left(T_{e}, T_{5}\right.$ and $\left.T_{10}\right) \ldots$

10 Location of thermocouple $T_{\text {out }}$ to record bearing exhaust air temperature....

11 Schematic view (not to scale) of cooling air supply system, instrumentation, and data acquisition system of high temperature gas foil bearing test rig. Flow path of force cooling air also shown. 
12 Zoomed photograph of test bearing to estimate its geometry.

13 Schematic view (not to scale) of test setup for static load and FB structural deflection test. Static load $45^{\circ}$ away from top foil trailing edge

14 Recorded foil bearing deflections (drive and free ends) versus static load for estimation of diametrical clearance

15 Identified FB structural stiffness versus bearing displacement. DE:

Drive end bearing, FE: Free end bearing .....

16 Identified FB structural stiffness versus static load. DE: Drive end bearing, FE: Free end bearing ....

17 Test case \#3. Heater set temperature at $150^{\circ} \mathrm{C}$. No rotor spinning: Recorded test system component temperature rises $\left(T_{i}-T_{a m b}\right.$; where $\left.i=r_{F E}, r_{D E, 1-10, \text { in, e, out }}\right)$ versus elapsed time. Axial cooling flow into bearings decreases from 420 to $0 \mathrm{~L} / \mathrm{min}$. Note different vertical scales ....

18 Test case \#6, Heater set temperature at $150^{\circ} \mathrm{C}$. Rotor speed of $10 \mathrm{krpm}$ : Recorded test system component temperature rises $\left(T_{i}-T_{a m b}\right.$; where $\left.i=r_{F E}, r_{D E, 1-10, \text { in, } e \text {, out }}\right)$ versus elapsed time. Axial cooling flow into bearings decreases from 420 to $0 \mathrm{~L} / \mathrm{min}$. Note different vertical scales ....

19 Test case \#2. $T_{h s}=100^{\circ} \mathrm{C}$. No rotor spinning: Surface plot of temperature rises at the rotor free end $\left(\operatorname{Tr}_{F E}-T_{a m b}\right)$, the free end bearing sleeve $\left(T_{1-4}-T_{a m b}\right)$ (arithmetic mean), the housing enclosure $\left(T_{e}-T_{a m b}\right)$, the drive end bearing sleeve $\left(T_{6-9}-T_{a m b}\right)$ (arithmetic mean), and the rotor drive end $\left(\operatorname{Tr}_{D E}-T_{a m b}\right)$ versus shaft axial location and versus cooling air flow rate ..

20 Test cases \#2 and \#5. $T_{h s}=100^{\circ} \mathrm{C}$ : Free end bearing temperature rise $\left(T_{1-4}-T_{a m b}\right)$ versus air temperature rise in the enclosure $\left(T_{e}-T_{a m b}\right)$. Arithmetic mean of $\left(T_{1}, T_{2}, T_{3}\right.$, and $\left.T_{4}\right)$ shown

21 Test cases \#2 and \#5. $T_{h s}=100^{\circ} \mathrm{C}$ : Drive end bearing temperature rise $\left(T_{6-9}-T_{a m b}\right)$ versus air temperature rise in the enclosure $\left(T_{e}-T_{a m b}\right)$. Arithmetic mean of $\left(T_{6}, T_{7}, T_{8}\right.$, and $\left.T_{9}\right)$ shown 
22 Test cases \#1-\#6, Heater set temperature $=65,100$, and $150^{\circ} \mathrm{C}$. No rotor spinning and rotor speed of 10, 20, and $30 \mathrm{krpm}$ : Recorded temperature difference of bearing sleeve OD above inlet cooling air temperature $\left(T_{1-4}-T_{e}\right)$ and $\left(T_{6-9}-T_{e}\right)$ versus cooling flow rate

23 Test cases \#1-\#6. Heater set temperature $=65,100$, and $150^{\circ} \mathrm{C}$. No rotor spinning and rotor speed of 10, 20, and $30 \mathrm{krpm}$ : Recorded temperature rise on bearing sleeve ODs, $\left(T_{1-4}-T_{a m b}\right)$ and $\left(T_{6-9}-T_{a m b}\right)$ per unit cooling flow rate $(\mathrm{L} / \mathrm{min})$ versus cooling flow rate.

24 Test cases \#1-\#6. Heater set temperature $=65,100$, and $150^{\circ} \mathrm{C}$. No rotor spinning and rotor speed of 10, 20, and $30 \mathrm{krpm}$ : Rotor OD temperature rise, $\left(\operatorname{Tr}_{F E^{-}} T_{a m b}\right)$ and $\left(\operatorname{Tr}_{D E^{-}} T_{a m b}\right)$ per unit cooling flow rate $(\mathrm{L} / \mathrm{min})$ versus cooling flow rate. Note different scales of vertical axes

25 Test cases \#1-\#3. No rotor spinning: Standard deviation of FE and DE bearing temperature rise versus elapsed time. $T_{1} \sim T_{4}$ : Standard deviation of FE bearing temperatures, $T_{6} \sim T_{9}$ : Standard deviation of DE bearing temperatures

26 Test cases \#4-\#6. Rotor speed of 10, 20, and $30 \mathrm{krpm}$ : Standard deviation of FE and DE bearing temperature rise versus elapsed time. $T_{1} \sim T_{4}$ : Standard deviation of FE bearing temperatures, $T_{6} \sim T_{9}$ : Standard deviation of DE bearing temperatures

27 Test case \#4: FFTs of rotor responses at rotor drive end, vertical (DV) and horizontal (DH) planes, and rotor free end, vertical (FV) and horizontal $(\mathrm{FH})$ planes. Rotor speed $=10,20$ and $30 \mathrm{krpm}$. Cooling flow into bearings from $\sim 350 \mathrm{~L} / \mathrm{min}$ to $\sim 50 \mathrm{~L} / \mathrm{min}$ for each set rotor speed. Heater set temperature $T_{h s}=65^{\circ} \mathrm{C}$

28 Test case \#4. Rotor orbits at drive end. Heater set temperature $T_{h s}=$ $65^{\circ} \mathrm{C}$. Cooling flow into bearings $\sim 350 \mathrm{~L} / \mathrm{min}$. Rotor speed set at 10 , 20, and $30 \mathrm{krpm}$. No slow roll compensation

29 Test case \#4. Rotor orbits at free end. Heater set temperature $T_{h s}=65^{\circ} \mathrm{C}$. Cooling flow into bearings $\sim 350 \mathrm{~L} / \mathrm{min}$. Rotor speed set at 10, 20, and $30 \mathrm{krpm}$. Note different scale between (a) and (b). No slow roll compensation. Note different scale for (b). 
30 Test case \#6: FFTs of rotor responses at rotor drive end vertical (DV) and horizontal (DH) planes, and rotor free end vertical (FV) and horizontal $(\mathrm{FH})$ planes. Rotor speed $=10 \mathrm{krpm}$. Cooling flow into bearings from $\sim 350 \mathrm{~L} / \mathrm{min}$ to $\sim 50 \mathrm{~L} / \mathrm{min}$. Heater set temperature $T_{h s}=150^{\circ} \mathrm{C}$

31 Test case \#6. Rotor orbits at free end. Heater set temperature $T_{h s}=150^{\circ} \mathrm{C}$. Cooling flow into bearings $\sim 350 \mathrm{~L} / \mathrm{min}$. rotor speed set at $10 \mathrm{krpm}$. No slow roll compensation

32 Test case \#7: Waterfalls of rotor motion during decelerating from $30 \mathrm{krpm}$ to rest Heater off, cooling flow rate $\sim 350 \mathrm{~L} / \mathrm{min}$, deceleration $=16.7 \mathrm{~Hz} / \mathrm{s}$. Rotor drive end, vertical (DV) and horizontal (DH) planes and rotor free end, vertical $(\mathrm{FV})$ and horizontal $(\mathrm{FH})$ planes

33 Test case \#9. $T_{h s}=100^{\circ} \mathrm{C}$ : Waterfalls of rotor motion during decelerating from $30 \mathrm{krpm}$ to rest Heater off, cooling flow rate $\sim 350 \mathrm{~L} / \mathrm{min}$, deceleration= $16.7 \mathrm{~Hz} / \mathrm{s}$. Rotor drive end, vertical (DV) and horizontal (DH) planes and rotor free end, vertical (FV) and horizontal $(\mathrm{FH})$ planes

34 Test cases \#7-\#9: Rotor amplitudes of synchronous response. Slow roll compensation at $2 \mathrm{krpm}$. Cooling flow rate $\sim 350 \mathrm{~L} / \mathrm{min}$

35 Test cases \#7-\#9: Rotor amplitude of $2 X$ (twice synchronous) response. Slow roll compensation at $2 \mathrm{krpm}$. Cooling flow rate $\sim 350 \mathrm{~L} / \mathrm{min}$

36 Test cases \#7 and \#9: Speed down from $30 \mathrm{krpm}$ to rest with ramp rate of $16.7 \mathrm{~Hz} / \mathrm{s}$. Phase differences of recorded imbalance response versus rotor speed. Cooling flow rate $\sim 350 \mathrm{~L} / \mathrm{min}$

37 Test cases \#7 and \#9: Speed down from $30 \mathrm{krpm}$ to rest with ramp rate of $16.7 \mathrm{~Hz} / \mathrm{s}$. Amplitude ratio of recorded imbalance response versus rotor speed. Cooling flow rate $\sim 350 \mathrm{~L} / \mathrm{min}$

38 Schematic side view of foil bearing with heat source warming hollow rotor and outer cooling stream $\left(T_{C o}, P_{C o}\right)$ flowing through thin film region and underneath top foil. Outer cooling flow exits to ambient pressure $\left(P_{a}\right)$. Taken from [46] 
39 Nomenclature for temperatures in a foil bearing operating with a hot rotor and an outer cooling gas stream. Schematic representation of heat flows shown. Taken from [46].

40 Prediction versus test data: Temperatures of bearing sleeves (free and drive ends) versus cooling flow rate. See Appendix $\mathrm{M}$ for complete inputs for prediction.

41 Prediction: Test case \#5. Thin film temperature fields in GFBs. $T_{h s}=100^{\circ} \mathrm{C}$, rotor speed at $30 \mathrm{krpm}$. Cooling flow rate per each bearing $175 \mathrm{~L} / \mathrm{min}$. Thermal mixing coefficient $\lambda=0.65$.

42 Prediction: Test case \#5. Thin film temperature fields in GFBs. $T_{h s}=100^{\circ} \mathrm{C}$, rotor speed at $30 \mathrm{krpm}$. Cooling flow rate per each bearing $25 \mathrm{~L} / \mathrm{min}$. Thermal mixing coefficient $\lambda=0.65$.

43 Prediction: $T_{h s}=100^{\circ} \mathrm{C}$. Drive end and free end foil bearing direct and cross-coupled stiffness versus rotor speed and increasing air cooling flow rates.

44 Prediction: $T_{h s}=100^{\circ} \mathrm{C}$. Drive end and free end foil bearing direct and cross-coupled damping coefficients versus rotor speed and increasing air cooling flow rates

45 Finite element model of test rotor supported on GFBs. Connecting rod and flexible coupling locate at drive end.

46 Predicted damped natural frequency map of test rotor-GFB system. Mode shapes denoted. Test cases $\# 5$ and $\# 9\left(T_{h s}=100^{\circ} \mathrm{C}\right)$.

47 Predicted damping ratio of test rotor-GFB system. Test cases \#5 and \#9 $\left(T_{h s}=100^{\circ} \mathrm{C}\right)$

48 Comparison of predicted and measured imbalance responses of test rotor supported on foil bearings. Estimated mass imbalance distribution noted.

A.1 Elastic modulus versus material temperature for Inconel 718, Inconel X750, and AISI4140. Taken from [49-52].

A.2 Thermal conductivity versus material temperature for Inconel 718, Inconel X750, and AISI4140. Taken from [49-52]. 
A.3 Thermal expansion coefficient versus material temperature for Inconel 718, Inconel X750, and AISI4140. Taken from [49-52]....

C.1 Test case \#1. $T_{h s}=65^{\circ} \mathrm{C}$. No rotor spinning: Recorded test system component temperature rises $\left(T_{i}-T_{a m b}\right.$; where $\left.{ }_{i=(a)} r_{F E \text { and 1, (b) }} r_{D E \text { and } e}\right)$ versus cooling flow rate.

C.2 Test case \#3. $T_{h s}=150^{\circ} \mathrm{C}$. No rotor spinning: Recorded test system component temperature rises $\left(T_{i}-T_{a m b}\right.$; where ${ }_{i=(\text { a) }} r_{F E \text { and 1, (b) }} r_{D E}$ and $\left.e\right)$ versus cooling flow rate

D.1 Schematic circuit diagram measuring voltage and current feeding the electrical heater.

D.2 Test case \#3. $T_{h s}=150^{\circ} \mathrm{C}$. No rotor spinning: Recorded (a) voltage and (b) current of the heater circuit versus cooling flow rate

D.3 Test case \#3. $T_{h s}=150^{\circ} \mathrm{C}$. No rotor spinning: Measured electric power of the cartridge heater versus cooling flow rate.

E.1 Test case \#1. Heater set temperature at $65^{\circ} \mathrm{C}$. No rotor spinning: Recorded test system components temperature rise $\left(T_{i}-T_{a m b}\right)_{i}=r_{F E}, r_{D E, 1-10, \text { in, } e \text {, out }}$ versus elapsed time. Axial cooling flow into bearings decreases from 420 to $0 \mathrm{~L} / \mathrm{min}$. Note different vertical scales)

E.2 Test case \#2. Heater set temperature at $100^{\circ} \mathrm{C}$. No rotor spinning: Recorded test system components temperature rise $\left(T_{i}-T_{a m b}\right)_{i=} r_{F E}, r_{D E, 1-10, \text { in, } e \text {, out }}$ versus elapsed time. Axial cooling flow into bearings decreases from 420 to $0 \mathrm{~L} / \mathrm{min}$. Note different vertical scales

E.3 Test case \#4, Heater set temperature at $65^{\circ} \mathrm{C}$. Rotor speed of 10,20 , and $30 \mathrm{krpm}$ : Recorded test system components temperature rise $\left(T_{i}-T_{a m b}\right)_{i}=r_{F E}, r_{D E, 1-10, \text { in, } e \text {, out }}$ versus elapsed time. Axial cooling flow into bearings decreases from 420 to $50 \mathrm{~L} / \mathrm{min}$. Note different vertical scales. 
E.4 Test case \#5, Heater set temperature at $100^{\circ} \mathrm{C}$. Rotor speed of 10, 20, and $30 \mathrm{krpm}$ : Recorded test system components temperature rise $\left(T_{i}-T_{a m b}\right)_{i=} r_{F E}, r_{D E, 1-10, \text { in, } e \text {, out }}$ versus elapsed time. Axial cooling flow into bearings decreases from 420 to $50 \mathrm{~L} / \mathrm{min}$. Note different vertical scales

G.1 Test cases \#1-\#6: recorded cooling flow rate versus supply air pressure .

H.1 Test cases \#1 and \#4. $T_{h s}=65^{\circ} \mathrm{C}$ : Free end bearing temperature rise $\left(T_{1-4}-T_{a m b}\right)$ versus air temperature rise in the feed enclosure $\left(T_{e}-T_{a m b}\right)$. Arithmetic mean of $\left(T_{1}, T_{2}, T_{3}\right.$, and $\left.T_{4}\right)$ shown .

H.2 Test cases \#1 and \#4. $T_{h s}=65^{\circ} \mathrm{C}$ : Drive end bearing temperature rise $\left(T_{6-9}-T_{a m b}\right)$ versus air temperature rise in the feed enclosure $\left(T_{e}-T_{a m b}\right)$. Arithmetic mean of $\left(T_{6}, T_{7}, T_{8}\right.$, and $\left.T_{9}\right)$ shown.

H.3 Test cases \#3 and \#6. $T_{h s}=150^{\circ} \mathrm{C}$ : Free end bearing temperature rise $\left(T_{1-4}-T_{a m b}\right)$ versus air temperature rise in the feed enclosure $\left(T_{e}-T_{a m b}\right)$. Arithmetic mean of $\left(T_{1}, T_{2}, T_{3}\right.$, and $\left.T_{4}\right)$ shown

H.4 Test cases \#3 and \#6. $T_{h s}=150^{\circ} \mathrm{C}$ : Drive end bearing temperature rise $\left(T_{6-9}-T_{a m b}\right)$ versus air temperature rise in the feed enclosure $\left(T_{e}-T_{a m b}\right)$. Arithmetic mean of $\left(T_{6}, T_{7}, T_{8}\right.$, and $\left.T_{9}\right)$ shown.

I.1 Schematic view (not to scale) of axial flows induced by forced cooling flow in the test foil bearing system

I.2 Test cases \#5. Heater set temperature $T_{h s}=100^{\circ} \mathrm{C}$. Rotor speed of 10, 20, and $30 \mathrm{krpm}$ : Shear factor of outer gap flow versus cooling flow rate. FE: Free end bearing, DE: Drive end bearing..

I.3 Test cases \#5. Heater set temperature $T_{h s}=100^{\circ} \mathrm{C}$. Rotor speed of 10, 20, and $30 \mathrm{krpm}$ : Dimensionless pressure (entrance pressure $P_{\text {ent }}$ over ambient pressure $P_{a}$ ) versus cooling flow rate. FE: Free end bearing, DE: Drive end bearing.

I.4 Test case \#5. Heater set temperature $T_{h s}=100^{\circ} \mathrm{C}$. Rotor speed of $30 \mathrm{krpm}$. Free end bearing: Dimensionless axial pressure distribution within outer gap versus cooling flow rate. $P_{\text {exit }}=P_{a}$ 
I.5 Test cases \#5. Heater set temperature $T_{h s}=100^{\circ} \mathrm{C}$. Rotor speed of 10 , 20, and $30 \mathrm{krpm}$ : Mass flow rate though outer gap over mass flow rate through inner gap versus cooling flow rate. $\left(c_{+} / h_{B}\right)^{3}$ also shown. FE: Free end bearing, DE: Drive end bearing.

I.6 Test cases \#5. Heater set temperature $T_{h s}=100^{\circ} \mathrm{C}$. Rotor speed of 10 , 20, and $30 \mathrm{krpm}$ : Axial flow Reynolds numbers of (a) inner and (b) outer cooling streams versus cooling flow rate. Note different vertical scale.

I.7 Test cases \#5. Heater set temperature $T_{h s}=100^{\circ} \mathrm{C}$. Rotor speed of 10, 20, and $30 \mathrm{krpm}$ : Circumferential flow Reynolds number for thin film gas region at the bearing exit plane $\left(P=P_{a}\right)$ versus cooling flow rate. FE: Free end bearing, DE: Drive end bearing

I.8 Test case \#5. Heater set temperature $T_{h s}=100^{\circ} \mathrm{C}$. Rotor speed of $30 \mathrm{krpm}$. Free end bearing: Dimensionless circumferential mean flow velocity versus dimensionless bearing axial length within bearing inner thin film region.

J.1 Test case \#7: Waterfalls of rotor motion during accelerating from rest to $30 \mathrm{krpm}$. Heater off, set cooling flow rate $350 \mathrm{~L} / \mathrm{min}$, acceleration= 16.7 Hz/s. Rotor drive end, vertical (DV) and horizontal (DH) planes and rotor free end, vertical $(\mathrm{FV})$ and horizontal $(\mathrm{FH})$ planes

J.2 Test case \#7: Amplitude of rotor synchronous response versus rotor speed. Speed up from rest to $30 \mathrm{krpm}$ with ramp rate of $16.7 \mathrm{~Hz} / \mathrm{s}$ Slow roll compensation $4100 \mathrm{rpm}$

J.3 Test case \#7: Phase differences of recorded imbalance response. $T_{h s}=65^{\circ} \mathrm{C}$. Speed up from rest to $30 \mathrm{krpm}$ with ramp rate of $16.7 \mathrm{~Hz} / \mathrm{s}$ Cooling flow rate $350 \mathrm{~L} / \mathrm{min}$

J.4 Test case \#7: Amplitude ratio of recorded imbalance response. $T_{h s}=65^{\circ} \mathrm{C}$. Cooling flow rate $350 \mathrm{~L} / \mathrm{min}$.

K.1 Acceleration spectra at (a) flexible coupling, (b) connecting rod, (c) rotor drive and (d) free ends. Uncertainty in frequency $16 \mathrm{~Hz}$. No shaft rotation. Ambient temperature $22^{\circ} \mathrm{C}$ 
L.1 Test case \#7. Drive end rotor orbits. Heater off. Speed down from $30 \mathrm{krpm}$ to rest with ramp rate of $16.7 \mathrm{~Hz} / \mathrm{s}$. Cooling flow rate $\sim 350 \mathrm{~L} / \mathrm{min}$. No slow roll compensation. Note different scale

L.2 Test case \#7. Free end rotor orbits. Heater off. Speed down from $30 \mathrm{krpm}$ to rest with ramp rate of $16.7 \mathrm{~Hz} / \mathrm{s}$. Cooling flow rate $\sim 350 \mathrm{~L} / \mathrm{min}$. No slow roll compensation

L.3 Test case \#9. Drive end rotor orbits. $T_{h s}=100^{\circ} \mathrm{C}$. Speed down from $30 \mathrm{krpm}$ to rest with ramp rate of $16.7 \mathrm{~Hz} / \mathrm{s}$. Cooling flow rate $\sim 350 \mathrm{~L} / \mathrm{min}$. No slow roll compensation. Note different scale .

L.4 Test case \#9. Free end rotor orbits. $T_{h s}=100^{\circ} \mathrm{C}$. Speed down from $30 \mathrm{krpm}$ to rest with ramp rate of $16.7 \mathrm{~Hz} / \mathrm{s}$. Cooling flow rate $\sim 350 \mathrm{~L} / \mathrm{min}$. No slow roll compensation

N.1 Prediction: Test case \#5. Thin film temperature fields in GFBs. $T_{h s}=100^{\circ} \mathrm{C}$, rotor speed at $10 \mathrm{krpm}$. Cooling flow rate per each bearing $175 \mathrm{~L} / \mathrm{min}$. Thermal mixing coefficient $\lambda=0.65$

N.2 Prediction: Test case \#5. Thin film temperature fields in GFBs. $T_{h s}=100^{\circ} \mathrm{C}$, rotor speed at $10 \mathrm{krpm}$. Cooling flow rate per each bearing $25 \mathrm{~L} / \mathrm{min}$. Thermal mixing coefficient $\lambda=0.65$

O.1 Prediction: Test case $\# 4 . T_{h s}=65^{\circ} \mathrm{C}$. Drive end and free end foil bearing direct and cross-coupled stiffness versus rotor speed and increasing air cooling flow rates

O.2 Prediction: Test case \#4. $T_{h s}=65^{\circ} \mathrm{C}$ Drive end and free end foil bearing direct and cross-coupled damping coefficients versus rotor speed and increasing air cooling flow rates

O.3 Prediction: Test case \#6. $T_{h s}=150^{\circ} \mathrm{C}$. Drive end and free end foil bearing force coefficients versus air cooling flow rates for rotor speed $=10 \mathrm{krpm}$ 


\section{LIST OF TABLES}

TABLE Page

1 Geometry of test hollow rotor and gas foil bearings (Unit: $\mathrm{mm}$ )............. 25

2 Test cases for three heater set temperatures $\left(T_{h s}\right)$ and four cooling flow rate conditions

3 Complete drive end bearing predicted dynamic force coefficients (whirl frequency synchronous with rotor speed)

4 Complete free end bearing predicted dynamic force coefficients (whirl frequency synchronous with rotor speed)

5 Predicted natural frequencies and damping ratios of rotor-GFB system for test cases \#4,5, and 7-9

A.1 Poisson's ratio, density, specific heat, and melting temperature of Inconel 718, Inconel X750, and AISI4140. Taken from [49-52]....

B.1 Specifications of major equipment and instrumentation for high temperature rotor-GFB test rig

F.1 Complete recorded data of temperature rises for test case \#1

F.2 Complete recorded data of temperature rises for test case \#2

F.3 Complete recorded data of temperature rises for test case \#3.....

F.4 Complete recorded data of temperature rises for test case \#4

F.5 Complete recorded data of temperature rises for test case \#5

F.6 Complete recorded data of temperature rises for test case \#6

M.1 Complete input parameters for GFB prediction

M.2 Drive end GFB: Predicted bearing static parameters

M.3 Free end GFB: Predicted bearing static parameters 


\section{CHAPTER I}

\section{INTRODUCTION}

Micro gas turbine engines $(<400 \mathrm{~kW})$ are light-weight compact units operating at extreme temperatures and at high rotor speeds to achieve the desired power with reduced emissions [1]. Employing gas foil bearings (GFBs) in micro gas turbines increases system efficiency and operating life while reducing system complexity [2]. GFBs also enable low drag power losses and maintenance-free system [3].

GFBs are compliant, self-acting, hydrodynamic bearings using ambient air or any other process gas as a lubricant. GFBs have been commercialized since the 1970's in air cycle machines in aircrafts. Recent advances in bearing structural components and solid lubricant coatings accompanied by accurate computational design tools anchored to reliable test data have widen the application range of GFBs [4-6]. Current commercial applications include micro gas turbines, compressors, turbo expanders, and turbochargers, for example.

Figure 1 shows photographs of a $1^{\text {st }}$ generation bump-type GFB, consisting of a rigid cartridge where corrugated bumps, as a compliant foundation, are assembled with a smooth arcuate top foil. The trailing edge of the top foil is affixed to the bearing cartridge and the bump foil strips support the rest of the top foil. The bump strip layers provide the bearing structural stiffness [7]. Coulomb-type damping arises due to material hysteresis and dry-friction between the bump strips and the top foil, as well as between 
the bump strips and the bearing inner surface [8].

The static and dynamic forced performance of GFBs relies on the geometry of the bump structure and its material properties [9,10]. Engineered coatings (solid lubricants) are typically applied on the surface of the top foil and/or the rotor to avoid excessive power losses and to minimize wear during frequent start and stop cycles [11].

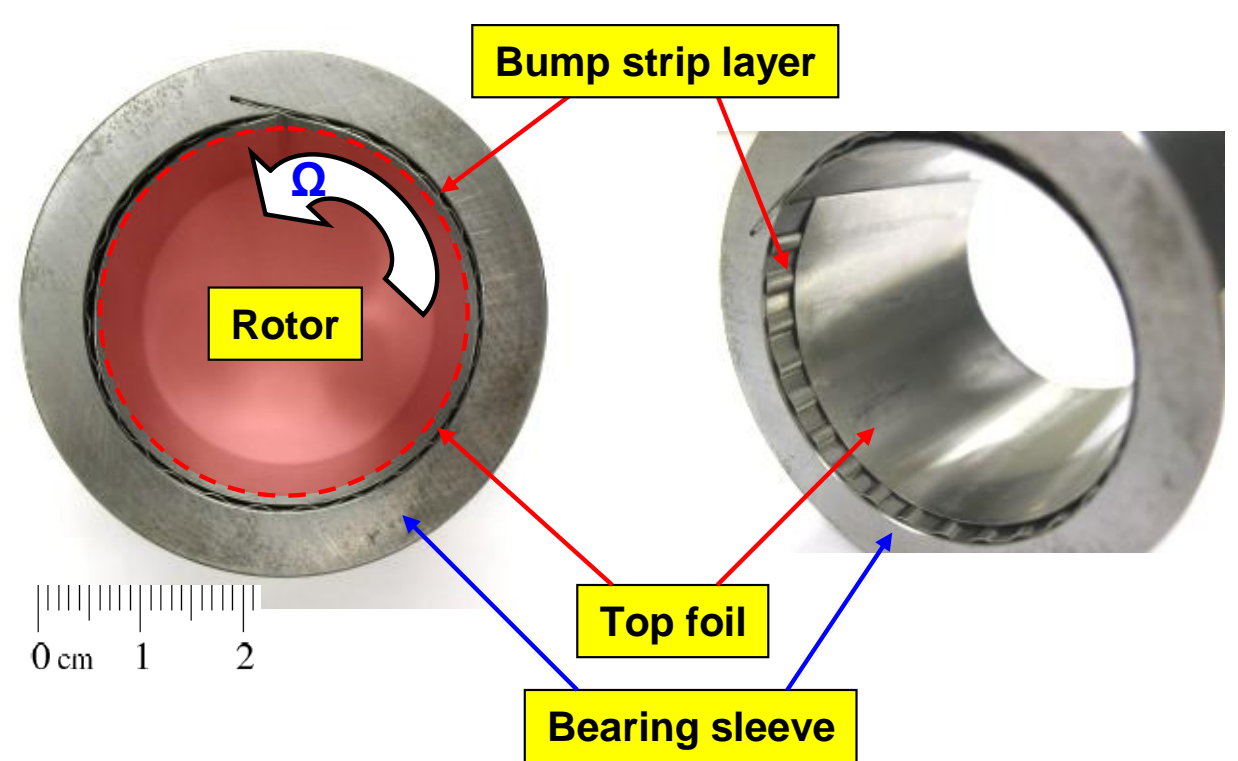

Fig. 1 Photographs of bump-type $1^{\text {st }}$ generation gas foil bearing for oil-free turbomachinery. Manufacturer: Korea Institute of Science and Technology (KIST).

An engineered thermal management is a necessity for the successful implementation of GFBs in high temperature applications. The most widespread approach for thermal control in a GFB system is to supply adequate amounts of air, flowing axially underneath the top foil and through the bump foils. A cooling gas flow assists to carry away heat and prevents GFBs from encountering thermal seizure, thus 
maintaining an adequate load capacity and thermal stability [12]. Since gases have a very low density, large mass flow rates are typically required to carry away (convect) thermal energy. At high speed and extreme temperature operating conditions, localized hotspots $^{1}$ in foil bearings can result in excessive thermal gradients and, likely, bearing seizures $[12,13]$.

Reliable testing of GFBs and the development of experimentally benchmarked predictive tools reinforce the path for reliable commercial implementations. An independent experimental database is a welcome addition must to gauge the accuracy of predictive computational tools. This data base must detail in full the test rotor and bearing system configuration with bump dimensions, and materials' mechanical properties, and the test conditions (i.e., system component temperatures, operating clearance and assembly preload, etc).

The present work, extending prior art [14], shows more measurements of bearings' and rotor temperatures and rotor motions in a laboratory rotor bearing system that operates at high temperature. An electric cartridge heater warms a hollow rotor and its supporting foil bearings. A further focus of the study is the investigation of adequate thermal management strategies using forced cooling flow into the GFBs. Most importantly, the measurements serve to benchmark a predictive analysis for the static and dynamic forced performance of GFBs [14]. The experimentally validated tool will significantly reduce time and expenses in further developments of micro-turbomachinery (MTM).

\footnotetext{
${ }^{1}$ A hot spot denotes the place where there is light rubbing of a rotor on the top foil surface that quickly generates heating and that is not conducted adequately into other parts of the bearing.
} 


\section{CHAPTER II}

\section{LITERATURE REVIEW}

In 1953, Block and van Rossum introduced compliant foil bearings [15]. Over the first four decades of FB development, GFBs were successfully deployed in several types of small turbomachinery, such as aircraft air cycle machines and microturbines. This is because GFBs fulfill most of the requirements of efficient oil-free turbomachinery by increasing the bearing load capacity and its reliability [16]. In 2006, Klaass and DellaCorte [17] provide a comprehensive review on the development of gas foil bearings for oil-free gas turbines over the previous 45 years. References $[18,19]$ report the efforts to demonstrate oil-free gas turbines employing multi-leaf type foil bearings during the 1970s and the 1980s.

Thermal considerations are mandatory when incorporating GFBs into high temperature applications. The most common method for thermal management in GFBrotor systems is to supply pressurized air at one end of the bearing to remove hot spots in the bearings.

Ruscitto et al. [20] conduct comprehensive experiments to determine the requirement of bearing cooling flow with a test foil bearing operates at $315^{\circ} \mathrm{C}$ ambient temperature. The test rig consists of an air turbine driven overhung shaft and a foil bearing. A furnace comprised of eight 500W quartz tubes houses a test journal and foil bearing. The shaft is supported on two ceramic hybrid ball bearings. The test foil bearing $\left(1^{\text {st }}\right.$ generation with $37.1 \mathrm{~mm}$ in diameter and length) is mounted outboard of the support 
ball bearings and is free to float on the air film generated in the bearing during shaft rotation. Two J-Type thermocouples are affixed on the backside of the bump foil. A forced cooling air flow, $210^{\circ} \mathrm{C}$ in inlet temperature and at $50-110 \mathrm{~L} / \mathrm{min}$ flow, is supplied to the test bearing to maintain a constant temperature (at $315^{\circ} \mathrm{C}$ ) while increasing rotor speed and static load to $45 \mathrm{krpm}$ and $111 \mathrm{~N}$, respectively. In the tests, the cooling air enters the test FB at the radial gap in the top foil, between the welded and the free ends. As the ambient temperature increases from room temperature to $315^{\circ} \mathrm{C}$, the load capacity of the test bearing increases by $8 \%$ (from 1.61 bar to 1.75 bar). The bearing temperature, nearly invariant to increases in the static load applied to the bearing, decreases as the strength of the cooling flow rate increases.

Without cooling flow into the bearing, DellaCorte [21] provides measurements of FB load capacity and torque during start-up and shut-down events up to $70 \mathrm{krpm}$ and operating at $700^{\circ} \mathrm{C}$. The overall layout and configuration of the test rig is similar with the test apparatus in Ref. [20]. Even though the operating temperature of the test GFB is extreme, no thermal management is attempted. The test bearing has an ID (inner diameter) of $35 \mathrm{~mm}$ and length of $25 \mathrm{~mm}$. The bearing cartridge and journal are made of Inconel 718. The load capacity and start-up/shut-down torque of the test bearing decrease with increasing in operating temperature. This is because the test bearing ID expands as the ambient temperature increases. A decrease in the bearing preload due to 
bearing cartridge expansion leads a decrease in bearing load capacity and torque. Note that a decrease in bearing preload eliminates the possibility of thermal runaway ${ }^{2}$.

Using the same test rig in [21], Radil et al. [23] perform experiments to evaluate the effectiveness of three different cooling methods (axial cooling, direct and indirect shaft cooling) for thermal management in a GFB. The authors claim that the axial cooling method, forcing air through the test bearing by pressurizing one side of the bearing cartridge slightly above ambient pressure, is the most effective to decrease bearing internal temperatures. The measured bearing temperatures during cooling air delivery determine the effectiveness of the cooling method. Three type-K thermocouples are embedded at the top foil spot weld location in the test foil bearing $\left(3^{\text {rd }}\right.$ generation, 50 $\mathrm{mm}$ in diameter $D$ and $48 \mathrm{~mm}$ in length $L$ ), with one in the middle and one at each edge, see Fig. 2. The experiments are conducted at $60 \mathrm{krpm}$ with a $222 \mathrm{~N}\left(W_{s}\right)$ static load (specific load $W_{s} / L D=0.93$ bar) on the test bearing. Note that, during the experiments, the furnace surrounds and heats the test bearing and rotating journal. For direct and indirect shaft cooling methods, see Figs. 3 (a) and (b), a $9.5 \mathrm{~mm}$ ID steel tube delivers hot air $\left(150-200^{\circ} \mathrm{C}\right.$, warmed by an electric tube heater) through the rotor ID.

In the direct cooling method (Fig. 3(a)), the air jet impinges on the rotor inner surface underneath the test bearing; while in the indirect cooling (Fig. 3 (b)), the air is forced on the drive end of the rotor. For the axial cooling method, see Fig. 3 (c), the test foil bearing and journal are enclosed inside a "can". Then, compressed air is supplied to the "can", thereby traveling axially through the test bearing and journal. For the axial

\footnotetext{
${ }^{2}$ Thermal runaway is a consequence of the thermal growth mismatch between the shaft and bearing and manifests as a continual increase in bearing preload [22].
} 
cooling method, the cooling air is supplied at ambient temperature, i.e., the cooling air is not heated by the electric tube heater. It is important to note that, for the axial cooling method, the cooling air temperature decreases from $400^{\circ} \mathrm{C}$ to $150^{\circ} \mathrm{C}$ as the air flow rate increases from 40 to $170 \mathrm{~L} / \mathrm{min}$. On the other hand, the cooling air temperature for the direct and indirect cooling methods is kept at $150-200^{\circ} \mathrm{C}$. Furthermore, while heating both the bearing and rotating journal (held inside the furnace), the authors identify the effectiveness of each cooling method based on the bearing temperature. Note that only the axial cooling method "directly" cools the test bearing while the others (direct and indirect cooling methods) do not.

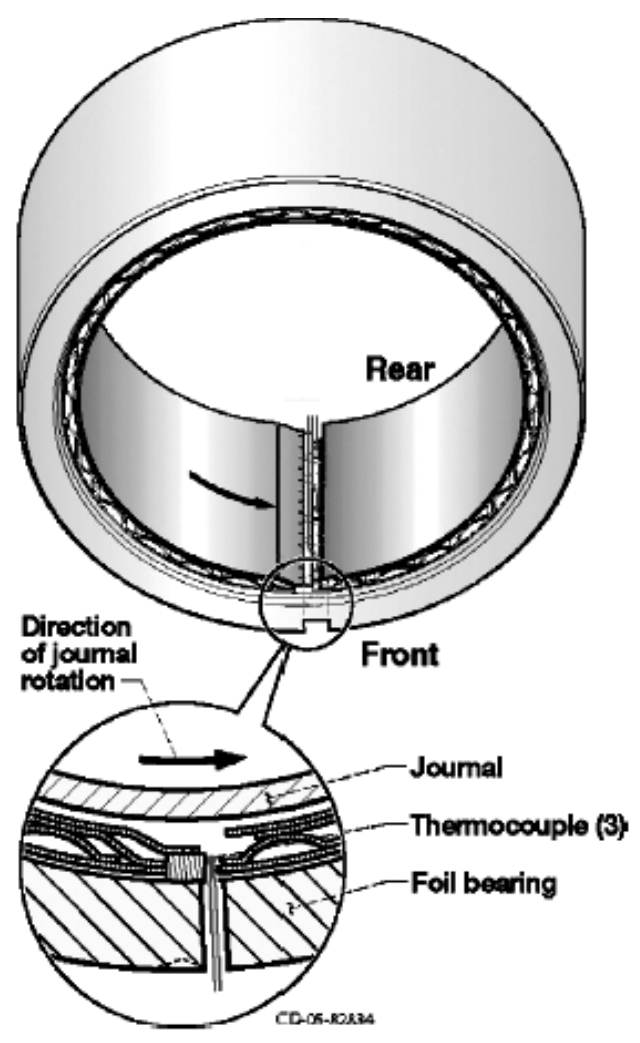

Fig. 2 Schematic view of thermocouple locations in a test foil bearing. Reproduced from [23]. 


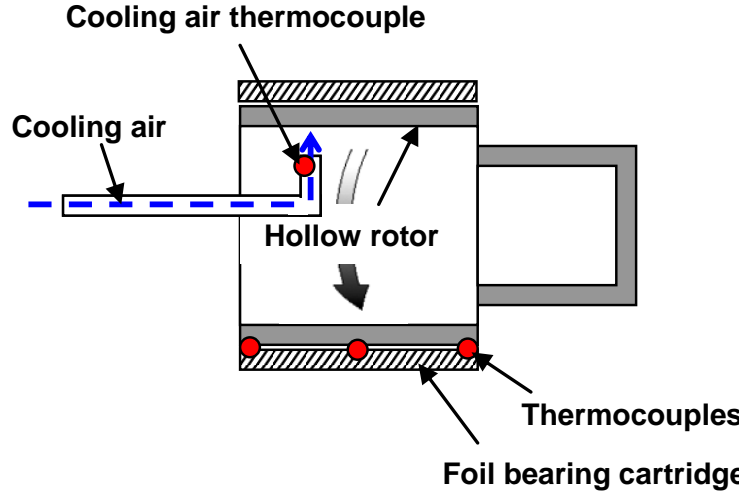

(a) Direct cooling method:

Cooling air guide tube towards rotor inner surface

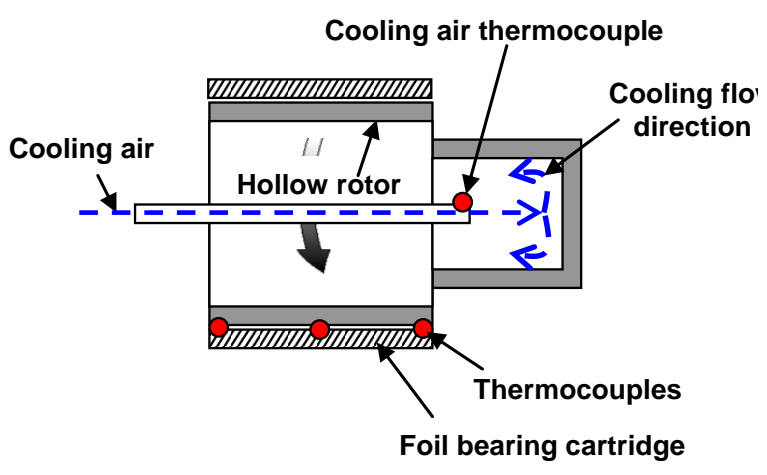

(b) Indirect cooling method:

Cooling air guide tube towards rotor back face

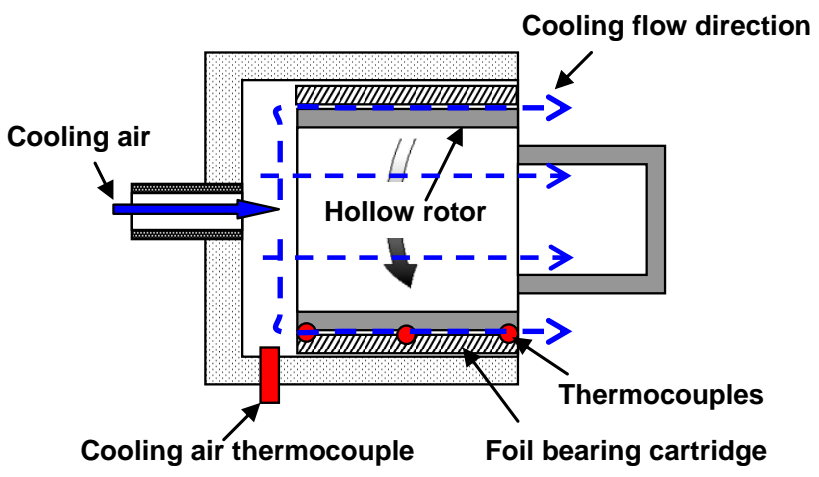

(c) Axial cooling method: Bearing enclosed with can.

Cooling air supply tube connected to can's closed end.

Fig. 3 Schematic views for three methods of foil bearing thermal management using forced cooling air. Taken from Ref. [23].

Lee and Kim [24] present temperature measurements on a three-pad FB for increasing cooling flow rates (up to $\sim 25 \mathrm{~L} / \mathrm{min}$ ) with static loads applied on the test bearing (to $\sim 100 \mathrm{~N}$ ) and for rotor speeds ranging from $30 \mathrm{krpm}$ to $40 \mathrm{krpm}$. The tests are conducted at room temperature without a heat source. The FB, $50.1 \mathrm{~mm}$ in (top foil) 
diameter and $37.5 \mathrm{~mm}$ in axial length, floats atop a (Inconel 718) shaft that is driven by a $3 \mathrm{~kW}$ electric motor. Static vertical loads are applied on the bearing by pulling a flexible string connected to the bearing housing. Cooling air is fed axially into one side of the test bearing while the other side is exposed to ambient air. The cooling scheme is similar to the axial cooling method in Ref. [23]. Temperatures are recorded at both the loaded and unloaded top foils, as well as the bearing housing ODs. At $35 \mathrm{krpm}$ with $76 \mathrm{~N}$ of static load, $8 \mathrm{~L} / \mathrm{min}$ of cooling air makes the top foil temperature $11 \%$ lower than that without cooling air (i.e, $75^{\circ} \mathrm{C}$ without cooling flow $\rightarrow 67^{\circ} \mathrm{C}$ with $8 \mathrm{~L} / \mathrm{min}$ cooling flow). On the other hand, at the same operating condition, the top foils' temperatures with cooling streams over $16 \mathrm{~L} / \mathrm{min}$ are just a few degrees lower than those at $16 \mathrm{~L} / \mathrm{min}$ cooling flow (i.e., $61^{\circ} \mathrm{C}$ at $16 \mathrm{~L} / \mathrm{min}$ cooling flow $\rightarrow 59^{\circ} \mathrm{C}$ at $25 \mathrm{~L} / \mathrm{min}$ cooling flow). Note that, as the cooling flow rate increases, the cooling air temperature into the bearing decreases (i.e., the air temperature in the plenum decreases from $40^{\circ} \mathrm{C}$ with $8 \mathrm{~L} / \mathrm{min}$ cooling air to $31^{\circ} \mathrm{C}$ with $25 \mathrm{~L} / \mathrm{min}$ cooling air). The same authors also present a thermohydrodynamic model to predict the transient thermal behavior of the rotor-FB system and compare predictions with the measurements. See Refs. [24,25] for more details on the authors' thermal analyses for the foil structure and rotor.

Dykas [12] investigates the effect of thermal management on the performance of foil thrust bearings. The test rig consists of a turbine-driven rotating shaft, supported on two foil journal bearings, a magnetic thrust bearing at one end maintaining axial position, and a foil thrust bearing at the other end. The maximum rotor speed is $80 \mathrm{krpm}$ while the test thrust bearing is heated to $540^{\circ} \mathrm{C}$. The test bearing comprises 8-pads, 43 
$\mathrm{mm}$ in ID (inner diameter) and $90 \mathrm{~mm}$ in OD (outer diameter), arranged in an annulus around a backing plate. Thermocouples, three per each pad, are attached to the backside of the bump foils using a thermally conductive epoxy. Forced cooling air enters the inner diameter of the bearing and exhausts to its outer diameter through the bump foil structure. Cooling flow rates, varying from 0 to $450 \mathrm{~L} / \mathrm{min}$, set to enhance the test bearing load capacity at high rotor speeds $(\sim 50 \mathrm{krpm})$; albeit the effect is small at low rotor speeds $(\sim 25 \mathrm{krpm})$. When testing at a fixed cooling flow rate, the bearing load capacity decreases with rotor speed. Inadequate thermal management renders thermoelastic distortions of the shaft and top foil surfaces, thereby reducing the load capacity of the test bearing.

The references above $[12,20,21,23,24]$ show bearing component-level tests. The following literature [26-28] presents system-level experimental work. Kirschmann and Agrawal [26] demonstrate a $2.2 \mathrm{kN}$ thrust class turbojet engine which implements a $2^{\text {nd }}$ generation FB (40 $\mathrm{mm}$ in diameter and length). The test FB replaces a roller bearing located between the compressor and turbine. During the operation at $55 \mathrm{krpm}, 280^{\circ} \mathrm{C}$ cooling air from an upstream supply is forced into the test bearing. A ceramic based solid film, offering performance superior to that of a silver alloy coating, coats the top foil. Lower preload FBs are preferable since they make the rotor start at a lower torque yielding less wear during start and shutdown cycles.

Walton et al. [27] perform exhaustive rotordynamic tests on a (290N thrust) miniature turbojet engine rotor, max. $150 \mathrm{krpm}$, mounted on $3^{\text {rd }}$ generation FBs. The light weight rotor (400 $\mathrm{g}$ ) is supported on two, $15 \mathrm{~mm}$ diameter, radial foil bearings and 
a multi-pad, $25 \mathrm{~mm}$ diameter, double acting thrust foil bearing. A series of rapid acceleration/deceleration tests from $75 \mathrm{krpm}$ to $15 \mathrm{krpm}$ are conducted while $345^{\circ} \mathrm{C}$ hot air is supplied to the test rig. The hot air warms the whole test rotor-bearing system, the test FB temperature reaching up to $290^{\circ} \mathrm{C}$ during the experiments. In the tests, cooling air at $290^{\circ} \mathrm{C}$ is directed through the foil thrust bearings; then it is pressurized into the inboard of the journal bearing while the outboard of the journal bearing is exposed to ambient pressure. The bearing temperature increases with rotor speed.

In Ref. [28], the same authors further demonstrate a turbojet engine integrating a hybrid support bearing system that uses a ball bearing and a foil bearing. The maximum rotor speed and bearing temperature are $60 \mathrm{krpm}$ and $650^{\circ} \mathrm{C}$, respectively. The hot section rolling element bearing and the entire existing lubrication system are replaced with a FB. The rotor is accelerated from rest to $60 \mathrm{krpm}$ while the bearing is cooled with an airflow rate of $566 \mathrm{~L} / \mathrm{min}$. When the cooling flow rate is below $140 \mathrm{~L} / \mathrm{min}$, the bearing temperatures continue to increase without indication of stabilizing, i.e., reaching thermal equilibrium. Higher rotor speeds and cooling flow rates render larger axial thermal gradients $\left(13^{\circ} \mathrm{C} / \mathrm{cm}\right)$. A large axial thermal gradient may result in uneven bearing and shaft growths, thereby altering the local bearing clearance. To verify the ability of the foil bearings to accommodate the centrifugal and thermal growths in the bearings and rotor, comprehensive transient performance tests (rapid start/stop cycle operations) are conducted at a bearing temperature of $650^{\circ} \mathrm{C}$. In an actual application, lower cooling flows are preferable so as not to compromise severely the engine compressor performance. 
Engineered thermal management strategies for high temperature GFB systems are customarily known in industry. LaRue et al. [29] develop a bearing support housing and cooling system for adequate thermal management of a GFB system in turbochargers (TCs) for diesel or gasoline engines. Note that the reference is the first production patent for an oil-free turbocharger. An effective thermal management is achieved by cooling the TC rotor and FBs (journal and thrust), as well as the TC center housing. The TC rotor is supported on two journal GFBs. Two double acting thrust bearings, positioned between the journal bearings, maintain the rotor axial position. Cooling air extracted from the engine intake duct downstream of the compressor is supplied to the center housing. The center housing includes a cooling air supply passage into the center housing bore. Cooling air is supplied into the thrust bearings first; then flowing into the journal bearings, to later return to the compressor inlet. The FB configuration with a double bump strip layer, as shown in Fig. 4, renders larger cooling flow paths than in a single-layer bump type FB, thereby increasing the air flow rate between the top foil and bearing housing. Several slots, see Fig. 4, in the center housing ID allow cooling air to pass underneath the bump strip layers. 


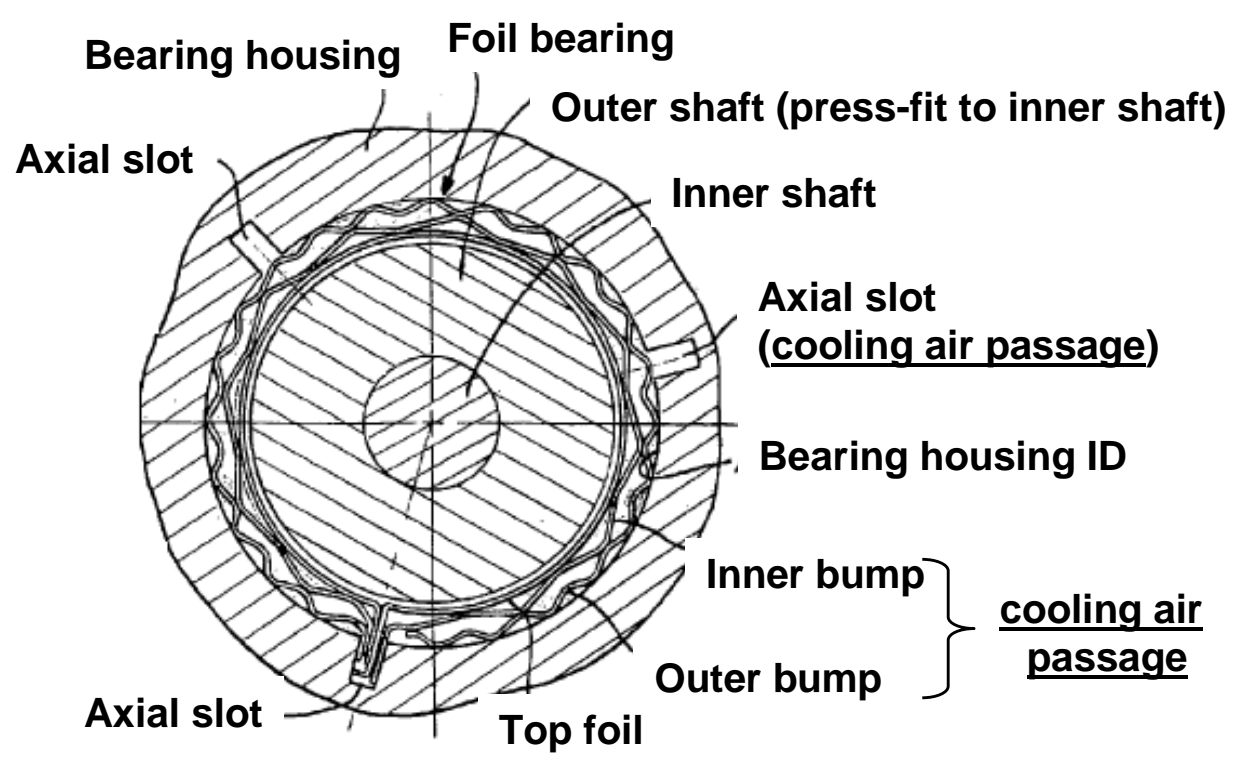

Fig. 4 Schematic view of radial foil bearing and its housing in an oil-free turbocharger. Reproduced from [29].

Lubell and Weissert [30] patent a rotor-bearing system integrating a sound thermal management strategy for oil-free gas turbines. A single gas foil bearing, named as first bearing, is located between a turbine and a compressor. The area between the compressor and the turbine generally experiences a higher temperature and larger load and stress as compared to the other portions of the rotor since it is close to the combustion chamber. Another gas foil bearing marked as the second bearing, is positioned far away from this area, opposite to the rotor turbine end. This configuration minimizes the cooling requirement for the second FB. A reduced rotor span between the compressor and turbine increases the gas flow from the compressor into the "first" GFB, thereby significantly decreasing the bearing operating temperature. Air bled from the 
compressor flows through the gap underneath the top foil, as well as inside the hollow rotor. This later flow remarkably decreases rotor temperature. A combination of carefully managed rotor and bearing bleed flows ensures adequate thermal management in the high temperature rotor-GFB system. Note that this rotor-bearing layout and cooling scheme is successfully applied in a commercial oil-free microturbine [31].

Except recent efforts at the author's laboratory [14], there is no open literature which fully details the geometry and materials of test foil bearings, and test conditions including cooling air flow rates and temperatures. San Andrés et al. [14] present measurements of bearing temperatures and rotor dynamic motions obtained in a hollow rotor supported on $2^{\text {nd }}$ generation GFBs. The test rotor surface is heated up to $157^{\circ} \mathrm{C}$ using an electric cartridge heater that is inserted loosely in a hollow rotor. The rotor weighs $1.065 \mathrm{~kg}$ and has $38.07 \mathrm{~mm}$ OD at the bearing locations. The extensive test results show that forced cooling flow has a limited effectiveness for operation at low shaft temperature conditions. 


\section{CHAPTER III}

\section{DESCRIPTION OF TEST ROTOR-BEARING SYSTEM AND}

INSTRUMENTATION

\subsection{Test Rig}

Figure 5 depicts photographs of the high temperature GFB rotordynamic test rig and its components. A solid AISI 4140 steel holds two test foil bearings and contains an enclosure to supply air with feed pressures for cooling the bearings when needed.

The hollow rotor (Inconel $718^{3}$ ) weighs $1.360 \mathrm{~kg}(13.33 \mathrm{~N})$ and is $200.66 \mathrm{~mm}$ long; its outer $\left(D_{o}\right)$ and inner diameter $\left(D_{i}\right)$ equaling $36.51 \mathrm{~mm}$ and $17.9 \mathrm{~mm}$, respectively $\left(D_{i} / D_{o}\right)=0.49$ (at ambient temperature). At each rotor end face, eight equally spaced threaded holes, $13 \mathrm{~mm}$ deep, at a radius of $15.5 \mathrm{~mm}$ serve to add known (im)balance masses.

The rotor OD (outer diameter) surface is coated with a proprietary solid lubricant designed for high temperature operation (up to $400^{\circ} \mathrm{C}$ ) [32]. The axial length of the coated portion is $50 \mathrm{~mm}$. The rotor OD has a $0.25 \mathrm{~mm}$ deep undercut at the locations of bearing placement to allow for deposition of the solid lubricant. The rotor pre-test surface root mean square roughness $\left(R_{R M S}\right)$ at the bearing locations is $0.22 \mu \mathrm{m}$ (manufacture provided) ${ }^{4}$.

\footnotetext{
${ }^{3}$ Appendix A lists the material properties of Inconel 718.

${ }^{4}$ This roughness is much finer than the typical surface roughness of PS304 coating [33], a NASAdeveloped high temperature composite coating. Plasma-sprayed PS304 coatings are generally limited to $R_{R M S}>0.25 \mu \mathrm{m}$, with $R_{R M S}=0.8 \mu \mathrm{m}$ typical after grinding and polishing [34].
} 
The center of mass of the rotor is $105.8 \mathrm{~mm}$ away from the rotor free end. The fractions of rotor weight acting on the drive end (DE) bearing and free end (FE) bearing equal 7.39 $\mathrm{N}$ and $5.94 \mathrm{~N}$, respectively. Two pairs of eddy current sensors facing the rotor ends record the dynamic displacements of the rotor along the vertical and horizontal axes.

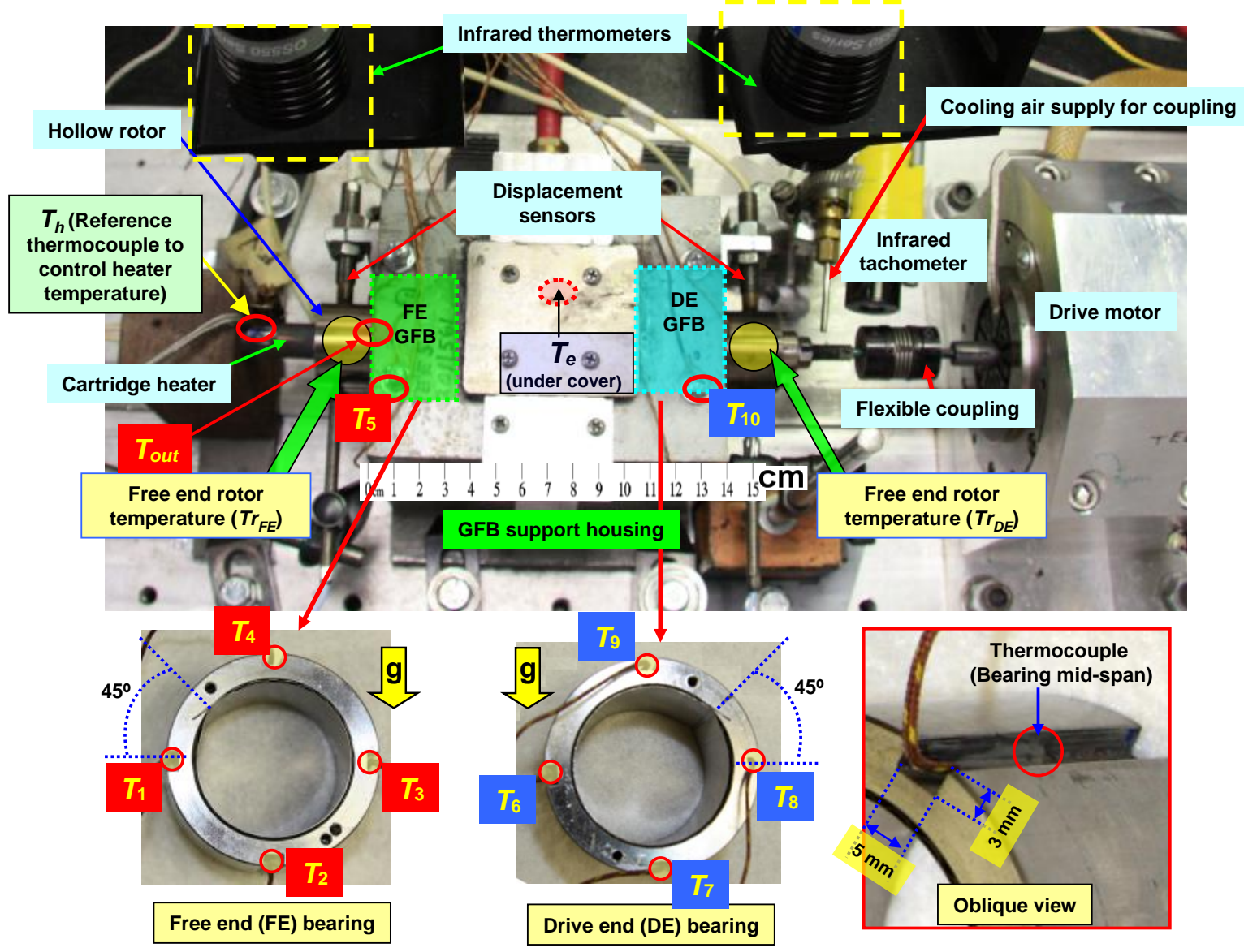

Fig. 5 Photographs of high temperature GFB rotordynamic test rig. $T_{1}-T_{10}, T_{h}, T_{\text {out }}$, and $T_{e}$ represent locations of temperature measurement. A bearing sleeve with an axial slot to route a thermocouple installed at the bearing mid-span also shown (oblique view). 
An electric cartridge heater, $15.875 \mathrm{~mm}$ in diameter, fits loosely inside the hollow rotor, see Fig. 6. The heater is rated at $1.6 \mathrm{~kW}$ when supplied with 240 VAC. Symbols $T_{1}-T_{10}, T_{h}, T_{e}, T_{o u t}, \operatorname{Tr}_{D E}$, and $\operatorname{Tr}_{F E}$ denote the locations for temperature measurements.

Four axial slots, depth $=3 \mathrm{~mm}$ and $90^{\circ}$ apart, are machined on the outer surface of the bearings. These grooves serve to route type-K thermocouples, each affixed with cold-weld compound onto the bearing OD at its middle axial plane; see Fig. 5. $T_{1}-T_{4}$ denote thermocouples on the FE bearing. Similarly, $T_{6}-T_{9}$ denote thermocouples affixed to the OD of the DE FB sleeve.

Figure 6 illustrates a schematic view (not to scale) for the dimensions of the test rotor, the cartridge heater, the housing and its air feed enclosure. Figures 5 and 6 depict the location of the thermocouple $T_{h}$ serving as a reference to control the electric heater circuit. Prior work, see Ref. [14], demonstrated that the heater warms unevenly the test rotor, with distinct axial and circumferential temperature gradients [14]. Clearly, the rotor (drive) end on the other side of the cartridge heater and next to the coupling is coldest. 


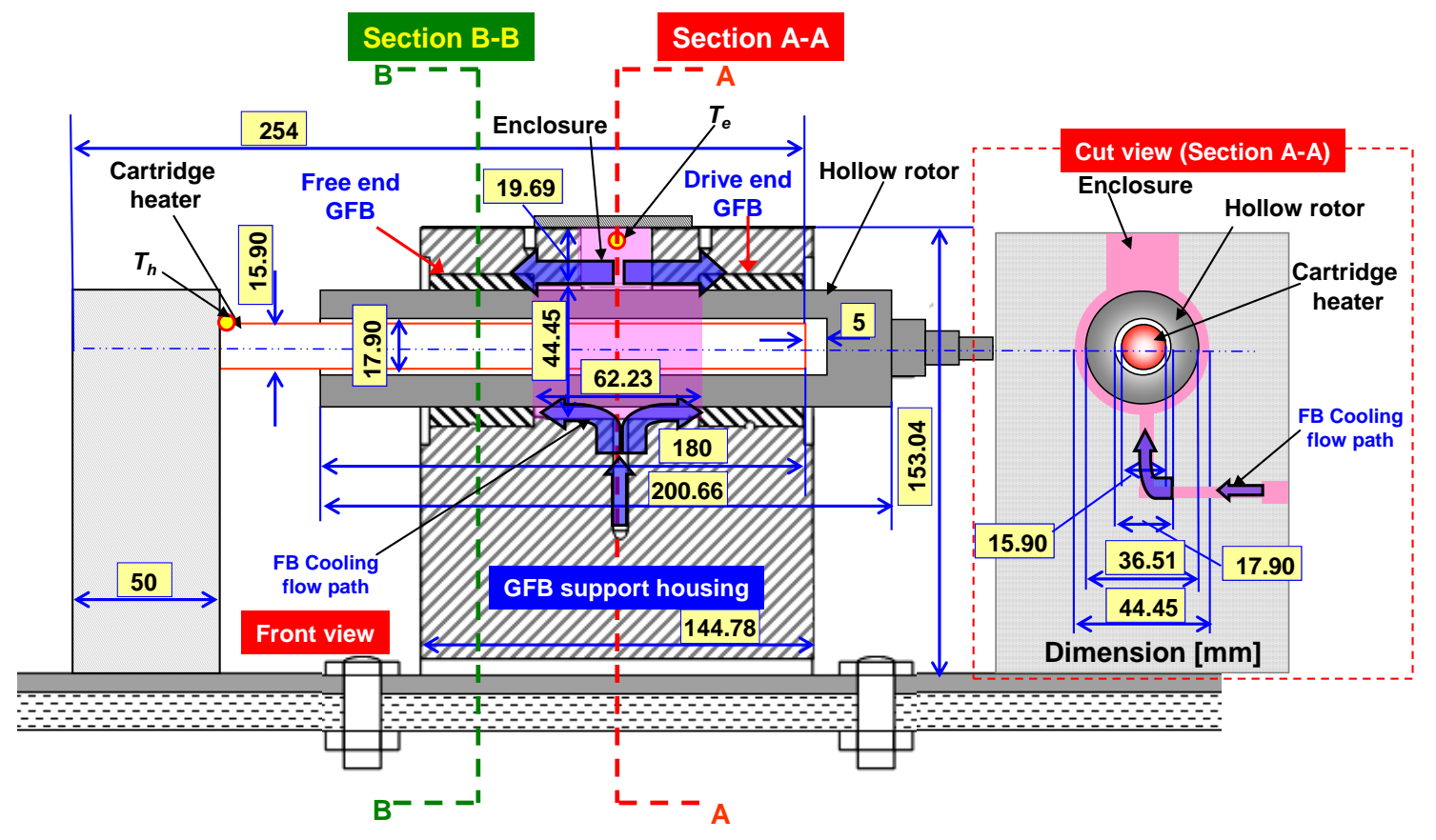

Fig. 6 Schematic view (not to scale) for dimensions $(\mathrm{mm})$ of test rotor, cartridge heater, bearing support housing air feed enclosure. Noted locations of thermocouples for feed enclosure air temperature $\left(T_{e}\right)$ and reference to control heater set temperature $\left(T_{h s}\right)$.

Figure 7 shows the bearing support housing with dimensions of thickness around the test bearings. The bearing housing is $16.51 \mathrm{~mm}$ and $85.73 \mathrm{~mm}$ thick at its thinnest and thickest locations, respectively. 


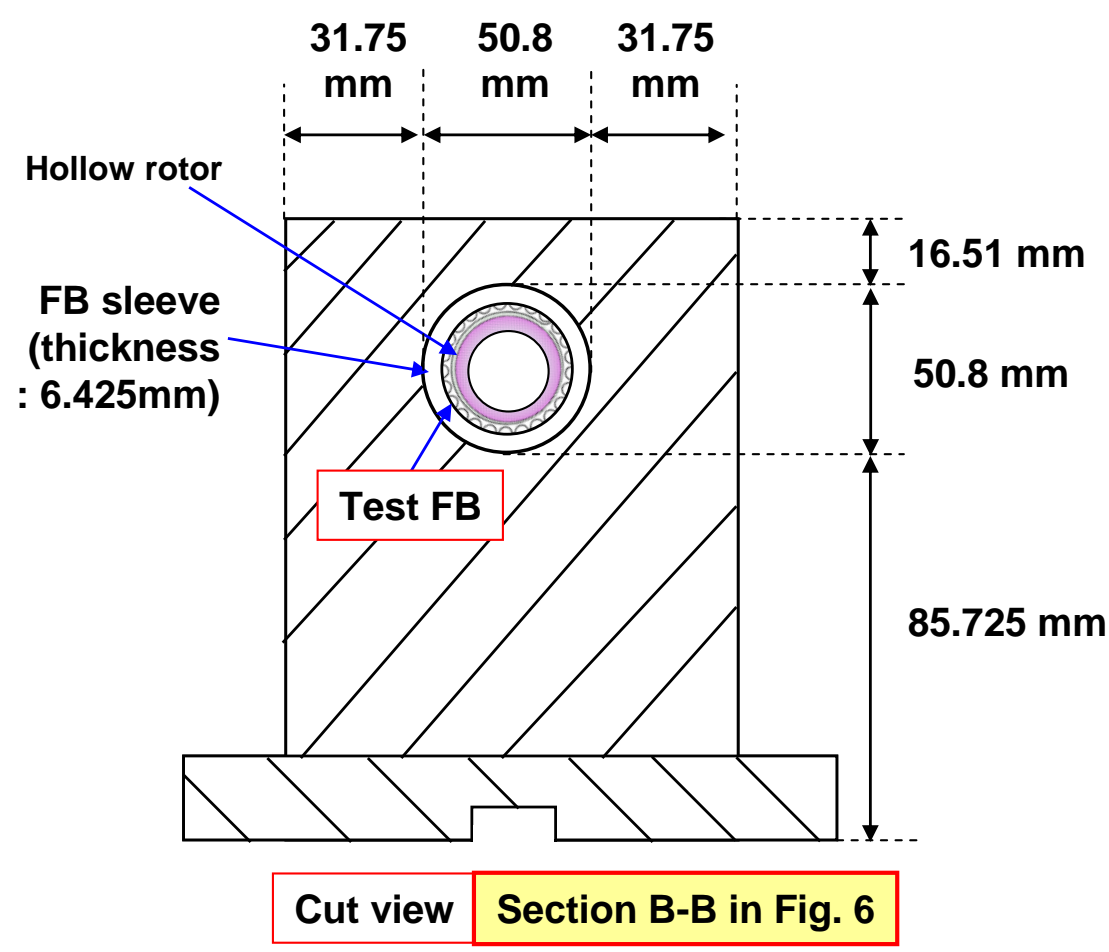

Fig. 7 Cut view (not to scale) of section B-B in Fig. 6 of bearing support housing with dimensions of wall thickness around test bearing. Material of bearing support housing and bearing sleeve: AISI 4140.

The drive motor (induction type with two electromagnetic poles), $9.5 \mathrm{~kW}$ at its maximum operating speed of $65 \mathrm{krpm}$, is rated with a $85 \mathrm{~N}-\mathrm{cm}$ torque at $6 \mathrm{krpm}$. A flexible coupling (35 $\mathrm{mm}$ in length, $25 \mathrm{~mm}$ in outer diameter, and $5.08 \mathrm{~mm}$ inner diameter) connects the rotor to a drive motor through an Inconel 718 slender rod (14.2 $\mathrm{mm}$ in length and $5.1 \mathrm{~mm}$ in diameter). The coupling rated (maximum service) torque and torsional stiffness are $2.0 \mathrm{~N}-\mathrm{m}$ and $1200 \mathrm{~N}-\mathrm{m} / \mathrm{rad}$, respectively. The maximum operating temperature of the inexpensive coupling is $120^{\circ} \mathrm{C}$. Hence, during the tests, a stream of shop air $\left(1.36\right.$ bar gauge and $\left.21^{\circ} \mathrm{C}\right)$ cools the flexible coupling. 
Two infrared thermometers record the rotor OD surface temperatures at the drive and free ends, hereby denoted as $\operatorname{Tr}_{D E}$ and $\operatorname{Tr}_{F E}$. The sensor has an adjustable emissivity setting. The distance-to-spot ratio (the ratio of the distance to the object and the diameter of the temperature measurement area) is 68:1 [35]. Presently, the sensor head locates 150 $\mathrm{mm}$ above the rotor surface. Hence, the displayed temperature averages the temperature over a $17 \mathrm{~mm}$ diameter area, refer to Fig. 8. A laser sighting device, installed in front of the sensor head, aids to focus the infrared spot from the sensor head on the rotor surface to be measured.

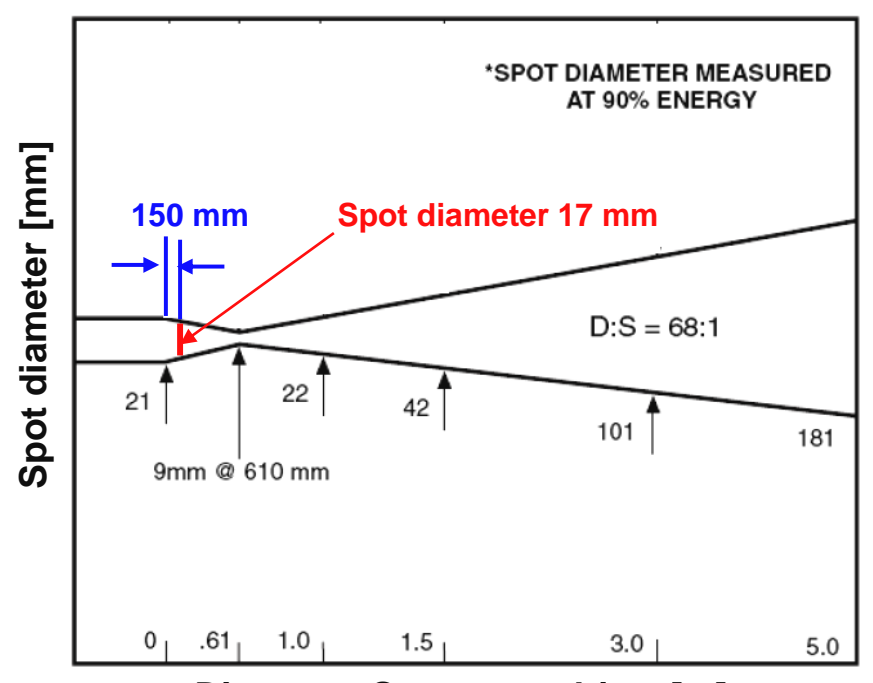

Distance: Sensor to object [m]

Fig. 8 Distance-to-spot ratio of infrared thermometer [35].

Figure 9 shows a photograph of the air feed enclosure at the mid plane of the bearings' housing (cover removed) with thermocouple $T_{e}$ that measures the gas temperature inside the enclosure, and thermocouples $T_{5}$ and $T_{10}$ recording temperatures 
on the outer surface of the thick housing. A thermocouple $T_{\text {out }}, 1.5 \mathrm{~mm}( \pm 0.25 \mathrm{~mm})$ above the rotor FE surface, measures the exhaust air temperature released into the ambient air from the FE test bearing, see Fig. 10.

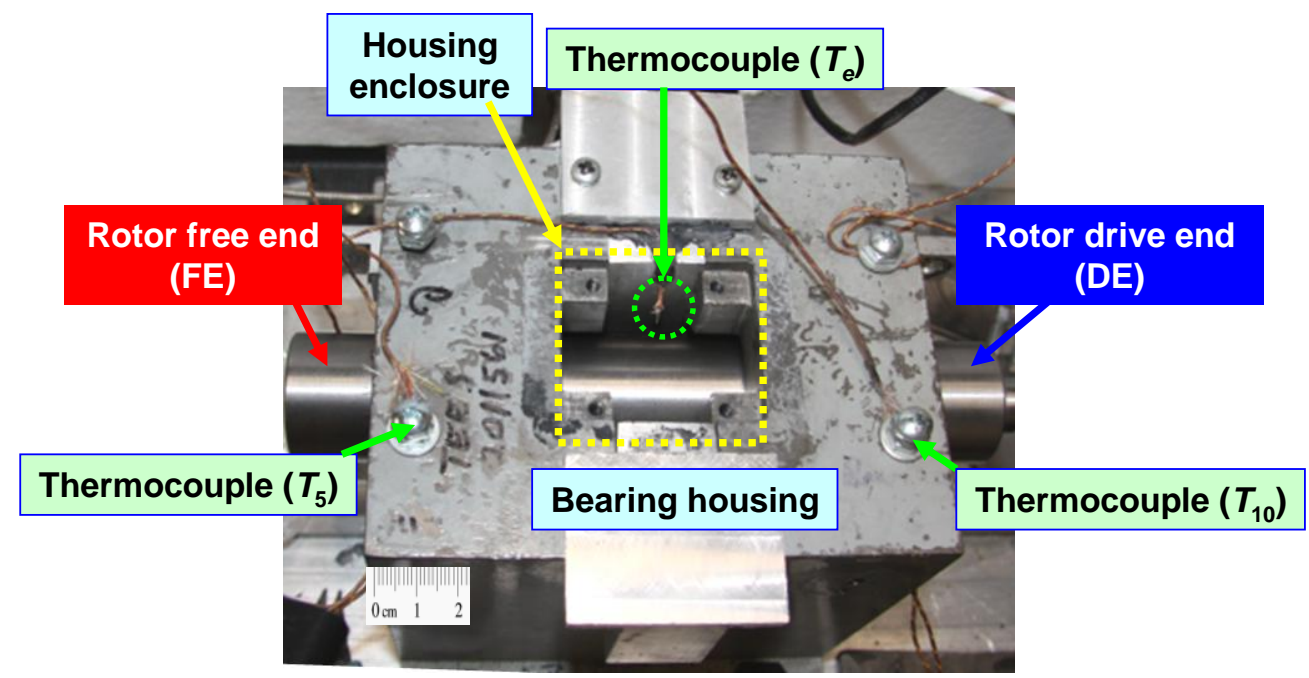

Fig. 9 Air feed enclosure at mid plane of bearing housing (cover removed for photograph) and locations of thermocouples $\left(T_{e}, T_{5}\right.$ and $\left.T_{10}\right)$.

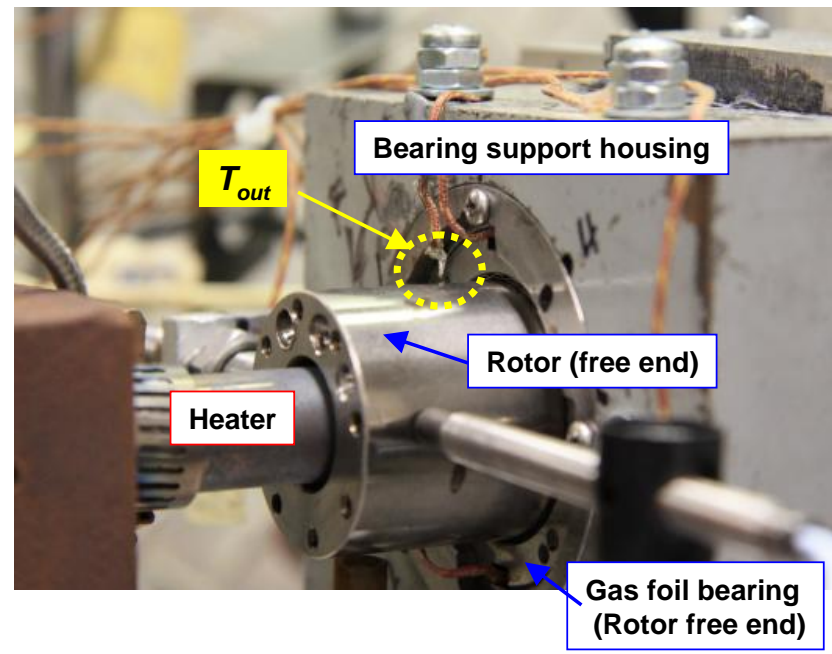

Fig. 10 Location of thermocouple $T_{\text {out }}$ to record bearing exhaust air temperature. 
Figure 11 depicts a layout of the supply air system into the test rig, the instrumentations, and the data acquisition system. Pressure gauge monitors the air supply pressure into the test bearings. A manually operated pressure regulator in the main shop air line serves to adjust the supply pressure (flow rate) into the bearings. The supplied air enters at one axial end of each test bearing, flows through the gas film region and underneath of the top foil, and exits through the other bearing end at ambient pressure, see the blue color arrows in Fig. 10. A gas flow meter ${ }^{5}$, max. $500 \mathrm{~L} / \mathrm{min}$, records cooling airflow rates into both foil bearings. A thermocouple $T_{i n}$ records the supply air temperature well upstream to the test rig.

The instruments displaying temperature digitally have uncertainties of $0.6^{\circ} \mathrm{C}$ and $1.7^{\circ} \mathrm{C}$ for the thermocouples and infrared sensor, respectively. Temperatures are read visually and recorded manually while commercial DAQ systems (Bentley Nevada $A D R E \circledR$ for Windows and LabVIEW®) record and save the rotor vibration test data while the rotor spins. An infrared tachometer serves as a keyphasor signal for data acquisition. Rotor displacement voltage signals from the displacement sensors are routed through a signal conditioner to bias their DC offset levels. Two analog oscilloscopes display the unfiltered real time rotor orbits recorded at the free and drive ends of the rotor. A two-channel dynamic signal analyzer displays the frequency content of selected motion signals.

\footnotetext{
${ }^{5}$ The flowmeter is calibrated by the manufacturer at 1 atmosphere and $21^{\circ} \mathrm{C}$. The uncertainty in the measured flow is $\pm 1.5 \%$ of the full scale range $(500 \mathrm{~L} / \mathrm{min})$.
} 


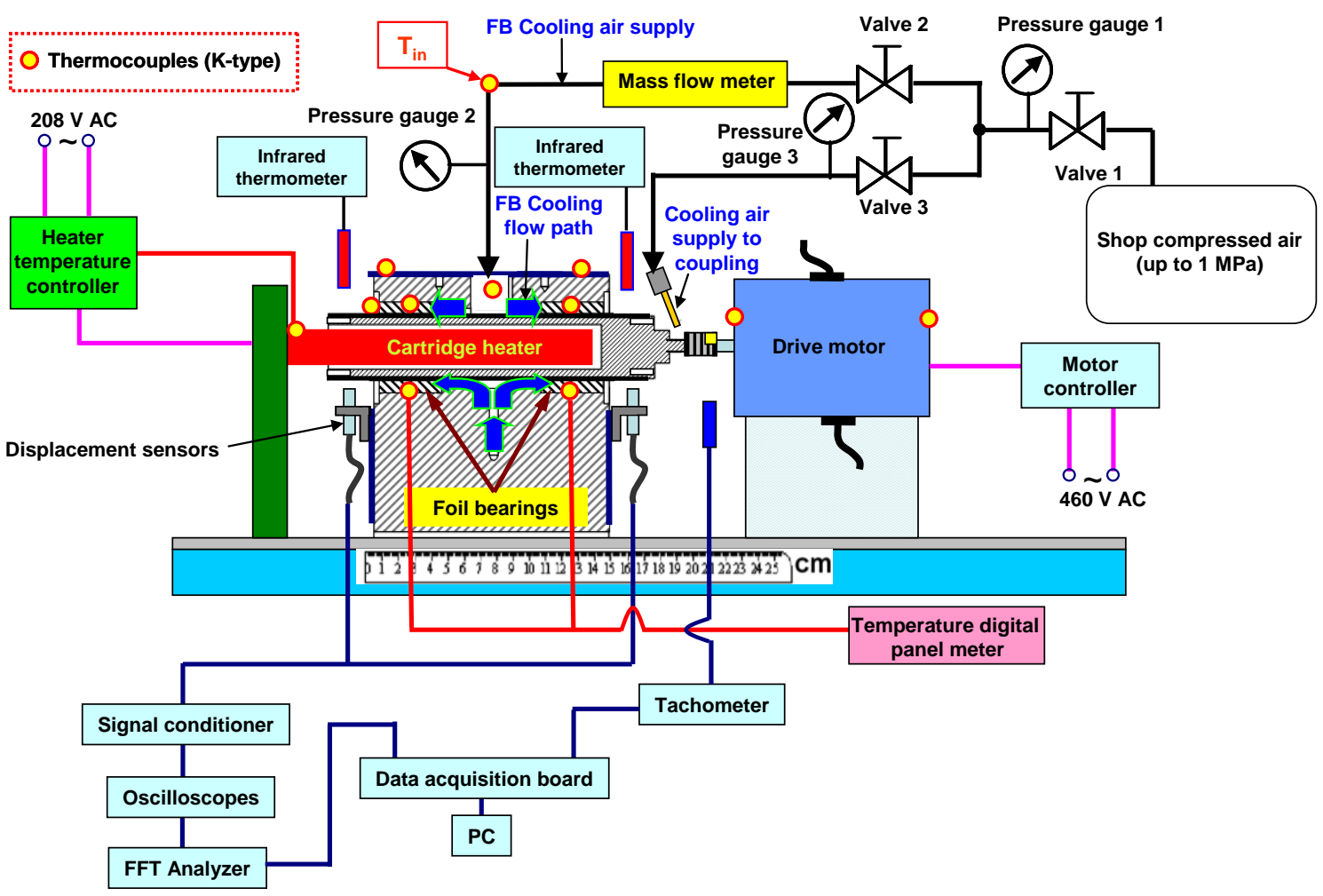

Fig. 11 Schematic view (not to scale) of cooling air supply system, instrumentation, and data acquisition system of high temperature gas foil bearing test rig. Flow path of force cooling air also shown. 
During rotor speed up and down conditions, ADRE® and LabVIEW® collect rotor displacements at $\Delta \mathrm{rpm}=50 \mathrm{rpm}$ and 1,000 rpm intervals, respectively. When the rotor operates at a constant speed $(10,20$, and $30 \mathrm{krpm}), A D R E \circledR$ stores data at $\Delta_{\text {time }}=10$ $\mathrm{s}$ intervals. The sampling size and rate for $A D R E \AA$ are $512\left(2^{9}\right)$ and $64\left(2^{6}\right)$ samples/revolution, respectively. The (user-defined) sampling size and rate for LabVIEW® are 2,048 $\left(2^{11}\right)$ and 10,000 samples/s, respectively.

Appendix B lists technical specifications of the equipment and instrumentation for the high temperature rotor-GFB test rig.

\subsection{Dimensions of Test Bearings and Estimation of Bearing Clearances}

Table 1 lists measured dimensions of both test foil bearings and the rotor $^{6}$. The bump pitch, length, height, arch radius, and arch angle are estimated from the zoomed photograph in Fig. 12. A foil bearing, $1^{\text {st }}$ generation type, has a single arcuate Inconel X$750^{7}$ top foil and a single bump strip layer (no axial splits). The top foils are bare, i.e., without any coating. The ends of the bump strip and top foil are inserted into a thin slot in the bearing cartridge, while the other ends are free [36]. Upon installation of both bearings, the orientation of the top foil trailing edge with respect to the vertical (gravity) plane is $45^{\circ}$.

\footnotetext{
${ }^{6}$ KIST designed and constructed the test foil bearings and rotor. KIST donated the components for the current research.

${ }^{7}$ Appendix A shows the material properties of Inconel X-750.
} 
Table 1. Geometry of test hollow rotor and gas foil bearings (Unit: $\mathrm{mm}$ )

\begin{tabular}{lc}
\hline \multicolumn{2}{c}{ Rotor } \\
\hline Outer diameter, $2 R_{O}$ & $36.51^{(1)^{*}}$ \\
Inner diameter, $2 R_{I}$ & $17.9^{(1)^{*}}$ \\
Material & Inconel 718 \\
& (KIST proprietary solid lubricant coated)
\end{tabular}

\section{Bearings}

Sleeve outer diameter, $D_{O}$

$50.8^{(1)^{*}}$

Sleeve wall thickness, $t_{B}$

$6.425^{(1)^{*}}$

Sleeve inner diameter, $D_{I}=D_{O}-2 t_{B}$

$37.95^{* *}$

Sleeve axial length, $L_{O}$

$38.1^{(1)^{*}}$

Sleeve material

AISI 4140

Top foil axial length, $L$

$38.1^{(1)^{*}}$

Top foil thickness, $t_{T}$

$0.12^{(1)^{*}}$ (bare surface)

Bump foil thickness, $t_{B}$

$0.12^{(1)^{*}}$

Number of Bumps, $N_{B}$

$26 \times 1$ axial

Bump pitch, $s_{0}$

$4.4^{(2)^{* * * *}}$

Bump length, $l_{B}$

$2.5^{(2)^{* * *}}$

Bump height, $h_{B}$

$0.50^{(2)^{* * *}}$

Bump arc radius, $r_{B}$

$2.25^{(2)^{* * *}}$

Bump arc angle, $\alpha_{B}(\mathrm{deg})$

$67^{(3)^{* * *}}$

Top foil inner diameter, $D_{T}=D_{I}-2\left(t_{T}+h_{B}\right)$

$36.71^{* *}$

Foil material

Inconel X-750

\begin{tabular}{l} 
Radial (assembly) clearance, $C_{r}=1 / 2\left(D_{T}-D_{S}\right)$ \\
\hline \hline Bearing mass (sleeve + bump foil + top foil): $0.25 \mathrm{~kg}$ \\
Uncertainty: (1) $\pm 0.005 \mathrm{~mm},(2) \pm 0.013 \mathrm{~mm},(3) \pm 5^{\circ}$ \\
$*$ Measured value using digital vernier caliper \\
$* *$ Calculated from other measured or estimated dimensions \\
$* * *$ Estimated from zoomed photograph in Fig. 12
\end{tabular}

$0.10^{*}$ 


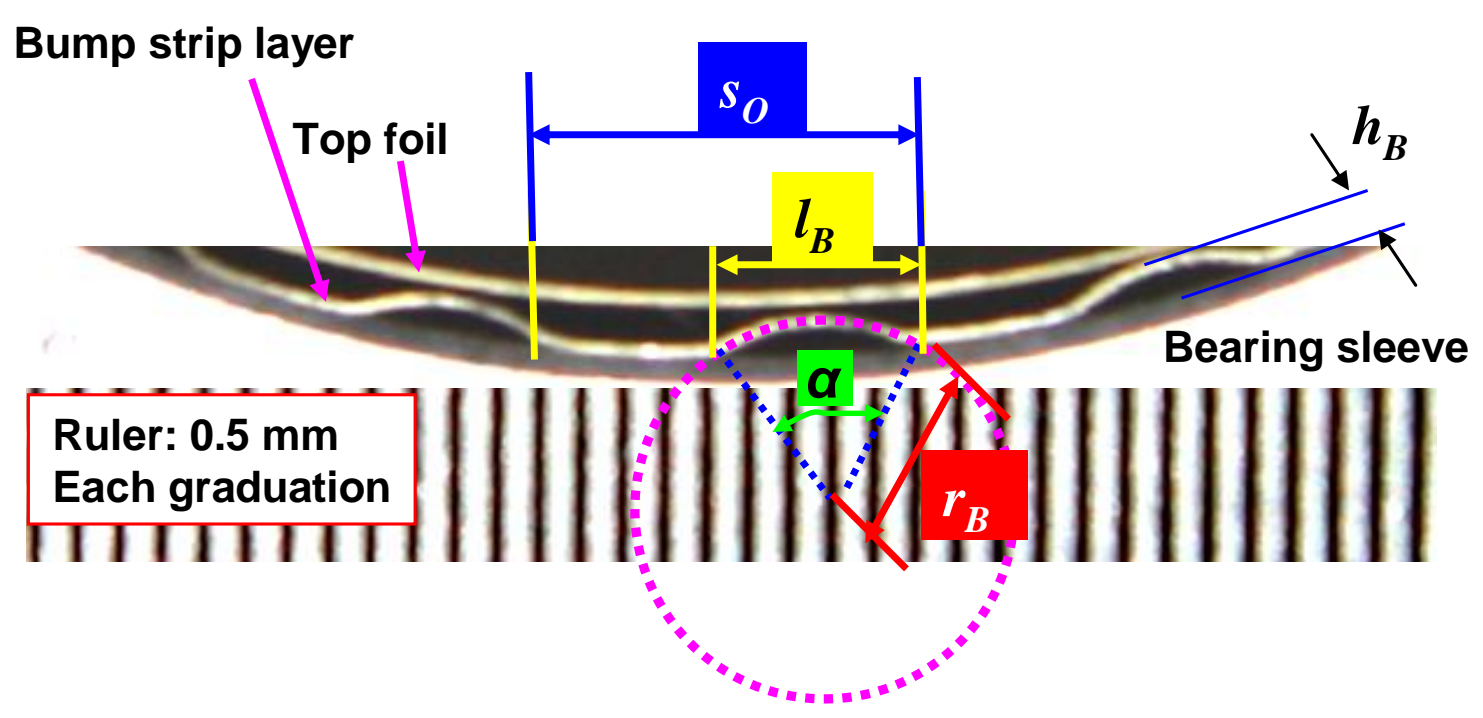

Fig. 12 Zoomed photograph of test bearing to estimate its geometry.

A series of static load versus FB deflection measurements serves to estimate the bearing radial clearance (at room temperature). Figure 13 shows the schematic view of the simple test setup and procedure to apply static loads into the test bearings resting on its rotor. During the static load tests, the test bearing is tightly fitted into a thick steel (AISI4140) bearing housing ${ }^{8}$. The thickness and mass of the bearing housing are 11.57 and $0.670 \mathrm{~kg}$, respectively. The orientation of the top foil trailing edge with respect to the vertical (gravity) plane is $45^{\circ}$.

To minimize the shaft elastic deflection under static loads, both ends of the shaft are secured to the lathe. A lathe tool holder displaces manually to deliver a static load on the bearing. A strain gauge load cell (uncertainty $0.45 \mathrm{~N}$ ) is affixed to the lathe tool

\footnotetext{
${ }^{8}$ The thick bearing housing aids to avoid undesirable deformation of the thin bearing sleeve due to the imposed static loads.
} 
holder and connected to the test bearing outer housing. Moving the lathe tool holder forward and backward provides push and pull forces onto the test bearing, respectively. An eddy current displacement sensor (uncertainty: $0.104 \mathrm{~V} / \mathrm{mm}$ ) facing the bearing OD measures the displacements of the test bearing. Measured shaft displacements are subtracted from the corresponding bearing displacements to obtain the actual bearing bump deflection.

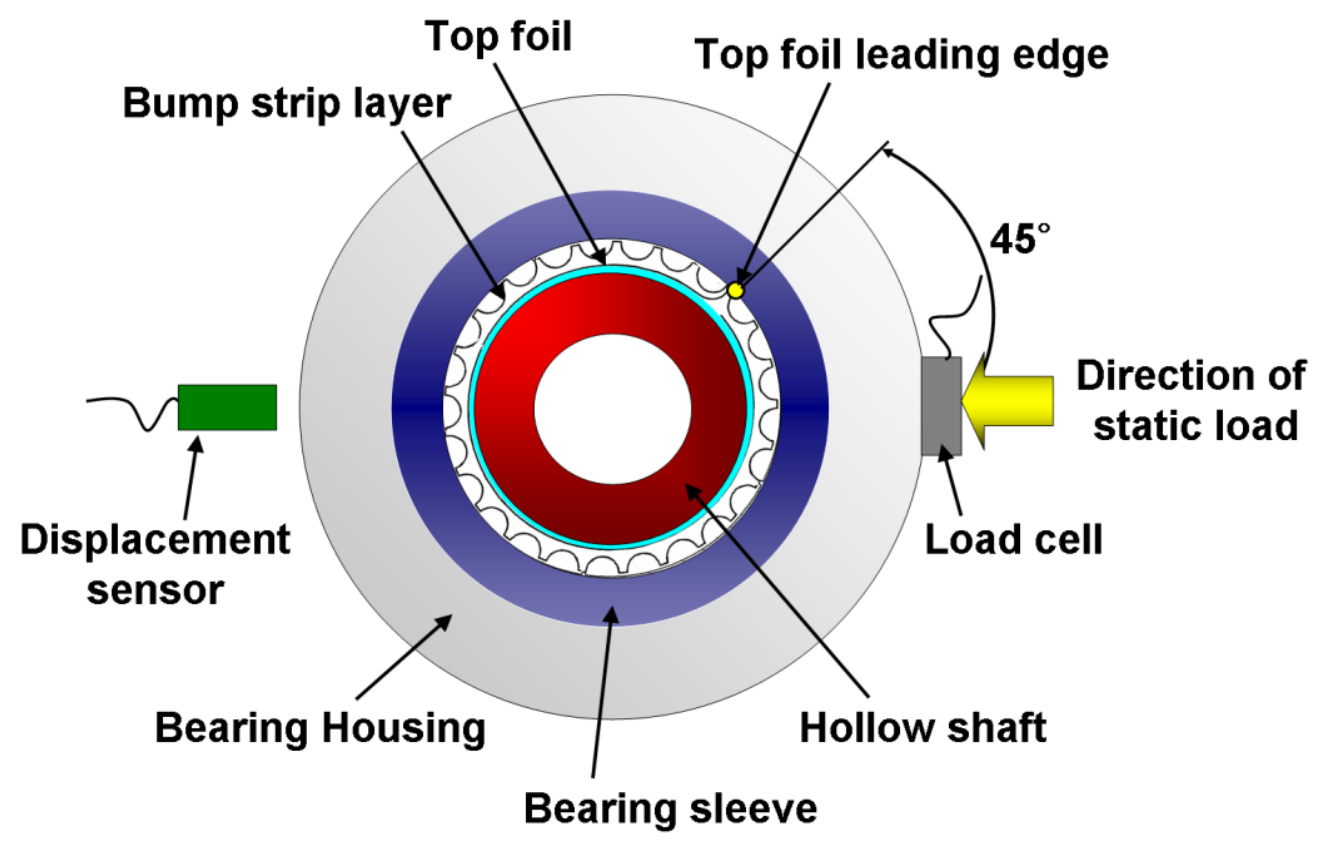

Fig. 13 Schematic view (not to scale) of test setup for static load and FB structural deflection test. Static load $45^{\circ}$ away from top foil trailing edge.

Figure 14 depicts the measured FB deflection versus applied static load for the free end (FE) and drive end (DE) bearings. The bearing forced deflection is highly nonlinear during consecutive loading-unloading cycle with a distinctive hysteresis loop 
showing dissipated mechanical energy. Note that once the bumps are active due to the applied static loads, the increase in bearing displacements for the FE bearing is more significant than the DE bearing". The "ad-hoc" radial clearance (i.e., radial play or sway space), defined as in Ref. [20], for both bearings is $\sim 100 \mu \mathrm{m}$. The agreement of "ad-hoc" clearance to the clearance derived from the bearing geometry is remarkable, see Table 1 .

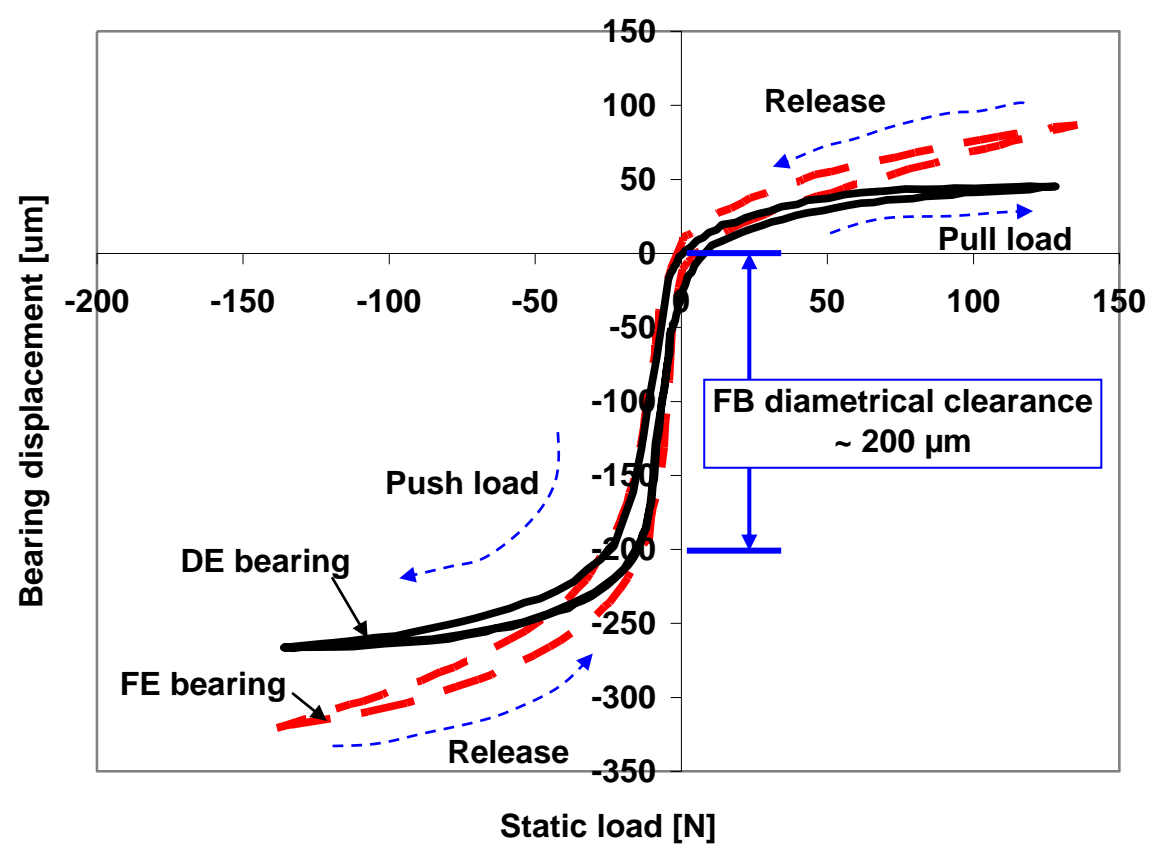

Fig. 14 Recorded foil bearing deflections (drive and free ends) versus static load for estimation of diametrical clearance.

A polynomial curve fit over the span of applied loads establishes an analytical relation between the static load $\left(F_{F B_{s}}\right)$ and the FB deflection $(r)$; i.e.,

\footnotetext{
${ }^{9}$ Inaccurate manufacturing of support structure, i.e., bump foils, may result in different structural stiffnesses between two test bearings.
} 
$F_{F B_{s}}=F_{0}+K_{1} r+K_{2} r^{2}+K_{3} r^{3}+K_{4} r^{4}+K_{5} r^{5}$ [37]. Therefore, the FB structural stiffness is the first spatial derivative of the curve fit, i.e., $K_{s}=\partial F_{F B_{s}} / \partial r$ $=K_{1}+2 K_{2} r+3 K_{3} r^{2}+4 K_{4} r^{3}+5 K_{5} r^{4}$

Figure 15 depicts the identified FB static structural stiffness. The FB stiffness shows a typical hardening effect as the bearing deflection increases. The structural stiffness of the DE bearing increases more rapidly than the FE bearing as the FB deflection increases. Figure 16 depicting the FB stiffness $\left(K_{s}\right)$ versus applied static load shows a strong load dependency.



Fig. 15 Identified FB structural stiffness versus bearing displacement. DE: Drive end bearing, FE: Free end bearing. 


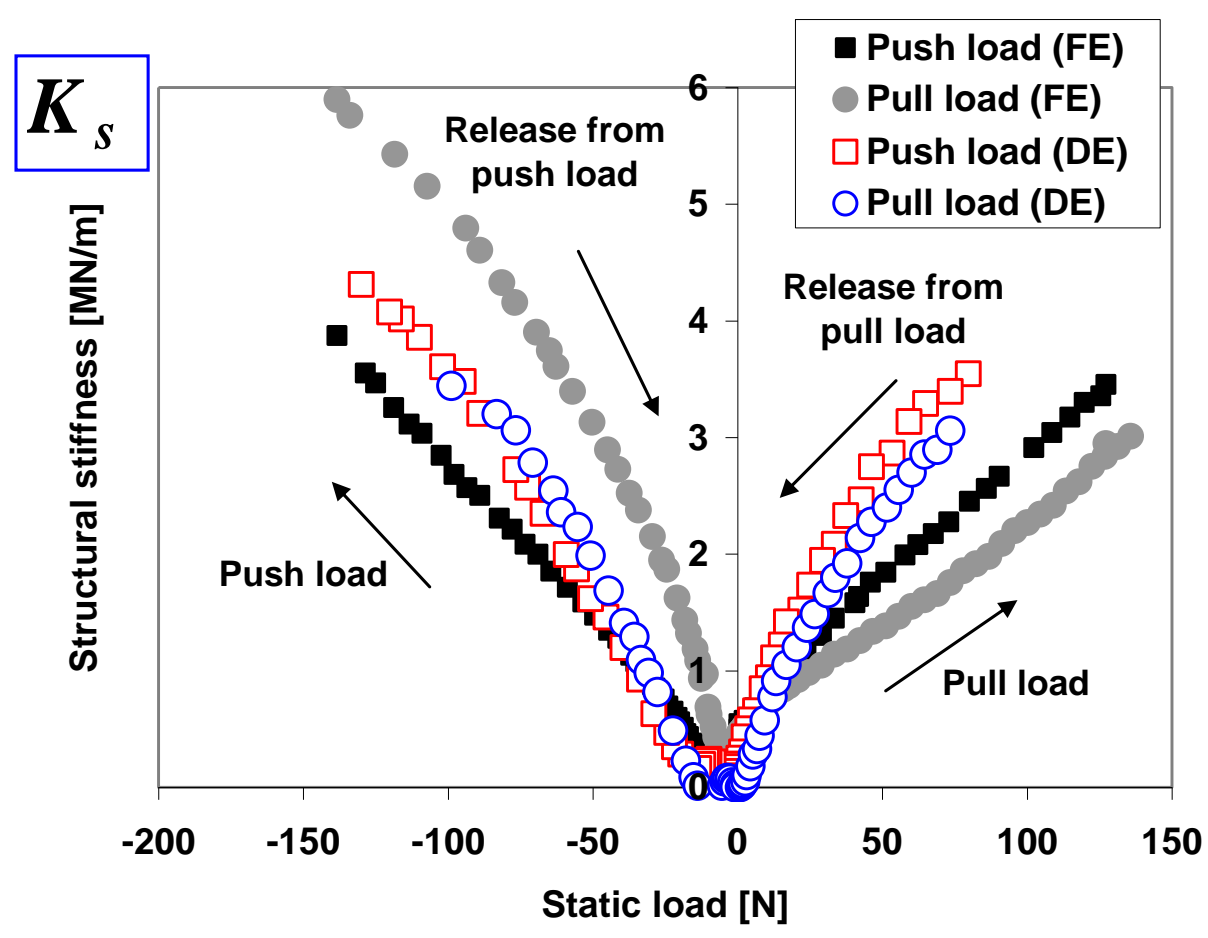

Fig. 16 Identified FB structural stiffness versus static load. DE: Drive end bearing, FE: Free end bearing.

From the mechanical hysteresis loop in Fig. 14, the FB structural loss factor estimated from $\gamma=\frac{1}{\pi K_{s} r^{2}} \oint F_{F B_{s}} d r$, where $K_{s}$ is a local (average) stiffness coefficient ${ }^{10}$, is $\sim 0.20$ for the test bearings [38]. Recall that the static load-FB deflection measurements substantially decrease the time and cost in evaluating the mechanical energy dissipation characteristic of bump-type foil bearings [39].

\footnotetext{
${ }^{10}$ The stiffness of the FB structure $\left(K_{s}\right)$ derived from positive displacements in the hysteresis loop in Fig. 14 is approximately $2.2 \mathrm{MN} / \mathrm{m}$, see Figs. 15 and 16.
} 


\section{CHAPTER IV}

\section{EXPERIMENTAL PROCEDURE}

Table 2 presents the matrix of operating conditions for tests with increasing rotor speeds (no rotor spinning, $10 \mathrm{krpm}, 20 \mathrm{krpm}$, and $30 \mathrm{krpm}$ ) and heater set temperatures $\left(T_{h s}=65^{\circ} \mathrm{C}, 100^{\circ} \mathrm{C}\right.$, and $\left.150^{\circ} \mathrm{C}\right)$. Test cases \#1-\#3 and \#4-\#6 represent conditions without and with rotor spinning, respectively. In the non-rotating shaft experiments (test cases \#1-\#3), a forced axial cooling flow rate into the test bearings decreases from $\sim 420$ $\mathrm{L} / \mathrm{min}$ to $0 \mathrm{~L} / \mathrm{min}$. While the rotor is spinning (test cases \#4-\#10), the weakest forced gas stream into the bearings is $\sim 50 \mathrm{~L} / \mathrm{min}$. This is because even small quantities of air are effective to promote the evacuation of hot air from the bearing ${ }^{11}$. In each test case, the heater set (reference) temperature $T_{h s}$ is kept constant as listed in the Table.

For test cases \#1-\#3, while the rotor is not spinning, at $T_{h s}=65^{\circ} \mathrm{C}, 100{ }^{\circ} \mathrm{C}$, and $150{ }^{\circ} \mathrm{C}$, the cooling flow rate into the bearings is decreased after $20-30$ minute intervals once a thermal steady state is achieved. In test cases \#4-\#6, the test system component temperatures are recorded while the rotor speed is set at 10,20 and finally $30 \mathrm{krpm}$. The cooling flow rate into the test bearings is decreased in a similar fashion as in test cases $\# 1-\# 3$. The flow rates quoted distribute into both test bearings.

During each experiment, the ambient temperature $T_{a m b}$, recorded away from the test rig, increases little, from $22^{\circ} \mathrm{C}$ at the beginning of the tests (heater off) to a

\footnotetext{
11 The qualitative assessment for GFB system thermal management requires considerable experience; thermal runaway could occur when very low or no cooling flow is supplied.
} 
maximum of $28^{\circ} \mathrm{C}$ when the heater set temperature $T_{h s}=150{ }^{\circ} \mathrm{C}$. This is because the safety cover of the test rig was not in place during the measurements.

Table 2. Test cases for three heater set temperatures $\left(T_{h s}\right)$ and four cooling flow rate conditions

\begin{tabular}{|c|c|c|c|c|}
\hline $\begin{array}{l}\text { Test } \\
\text { case \# }\end{array}$ & $\begin{array}{c}\text { Heater set } \\
\text { temperature }\left[{ }^{\circ} \mathrm{C}\right]\end{array}$ & $\begin{array}{c}\text { Rotor speed } \\
{[\mathrm{krpm}]}\end{array}$ & $\begin{array}{c}\text { Set cooling flow rate }{ }^{12} \\
\text { (into two bearings) }[\mathrm{L} / \mathrm{min}]\end{array}$ & $\begin{array}{l}\text { Time } \\
{[\mathrm{min}]}\end{array}$ \\
\hline 1 & 65 & 0 & $350 \rightarrow 250 \rightarrow 150 \rightarrow 50 \rightarrow 0$ & 87 \\
\hline 2 & 100 & 0 & $350 \rightarrow 250 \rightarrow 150 \rightarrow 50 \rightarrow 0$ & 84 \\
\hline 3 & 150 & 0 & $350 \rightarrow 250 \rightarrow 150 \rightarrow 50 \rightarrow 0$ & 108 \\
\hline 4 & 65 & $10 \rightarrow 20 \rightarrow 30$ & $350 \rightarrow 250 \rightarrow 150 \rightarrow 50$ & 248 \\
\hline 5 & 100 & $10 \rightarrow 20 \rightarrow 30$ & $350 \rightarrow 250 \rightarrow 150 \rightarrow 50$ & 266 \\
\hline 6 & 150 & 10 & $350 \rightarrow 250 \rightarrow 150 \rightarrow 50$ & 136 \\
\hline 7 & Off & 30 & 350 & 30 \\
\hline 8 & 65 & 30 & 350 & 30 \\
\hline 9 & 100 & 30 & 350 & 30 \\
\hline \multirow[t]{2}{*}{10} & 100 & 30 & 50 & 30 \\
\hline & & & & $\begin{array}{c}\text { Overall } \\
1049 \\
\text { min }\end{array}$ \\
\hline
\end{tabular}

${ }^{12}$ In the experiments, the operator sets the cooling flow rate at $350 \mathrm{~L} / \mathrm{min}, 250 \mathrm{~L} / \mathrm{min}, 150 \mathrm{~L} / \mathrm{min}$, and 50 L/min. However, as shown in Figs. 18 and 19 later, the cooling flow rate into the test bearings is not constant, i.e., it varies with time elapsed. Due to the limited compressed air reservoir (tank) capacity, cooling gas flow from the shop compressed air line provides fluctuating air flow rates. 
Table 2 also shows the time elapsed for each test case. The temperatures are carefully recorded until reaching a thermal equilibrium state. Recall that the sides of the safety cover remain open to reduce the operating time for thermal equilibrium condition of the test system and to minimize thermal damage of the instrumentation ${ }^{13}$ and drive motor.

The procedure for the current experiments is to

1) Affix the motor support housing on the rig base plate.

2) Install the drive motor.

3) Clean the bearing support housing inner surfaces in contact with the bearing sleeve OD.

4) Insert the test bearings into the rig housing. The bearings must be installed into the rig housing without any perceptible play or looseness. For each bearing, a stainless steel shim, $\sim 350^{\circ}$ in circumferential extent with $25.4 \mu \mathrm{m}$ thickness, is inserted between the bearing sleeve OD and rig housing ID. Light pressure, manually applied, is required to assemble mating parts. This interference fit corresponds with FN1 light drive fit defined in AISI Standard B4.1 [40]. The side caps pushing on the bearing sides assure the tight assembly of the bearings into the rig housing.

5) Insert the rotor into its bearings.

6) Align the rotor with respect to the motor shaft by inserting metal shims underneath the bearing support housing.

\footnotetext{
${ }^{13}$ Maximum operating temperature of the infrared thermometer sensor head is $50^{\circ} \mathrm{C}$.
} 
7) Affix the bearing support housing on the rig base plate.

8) Connect the rotor and the drive motor through a flexible coupling.

9) Install the eddy-current displacement sensors to measure shaft displacements.

10) Check the clearance of each bearing through an oscilloscope by manually rotating the test rotor. The clearances between the free end (FE) and drive end (DE) bearings must be similar.

11) Insert the cartridge heater into the hollow test rotor and affix it to the rig base plate.

12) Affix the steel tube, for cooling of the flexible coupling, on the rig base plate.

13) Install infrared thermometers to measure the shaft surface temperature. Focus the infrared spot of the sensor head on the shaft surfaces using a laser sighting device.

14) Install a tachometer and focus its infrared spot on a reflective tape affixed at the coupling surface.

15) Verify proper connections, conditioning, and gains from displacement sensors keyphasor input to the data acquisition systems.

16) Open air valve (1) fully to supply forced cooling air into the test bearings and the coupling. Regulate air supply valve (3) at pressure of 1.36 bar (20 psig) for cooling of the flexible coupling. Then, regulate air valve (2) to set the cooling mass flow rate into the bearings. See Fig. 10 for locations of air valves (1) through (3).

17) Turn the heater controller on and set the heater reference temperature. 
18) Prepare the configuration of data acquisition system, and start recording the rotor response.

19) Turn motor controller power on and operate the motor. Presently, the motor pre-set ramp rate (both acceleration and deceleration) is $16.7 \mathrm{~Hz} / \mathrm{s}$.

20) Record manually temperatures of the test system components at 3-4 minute intervals.

During the experiments with test case \#6, the rotor speed was increased to 20 krpm after 136 minutes of elapsed operation time. Then, the operator heard a noise, akin to that of rubbing of parts. Thus, the operator immediately turned off the drive motor as well the cartridge heater to avoid permanent damage of the test bearings ${ }^{14}$. The operator removed the rotor from its bearings and inspected both rotor and bearings. There was no evidence of damage of the test bearings. Then, the rotor was reinserted into the bearings for further rotordynamic experiments.

After completion of the extensive experiments with test cases \#1 through \#6, rotor speed-down tests were conducted. Recall that the drive motor is controlled to speed down the rotor with a constant ramp rate of $16.7 \mathrm{~Hz} / \mathrm{s}$; therefore, the rotor is not coasting down. The power to the cartridge heater is turned off after the rotor has fully rested on its bearings. In all tests, only baseline rotor motions are measured (no added imbalance masses).

\footnotetext{
${ }^{14}$ Note that the maximum test temperature is not limited by the heater capability.
} 


\section{CHAPTER V}

\section{EXPERIMENTAL RESULTS: TEMPERATURE MEASUREMENTS}

\subsection{Temperature Rise of System Components versus Elapsed Time}

\section{Measurements without rotor spinning}

While the heater set (reference) temperature $T_{h s}$ is fixed at $150{ }^{\circ} \mathrm{C}$ with a stationary (non-rotating) shaft, Fig. 17 depicts temperature rises $\left(T_{i}-T_{a m b}\right)$ where ${ }_{i=} r_{F E}$, $\left.r_{D E, 1-10, \text { in, e, out }}\right)$ of the test system components versus elapsed time. The measurements correspond to test case \#3. See Figs. 5, 6, 9 and 10 for the thermocouples designation and location.

As seen in Fig.17, the temperature of each test component increases steadily with elapsed test time. Recall that the cartridge heat does not flow uniformly along the heater axial length; and hence a distinctive thermal gradient is evident ${ }^{15}$. The tests reproduce similar conditions as in a bearing supporting the hot end of a micro gas turbine, for example [41]. As expected, the temperatures at the rotor OD are much higher than those for the other system components. Note that $T_{i n}$, the supply air temperature, is constant $\left(T_{\text {in }}=T_{a m b}+\sim 2^{\circ} \mathrm{C}\right) . T_{\text {out }}{ }^{16}$, the exhaust air temperature released into the ambient air from the free end bearing (see Fig. 10), follows a similar trend as the enclosure temperature $\left(T_{e}\right)$ but with a smaller magnitude, i.e., $\left(T_{\text {out }}-T_{a m b}\right)=1^{\circ} \mathrm{C} \rightarrow 9^{\circ} \mathrm{C}$ and $\left(T_{e}-T_{a m b}\right)=1^{\circ} \mathrm{C} \rightarrow 23^{\circ} \mathrm{C}$ for cooling rates ranging from $350 \mathrm{~L} / \mathrm{min}$ to $50 \mathrm{~L} / \mathrm{min}$. Note $T_{e}>T_{\text {out }}>T_{\text {in }}$.

\footnotetext{
${ }^{15}$ Recall that the heater temperature controller sets the heater surface temperature at one location (Fig. 5).

${ }^{16}$ Thermocouple $T_{\text {out }}$ locates at $1.5 \mathrm{~mm}( \pm 0.25 \mathrm{~mm})$ above the rotor FE surface and $8 \mathrm{~mm}( \pm 0.5 \mathrm{~mm})$ away from the outboard plane of the FE bearing top foil. Therefore, the recorded temperature does not fully represent the exhaust air temperature leaving the free end bearing.
} 


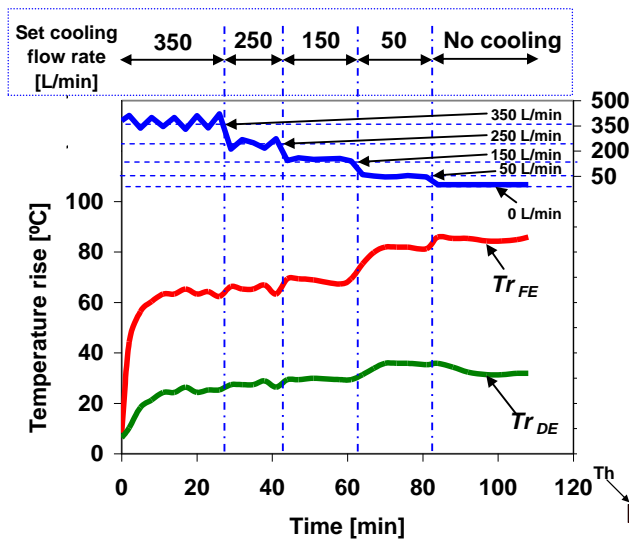

(a) Rotor OD:

Free end $\left(\operatorname{Tr}_{F E}\right)$ and drive end $\left(\operatorname{Tr}_{D E}\right)$

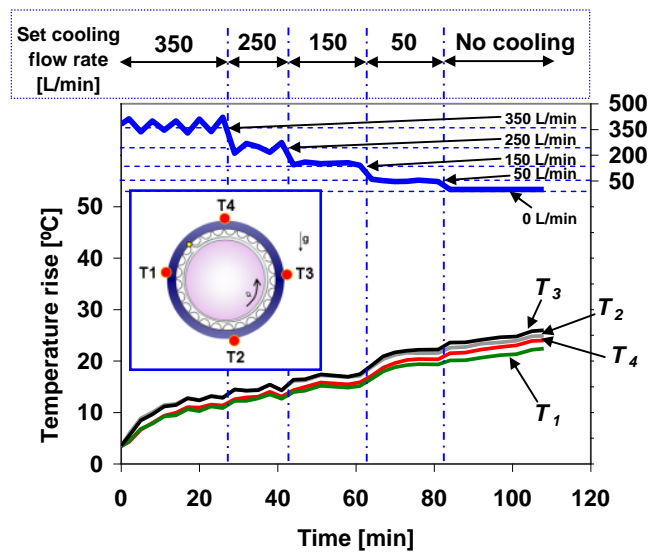

(c) FE bearing sleeve OD $\left(T_{1}-T_{4}\right)$

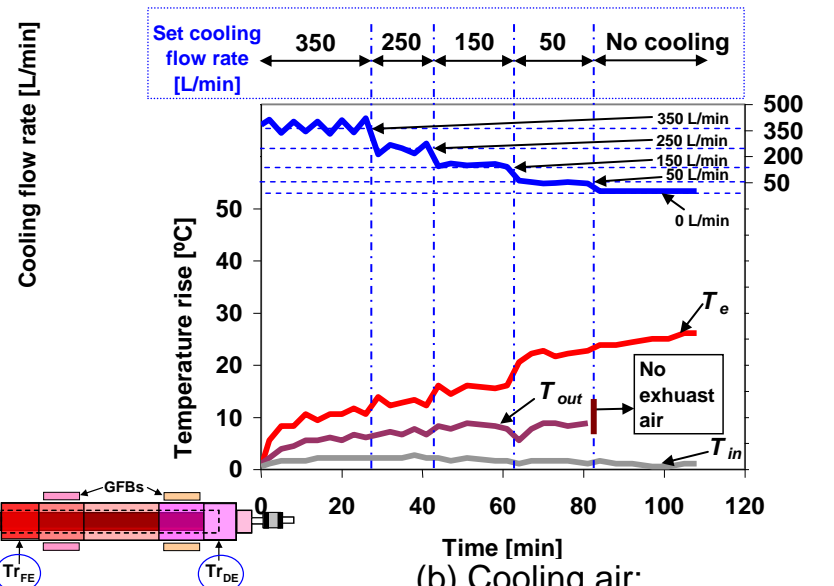

(b) Cooling air:

Upstream $\left(T_{\text {in }}\right)$, enclosure $\left(T_{e}\right)$, and exhaust $\left(T_{\text {out }}\right)$

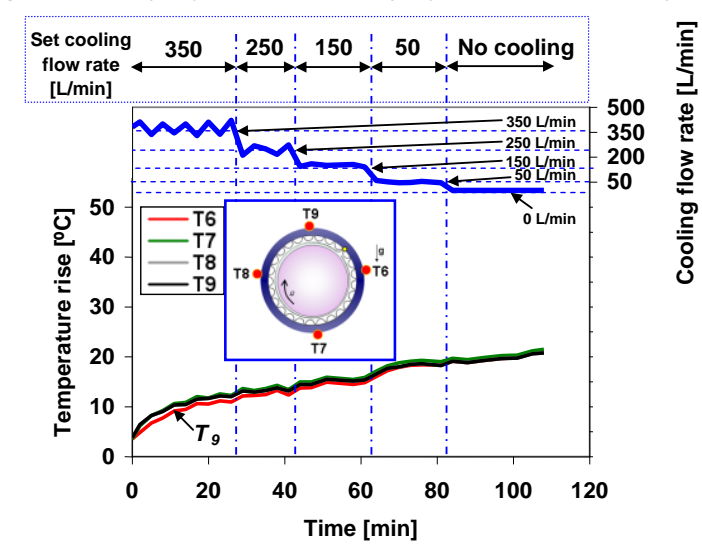

(d) DE bearing sleeve OD $\left(T_{6}-T_{9}\right)$
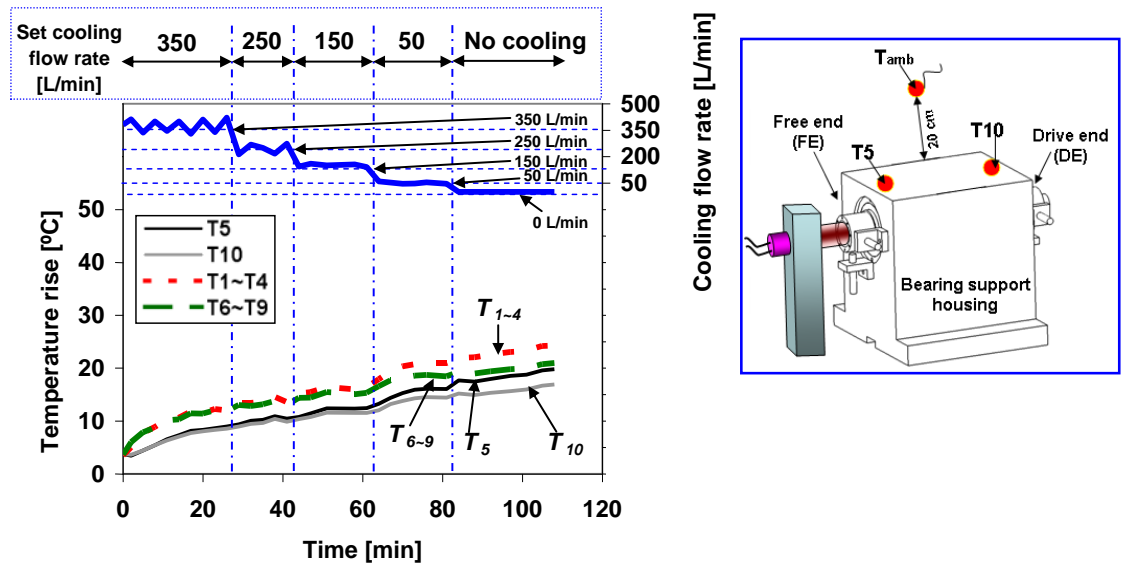

(e) Bearing housing surface $\left(T_{5}\right.$ and $\left.T_{10}\right)$ and bearing mean temperature (FE: $\left.T_{1-4}, \mathrm{DE}: T_{6-9}\right)$ Fig. 17 Test case \#3. Heater set temperature at $150^{\circ} \mathrm{C}$. No rotor spinning: Recorded test

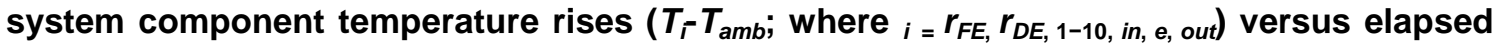
time. Axial cooling flow into bearings decreases from 420 to $0 \mathrm{~L} / \mathrm{min}$. Note different vertical scales. 
Recall that $T_{1}-T_{4}$ and $T_{6}-T_{9}$ are the temperatures measured at the OD of the bearing sleeve mid-plane ${ }^{17}$, see Fig. 5. As shown in Fig. 17 (c), the temperature rises are different depending on the bearing OD circumferential location $\left(T_{3}>T_{2}>T_{4}>T_{1}\right)$, even without rotor spinning. The small differences in these four temperatures in the bearings are attributed to the differences in the rotor surface temperature along its circumference, see Ref. [14]. On the other hand, $T_{6} \approx T_{7} \approx T_{8} \approx T_{9}$ for the (rotor) drive end bearing, see Fig. 17 (d).

In Fig. 17 (e), $T_{1-4}$ and $T_{6-9}$ represent the arithmetic mean from the four measurements around the bearing circumference. Details on the standard deviation for the four measurements follow later (Section 5.4).

$T_{5}$ and $T_{10}$, the bearing support housing surface temperatures, are lower (up to $5^{\circ} \mathrm{C}$ ) than the bearing sleeve temperatures, $T_{1-4}$ and $T_{6-9}$. Recall that the heat input into the test rig is disposed into the ambient condition of the laboratory room.

To evaluate repeatability of the test method, three additional temperature measurement tests were conducted. As an example, Appendix C shows the recorded temperature rise of $T_{1}, T_{e}, \operatorname{Tr}_{F E}$ and $\operatorname{Tr}_{D E}$ versus the air cooling flow rate. The results demonstrate acceptable repeatability, with an average variability less than $5^{\circ} \mathrm{C}$.

Appendix D presents the electric power measurements on the cartridge heater at $T_{h s}=150^{\circ} \mathrm{C}$ with a non-rotating shaft. While the cooling flow rate decreases from $\sim 400$ $\mathrm{L} / \mathrm{min}$ to $\sim 150 \mathrm{~L} / \mathrm{min}$, the electric power to maintain $T_{h s}$ decreases slightly with cooling

\footnotetext{
${ }^{17}$ The recorded bearing sleeve temperatures $\left(T_{1}-T_{4}\right)$ and $\left(T_{6}-T_{9}\right)$ are representative of the bearing ID temperatures. Chapter VII shows the details on predicted radial temperature profiles in the test FB.
} 
flow rate, i.e., $\sim 1,160 \mathrm{~W}$ (at $\sim 400 \mathrm{~L} / \mathrm{min}$ ) $\rightarrow \sim 1,140 \mathrm{~W}$ (at $\sim 150 \mathrm{~L} / \mathrm{min}$ ). However, when the cooling flow rate further decreases from $150 \mathrm{~L} / \mathrm{min}$ to $0 \mathrm{~L} / \mathrm{min}$, the power increases from $\sim 1,140 \mathrm{~W}$ to $\sim 1,160 \mathrm{~W}$.

\section{Measurements with rotor spinning at $10 \mathrm{krpm}$}

For test case \#6 $\left(T_{h s}=150^{\circ} \mathrm{C}\right)$, Fig. 18 depicts temperature rises $\left(T_{i}-T_{a m b}\right)$ where ${ }_{i}$ $\left.=r_{F E}, r_{D E, 1-10, \text { in }, \text { e, out }}\right)$ of the test system components versus elapsed test time. The cooling flow rate into the bearings decreases from $\sim 420 \mathrm{~L} / \mathrm{min}$ to $\sim 50 \mathrm{~L} / \mathrm{min}$ at $\sim 100 \mathrm{~L} / \mathrm{min}$ decrements. In Fig. 18, the trend of the temperatures' increase with time elapsed for each system component is similar as those in Fig. 17 (non-rotating shaft condition) ${ }^{18}$. The maximum rotor $\mathrm{OD}$ and bearing sleeve $\mathrm{OD}$ temperature rises are as high as $93^{\circ} \mathrm{C}$ and $31^{\circ} \mathrm{C}$, respectively.

Figures 17 and 18 also demonstrate that the tests took enough time to reach steady state thermal conditions. Further discussion on the effects of cooling flow rate into the bearings, rotor speed, and rotor OD temperature follow later. For test cases \#1, $\# 2$, \#4, and \#5, Appendix E shows the complete temperature data of each system component versus elapsed time. In addition, Appendix $\mathrm{F}$ contains the complete raw data of the recorded temperatures presented in this chapter. Appendix G presents the recorded cooling flow rate versus supply pressure for test cases \#1-\#6.

\footnotetext{
${ }^{18}$ Figure 18 (d) shows $T_{7}>T_{6}>T_{8}>T_{9}$. However, the differences among four measurements are less than $2{ }^{\circ} \mathrm{C}$.
} 


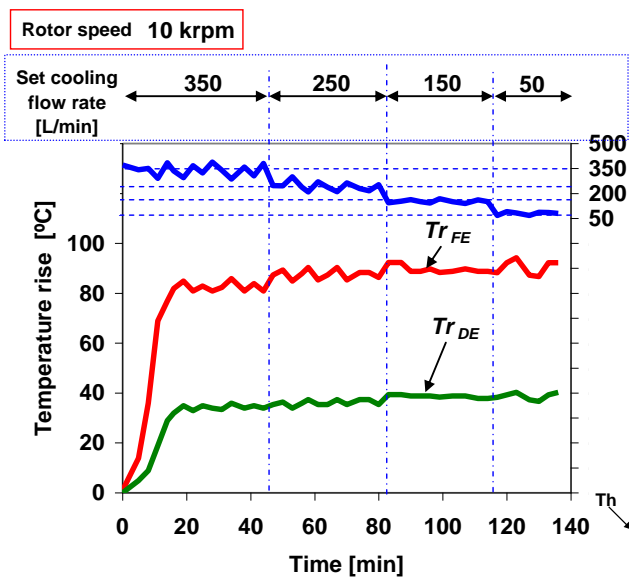

(a) Rotor OD:

Free end $\left(T r_{F E}\right)$ and drive end $\left(T r_{D E}\right)$

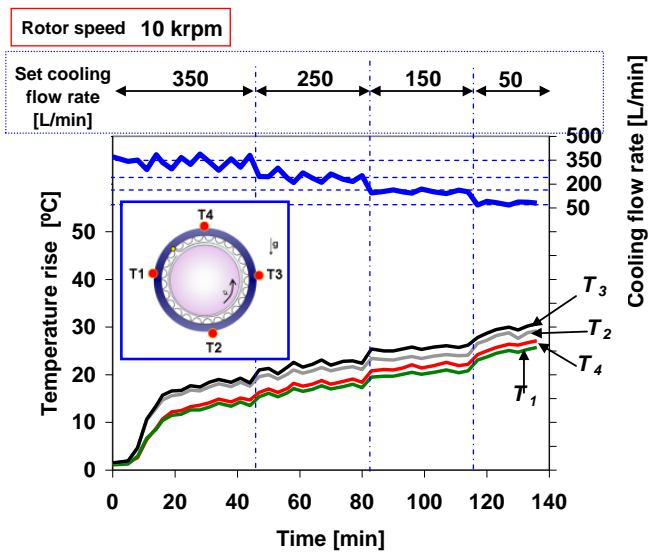

(c) FE bearing sleeve OD $\left(T_{1}-T_{4}\right)$

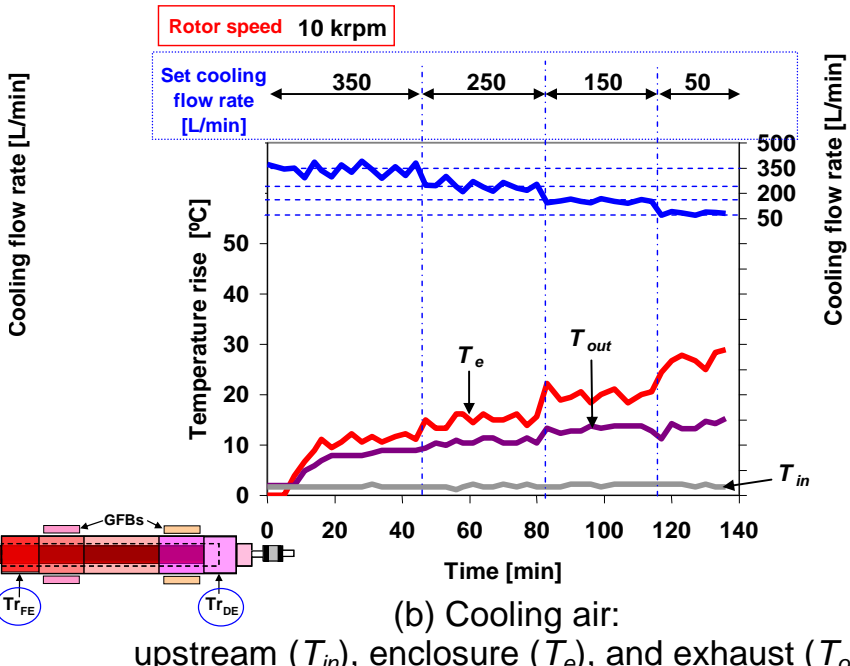

(b) Cooling air:

upstream $\left(T_{\text {in }}\right)$, enclosure $\left(T_{e}\right)$, and exhaust $\left(T_{\text {out }}\right)$
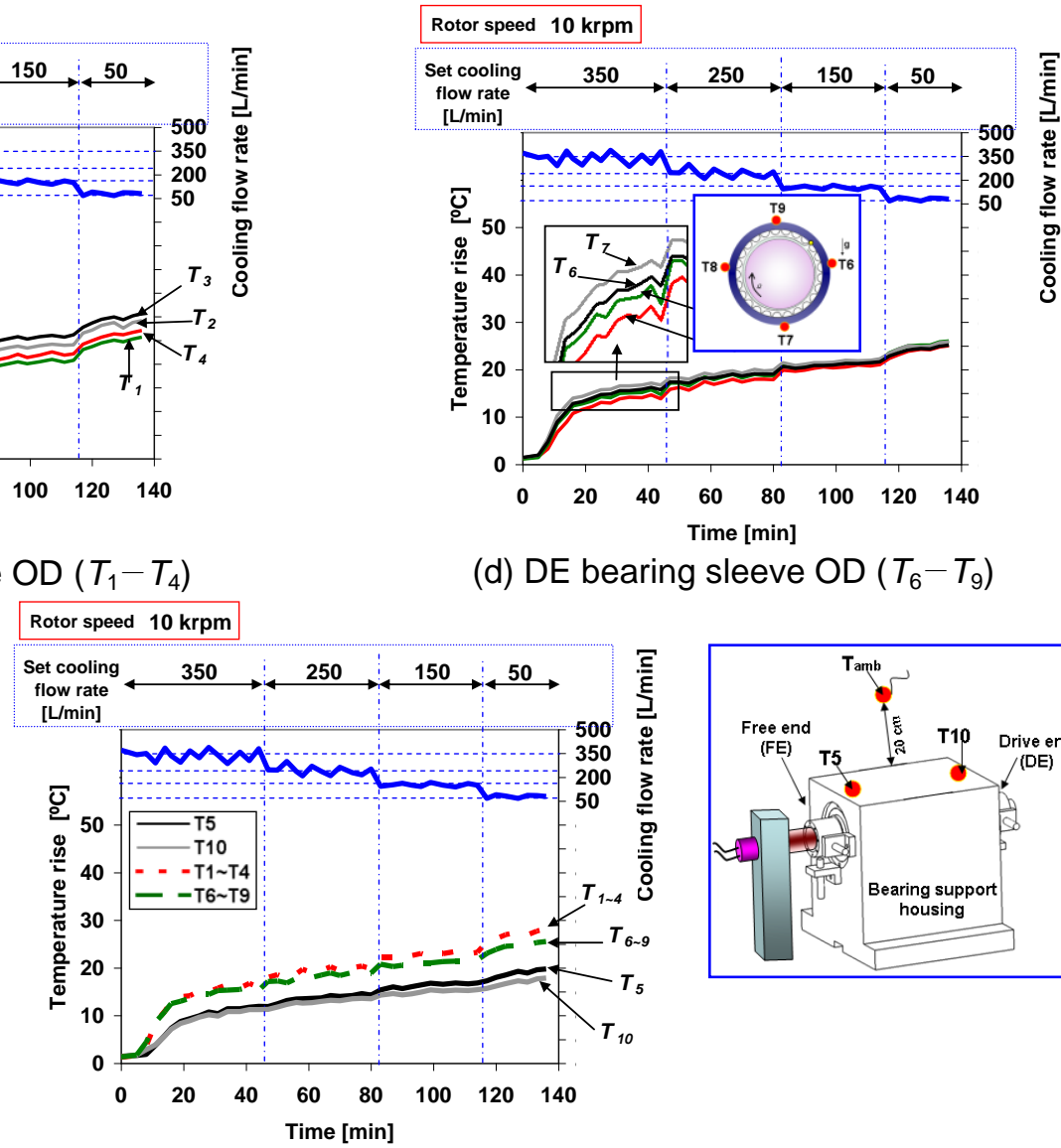

(d) DE bearing sleeve OD $\left(T_{6}-T_{9}\right)$
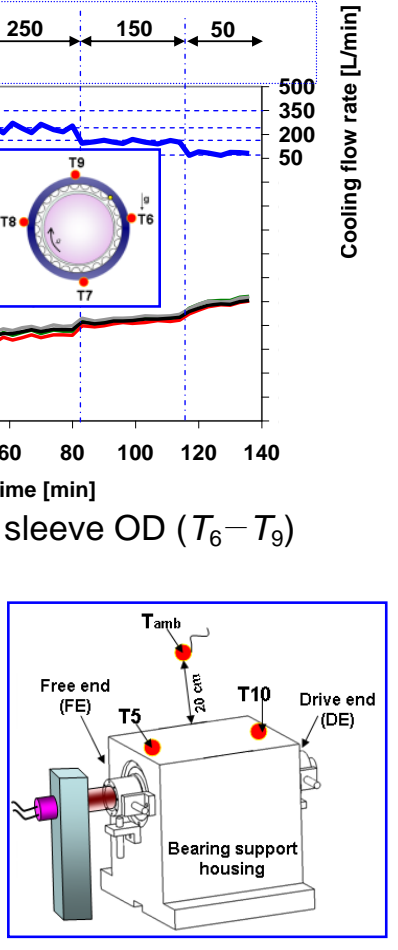

(e) Bearing housing surface ( $T_{5}$ and $\left.T_{10}\right)$ and bearing mean temperature (FE: $\left.T_{1-4}, \mathrm{DE}: T_{6-9}\right)$ Fig. 18 Test case \#6, Heater set temperature at $150^{\circ} \mathrm{C}$. Rotor speed of $10 \mathrm{krpm}$ : Recorded

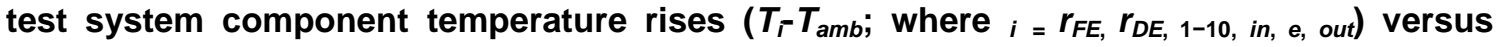
elapsed time. Axial cooling flow into bearings decreases from 420 to $0 \mathrm{~L} / \mathrm{min}$. Note different vertical scales. 


\subsection{Rotor Surface and Bearing Sleeve Temperatures versus Cooling Flow Rate}

For test case \#2 $\left(T_{h s}=100^{\circ} \mathrm{C}\right.$ and no rotor spinning), Fig. 19 depicts surface plots of temperature rises at the rotor free end $\left(\operatorname{Tr}_{F E}-T_{a m b}\right)$, the free end bearing sleeve $\left(T_{1-4}-\right.$ $T_{a m b}$ ) (arithmetic mean), the housing enclosure $\left(T_{e}-T_{a m b}\right)$, the drive end bearing sleeve $\left(T_{6-9}-T_{a m b}\right)$ (arithmetic mean), and the rotor drive end $\left(\operatorname{Tr}_{D E}-T_{a m b}\right)$ versus shaft axial location and versus cooling air flow rate. The inset graph displays the location of the thermocouples. The figure clearly shows a pronounced temperature drop along the shaft axial length from the rotor free end (FE) toward the drive end (DE), $\operatorname{Tr}_{F E} \gg \operatorname{Tr}_{D E}{ }^{19}$. Recall the test rotor is a heat source with its OD surface at a higher temperature than the gas film ${ }^{20}$.

The temperatures along the rotor axial length drop quickly due to the convection of thermal energy by the forced cooling gas stream. Recall the air feeding enclosure is located at the mid-plane of the test rotor. Incidentally, recall that the rotor OD temperatures $\operatorname{Tr}_{F E}$ and $\operatorname{Tr}_{D E}$ are recorded on the outer boards of each bearing cartridge.

The mean temperatures of the FE and DE bearing sleeves are almost identical. Recall that the bearing mean temperatures $T_{1-4}$ and $T_{6-9}$, derived from four measurements taken around the bearing sleeve circumference, do not have a significant standard deviation, see figures on pages 53 and 54. For each rotor speed, the system component temperatures hardly change for cooling flow rates larger than $\sim 300 \mathrm{~L} / \mathrm{min}$.

\footnotetext{
${ }^{19}$ Presently, as shown in Appendix E, the maximum axial thermal gradient reaches up to $\sim 55^{\circ} \mathrm{C}$ from the rotor FE toward its DE.

${ }^{20}$ When the rotor is at a lower temperature due to an inner cooling flow (i.e., the cooling stream flows through the hollow rotor to cool directly the rotor ID), thermal energy flows from the gas film to the rotor surface. For this case, a hollow rotor becomes a sink of thermal energy.
} 
With cooling flow rates from $420 \mathrm{~L} / \mathrm{min}$ to $150 \mathrm{~L} / \mathrm{min}$, the rotor and bearing temperatures steadily decrease. On the other hand, the system components temperatures suddenly increase when the cooling flow decreases from $\sim 150 \mathrm{~L} / \mathrm{min}$ to $\sim 50 \mathrm{~L} / \mathrm{min}$. For example, $\operatorname{Tr}_{F E}$ increases by $20 \%\left(50^{\circ} \mathrm{C} \rightarrow 60^{\circ} \mathrm{C}\right)$ with cooling flow decreasing from 150 $\mathrm{L} / \mathrm{min}$ to $50 \mathrm{~L} / \mathrm{min}$. The air temperature in the enclosure $T_{e}$ increases linearly with rotor temperature while the air cooling flow rate decreases.

Note that the bearing temperatures follow a similar trend as the enclosure air temperature $\left(T_{e}\right)$, see Figs. 20 and 21 and Appendix H. In general, $T_{e}$ increases as the cooling flow rate decreases due to the longer residence of air particles inside the enclosure.

Details on the bearing housing surface temperatures $T_{5}$ and $T_{10}$ are omitted for brevity. In general, $T_{5}$ and $T_{10}$ show similar trends as $T_{1-4}$ and $T_{6-9}$ depicted in Fig. 19 , albeit with lower magnitudes. The decrease in temperature from a bearing sleeve OD to the support housing surface is due to heat conduction and convection to ambient air surrounding the test rig. 


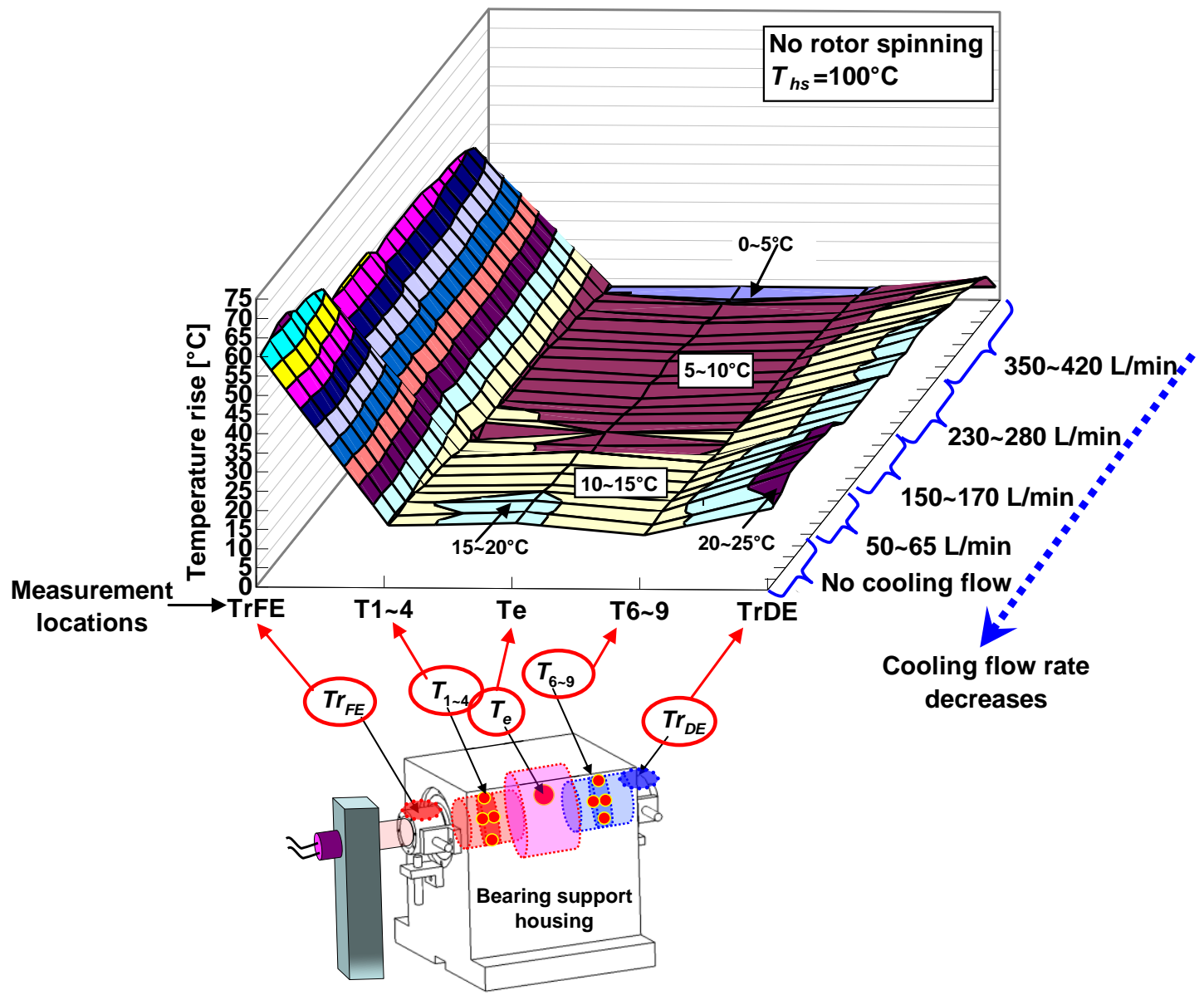

Fig. 19 Test case \#2. $T_{h s}=100^{\circ} \mathrm{C}$. No rotor spinning: Surface plot of temperature rises at the rotor free end $\left(T r_{F E}-T_{a m b}\right)$, the free end bearing sleeve $\left(T_{1-4}-T_{a m b}\right)$ (arithmetic mean), the housing enclosure $\left(T_{e}-T_{a m b}\right)$, the drive end bearing sleeve $\left(T_{6-9}-T_{a m b}\right)$ (arithmetic mean), and the rotor drive end ( $\left.T r_{D E}-T_{a m b}\right)$ versus shaft axial location and versus cooling air flow rate.

Figures 20 and 21 depict the arithmetic mean temperatures on the bearing sleeves, $\left(T_{1-4}-T_{a m b}\right)(\mathrm{FE})$ and $\left(T_{6-9}-T_{a m b}\right)(\mathrm{DE})$, versus air temperature in the enclosure $\left(T_{e}-T_{a m b}\right)$, respectively. The measurements correspond to test cases \#2 through \#5. 
Appendix $\mathrm{H}$ shows more test data at $T_{h s}=65^{\circ} \mathrm{C}$ and $150^{\circ} \mathrm{C}$. In the figures, the dash line denotes a condition where the bearing temperature is identical to the enclosure air temperature. The bearing temperature linearly increases with the enclosure air temperature as the cooling flow rate into the bearings decreases. When the rotor is stationary (i.e., no rotor spinning), $\left(T_{1-4}-T_{a m b}\right) \approx\left(T_{e}-T_{a m b}\right)$ and $\left(T_{6-9}-T_{a m b}\right) \approx\left(T_{e}-T_{a m b}\right)$ for cooling flow rate $>100 \mathrm{~L} / \mathrm{min}$.

In general, the air temperature inside the enclosure is lower than that in the bearings sleeve OD. However, while operating at 0 and $10 \mathrm{krpm}$ and with cooling flow rate less than $100 \mathrm{~L} / \mathrm{min}$, air temperatures in the enclosure are slightly higher than the bearing temperatures. For example, see Figs. 20 (a) and (b) and Figs. 21 (a) and (b). This is because, when no (or small) cooling flow is forced into the bearings, the air in the enclosure acts as a thermal sink since the enclosure is not open to ambient (i.e., closed, see Fig. 5). While no cooling flow is supplied into the bearings, $T_{e}$ increases because of natural convection and radiation from the rotor OD. Recall that the air temperature $\left(T_{e}\right)$ in the enclosure also increases as the rotor temperature rises (see Figs. 17 and 18, and Appendix E). In addition, $T_{e}$ increases with rotor speed due to windage effects (added drag or fluid resistance to rotation) ${ }^{21}[42,43]$. It is important to note that the air temperature $\left(T_{e}\right)$ in the enclosure can be also regarded as the inlet cooling stream temperature into the bearing.

\footnotetext{
${ }^{21}$ Windage effect occurs between two surfaces moving in relation to each other. This effect strongly depends on the rotor surface speed, rotor-stator clearance and "wetted" area, surface roughness, and fluid properties, in particular the gas pressure [44]. Presently, the windage effect inside the enclosure is not quantified.
} 


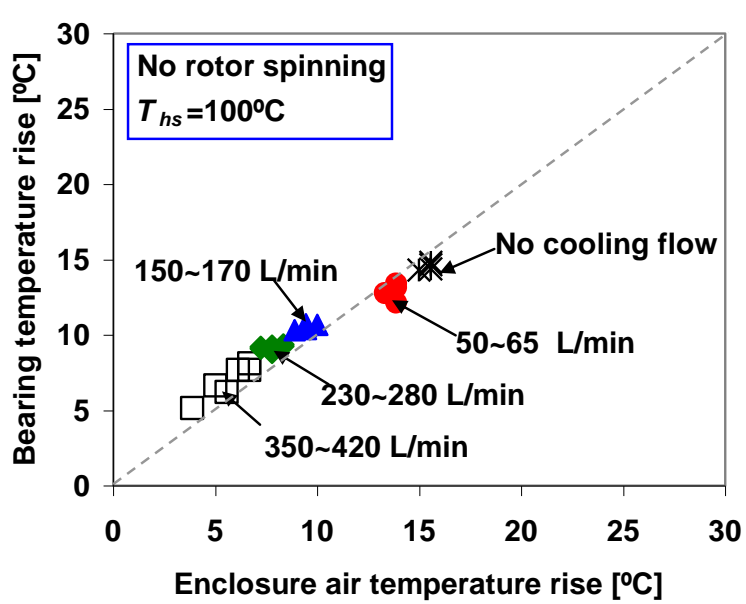

(a) No rotor spinning

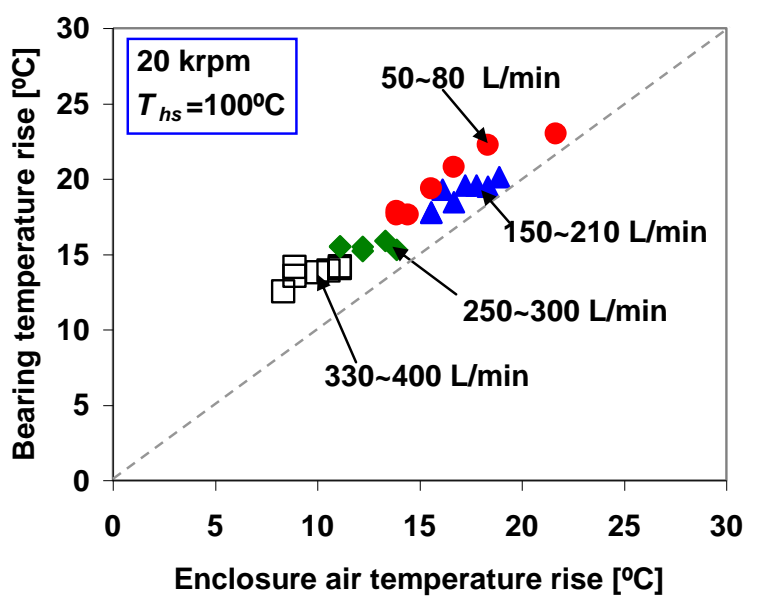

(c) $20 \mathrm{krpm}$

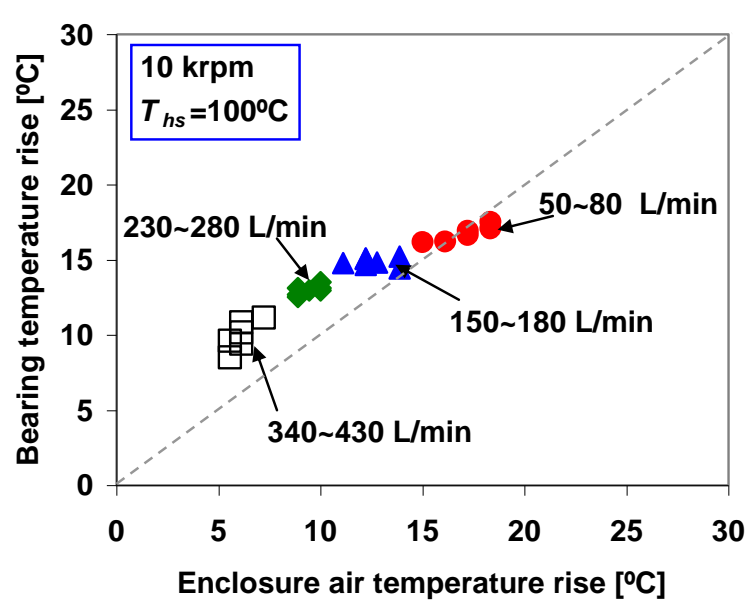

(b) $10 \mathrm{krpm}$

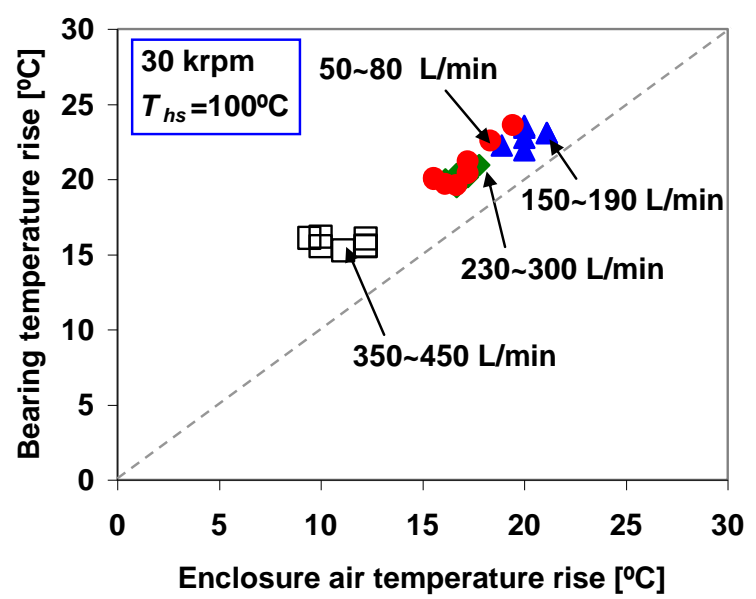

(c) $30 \mathrm{krpm}$

Fig. 20 Test cases \#2 and \#5. $T_{h s}=100^{\circ} \mathrm{C}$ : Free end bearing temperature rise $\left(T_{1-4}-T_{a m b}\right)$ versus air temperature rise in the enclosure $\left(T_{e}-T_{a m b}\right)$. Arithmetic mean of $\left(T_{1}, T_{2}, T_{3}\right.$, and $\left.T_{4}\right)$ shown. 


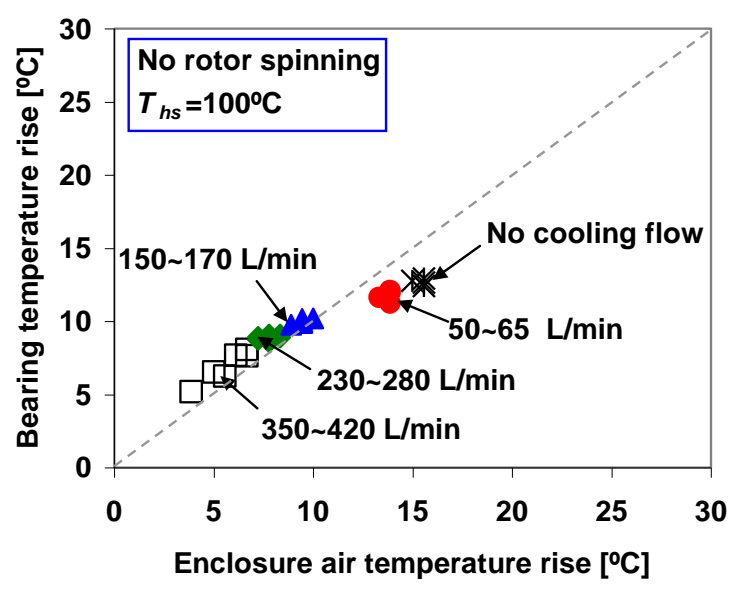

(a) No rotor spinning

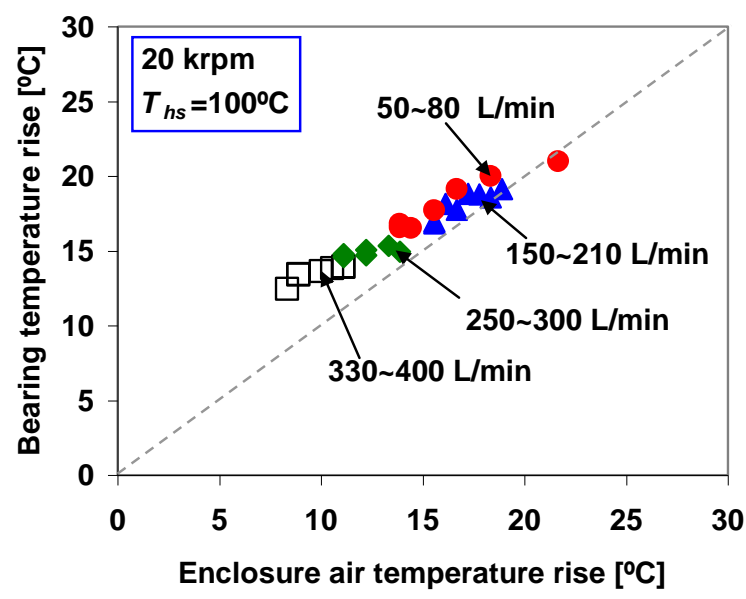

(c) $20 \mathrm{krpm}$

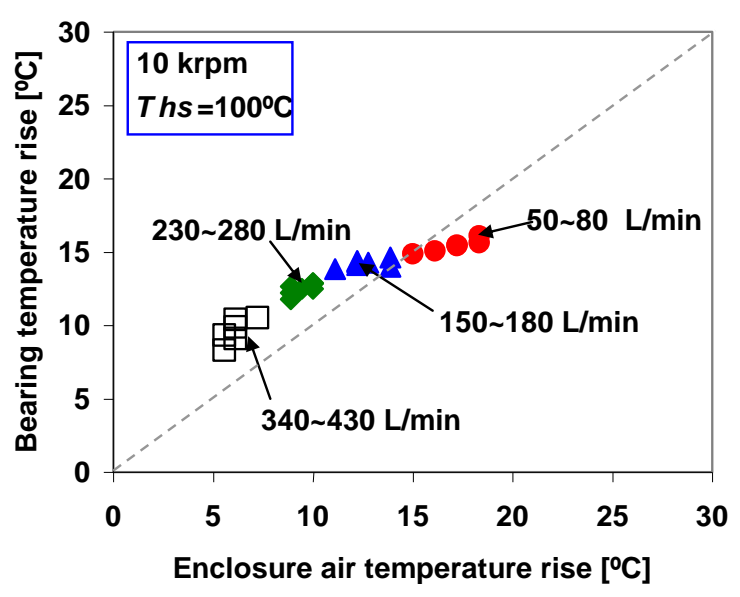

(b) $10 \mathrm{krpm}$

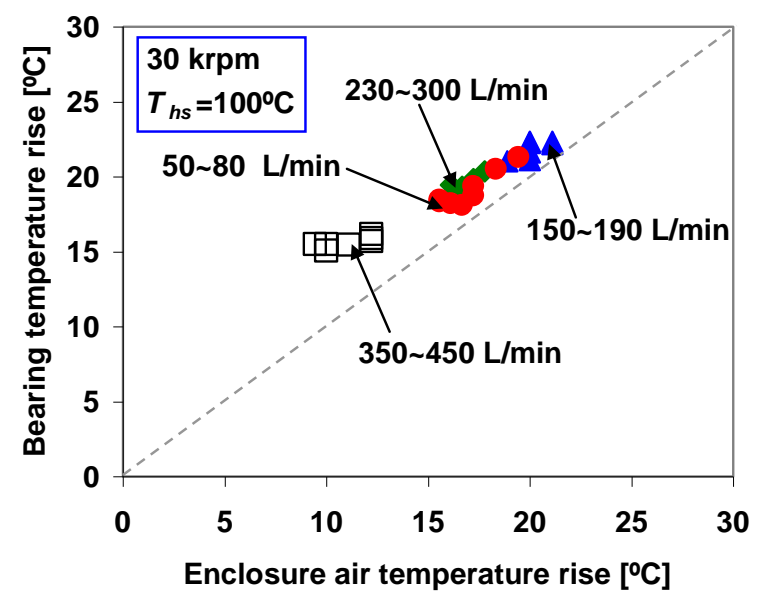

(d) $30 \mathrm{krpm}$

Fig. 21 Test cases \#2 and \#5. $T_{h s}=100^{\circ} \mathrm{C}$ : Drive end bearing temperature rise $\left(T_{6-9}-T_{a m b}\right)$ versus air temperature rise in the enclosure $\left(T_{e}-T_{a m b}\right)$. Arithmetic mean of $\left(T_{6}, T_{7}, T_{8}\right.$, and $\left.T_{9}\right)$ shown.

The temperature difference $\left(T_{i}-T_{e}\right)$ where ${ }_{i=1-4}$ and $6_{-9}$ of the bearings above the air temperature in the enclosure $\left(T_{e}\right)$ shows the temperature rise relative to the forced 
inlet cooling stream temperature. Therefore, $\left(T_{i}-T_{e}\right)$ leads to determine the effect of cooling flow rate and rotor speed on the bearing temperatures.

Figure 22 depicts the arithmetic mean temperatures of the bearing sleeve ODs above the inlet cooling air temperature $\left(T_{1-4}-T_{e}\right)$ for the FE bearing and $\left(T_{6-9}-T_{e}\right)$ for the DE bearing versus cooling flow rate for increasing heater set temperatures $\left(T_{h s}=65^{\circ} \mathrm{C}\right.$, $100^{\circ} \mathrm{C}$, and $150^{\circ} \mathrm{C}$ ) and three rotor speeds (10, 20 and $\left.30 \mathrm{krpm}\right)$. Data shown in Figs. 17-18 and Appendix E are combined to make Fig. 22. Recall Figs. 5, 6, 9 and 10 for the location of the thermocouples.

Temperature differences between the bearing sleeve OD and the air inside the enclosure are nearly invariant while increasing the cooling flow rate. That is $\left(T_{i}-T_{e}\right)$ at 10-30 krpm are a few degrees $\left(<10^{\circ} \mathrm{C}\right)$ higher than those for the no rotor spinning condition due to the increase in shear drag power within the gas film in the bearing while the shaft rotates. Recall that $\left(T_{i}-T_{e}\right)<0^{\circ} \mathrm{C}^{22}$ for cooling flow rates lesser than $100 \mathrm{~L} / \mathrm{min}$ is due to a bearing housing feed enclosure at its center that is not open to ambient. The supply air temperature well upstream of the test rig is shown in Figs. 17 and 18 and Appendix E.

\footnotetext{
${ }^{22}$ This condition represents the air inside the enclosure is hotter than the bearing ODs.
} 

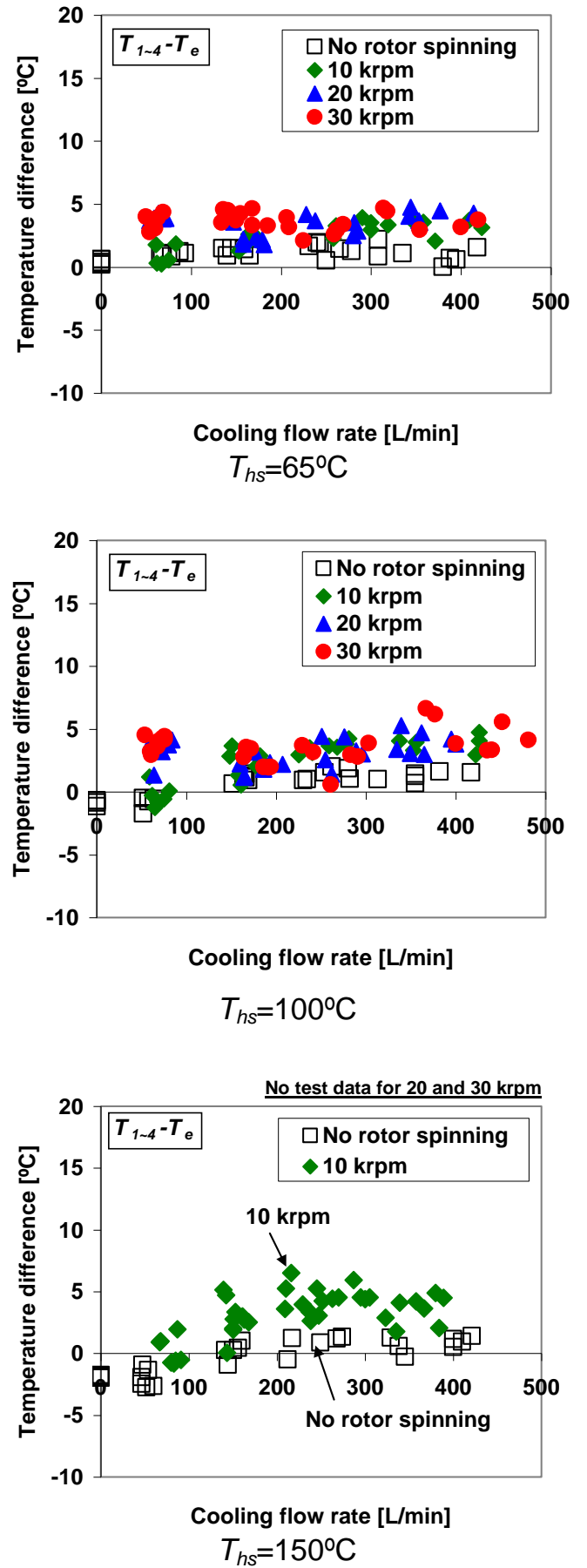

(a) Arithmetic mean temperature of free end (FE) bearing sleeve OD temperature: $T_{1-4}$
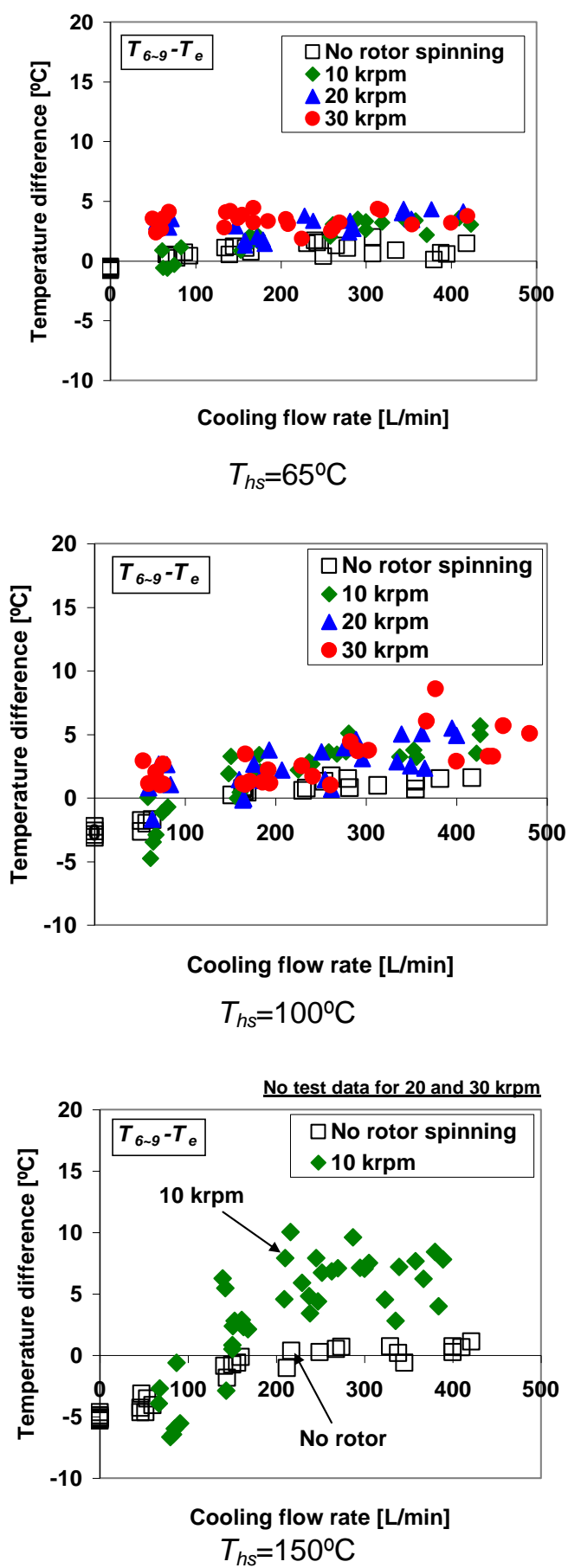

(b) Arithmetic mean temperature of drive end (DE) bearing sleeve OD temperature: $T_{6-9}$

Fig. 22 Test cases \#1-\#6, Heater set temperature $=65,100$, and $150^{\circ} \mathrm{C}$. No rotor spinning and rotor speed of 10,20 , and $30 \mathrm{krpm}$ : Recorded temperature difference of bearing sleeve OD above inlet cooling air temperature $\left(T_{1-4}-T_{e}\right)$ and $\left(T_{6-9}-T_{e}\right)$ versus cooling flow rate. 


\subsection{Rotor and Bearing Sleeve Temperature Rises per Unit Cooling Flow Rate: Cooling Capability of Forced Axial Flow}

The temperature rise per unit cooling flow rate gives more insight to realize its effects on the thermal performance of the test rotor-bearings system. Figures 23 and 24 show the recorded temperature rise $\left(T_{i}-T_{a m b}\right)_{i=} r_{F E}, r_{D E, 1-4, \text { and 6-9 }}$ divided by the cooling flow rate $(\mathrm{L} / \mathrm{min})$ versus increasing cooling flow rate for various heater temperatures $\left(T_{h s}\right)$ from $65^{\circ} \mathrm{C}$ to $150^{\circ} \mathrm{C}$.

The cooling capability of the forced axial flow on the bearing and rotor temperatures shows a nearly exponential decay. In particular, with cooling flow rates over $300 \mathrm{~L} / \mathrm{min}$, the cooling capability of the forced axial flow for the test bearing is less than $0.05^{\circ} \mathrm{C} / \mathrm{L} / \mathrm{min}$, hardly changing with flow rate. The cooling effectiveness of the forced cooling stream is most distinct at the free end rotor OD and at $30 \mathrm{krpm}$. It is important to note that the cooling stream takes away most of the heat from the back of the top foil, with little heat conduction into the bearing sleeve.

For cooling flow rates of increasing strength, Appendix I shows predictions for the axial and circumferential flow Reynolds numbers that identify the flow characteristics of the inner and outer cooling streams. Laminar flow prevails through the inner film gap (i.e., thin film gas region); while for the outer cooling flow, a transition from laminar flow to turbulent flow occurs when the cooling flow is larger than $\sim 115$ $\mathrm{L} / \mathrm{min}$ (per bearing). 


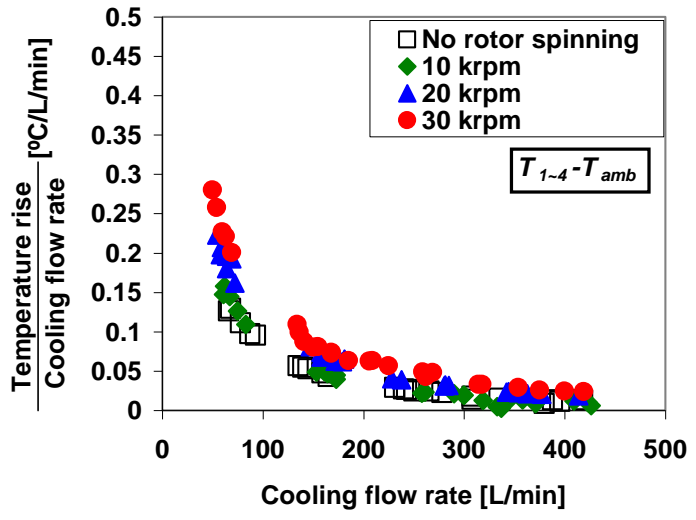

$T_{h s}=65^{\circ} \mathrm{C}$

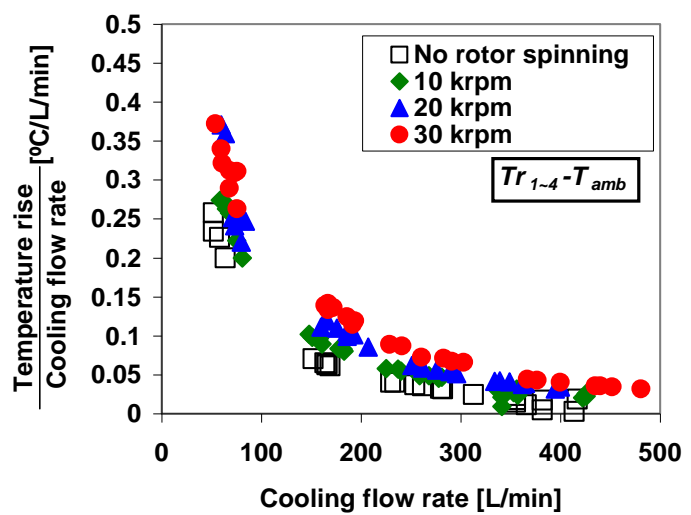

$T_{h s}=100^{\circ} \mathrm{C}$

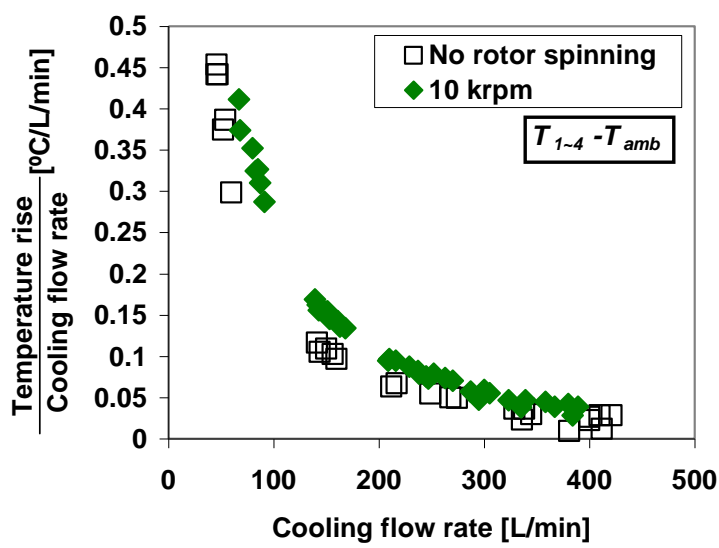

$T_{h s}=150^{\circ} \mathrm{C}$ : No test data for 20 and $30 \mathrm{krpm}$

(a) Arithmetic mean temperature of free end

(FE) bearing sleeve OD temperature: $T_{1-4}$

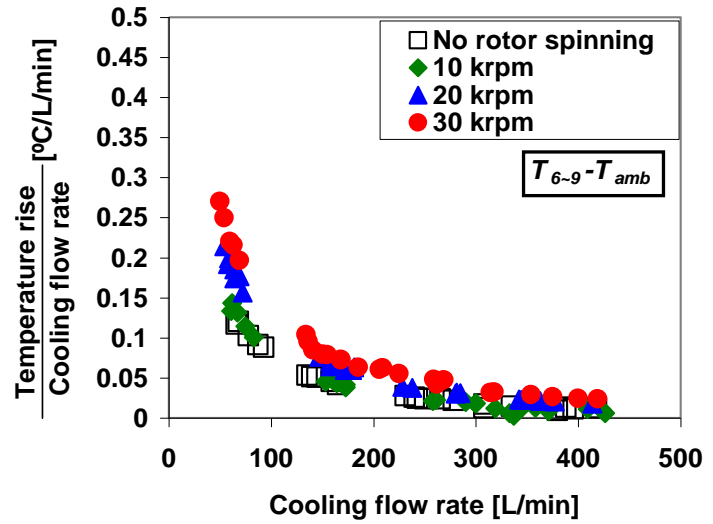

$T_{h s}=65^{\circ} \mathrm{C}$

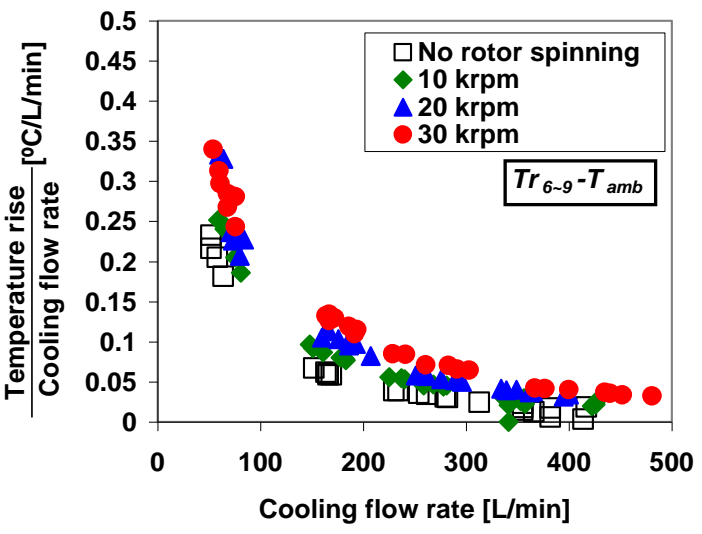

$$
T_{h s}=100^{\circ} \mathrm{C}
$$

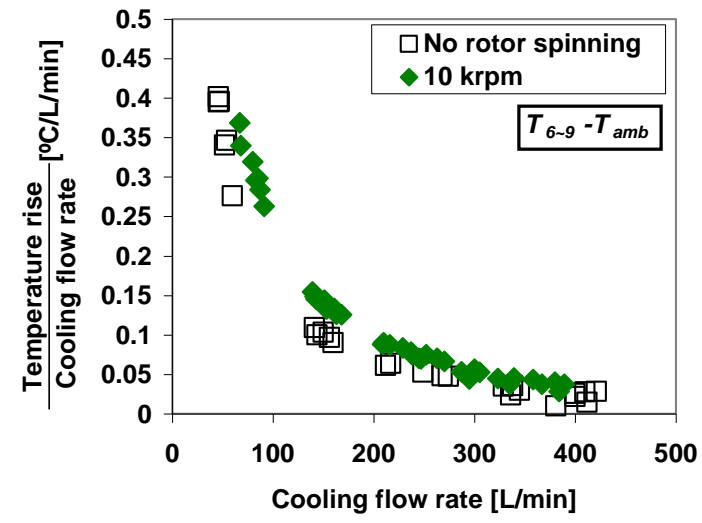

$T_{h s}=150^{\circ} \mathrm{C}:$ No test data for 20 and $30 \mathrm{krpm}$

(b) Arithmetic mean temperature of drive end (DE) bearing sleeve OD temperature: $T_{6-9}$

Fig. 23 Test cases \#1-\#6. Heater set temperature $=65,100$, and $150^{\circ} \mathrm{C}$. No rotor spinning and rotor speed of 10, 20, and $30 \mathrm{krpm}$ : Recorded temperature rise on bearing sleeve ODs, $\left(T_{1-4}-T_{a m b}\right)$ and $\left(T_{6-9}-T_{a m b}\right)$ per unit cooling flow rate (L/min) versus cooling flow rate. 


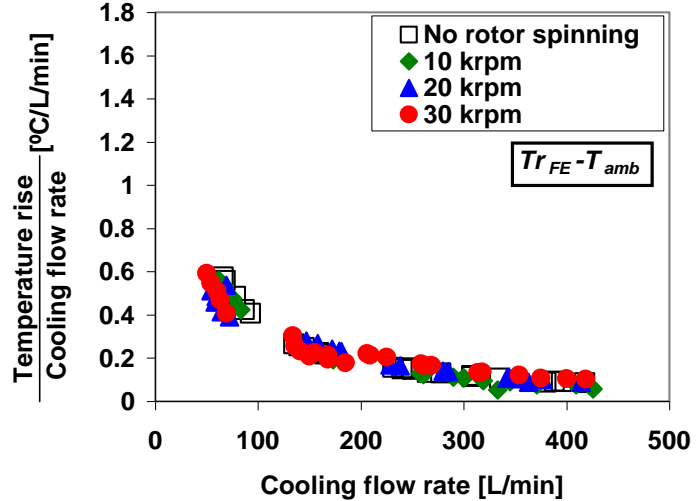

$T_{h s}=65^{\circ} \mathrm{C}$

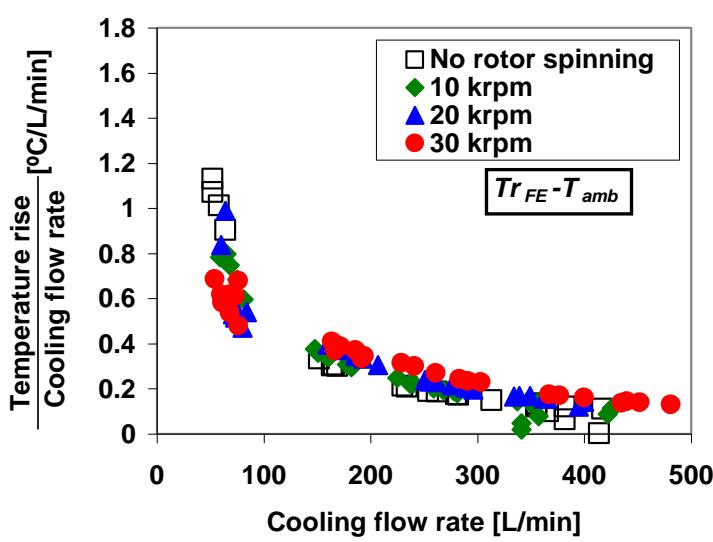

$T_{h s}=100^{\circ} \mathrm{C}$

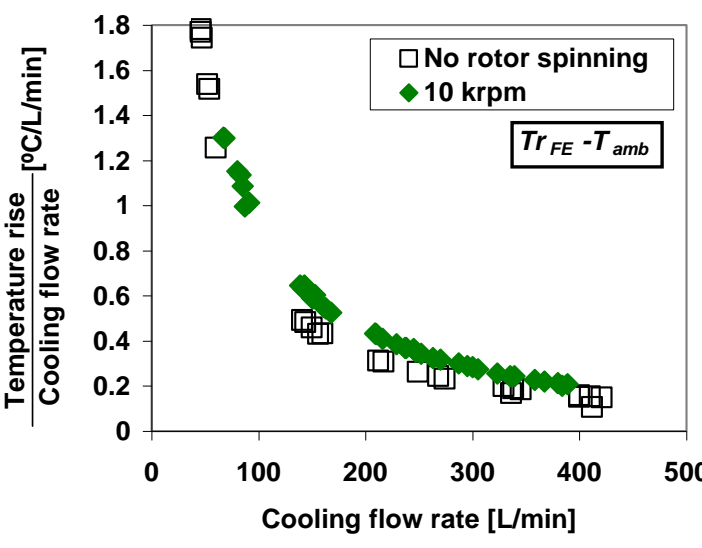

$T_{h s}=150^{\circ} \mathrm{C}:$ No test data for 20 and $30 \mathrm{krpm}$

(a) Rotor free end OD $\left(\operatorname{Tr}_{F E}\right)$

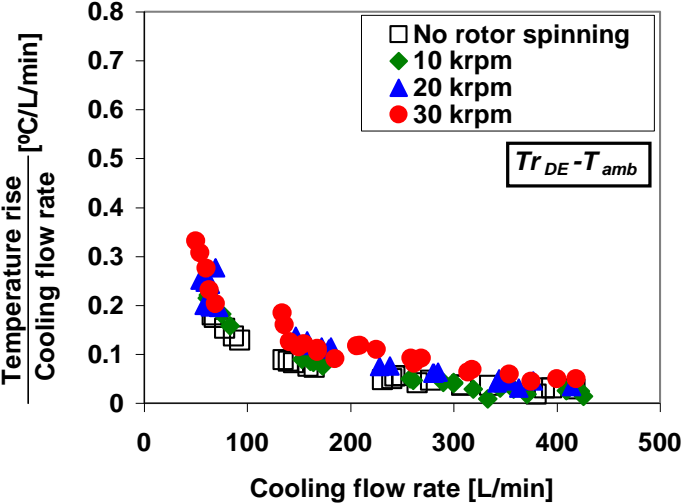

$T_{h s}=65^{\circ} \mathrm{C}$

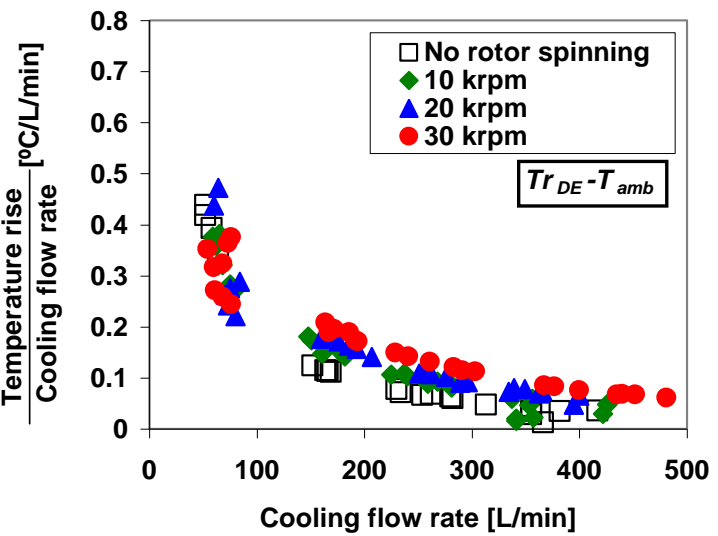

$T_{h s}=100^{\circ} \mathrm{C}$

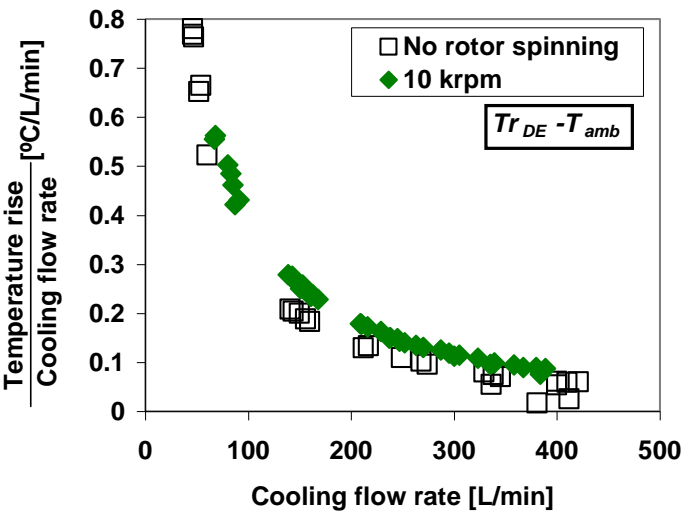

$T_{\text {hs }}=150^{\circ} \mathrm{C}$ : No test data for 20 and $30 \mathrm{krpm}$

(b) Rotor drive end OD $\left(\operatorname{Tr}_{D E}\right)$

Fig. 24 Test cases \#1-\#6. Heater set temperature=65, 100, and $150^{\circ} \mathrm{C}$. No rotor spinning and rotor speed of 10, 20, and $30 \mathrm{krpm}$ : Rotor OD temperature rise, $\left(\operatorname{Tr}_{\mathrm{FE}} \boldsymbol{T}_{\mathrm{amb}}\right)$ and ( $\operatorname{Tr}_{\mathrm{DE}}$ $\left.T_{a m b}\right)$ per unit cooling flow rate $(\mathrm{L} / \mathrm{min})$ versus cooling flow rate. Note different scales of vertical axes. 


\subsection{Temperatures on Bearing Sleeves}

While the shaft is non-rotating and while rotating at $10 \mathrm{krpm}$, Figs. 25 and 26 show the standard deviation of the four temperatures recorded on the OD circumference of the FE and DE bearing sleeves versus elapsed time. The standard deviation is a measure of the temperatures dispersion from the average value (an arithmetic mean). Recall Figs. 17-18 and Appendix E for two bearings temperatures. Note that, even without rotor spinning, the temperature rises are different around the bearing circumference location due to the unevenness of the heater temperature along its circumference. As the rotor spins, the temperatures at the bearing circumferential locations increase. The FE bearing OD sleeve temperatures $\left(T_{1}\right.$ through $\left.T_{4}\right)$ show more variation around the bearing circumference than on the drive end bearing $\left(T_{6}\right.$ through $T_{9}$ ). A small temperature difference among the four thermocouples on each bearing leads to a uniform circumferential thermal growth of the bearing sleeve. In general, the standard deviation of the four bearing temperatures slightly increases with the cooling flow rate, i.e., higher cooling flow rate results in a more pronounced circumferential temperature gradient. 


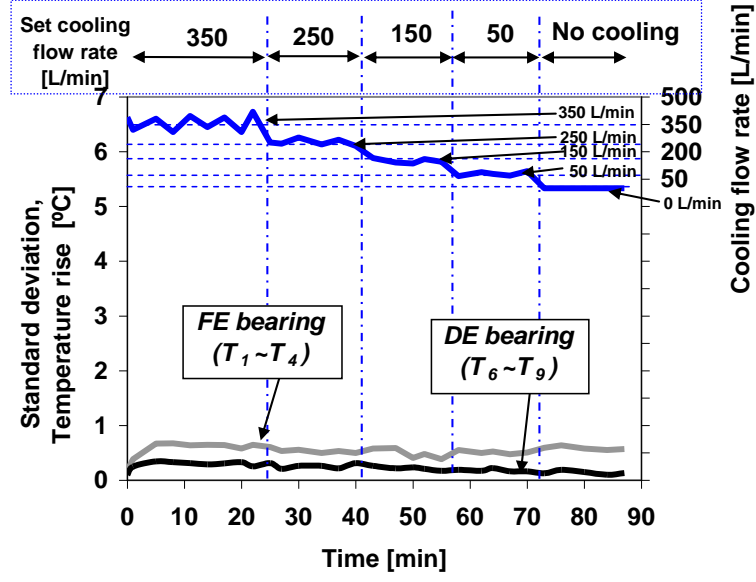

(a) Test case \#1: $T_{h s}=65^{\circ} \mathrm{C}$

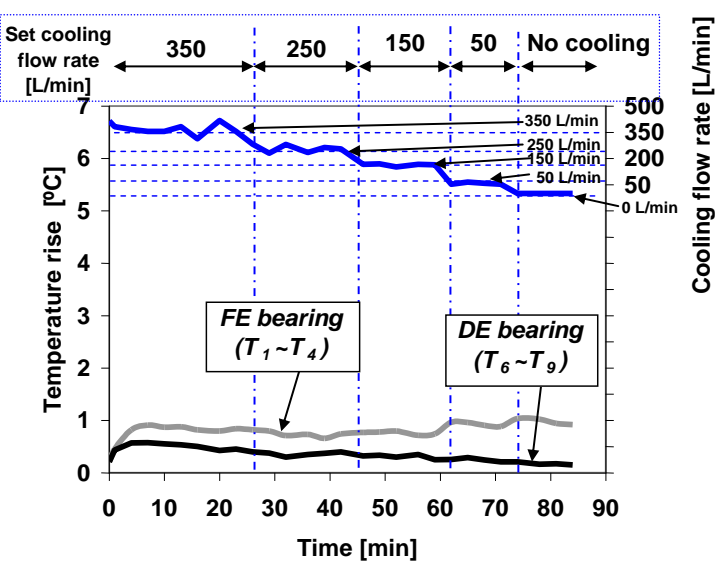

(b) Test case \#2: $T_{h s}=100^{\circ} \mathrm{C}$

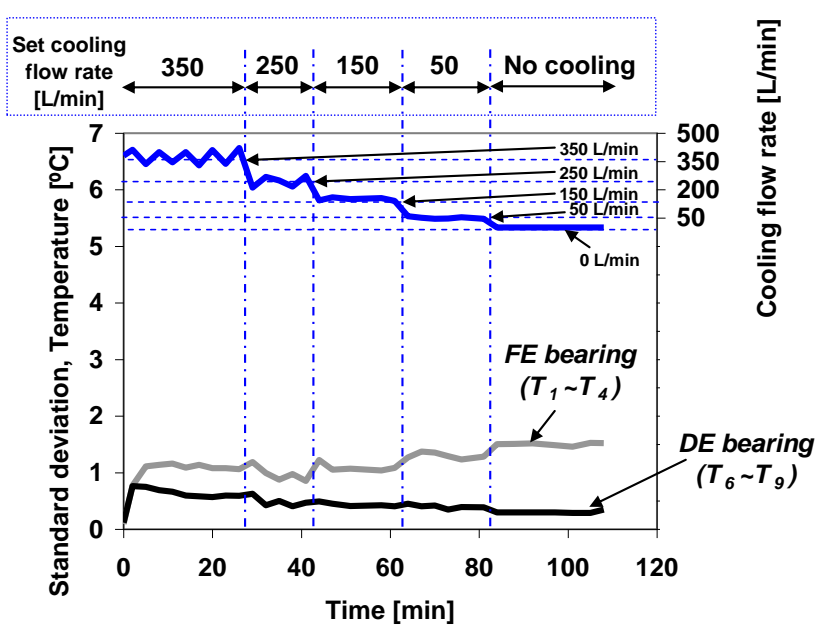

(c) Test case \#3: $T_{h s}=150^{\circ} \mathrm{C}$

Fig. 25 Test cases \#1-\#3. No rotor spinning: Standard deviation of FE and DE bearing temperature rise versus elapsed time. $T_{1} \sim T_{4}$ : Standard deviation of $\mathrm{FE}$ bearing temperatures, $T_{6} \sim T_{9}$ : Standard deviation of DE bearing temperatures. 


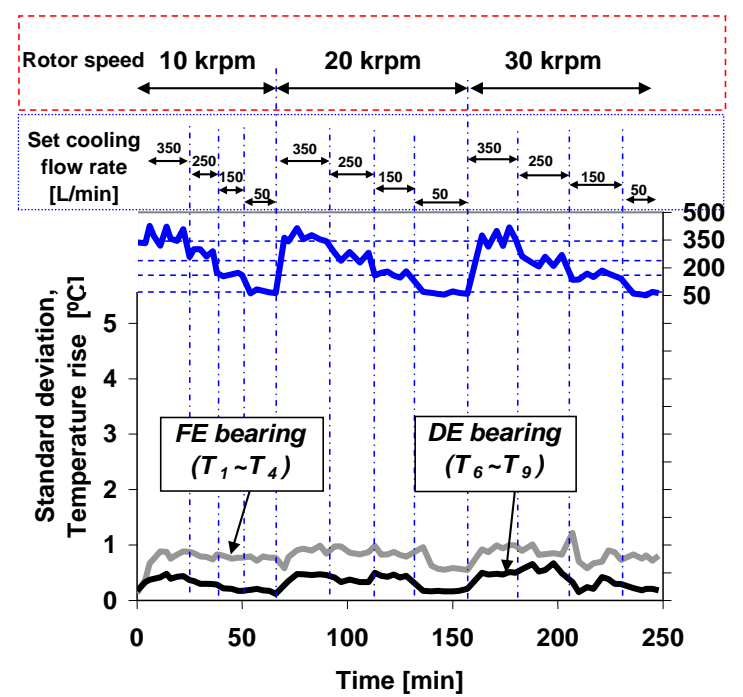

(a) Test case \#1: $T_{h s}=65^{\circ} \mathrm{C}$

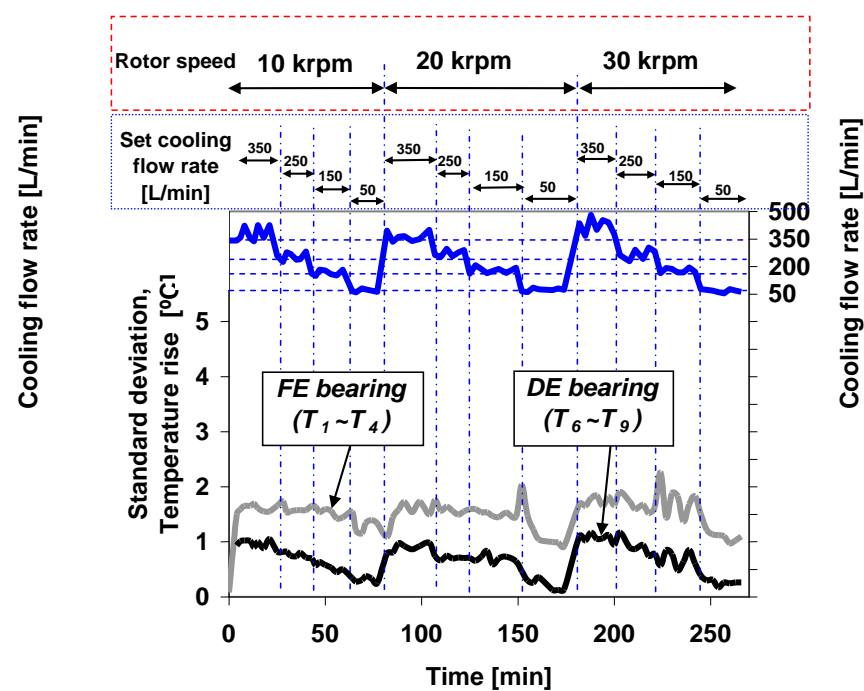

(b) Test case \#2: $T_{h s}=100^{\circ} \mathrm{C}$

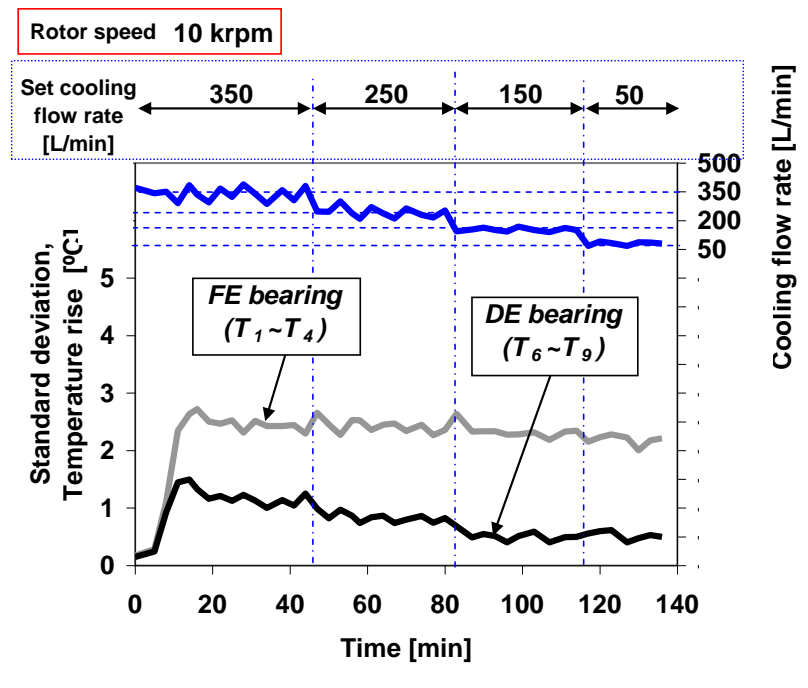

(c) Test case \#3: $T_{h s}=150^{\circ} \mathrm{C}$

Fig. 26 Test cases \#4-\#6. Rotor speed of 10, 20, and $30 \mathrm{krpm}$ : Standard deviation of FE and DE bearing temperature rise versus elapsed time. $T_{1} \sim T_{4}$ : Standard deviation of FE bearing temperatures, $T_{6} \sim T_{9}$ : Standard deviation of DE bearing temperatures. 


\section{CHAPTER VI}

\section{EXPERIMENTAL RESULTS: ROTORDYNAMIC RESPONSE MEASUREMENTS}

\subsection{Fixed Rotor Speed Operation}

For test case \#4, Fig. 27 depicts waterfall plots of rotor vertical and horizontal motions recorded at the rotor free and drive ends and while the rotor speed equals 10,20 and $30 \mathrm{krpm}$. In the following, the designations $\mathrm{FV}$ and $\mathrm{FH}$ corresponds to the rotor responses at the free end rotor side, vertical and horizontal planes, respectively. A similar notation follows for the rotor drive sides, DV and DH. The measurement corresponds to operation with the heater set temperature $\left(T_{h s}\right)$ at $65{ }^{\circ} \mathrm{C}$. Each graph on the figure labels the rotor speed and the overall test time.

The data shows that the cooling flow rate does not affect the amplitude and frequency contents of rotordynamic displacements. Recall Fig. E.3 for details on cooling flow rate changes versus elapsed time. Along the drive end (DE) bearing, the rotor displacements are mainly synchronous, while at the free end $(\mathrm{FE})$ plane the $2 \mathrm{X}$ (twice synchronous) whirl motions are distinct with large amplitude at the highest speed of 30 $\mathrm{krpm}$. For FV plane, the $2 \mathrm{X}$ rotor response amplitude is $3-4$ times larger than that of the $1 \mathrm{X}$ rotor response over the entire rotor speed range. The $2 \mathrm{X}$ rotor motions may be due to the misalignment between the rotor and drive motor. Note that, for the three rotor speeds and during the elapsed times of testing, no subsynchronous whirl motions ever appeared. 


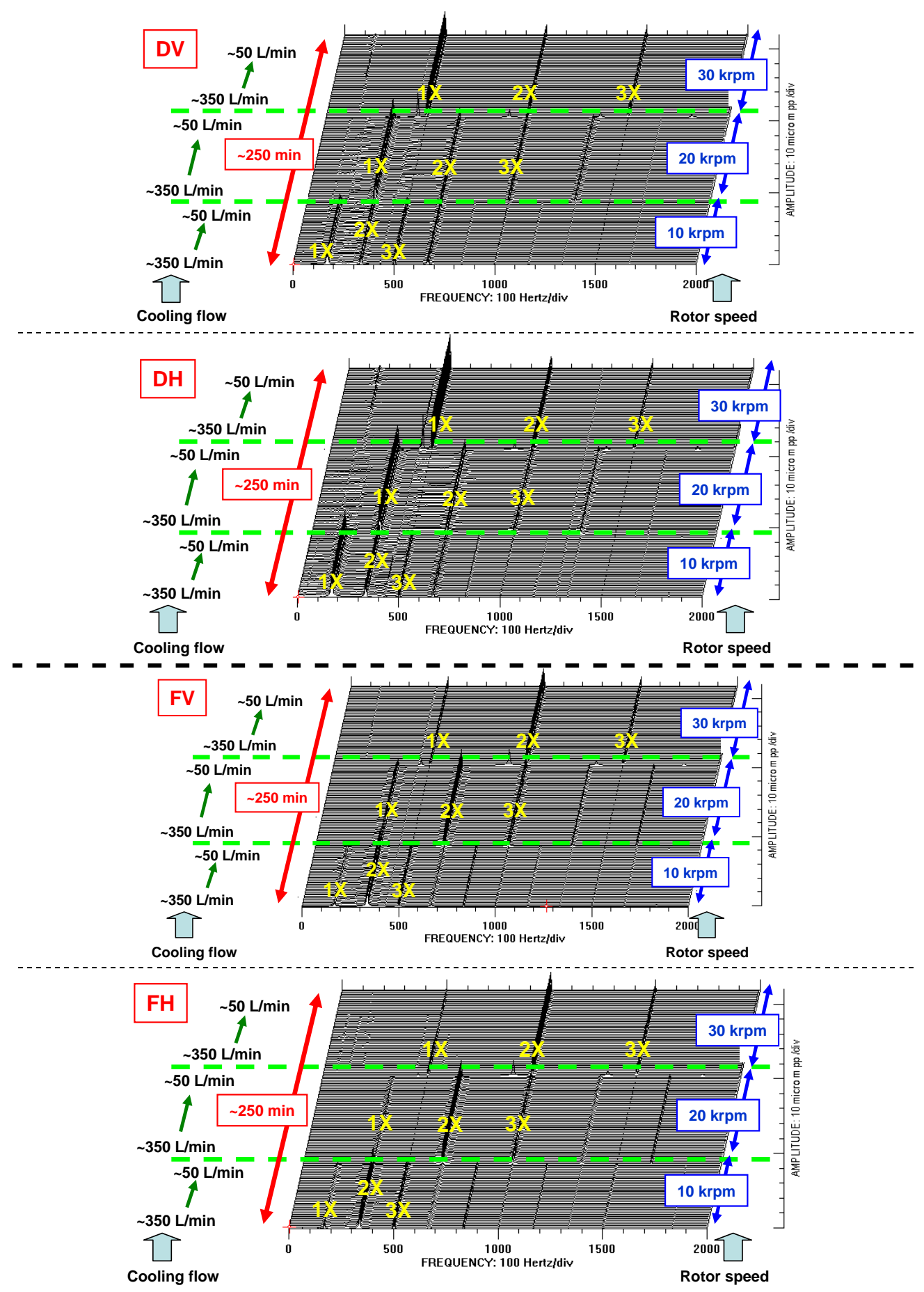

Fig. 27 Test case \#4: FFTs of rotor responses at rotor drive end, vertical (DV) and horizontal (DH) planes, and rotor free end, vertical (FV) and horizontal (FH) planes. Rotor speed $=10,20$ and $30 \mathrm{krpm}$. Cooling flow into bearings from $\sim 350 \mathrm{~L} / \mathrm{min}$ to $\sim 50 \mathrm{~L} / \mathrm{min}$ for each set rotor speed. Heater set temperature $T_{h s}=65^{\circ} \mathrm{C}$. 
Figures 28 and 29 depict the rotor whirl orbits, (a) unfiltered, (b) synchronous, and (c) $2 \mathrm{X}$ at the rotor drive and free ends, respectively, for rotor speeds equal to 10,20 , and $30 \mathrm{krpm}$. In the figures, the rotor orbit combines the time based waveform data from a pair of orthogonally mounted displacement sensors ( $X$ : transducer along the horizontal direction, $Y$ : transducer along the vertical direction) to show the dynamic motion of the shaft centerline. The center of the orbit plot is defined by the average values of the $X$ and $Y$ time based waveforms. In addition, a keyphasor mark (the blank/dot sequence in the figures) represents the location of the shaft centerline at the instant when the once-perrevolution mark passes a tachometer (keyphasor transducer). The blank/dot sequence also shows the direction of rotor motion with time.

Recall that for rotor response along the rotor drive end, the synchronous (1X) whirl motion is dominant while the amplitude of $2 \mathrm{X}$ (twice synchronous) rotor response are larger than the $1 \mathrm{X}$ rotor response recorded near the rotor free end. In Fig. 28 (b) (DE rotor orbits), rotor synchronous speed motion amplitude along the horizontal plane remain similar with increasing rotor speed; while the vertical motion amplitude increases with rotor speed. The $2 \mathrm{X}$ rotor orbit shapes (amplitude and phase angle) do not change with rotor speed.

The rotor synchronous speed rotor orbits measured at the rotor FE, shown in Fig. 29 (b), are highly elliptical, thereby showing the anisotropic character of the bearing stiffnesses. The stiffnesses of the FE bearing along horizontal plane are higher than those along vertical direction. Note the distinctive backward whirl motions in the $2 \mathrm{X}$ rotor orbits. Note the scale difference of Fig. 29 (b) to Figs.29 (a) and (c). 
The keyphasor mark shows that the synchronous (1X) orbits at each rotor end are out of phase, representing a conical mode shape of the (rigid) rotor. The angle of the major axis of the elliptical $2 \mathrm{X}$ orbit is $\sim 45^{\circ}$ from the horizontal plane. This coincides with the direction of the top foil trailing edge.

For test case \#6, Fig. 30 depicts the waterfall plots of rotor vertical and horizontal motions recorded at the rotor drive and free ends. The measurement corresponds to a rotor speed of $10 \mathrm{krpm}$, and bearing supplied with cooling flow rates varying from $\sim 350$ $\mathrm{L} / \mathrm{min}$ to $\sim 50 \mathrm{~L} / \mathrm{min}$. Similar as in Fig. 27 , there is no noticeable difference in rotor displacement amplitudes and frequency content while increasing the cooling flow rate into the bearings.

Note that the rotor OD temperature does not affect the amplitude and frequency contents of the rotor dynamic displacements, compare Figs. $27\left(T_{h s}=65^{\circ} \mathrm{C}\right)$ and $30\left(T_{h s}\right.$ $=150^{\circ} \mathrm{C}$ ). The rotor whirl orbits (unfiltered, synchronous, and $2 \mathrm{X}$ ) at $10 \mathrm{krpm}$ depicted in Fig. 31 also display nearly identical amplitudes and shapes with Figs. 28 and 29 (see the leftmost figures for $10 \mathrm{krpm}$ ), thereby rendering no changes in rotor response amplitude and phase angle due to increases in the rotor OD temperature. 

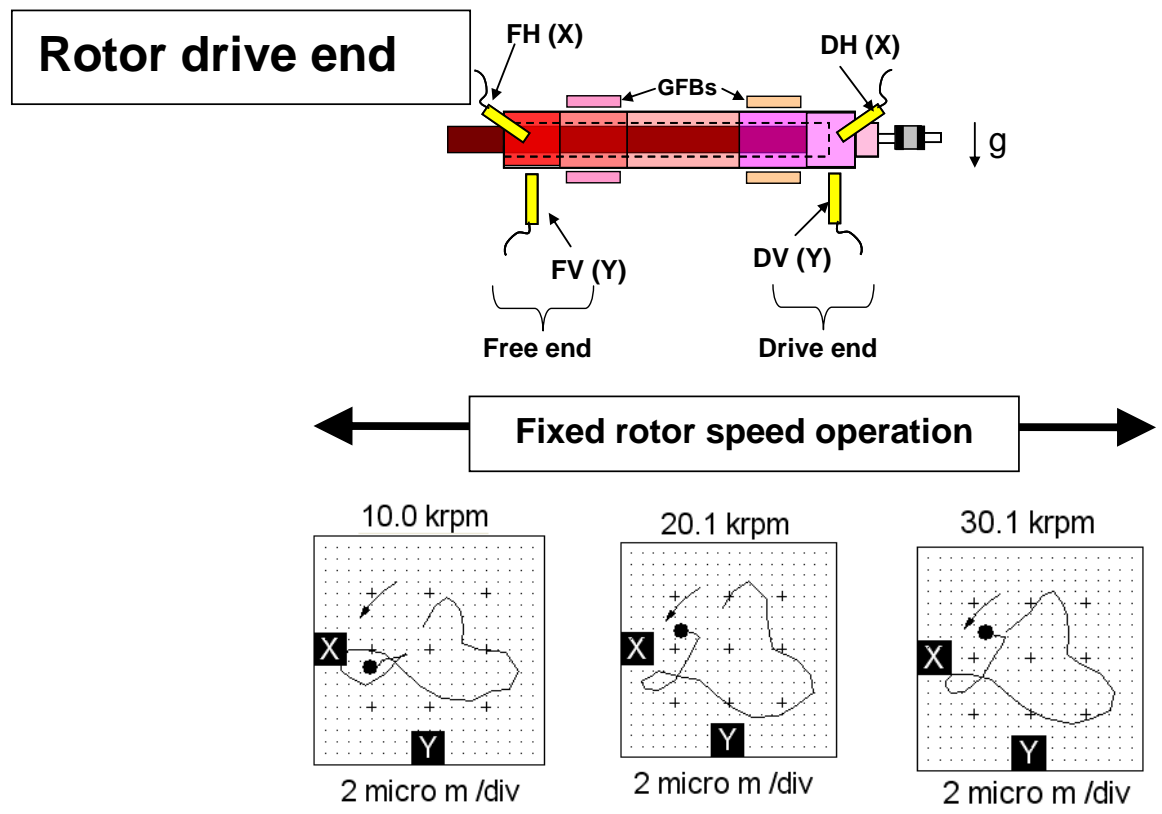

Overall

(a) Rotor unfiltered orbits
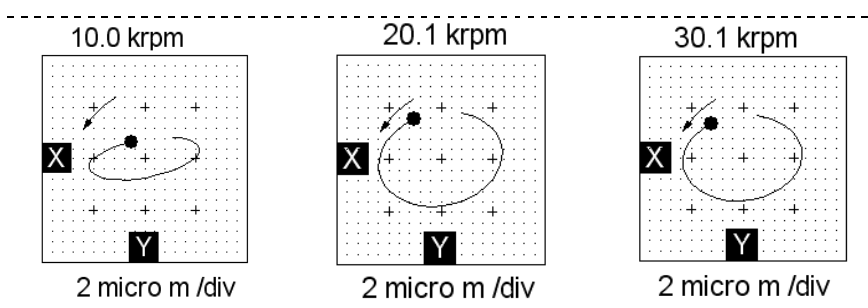

$1 X$

(b) Synchronous speed rotor orbits
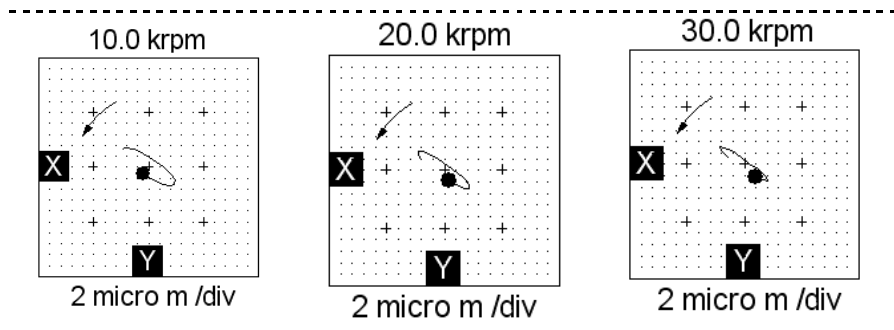

$2 X$

(c) $2 X$ rotor orbits

Fig. 28 Test case \#4. Rotor orbits at drive end. Heater set temperature $T_{\text {hs }}=65^{\circ} \mathrm{C}$. Cooling flow into bearings $\sim 350 \mathrm{~L} / \mathrm{min}$. Rotor speed set at 10, 20, and $30 \mathrm{krpm}$. No slow roll compensation. 

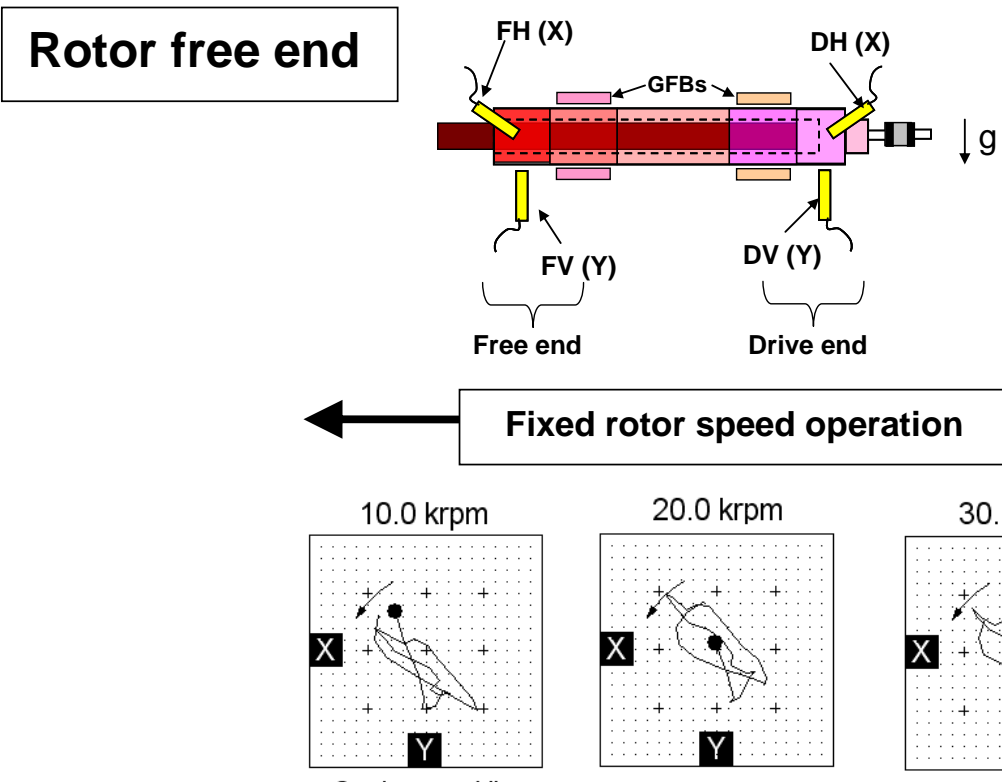

Fixed rotor speed operation

2 micro $\mathrm{m} / \mathrm{div}$
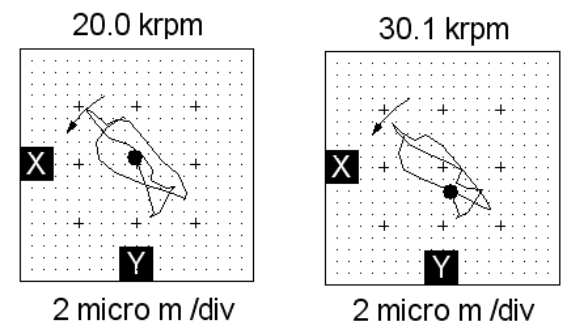

Overall

(a) Rotor unfiltered orbits

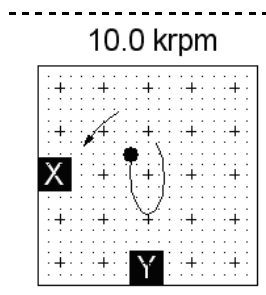

$0.5 \mathrm{micro} \mathrm{m} / \mathrm{div}$

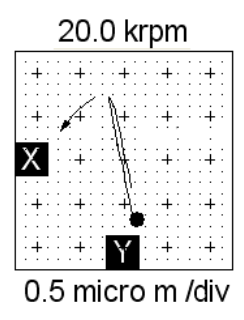

$1 X$

(b) Synchronous speed rotor orbits

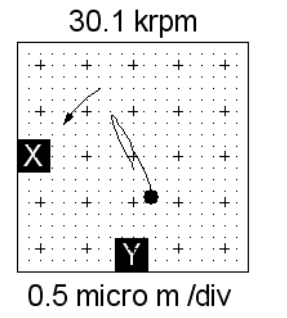

$2 X$

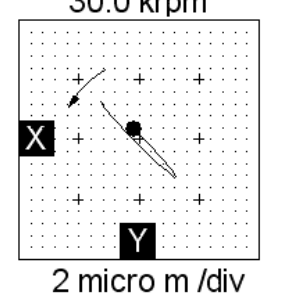

(c) $2 X$ rotor orbits

Fig. 29 Test case \#4. Rotor orbits at free end. Heater set temperature $T_{h s}=65 \circ C$. Cooling flow into bearings $\sim 350 \mathrm{~L} / \mathrm{min}$. Rotor speed set at 10,20 , and $30 \mathrm{krpm}$. Note different scale between (a) and (b). No slow roll compensation. Note different scale for (b). 

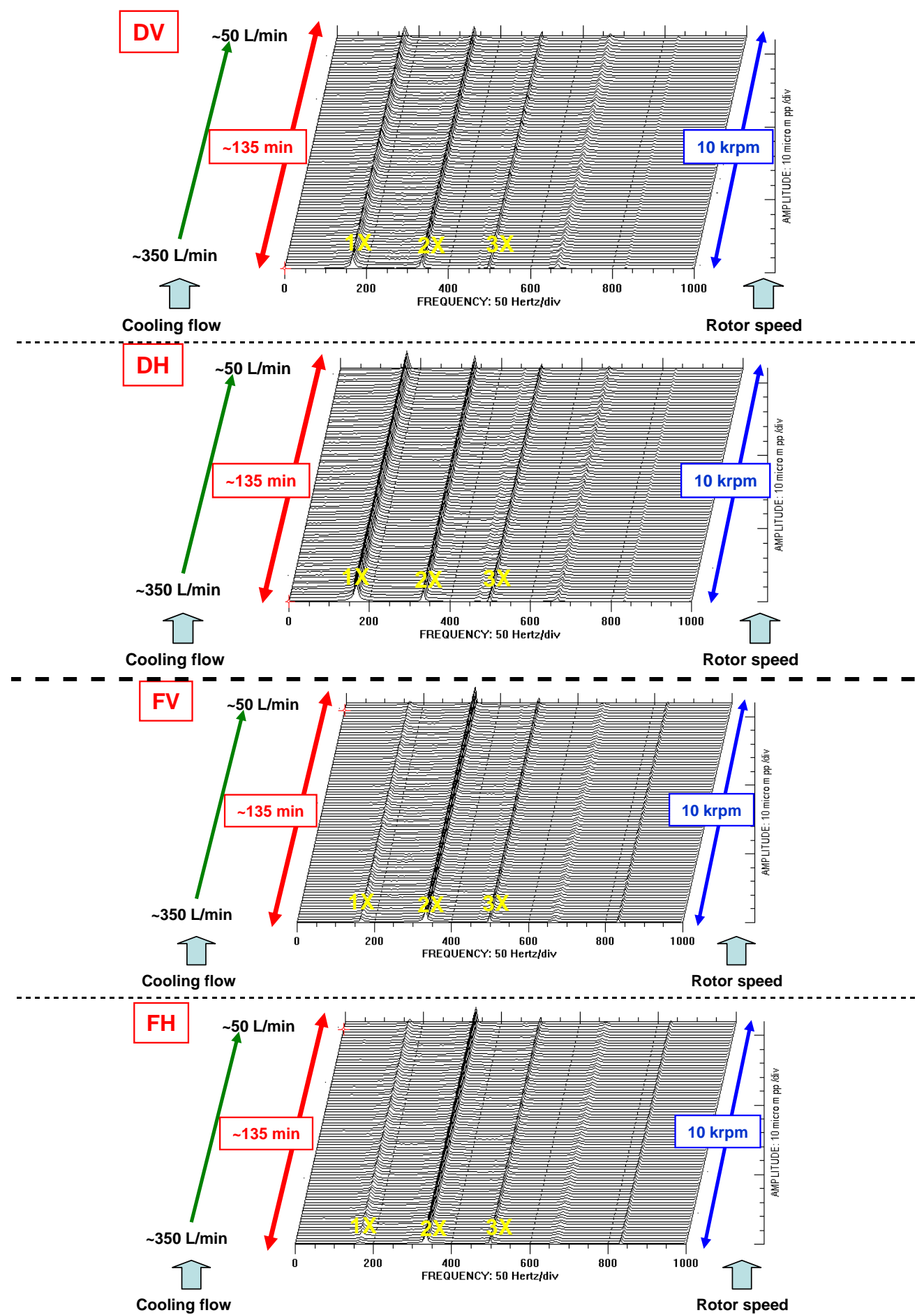

Fig. 30 Test case \#6: FFTs of rotor responses at rotor drive end vertical (DV) and horizontal (DH) planes, and rotor free end vertical (FV) and horizontal (FH) planes. Rotor speed $=10 \mathrm{krpm}$. Cooling flow into bearings from $\sim 350 \mathrm{~L} / \mathrm{min}$ to $\sim 50 \mathrm{~L} / \mathrm{min}$. Heater set temperature $T_{h s}=150{ }^{\circ} \mathrm{C}$. 


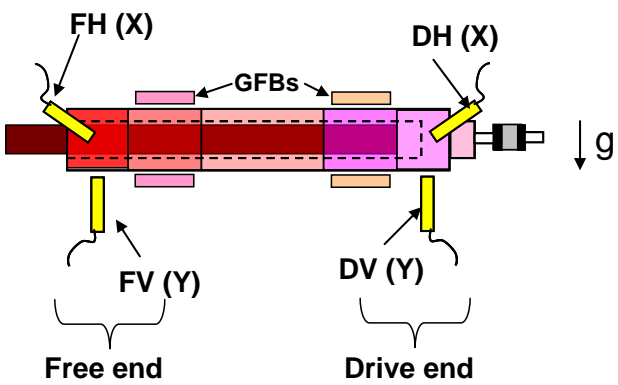

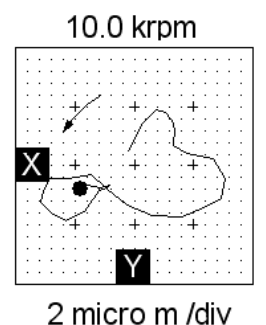

Unfiltered rotor orbit



Synchronous speed rotor orbit

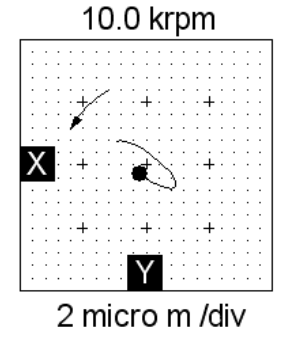

$\underline{2 X \text { rotor orbit }}$

(a) Rotor drive end (DE)

$10.0 \mathrm{krpm}$

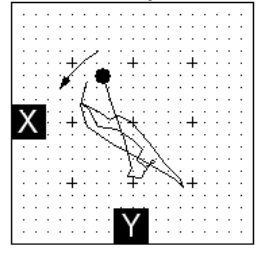

2 micro $\mathrm{m} / \mathrm{div}$

Unfiltered rotor orbit
$10.0 \mathrm{krpm}$

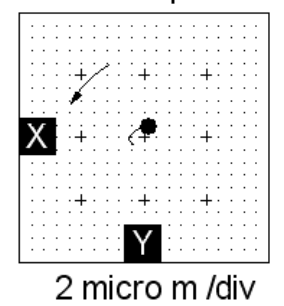

Synchronous speed rotor orbit
$10.0 \mathrm{krpm}$

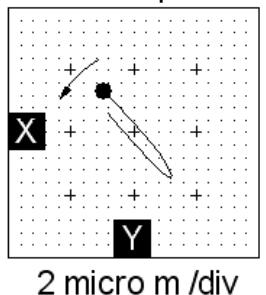

$\underline{2 X \text { rotor orbit }}$

(b) Rotor free end (FE)

Fig. 31 Test case \#6. Rotor orbits at free end. Heater set temperature $T_{h s}=150^{\circ} \mathrm{C}$. Cooling flow into bearings $\sim 350 \mathrm{~L} / \mathrm{min}$. rotor speed set at $10 \mathrm{krpm}$. No slow roll compensation. 


\subsection{Rotor Deceleration with Constant Speed Ramp Rate}

While decelerating from $30 \mathrm{krpm}$ to rest, Figs. 32 and 33 show waterfall plots of the rotor motions depicting the amplitude and frequency content of the rotor dynamic displacements for test cases \# 7 and \#9, respectively. Recall that the set speed ramp rate of the drive motor is $16.7 \mathrm{~Hz} / \mathrm{s}$. There are no major differences between the rotor responses for operation with either the heater off and with the heater on at temperature $T_{h s}=100{ }^{\circ} \mathrm{C}$. For the rotor free end, the $2 \mathrm{X}$ whirl motions dominate rotor response above 12 krpm. See Figs. 34 and 35 later for rotor response amplitude of each frequency component (1X and $2 \mathrm{X})$.

Appendix $\mathrm{J}$ depicts the recorded amplitudes of synchronous rotor response during a rotor speed-up from rest to $30 \mathrm{krpm}$. The rotor dynamic responses during rotor acceleration are quite different with those during rotor deceleration although the speed ramp rate is identical $|16.7 \mathrm{~Hz} / \mathrm{s}|$. The flexible coupling has a lateral stiffness coefficient of $4.4 \times 10^{3} \mathrm{~N} / \mathrm{m}^{23}$. The stiff coupling and short connecting rod (length $4.4 \mathrm{~mm}$ and diameter $5.08 \mathrm{~mm}$ ) may not fully isolate the rotor-GFB system from the drive motor system.

\footnotetext{
${ }^{23}$ This is an experimentally determined value. Reference [14] details the test method.
} 


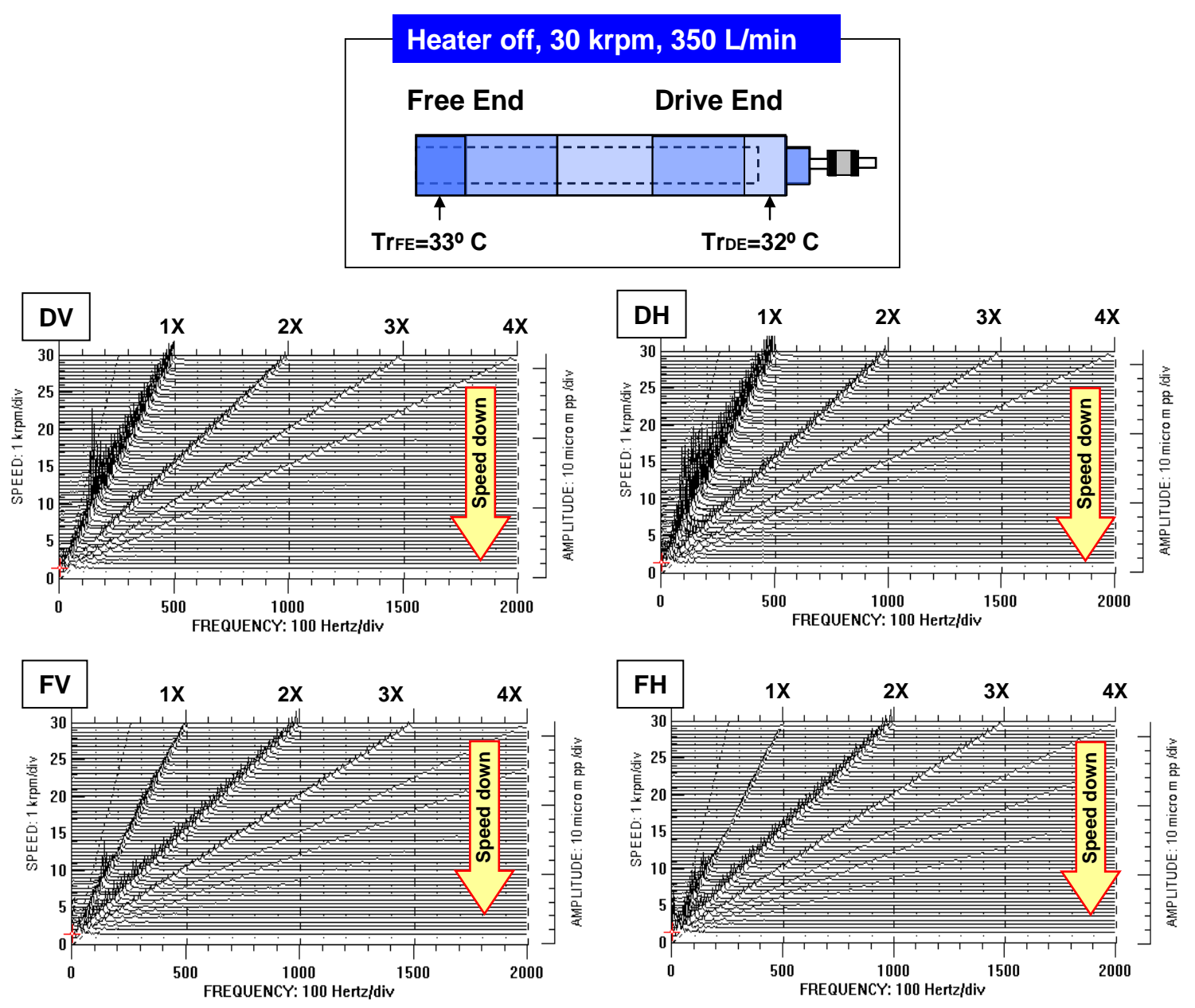

Fig. 32 Test case \#7: Waterfalls of rotor motion during decelerating from $\mathbf{3 0} \mathbf{k r p m}$ to rest Heater off, cooling flow rate $\sim 350 \mathrm{~L} / \mathrm{min}$, deceleration= $16.7 \mathrm{~Hz} / \mathrm{s}$. Rotor drive end, vertical (DV) and horizontal (DH) planes and rotor free end, vertical (FV) and horizontal (FH) planes. 


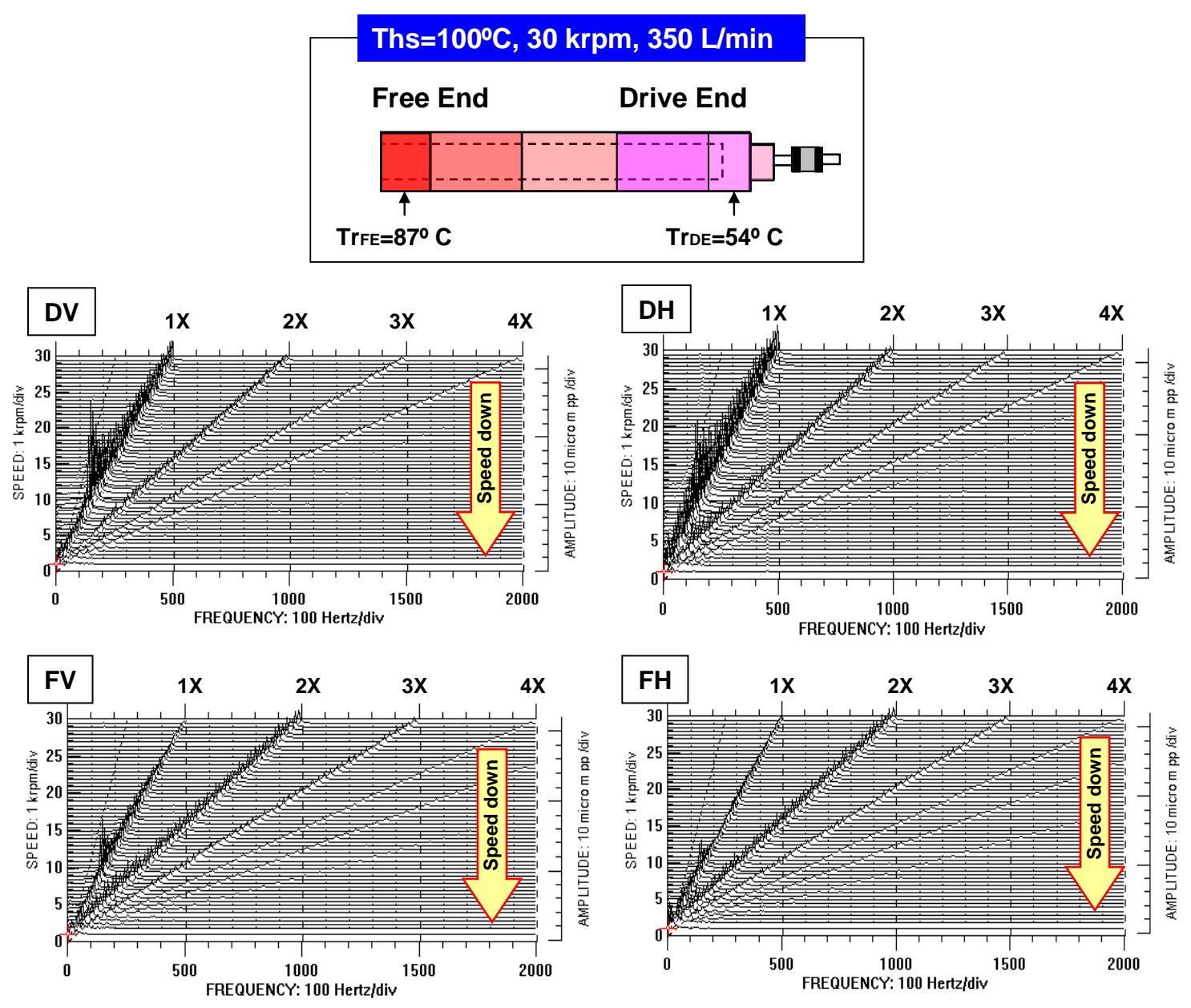

Fig. 33 Test case \#9. $T_{h s}=100^{\circ} \mathrm{C}$ : Waterfalls of rotor motion during decelerating from 30 krpm to rest Heater off, cooling flow rate $\sim 350 \mathrm{~L} / \mathrm{min}$, deceleration= $16.7 \mathrm{~Hz} / \mathrm{s}$. Rotor drive end, vertical (DV) and horizontal (DH) planes and rotor free end, vertical (FV) and horizontal (FH) planes. 
For operation at two heater set temperatures $\left(T_{h s}=65{ }^{\circ} \mathrm{C}\right.$ and $\left.100{ }^{\circ} \mathrm{C}\right)$ and also while at ambient temperature (i.e., heater off), Fig. 34 depicts rotor amplitudes of synchronous response recorded during rotor speed-down (deceleration) tests from 30 $\mathrm{krpm}$ with a cooling flow rate $\sim 350 \mathrm{~L} / \mathrm{min}$. Slow roll compensation at $2 \mathrm{krpm}$ excludes rotor run-out amplitudes. Recall that $\Delta \mathrm{rpm}=50$ in the DAQ system (ADRE®). The measurements are taken at the rotor drive and free ends, vertical and horizontal planes without imbalance masses.

The synchronous rotor responses along the vertical plane, for both drive and free ends, show a distinctive peak at 8-9 krpm. On the other hand, along the rotor horizontal planes for the drive and free ends, two critical speeds (corresponding to rigid body modes, cylindrical conical and conical, see figures on pages 86 and 87) are evident due to the bearing stiffness asymmetry in the vertical and horizontal directions.

Rotor operation beyond the system critical speed shows a significant decrease in amplitudes of rotor motion. For example, $|\mathrm{DV}|_{\text {at critical speed }} \approx 7 \times|\mathrm{DV}|_{\text {at } 30 \mathrm{krpm}}$, where $|\mathrm{DV}|$ denotes rotor motion amplitudes recorded at the drive end of the rotor along the vertical plane. In general, rotor motion amplitudes at the drive end are larger than that at free end.

Overall, no prominent differences are apparent in synchronous rotor response for operation at ambient temperature and at the hottest shaft temperature $\left(T_{h s}=100^{\circ} \mathrm{C}\right)$. The inset figures depict the measured rotor temperature corresponding to the respective heater set temperature. 


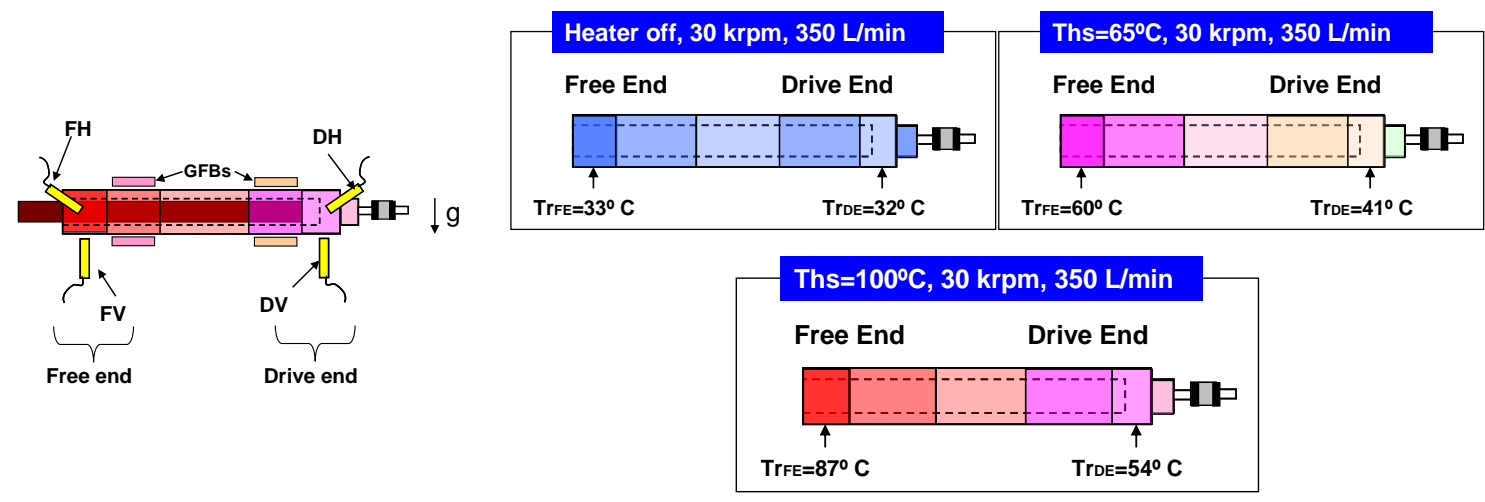

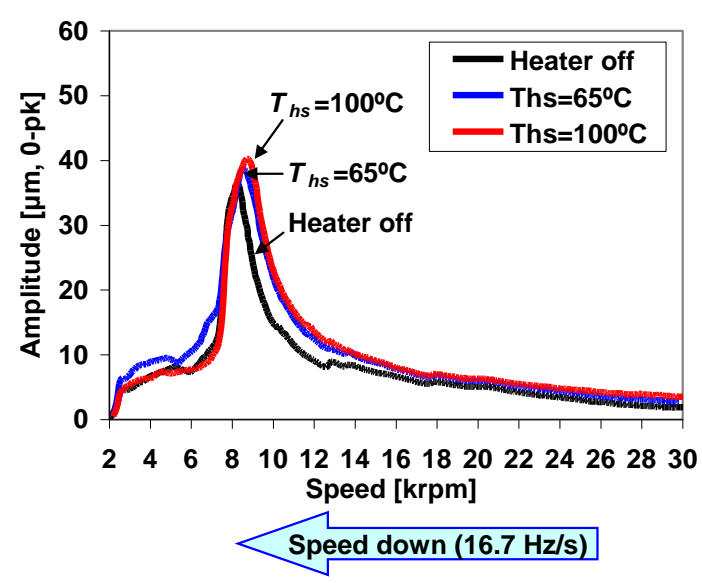

(a) Rotor drive end vertical plane (DV)

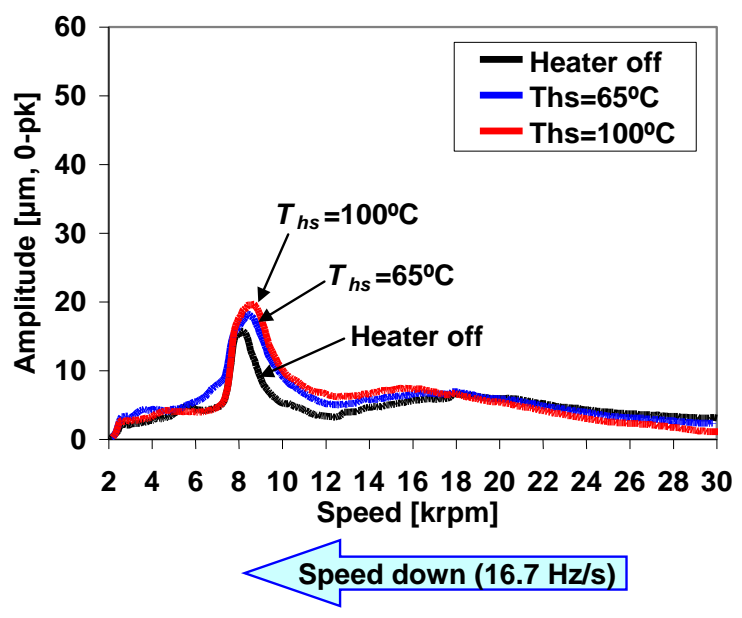

(c) Rotor free end vertical plane (FV)

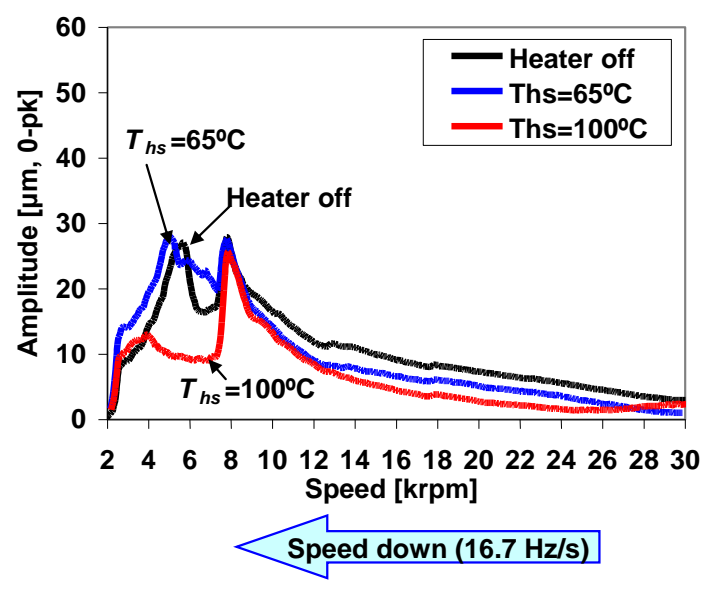

(b) Rotor drive end horizontal plane (DH)

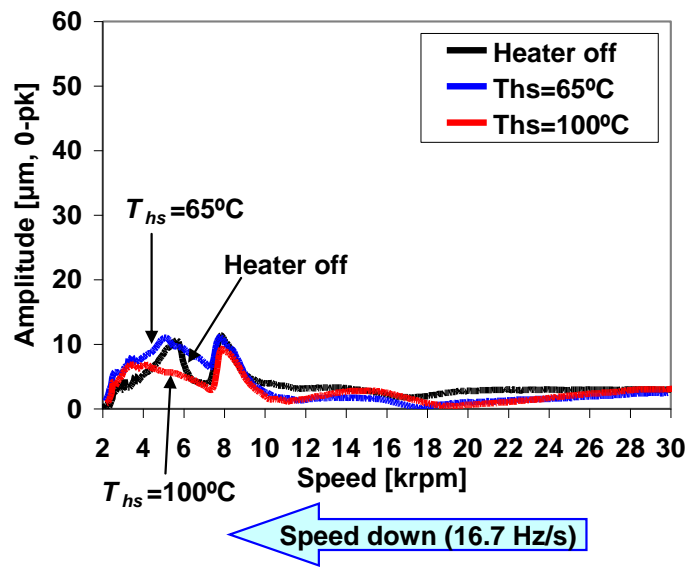

(d) Rotor free end horizontal plane (FH)

Fig. 34 Test cases \#7-\#9: Rotor amplitudes of synchronous response. Slow roll compensation at $2 \mathrm{krpm}$. Cooling flow rate $\sim 350 \mathrm{~L} / \mathrm{min}$. 
Figure 35 depicts the $2 \mathrm{X}$ (twice synchronous) rotor response amplitudes for test cases \#7-\#9. The $2 \mathrm{X}$ rotor response amplitudes do not vary with rotor OD temperature, i.e., the rotor response are almost identical while increasing $T_{h s}$ up to $100^{\circ} \mathrm{C}$. Beyond the system critical speed $(\sim 8 \mathrm{krpm})$, the $2 \mathrm{X}$ rotor motion amplitudes along the rotor $\mathrm{FE}$ increase with rotor speed. On the other hand, the $2 \mathrm{X}$ rotor motions along the rotor $\mathrm{DE}$ remain similar amplitude above $10 \mathrm{krpm}$.

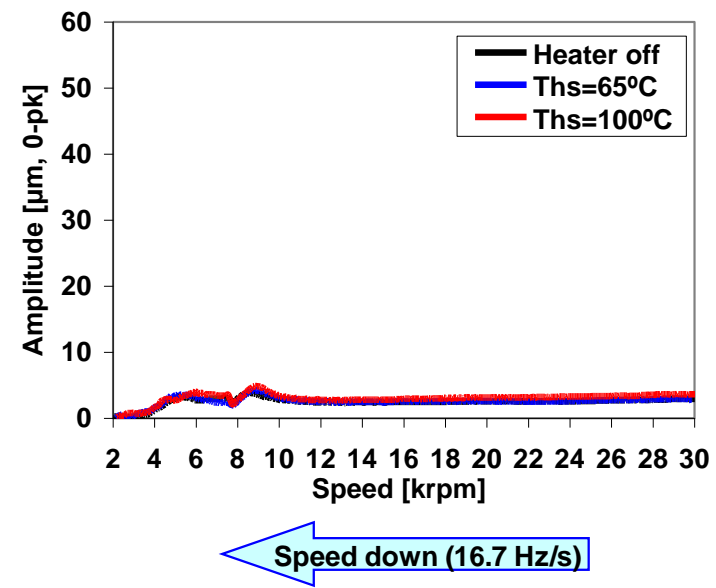

(a) Rotor drive end vertical plane (DV)

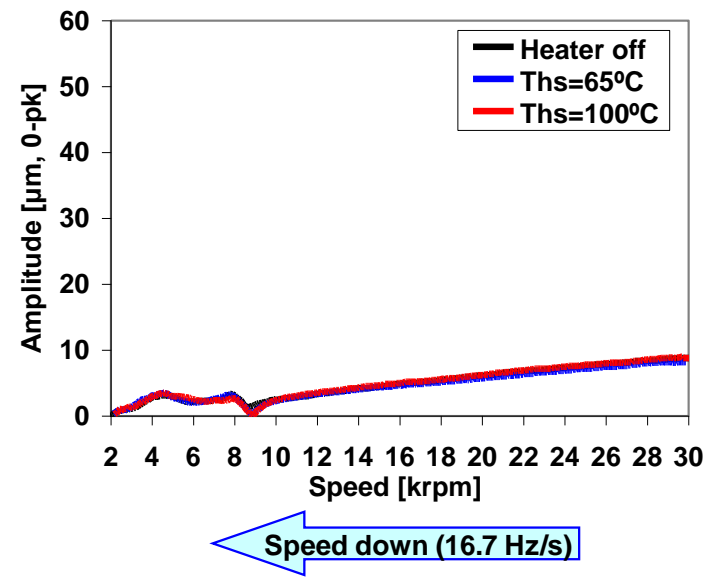

(c) Rotor free end vertical plane (FV)

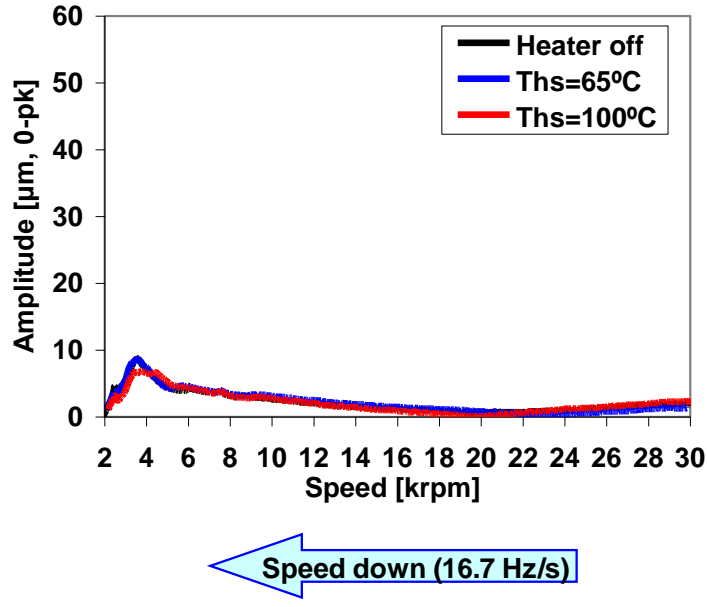

(b) Rotor drive end horizontal plane (DH)

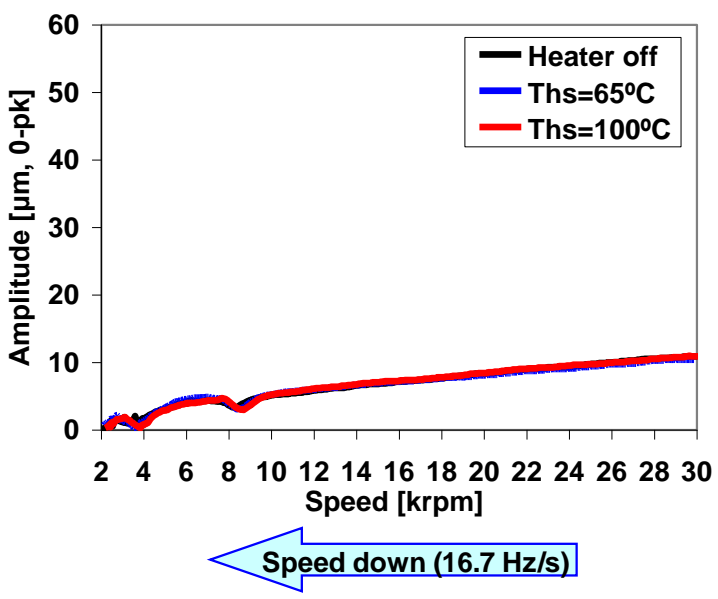

(d) Rotor free end horizontal plane (FH)

Fig. 35 Test cases \#7-\#9: Rotor amplitude of $2 X$ (twice synchronous) response. Slow roll compensation at $2 \mathrm{krpm}$. Cooling flow rate $\sim 350 \mathrm{~L} / \mathrm{min}$. 
Impact load tests on the rotor show a distinctive flexural mode due to the soft connecting rod and coupling at $1.5 \mathrm{kHz}(90 \mathrm{krpm})$, see Appendix K. Therefore, the test rotor is regarded as a rigid body within the rotor speed range to $30 \mathrm{krpm}$. The shape of the synchronous responses can be readily determined by subtracting the phase angles of the measured displacements at each end of the rotor $^{24}$.

For test cases \# 7 and \#9, Fig. 36 depicts a phase difference of 180 deg while traversing the speeds with largest response amplitudes. Therefore, a conical mode is prevalent while traversing the critical speeds of the rotor bearing system. For increasing rotor OD temperature, the phase differences $(\angle \mathrm{FH}-\angle \mathrm{DH})$ have similar trends, but are less consistent in the shift amount than $(\angle \mathrm{FV}-\angle \mathrm{DV})$ because the response amplitudes along the horizontal plans are considerably small $(<3 \mu \mathrm{m}$ above $10 \mathrm{krpm})$.

Figure 37 displays the ratio of amplitudes recorded at the rotor drive and free ends along the vertical and horizontal planes. This ratio aids to determine the relative size of the end displacements. In general, the rotor response at the drive end renders higher amplitude than the free end. At the system critical speed $(\sim 8 \mathrm{krpm})$, the rotor motions at DE are twice larger than those at FE. As the rotor speed decreases from 30 $\mathrm{krpm}$, the node in the conical mode moves from the rotor center (because of nearly identical amplitudes of motion at each end) toward the drive end of the rotor. For both test cases, the ratios of amplitudes (DE over FE) are largest at rotor speeds of $\sim 11 \mathrm{krpm}$ and $19 \mathrm{krpm}$. Appendix L fully presents rotor whirl orbits for test cases \#7 and \#9.

\footnotetext{
${ }^{24}$ Operation with near 0 deg phase difference indicates a cylindrical mode, while a phase difference of 180 deg denotes a conical mode.
} 
More experimental data for test cases \#8-\#10 is omitted for brevity. Overall, there is no noticeable difference in rotor response for test cases \#7-\#10.

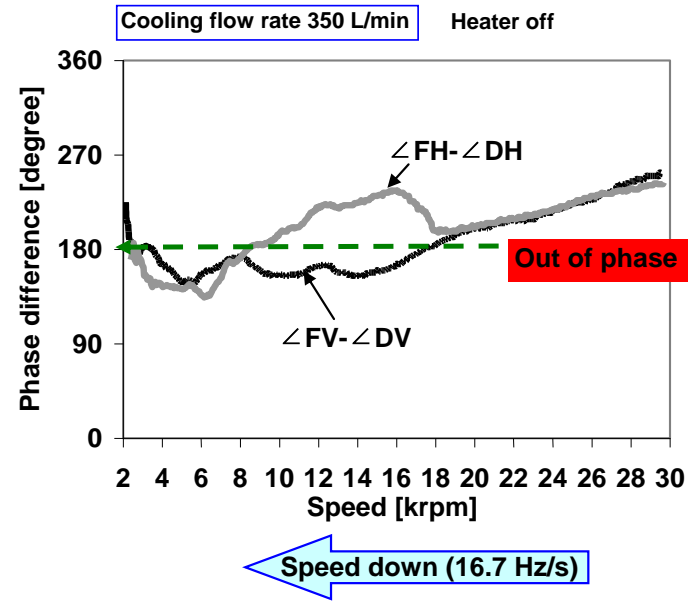

(a) Test case \#7: Heater off

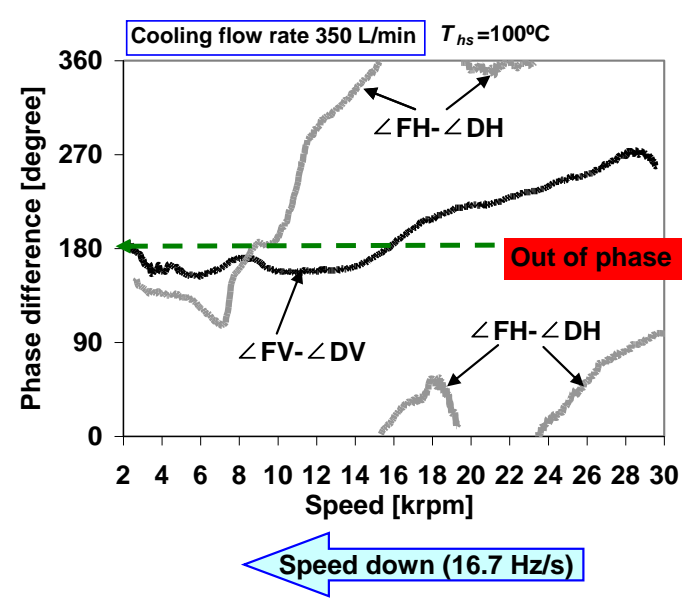

(b) Test case \#9: $T_{h s}=100 \stackrel{\circ}{C}$

Fig. 36 Test cases \#7 and \#9: Speed down from $30 \mathrm{krpm}$ to rest with ramp rate of 16.7 $\mathrm{Hz} / \mathrm{s}$. Phase differences of recorded imbalance response versus rotor speed. Cooling flow rate $\sim 350 \mathrm{~L} / \mathrm{min}$.

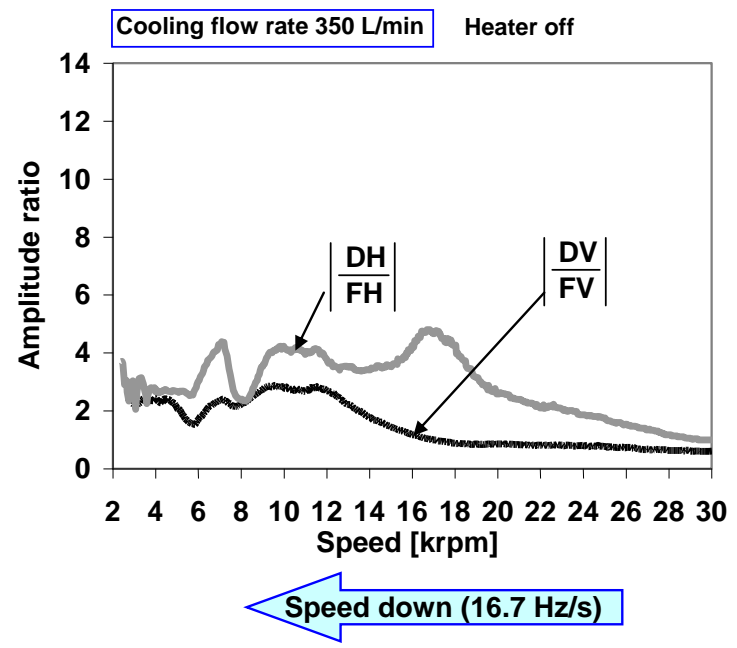

(a) Test case \#7: Heater off

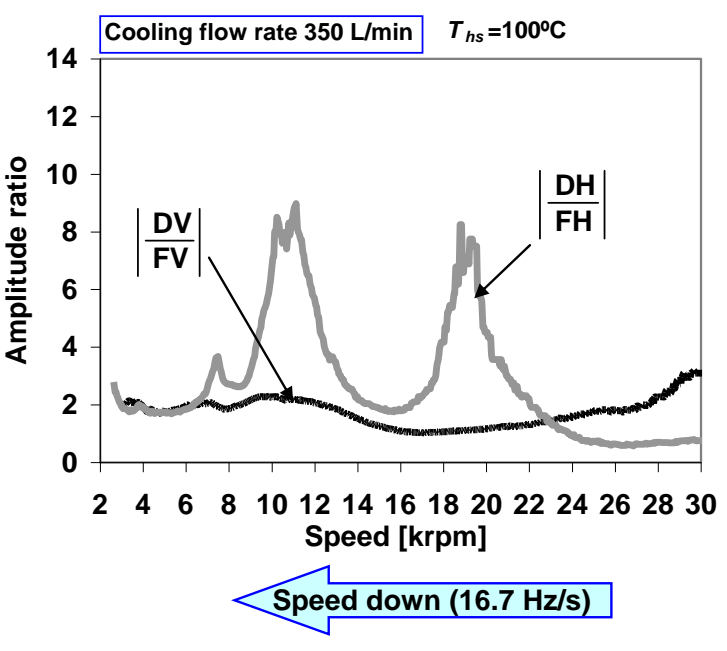

(b) Test case \#9: $T_{h s}=100 \stackrel{\circ}{C}$

Fig. 37 Test cases \#7 and \#9: Speed down from $30 \mathrm{krpm}$ to rest with ramp rate of 16.7 $\mathrm{Hz} / \mathrm{s}$. Amplitude ratio of recorded imbalance response versus rotor speed. Cooling flow rate $\sim 350 \mathrm{~L} / \mathrm{min}$. 


\section{CHAPTER VII}

\section{PREDICTIONS OF BEARING TEMPERATURES AND ROTORDYNAMIC RESPONSE AND COMPARISONS TO EXPERIMENTAL DATA}

San Andrés and Kim [14] develop a model for thermal energy transport in a hotrotor-GFB system with cooling flow paths to predict the bearing temperature and pressure fields, static load capacity and power loss, and dynamic force coefficients. The analysis couples the gas film pressure equation to the thermal energy transport equation with appropriate boundary conditions. The model accounts for forced cooling conditions and an actual operating clearance determined from thermal changes in material properties and the mechanical components thermal and centrifugal growths.

Figure 38 depicts a schematic view of a GFB with a hollow shaft with uniform heat source and a cooling air flow supplied on one side of the bearing and flowing through the gap underneath the top foil. In the model, the inner and outer cooling gas streams are regarded as sinks of thermal energy. In addition, the cooling stream is large enough to remain at a uniform temperature $\left(T_{C o}\right)$ while advecting (removing) heat from the top foil back surface at temperature $\left(T_{F o}\right)$. Figure 39 shows the complex heat flow

paths in a GFB. The nomenclature for temperatures is also noted. References $[14,45,46]$ fully detail the TEHD model for prediction of GFBs static and dynamic forced performance.

Presently, thermal expansion of the whole test rig casing is not considered in the predictions. In the model, an empirically derived thermal mixing coefficient $\lambda=0.65$ 
represents best the gas flow and thermal energy balance at the conjunction of the top foil leading and trailing edges $[14,46]^{25}$.

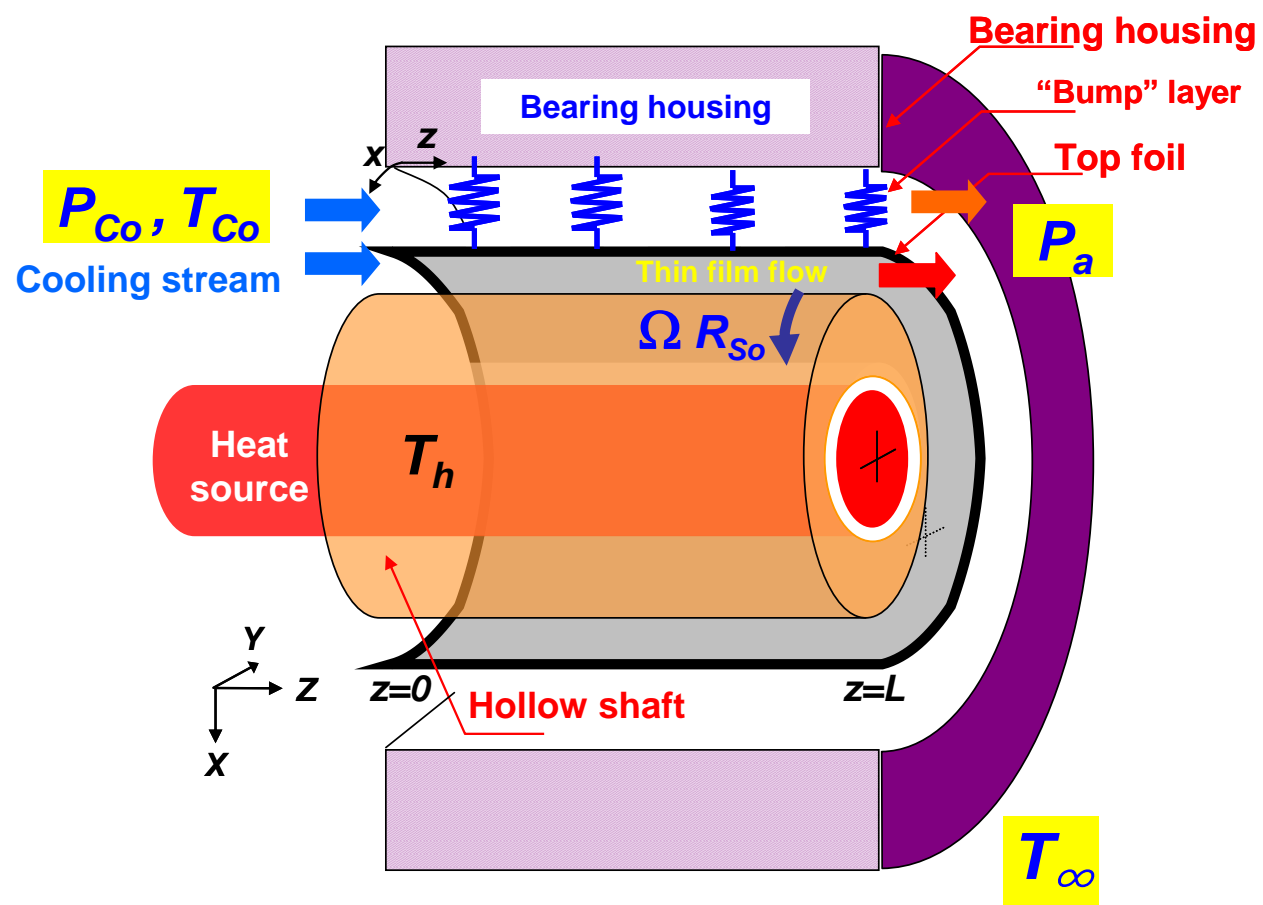

Fig. 38 Schematic side view of foil bearing with heat source warming hollow rotor and outer cooling stream $\left(T_{C o}, P_{C o}\right)$ flowing through thin film region and underneath top foil. Outer cooling flow exits to ambient pressure $\left(P_{\mathrm{a}}\right)$. Taken from [46].

\footnotetext{
${ }^{25}$ The thermal mixing coefficient $\lambda$ denotes the fraction of upstream gas flow (top foil trailing edge) reentering the thin film of the GFB at the leading edge of the top foil. $\lambda$ is an empirical parameter depending on the foil bearing arrangement and the cooling method. Reference [47] discusses thoroughly the mixing flow and inlet temperature at the leading edge of top foil. References [24,25] derive a similar mixing model and add CFD prediction validations.
} 


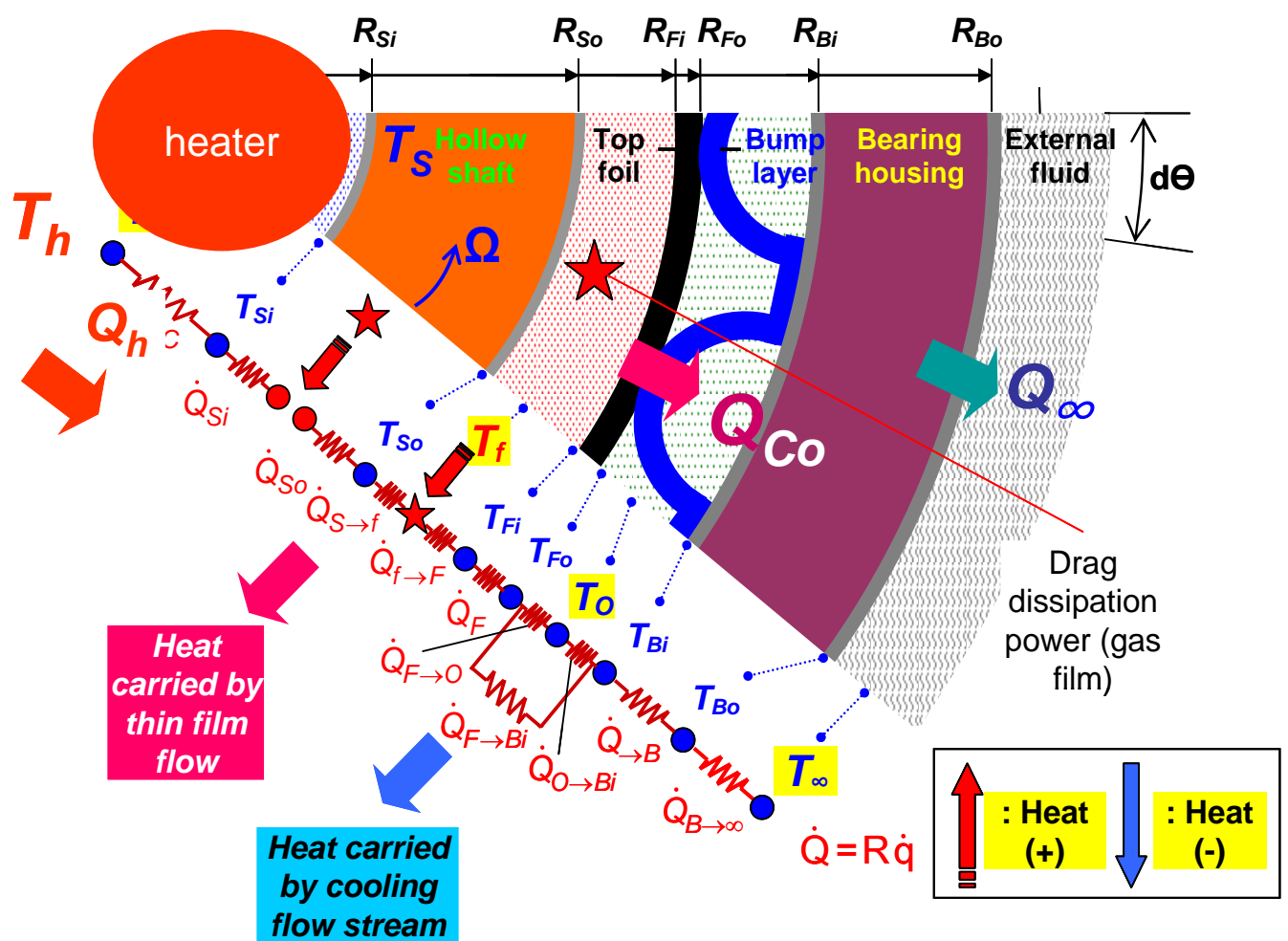

Fig. 39 Nomenclature for temperatures in a foil bearing operating with a hot rotor and an outer cooling gas stream. Schematic representation of heat flows shown. Taken from [46].

\subsection{Prediction of Bearing Temperatures and Comparison to Test Data}

Model predictions are compared to the temperature measurements while the test rig operates without and with a forced cooling gas flow $(0-350 \mathrm{~L} / \mathrm{min})$. Appendix $\mathrm{M}$ shows complete input data for the bearing predictive model including the bearings and rotor dimensions and structural properties, operating clearances, and cooling flows. The appendix also lists the predicted (peak and average) film temperatures, (peak and average) bearing cartridge ID temperatures, and static load parameters (journal 
eccentricity, attitude angle, minimum film thickness and drag torque). Discussions on the predicted static load parameters follow in Section 7.2.

For test cases \#4-\#6, Fig. 40 depicts the predicted and measured temperatures of the bearing sleeve mid-span OD versus cooling flow rate for rotor speed at 10, 20, and $30 \mathrm{krpm}$. Symbols and continuous lines represent the test data and the THD model predictions, respectively. Presently, predicted GFB housing ID temperatures are compared to the measure temperatures at the bearing sleeve OD. In the analysis, cooling flow rates into each test bearing are $175 \mathrm{~L} / \mathrm{min}, 125 \mathrm{~L} / \mathrm{min}, 75 \mathrm{~L} / \mathrm{min}$, and $25 \mathrm{~L} / \mathrm{min}$, half of the total supply cooling stream of $350,250,150$, and $50 \mathrm{~L} / \mathrm{min}^{26}$. Recall (see Section 3.1) that the applied static loads on the drive and free end bearings are $7.39 \mathrm{~N}$ and 5.94 $\mathrm{N}$, respectively. In the prediction, for each rotor speed and cooling flow rate, the inlet cooling stream temperature $T_{C o}=T_{e}$ (enclosure air temperature) and the rotor OD temperature is uniform and equal to either $\operatorname{Tr}_{F E}$ or $\operatorname{Tr}_{D E}$. Note that the rotor temperatures at the bearing locations are estimated from a constant temperature gradient (linear temperature drop) from the recorded rotor FE and DE temperatures $\left(\operatorname{Tr}_{F E} \text { and } \operatorname{Tr}_{D E}\right)^{27}$.

Figure 40 depicts the arithmetic mean value from four recorded temperatures $T_{1}$ to $T_{4}$ for the FE bearing cartridge $\mathrm{OD}$, and $T_{6}$ to $T_{9}$ for the DE bearing $\mathrm{OD}^{28}$. Recall that the computational model accounts for material property changes and the bearing

\footnotetext{
${ }^{26}$ It is assumed that the flow rates distribute evenly into the two test bearings.

${ }^{27}$ As shown in Figs. 19 through 22, the actual temperatures of the rotor OD at the bearing locations are slightly lower than the estimated temperatures used for the predictions.

${ }^{28}$ The bearing temperatures are measured along the bearing sleeve OD mid-plane shown in Fig. 5 . Typically, the gas film peak temperature is at the bearing mid-plane and along the loading direction [23].
} 
components' expansion and shaft centrifugal growth due to temperature increases and rotational speed, respectively.

In general, predicted temperatures are in good agreement with measurements. The trends also appear quite similar. Note that the difference between prediction and measurement decreases as the rotor speed increases. However, predictions for the FE bearings at the hottest rotor temperature and lowest cooling flow rate condition are $22 \%$ higher than the recorded temperatures. The discrepancies are due to the large temperature gradient along the heater axial length (particularly) on the rotor free end, the side facing the hottest section of the heater cartridge. Reference [14] also reports similar findings.

At rotor speed of $30 \mathrm{krpm}$ and for test case \#5 $\left(T_{h s}=100^{\circ} \mathrm{C}\right)$, Figs. 41 and 42 depict the predicted GFB film mean temperature fields for operation with $175 \mathrm{~L} / \mathrm{min}$ and $25 \mathrm{~L} / \mathrm{min}$ forced cooling stream, respectively. The figure caption shows cooling air inlet temperature, rotor surface temperature, and ambient temperature for each case. Note that the bearing OD and rotor ID are exposed to ambient temperature $T_{a m b}$. See Tables 3 and 4 later for details on the predicted journal eccentricity, journal attitude angle, and minimum film thickness. Recall that the top foil leading edge locates at $\Theta=45^{\circ}$ where fresh gas enters into the film. The gas film temperature increases from $45^{\circ}<\Theta<200^{\circ}$ where the bulk of the shear mechanical energy is generated. The predicted gas film temperature at the bearing mid-plane grows as the rotor surface temperature increases. For operation at $10 \mathrm{krpm}$ in test case \#5, Appendix $\mathrm{N}$ shows the predicted GFB film temperature fields for operating with $175 \mathrm{~L} / \mathrm{min}$ and $25 \mathrm{~L} / \mathrm{min}$ forced cooling stream. 

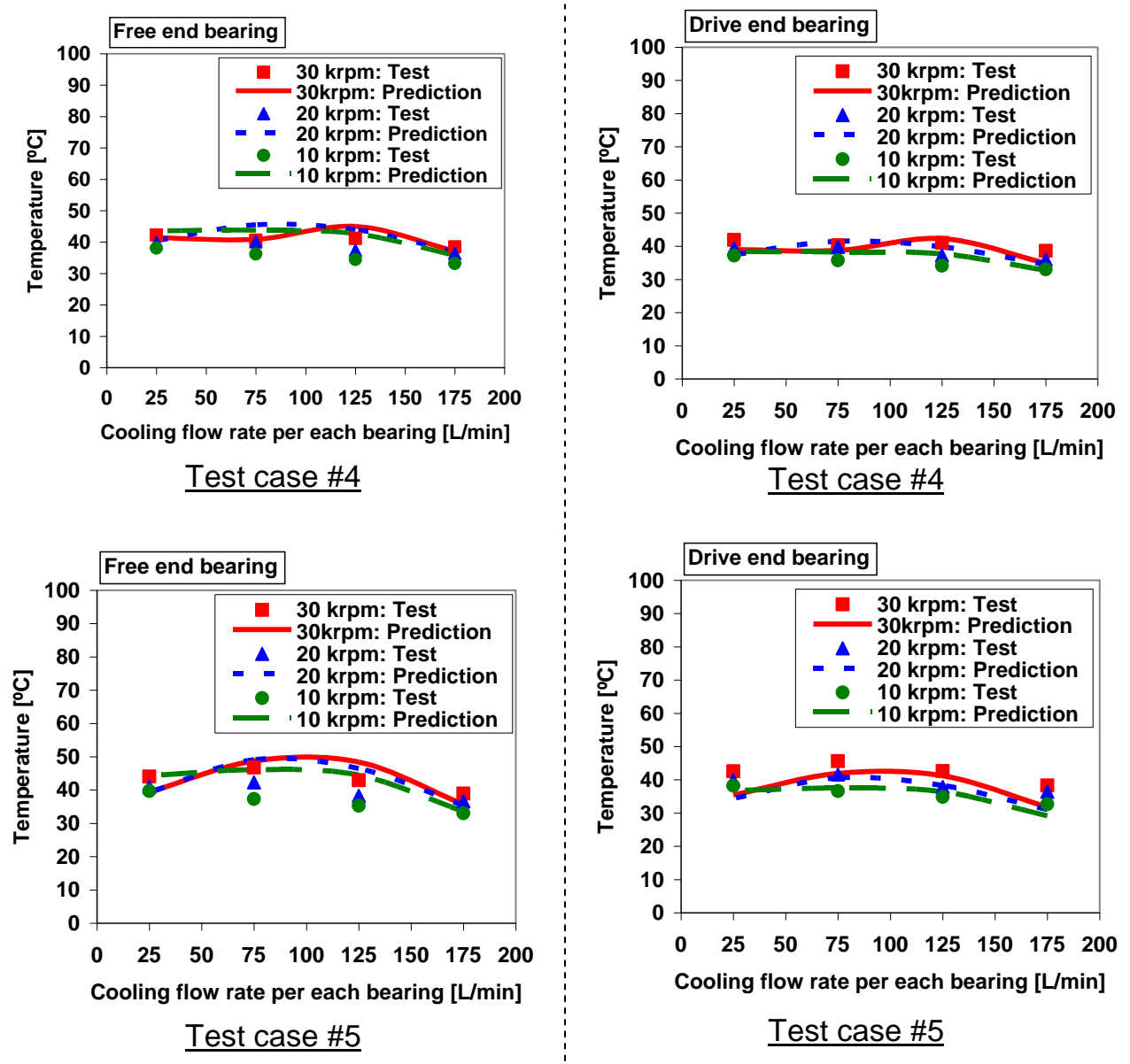

\section{$\underline{\text { Test case \#5 }}$}
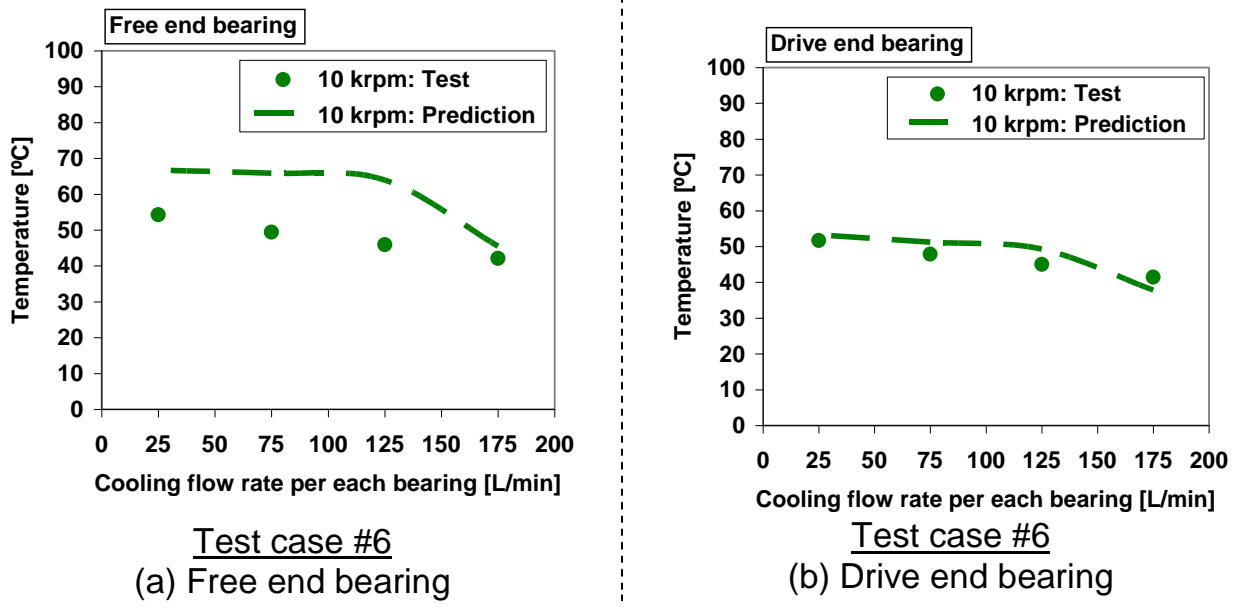

Fig. 40 Prediction versus test data: Temperatures of bearing sleeves (free and drive ends) versus cooling flow rate. See Appendix $M$ for complete inputs for prediction. 


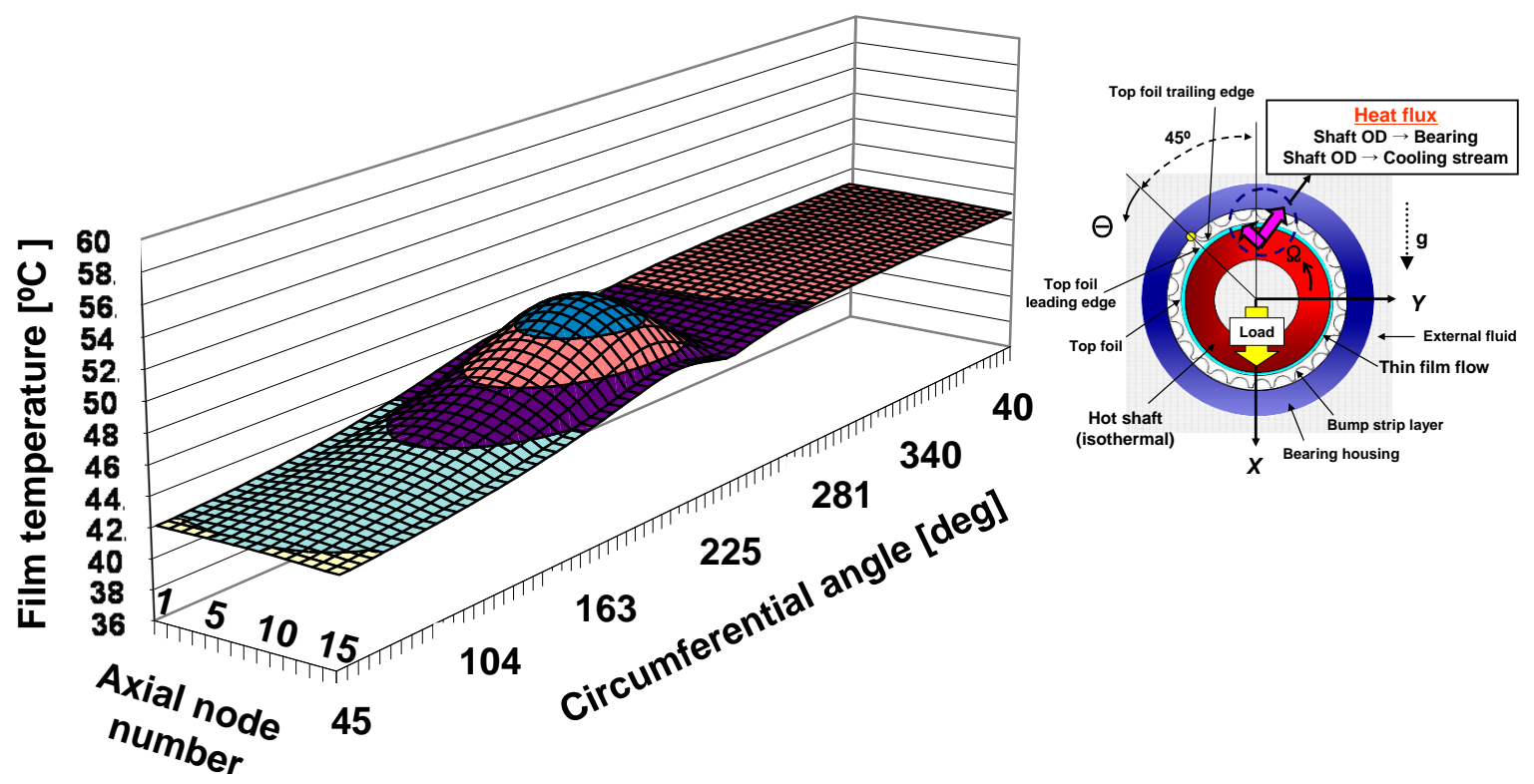

(a) Drive end bearing

(Cooling stream inlet temperature $=33^{\circ} \mathrm{C}$, uniform rotor $\mathrm{OD}$ temperature $=61^{\circ} \mathrm{C}, T_{a}=23^{\circ} \mathrm{C}$ )

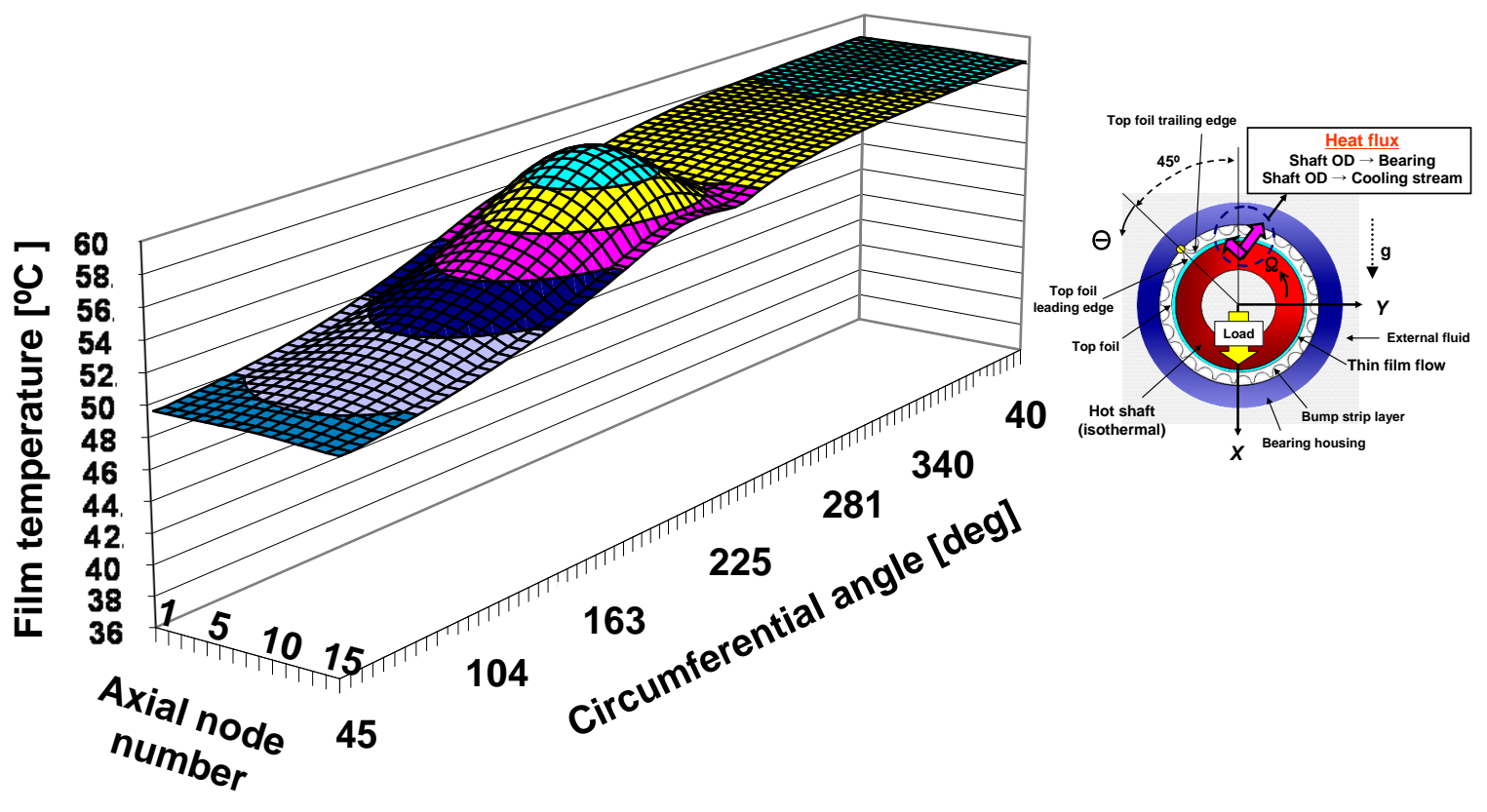

(b) Free end bearing

(Cooling stream inlet temperature $=33^{\circ} \mathrm{C}$, uniform rotor $\mathrm{OD}$ temperature $=80^{\circ} \mathrm{C}, T_{a}=23^{\circ} \mathrm{C}$ )

Fig. 41 Prediction: Test case \#5. Thin film temperature fields in GFBs. $T_{h s}=100^{\circ} \mathrm{C}$, rotor speed at $30 \mathrm{krpm}$. Cooling flow rate per each bearing $175 \mathrm{~L} / \mathrm{min}$. Thermal mixing coefficient $\lambda=0.65$. 


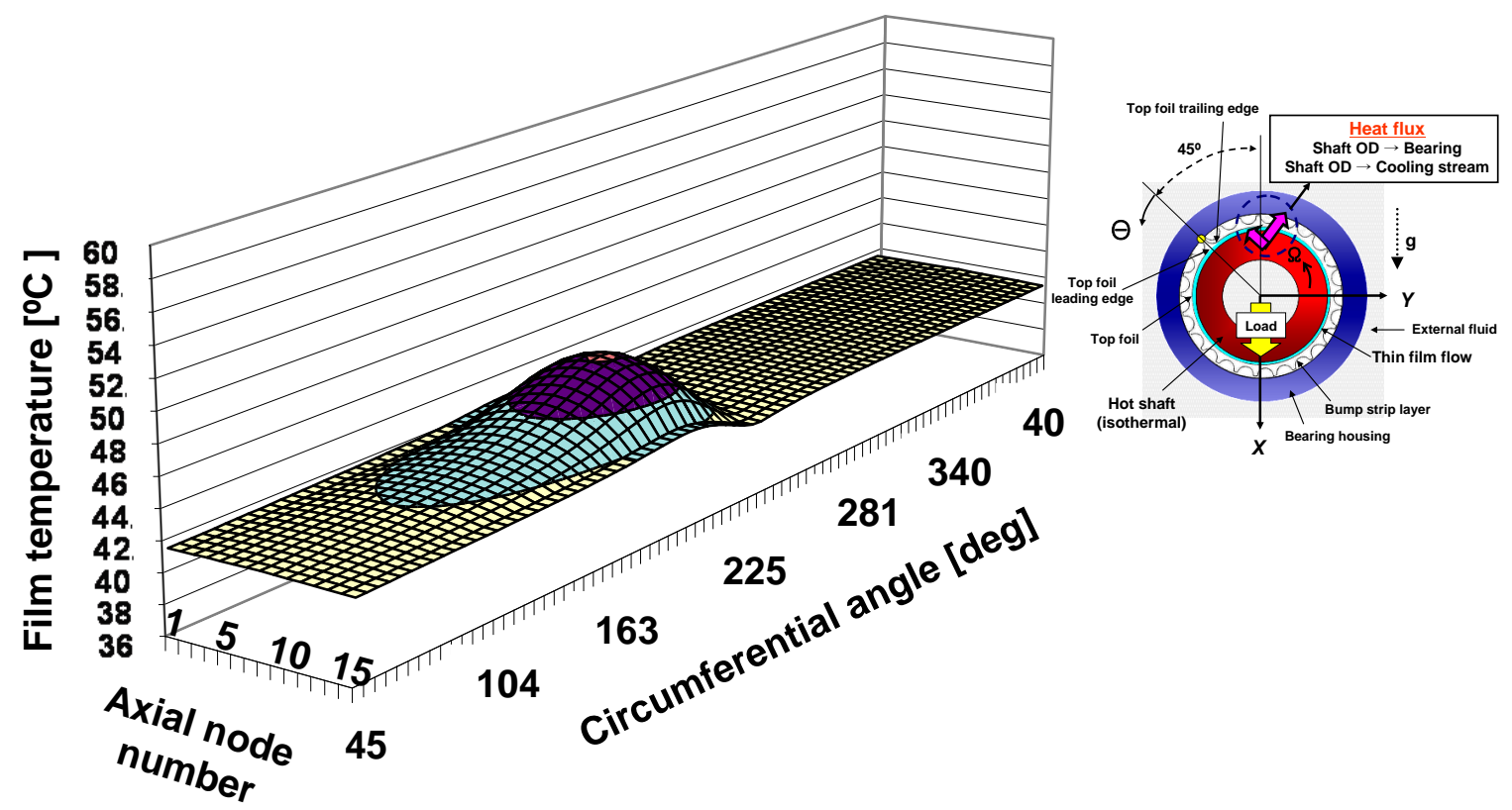

(a) Drive end bearing

(Cooling stream inlet temperature $=41^{\circ} \mathrm{C}$, uniform rotor $\mathrm{OD}$ temperature $=45^{\circ} \mathrm{C}, T_{a}=24^{\circ} \mathrm{C}$ )

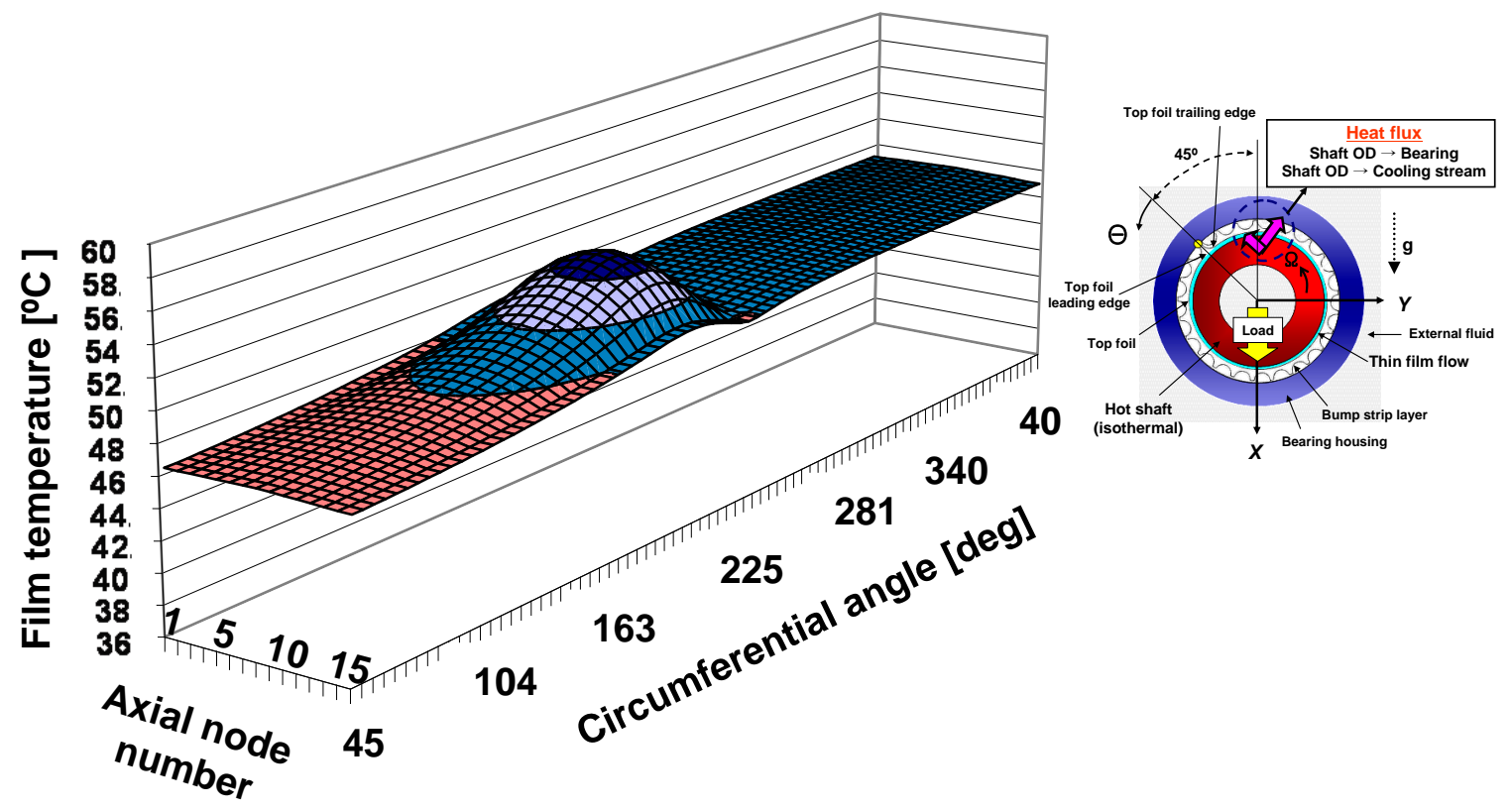

(b) Free end bearing

(Cooling stream inlet temperature $=41^{\circ} \mathrm{C}$, uniform rotor $\mathrm{OD}$ temperature $=56^{\circ} \mathrm{C}, T_{a}=24^{\circ} \mathrm{C}$ )

Fig. 42 Prediction: Test case \#5. Thin film temperature fields in GFBs. $T_{h s}=100^{\circ} \mathrm{C}$, rotor speed at $30 \mathrm{krpm}$. Cooling flow rate per each bearing $25 \mathrm{~L} / \mathrm{min}$. Thermal mixing coefficient $\lambda=0.65$. 


\subsection{Prediction of Rotor Imbalance Responses and Comparison to Test Data}

The rotordynamic analysis consists of modeling of the test rotor structure using XLTRC $^{2} \circledast$ and predicting the force coefficients of GFBs using XLGFBTH@. Tables 3 and 4 list the predicted GFB dynamic force coefficients at a frequency synchronous with rotor speed.

Appendix M shows the predicted GFB journal eccentricity, attitude angle, minimum film thickness, and drag torque. The cooling flow rate into each bearing decreases from $175 \mathrm{~L} / \mathrm{min}$ to $25 \mathrm{~L} / \mathrm{min}$ with a $50 \mathrm{~L} / \mathrm{min}$ interval. The static load on each bearing equals a fraction of the rotor weight, 7.39 $\mathrm{N}$ and $5.94 \mathrm{~N}$ on the drive end and free end bearings, respectively. As the rotor speed increases, the journal eccentricity decreases while the journal attitude angle, the minimum film thickness and the bearing drag torque increase. In general, the journal eccentricity decreases with rotor OD temperature. The GFB operating at $T_{h s}=150^{\circ} \mathrm{C}$ with low cooling stream $(25 \mathrm{~L} / \mathrm{min}$ per bearing) shows the largest journal eccentricities. Note that the minimum film thickness largely relies on gas viscosity and the bearing operating clearance. The attitude angle, minimum film thickness, and drag torque do not change noticeably with rotor temperature. When the rotor speed increases from $10 \mathrm{krpm}$ to $30 \mathrm{krpm}$, the predicted bearing drag torque increases nearly twice.

For test case \#5, Figs. 43 and 44 depict the GFB force coefficients calculated at a whirl frequency synchronous with rotor speed. Note that direction $X$ is along the static load direction, i.e., vertical. In each figure, graphs (a) and (b) depict the stiffness and damping coefficients for the drive end bearing; graphs (c) and (d) display those for the 
free end bearing. Note the different vertical scale between the direct and cross-coupled force coefficients. The inset figure shows the coordinate system.

High rotor speed renders lower stiffness and damping coefficients, both direct and cross-coupled. The force coefficients along the static load direction $(X)$ are larger than those along the $Y$ direction (horizontal), i.e., $K_{x x}>K_{y y}$ and $C_{x x}>C_{y y}$ denoting stiffness and damping asymmetry. Note that the GFB rotordynamic force coefficients do not change significantly with the strength of the cooling flow rate. The cross-coupled stiffnesses decrease with rotor speed due to high eccentricities $(71 \mu \mathrm{m}-121 \mu \mathrm{m}$, see Appendix M). Recall that for the non-rotating shaft at room temperature, the estimated radial clearance for each bearing is $\sim 100 \mu \mathrm{m}$ (Fig. 14). Appendix O displays the predicted GFB force coefficients for test cases \#4 and \#6. In general, the stiffness and damping coefficients of the drive end bearing are slightly higher than those of the free end bearing due to its larger static load mainly. 
Table 3 Complete drive end bearing predicted dynamic force coefficients (whirl frequency synchronous with rotor speed)

\begin{tabular}{|c|c|c|c|c|c|c|c|c|c|c|c|c|c|c|}
\hline $\begin{array}{c}\text { Test } \\
\text { Case } \\
\#\end{array}$ & $\begin{array}{c}T_{h s} \\
{\left[{ }^{\circ} \mathrm{C}\right]}\end{array}$ & $\begin{array}{c}\text { Rotor } \\
\text { speed } \\
{[\mathrm{krpm}]}\end{array}$ & $\begin{array}{c}\text { Cooling } \\
\text { flow rate } \\
\text { (per bearing) } \\
{[\mathrm{L} / \mathrm{min}]} \\
\end{array}$ & $\begin{array}{c}T_{C o} \\
=T_{e} \\
{\left[{ }^{\circ} \mathrm{C}\right]} \\
(1)\end{array}$ & $\begin{array}{l}T_{a m b} \\
{\left[{ }^{\circ} \mathrm{C}\right]} \\
(1)\end{array}$ & $\begin{array}{c}\text { Rotor } \\
\text { OD } \\
{\left[{ }^{\circ} \mathrm{C}\right]} \\
(1)(2)\end{array}$ & $\begin{array}{c}K_{x x} \\
{[\mathrm{MN} / \mathrm{m}]}\end{array}$ & $\begin{array}{c}K_{x y} \\
{[\mathrm{MN} / \mathrm{m}]}\end{array}$ & $\begin{array}{c}K_{y x} \\
{[\mathrm{MN} / \mathrm{m}]}\end{array}$ & $\begin{array}{c}K_{y y} \\
{[\mathrm{MN} / \mathrm{m}]}\end{array}$ & $\begin{array}{c}C_{x x} \\
{[\mathrm{Ns} / \mathrm{m}]}\end{array}$ & $\begin{array}{c}C_{x y} \\
{[\mathrm{Ns} / \mathrm{m}]}\end{array}$ & $\begin{array}{c}C_{y x} \\
{[\mathrm{Ns} / \mathrm{m}]}\end{array}$ & $\begin{array}{c}C_{y y} \\
{[\mathrm{Ns} / \mathrm{m}]}\end{array}$ \\
\hline 7 & Off & 10 & 175 & 25 & 23 & 33 & 0.83 & 0.55 & 0.09 & 0.29 & 896 & 235 & 416 & 250 \\
\hline 7 & Off & 20 & 175 & 25 & 23 & 33 & 0.50 & 0.43 & 0.03 & 0.29 & 332 & 99 & 189 & 163 \\
\hline 7 & Off & 30 & 175 & 25 & 23 & 33 & 0.39 & 0.37 & -0.01 & 0.29 & 188 & 51 & 114 & 123 \\
\hline 4,8 & 65 & 10 & 175 & 30 & 29 & 43 & 0.78 & 0.52 & 0.08 & 0.28 & 841 & 225 & 396 & 250 \\
\hline 4,8 & 65 & 20 & 175 & 32 & 29 & 50 & 0.46 & 0.40 & 0.01 & 0.28 & 307 & 93 & 177 & 164 \\
\hline 4,8 & 65 & 30 & 175 & 36 & 28 & 53 & 0.36 & 0.35 & -0.02 & 0.28 & 174 & 47 & 106 & 125 \\
\hline 5,9 & 100 & 10 & 175 & 28 & 22 & 49 & 0.79 & 0.50 & 0.08 & 0.26 & 828 & 219 & 376 & 228 \\
\hline 5,9 & 100 & 20 & 175 & 33 & 23 & 55 & 0.47 & 0.38 & 0.02 & 0.25 & 302 & 92 & 168 & 147 \\
\hline 5,9 & 100 & 30 & 175 & 33 & 23 & 61 & 0.36 & 0.33 & -0.01 & 0.26 & 169 & 49 & 102 & 113 \\
\hline 6 & 150 & 10 & 175 & 37 & 26 & 70 & 0.74 & 0.46 & 0.07 & 0.23 & 749 & 206 & 340 & 211 \\
\hline 4 & 65 & 10 & 125 & 31 & 29 & 45 & 0.77 & 0.51 & 0.08 & 0.27 & 822 & 223 & 387 & 244 \\
\hline 4 & 65 & 20 & 125 & 34 & 29 & 50 & 0.46 & 0.39 & 0.01 & 0.27 & 301 & 92 & 173 & 159 \\
\hline 4 & 65 & 30 & 125 & 38 & 28 & 57 & 0.36 & 0.33 & -0.02 & 0.27 & 168 & 46 & 102 & 120 \\
\hline 5 & 100 & 10 & 125 & 31 & 22 & 51 & 0.84 & 0.49 & 0.09 & 0.23 & 853 & 218 & 367 & 206 \\
\hline 5 & 100 & 20 & 125 & 35 & 23 & 56 & 0.47 & 0.36 & 0.03 & 0.23 & 290 & 90 & 157 & 129 \\
\hline 5 & 100 & 30 & 125 & 40 & 23 & 64 & 0.36 & 0.31 & -0.03 & 0.22 & 159 & 49 & 94 & 96 \\
\hline 6 & 150 & 10 & 125 & 42 & 27 & 72 & 0.81 & 0.44 & 0.09 & 0.20 & 759 & 199 & 321 & 180 \\
\hline 4 & 65 & 10 & 75 & 34 & 28 & 46 & 0.77 & 0.51 & 0.08 & 0.27 & 818 & 223 & 385 & 244 \\
\hline 4 & 65 & 20 & 75 & 38 & 28 & 53 & 0.45 & 0.38 & 0.01 & 0.27 & 296 & 91 & 170 & 158 \\
\hline 4 & 65 & 30 & 75 & 36 & 28 & 49 & 0.36 & 0.34 & -0.02 & 0.28 & 173 & 48 & 105 & 122 \\
\hline 5 & 100 & 10 & 75 & 34 & 22 & 54 & 0.81 & 0.48 & 0.09 & 0.23 & 782 & 205 & 343 & 200 \\
\hline 5 & 100 & 20 & 75 & 40 & 23 & 60 & 0.47 & 0.35 & 0.03 & 0.22 & 284 & 88 & 153 & 125 \\
\hline 5 & 100 & 30 & 75 & 43 & 23 & 64 & 0.36 & 0.31 & -0.02 & 0.22 & 159 & 50 & 94 & 96 \\
\hline 6 & 150 & 10 & 75 & 48 & 27 & 75 & 0.77 & 0.42 & 0.08 & 0.20 & 694 & 185 & 297 & 170 \\
\hline 4 & 65 & 10 & 25 & 38 & 28 & 46 & 0.77 & 0.51 & 0.08 & 0.27 & 818 & 224 & 386 & 245 \\
\hline 4 & 65 & 20 & 25 & 37 & 29 & 44 & 0.47 & 0.40 & 0.02 & 0.28 & 309 & 94 & 178 & 161 \\
\hline 4 & 65 & 30 & 25 & 39 & 29 & 47 & 0.37 & 0.35 & -0.02 & 0.28 & 173 & 48 & 106 & 122 \\
\hline 5,10 & 100 & 10 & 25 & 40 & 23 & 50 & 0.82 & 0.49 & 0.09 & 0.24 & 796 & 209 & 351 & 202 \\
\hline 5,10 & 100 & 20 & 25 & 38 & 23 & 45 & 0.48 & 0.39 & 0.03 & 0.25 & 306 & 93 & 168 & 140 \\
\hline 5,10 & 100 & 30 & 25 & 41 & 24 & 45 & 0.37 & 0.34 & -0.04 & 0.25 & 172 & 51 & 103 & 107 \\
\hline 6 & 150 & 10 & 25 & 57 & 28 & 79 & 0.73 & 0.40 & 0.08 & 0.19 & 637 & 173 & 275 & 161 \\
\hline
\end{tabular}

(1) Obtained from the test data. Input parameters in the analytical model

(2) Represent rotor temperatures at the bearing locations. Estimated from a constant temperature gradient (linear temperature drop) from the recorded rotor FE and DE temperatures $\left(\operatorname{Tr}_{F E}\right.$ and $\left.\operatorname{Tr}_{D E}\right)$. 
Table 4 Complete free end bearing predicted dynamic force coefficients (whirl frequency synchronous with rotor speed)

\begin{tabular}{|c|c|c|c|c|c|c|c|c|c|c|c|c|c|c|}
\hline $\begin{array}{c}\text { Test } \\
\text { Case } \\
\#\end{array}$ & $\left|\begin{array}{c}T_{h s} \\
{\left[{ }^{\circ} \mathrm{C}\right]}\end{array}\right|$ & $\begin{array}{c}\text { Rotor } \\
\text { speed } \\
{[\mathrm{krpm}]}\end{array}$ & $\begin{array}{c}\text { Cooling } \\
\text { flow rate } \\
\text { (per bearing) } \\
{[\mathrm{L} / \mathrm{min}]} \\
\end{array}$ & $\begin{array}{l}T_{C o} \\
=T_{e} \\
{\left[{ }^{\circ} \mathrm{C}\right]} \\
(1)\end{array}$ & $\begin{array}{l}T_{a m b} \\
{\left[{ }^{\circ} \mathrm{C}\right]} \\
(1)\end{array}$ & $\begin{array}{c}\text { Rotor } \\
\text { OD } \\
{\left[{ }^{\circ} \mathrm{C}\right]} \\
(1)(2)\end{array}$ & $\begin{array}{c}K_{x x} \\
{[\mathrm{MN} / \mathrm{m}]}\end{array}$ & $\begin{array}{c}K_{x y} \\
{[\mathrm{MN} / \mathrm{m}]}\end{array}$ & $\begin{array}{c}K_{y x} \\
{[\mathrm{MN} / \mathrm{m}]}\end{array}$ & $\begin{array}{c}K_{y y} \\
{[\mathrm{MN} / \mathrm{m}]}\end{array}$ & $\begin{array}{c}C_{x x} \\
{[\mathrm{Ns} / \mathrm{m}]}\end{array}$ & $\begin{array}{c}C_{x y} \\
{[\mathrm{Ns} / \mathrm{m}]}\end{array}$ & $\begin{array}{c}C_{y x} \\
{[\mathrm{Ns} / \mathrm{m}]}\end{array}$ & $\begin{array}{c}C_{y y} \\
{[\mathrm{Ns} / \mathrm{m}]}\end{array}$ \\
\hline 7 & Off & 10 & 175 & 25 & 23 & 33 & 0.53 & 0.42 & 0.03 & 0.23 & 702 & 218 & 349 & 242 \\
\hline 7 & Off & 20 & 175 & 25 & 23 & 33 & 0.32 & 0.32 & -0.02 & 0.23 & 258 & 86 & 153 & 154 \\
\hline 7 & Off & 30 & 175 & 25 & 23 & 33 & 0.26 & 0.28 & -0.05 & 0.23 & 147 & 43 & 90 & 116 \\
\hline 4,8 & 65 & 10 & 175 & 30 & 29 & 56 & 0.49 & 0.37 & 0.03 & 0.20 & 621 & 198 & 307 & 218 \\
\hline 4,8 & 65 & 20 & 175 & 32 & 29 & 63 & 0.29 & 0.28 & -0.03 & 0.20 & 225 & 77 & 131 & 136 \\
\hline 4,8 & 65 & 30 & 175 & 36 & 28 & 67 & 0.24 & 0.25 & -0.05 & 0.20 & 129 & 39 & 77 & 104 \\
\hline 5,9 & 100 & 10 & 175 & 28 & 22 & 65 & 0.49 & 0.35 & 0.03 & 0.19 & 603 & 193 & 293 & 207 \\
\hline 5,9 & 100 & 20 & 175 & 33 & 23 & 74 & 0.29 & 0.27 & -0.02 & 0.18 & 217 & 76 & 125 & 130 \\
\hline 5,9 & 100 & 30 & 175 & 33 & 23 & 80 & 0.23 & 0.23 & -0.05 & 0.19 & 124 & 39 & 74 & 99 \\
\hline 6 & 150 & 10 & 175 & 37 & 26 & 98 & 0.45 & 0.30 & 0.02 & 0.16 & 519 & 173 & 252 & 182 \\
\hline 4 & 65 & 10 & 125 & 31 & 29 & 57 & 0.50 & 0.36 & 0.03 & 0.19 & 600 & 189 & 288 & 194 \\
\hline 4 & 65 & 20 & 125 & 34 & 29 & 63 & 0.29 & 0.27 & -0.02 & 0.18 & 217 & 76 & 124 & 121 \\
\hline 4 & 65 & 30 & 125 & 38 & 28 & 69 & 0.23 & 0.23 & -0.04 & 0.18 & 122 & 40 & 73 & 91 \\
\hline 5 & 100 & 10 & 125 & 31 & 22 & 67 & 0.51 & 0.33 & 0.04 & 0.17 & 570 & 177 & 263 & 171 \\
\hline 5 & 100 & 20 & 125 & 35 & 23 & 75 & 0.29 & 0.25 & -0.01 & 0.16 & 206 & 74 & 115 & 109 \\
\hline 5 & 100 & 30 & 125 & 40 & 23 & 85 & 0.22 & 0.21 & -0.03 & 0.16 & 114 & 40 & 68 & 81 \\
\hline 6 & 150 & 10 & 125 & 42 & 27 & 103 & 0.48 & 0.27 & 0.03 & 0.13 & 473 & 150 & 211 & 135 \\
\hline 4 & 65 & 10 & 75 & 34 & 28 & 60 & 0.50 & 0.35 & 0.03 & 0.18 & 591 & 185 & 281 & 188 \\
\hline 4 & 65 & 20 & 75 & 38 & 28 & 66 & 0.29 & 0.26 & -0.01 & 0.18 & 214 & 75 & 122 & 118 \\
\hline 4 & 65 & 30 & 75 & 36 & 28 & 58 & 0.24 & 0.24 & -0.04 & 0.19 & 128 & 41 & 77 & 97 \\
\hline 5 & 100 & 10 & 75 & 34 & 22 & 70 & 0.51 & 0.32 & 0.03 & 0.16 & 561 & 174 & 257 & 166 \\
\hline 5 & 100 & 20 & 75 & 40 & 23 & 80 & 0.29 & 0.24 & -0.01 & 0.16 & 200 & 73 & 112 & 105 \\
\hline 5 & 100 & 30 & 75 & 43 & 23 & 83 & 0.22 & 0.21 & -0.03 & 0.16 & 114 & 40 & 68 & 81 \\
\hline 6 & \begin{tabular}{|l|}
150 \\
\end{tabular} & 10 & 75 & 48 & 27 & 106 & 0.48 & 0.27 & 0.03 & 0.13 & 466 & 148 & 208 & 133 \\
\hline 4 & 65 & 10 & 25 & 38 & 28 & 59 & 0.51 & 0.35 & 0.03 & 0.18 & 594 & 186 & 283 & 189 \\
\hline 4 & 65 & 20 & 25 & 37 & 29 & 53 & 0.30 & 0.28 & -0.02 & 0.19 & 227 & 79 & 132 & 130 \\
\hline 4 & 65 & 30 & 25 & 39 & 29 & 56 & 0.24 & 0.25 & -0.04 & 0.19 & 128 & 41 & 78 & 97 \\
\hline 5,10 & 100 & 10 & 25 & 40 & 23 & 66 & 0.51 & 0.33 & 0.03 & 0.17 & 574 & 178 & 265 & 172 \\
\hline 5,10 & 100 & 20 & 25 & 38 & 23 & 57 & 0.30 & 0.27 & -0.01 & 0.18 & 224 & 78 & 127 & 121 \\
\hline 5,10 & 100 & 30 & 25 & 41 & 24 & 56 & 0.24 & 0.24 & -0.04 & 0.19 & 128 & 42 & 77 & 94 \\
\hline 6 & \begin{tabular}{|l|}
150 \\
\end{tabular} & 10 & 25 & 57 & 28 & 110 & 0.48 & 0.27 & 0.03 & 0.13 & 473 & 150 & 211 & 135 \\
\hline
\end{tabular}

(1) Obtained from the test data. Input parameters in the analytical model

(2) Represent rotor temperatures at the bearing locations. Estimated from a constant temperature gradient (linear temperature drop) from the recorded rotor FE and DE temperatures $\left(\operatorname{Tr}_{F E}\right.$ and $\left.\operatorname{Tr}_{D E}\right)$. 


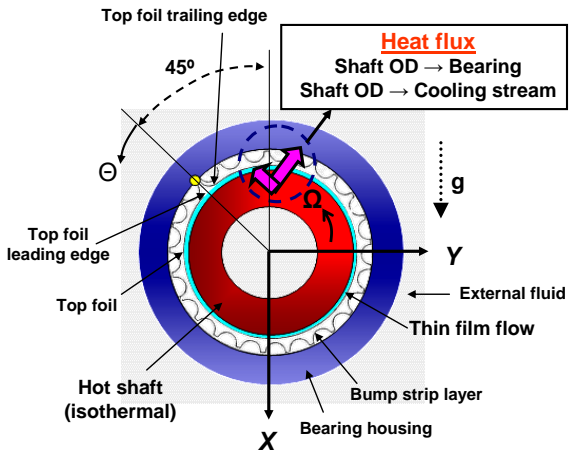

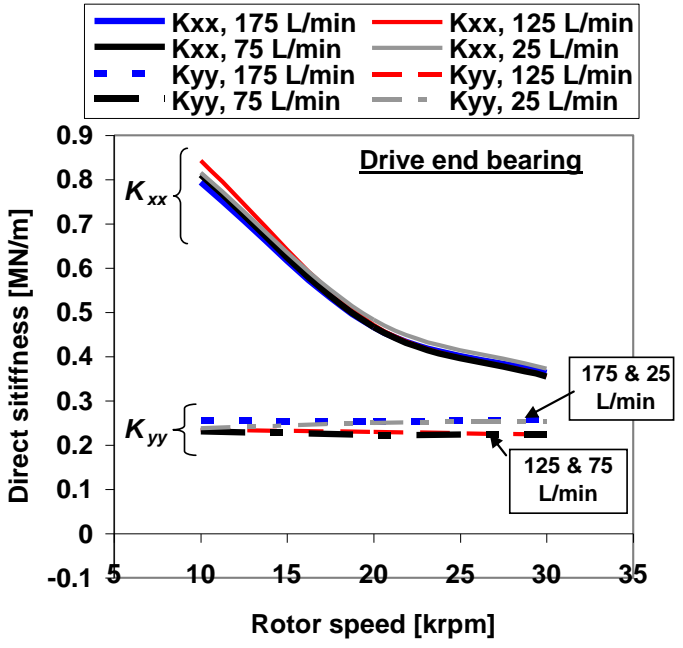

(a) Direct stiffness. Drive end bearing

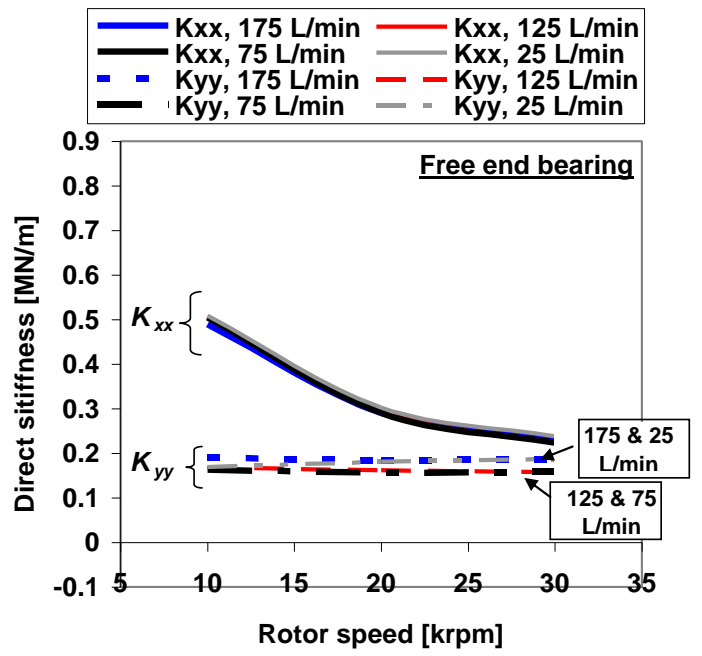

(c) Direct stiffness. Free end bearing

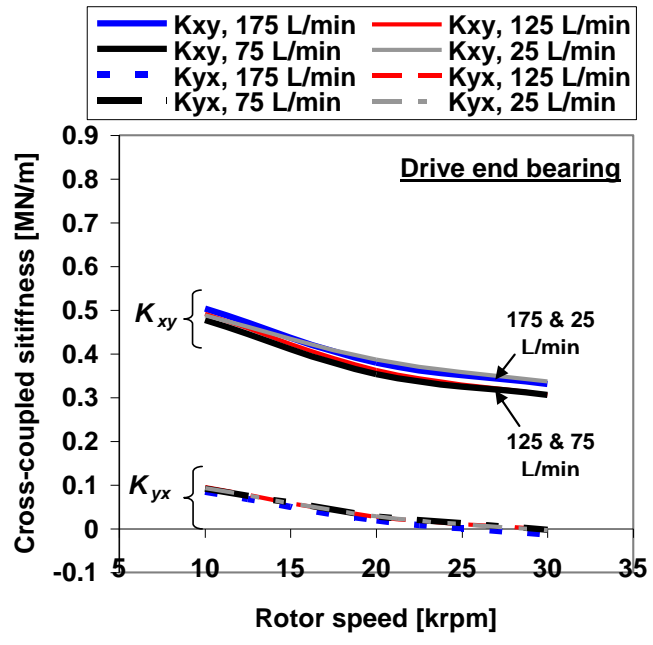

(b) Cross-coupled stiffness: Drive end bearing

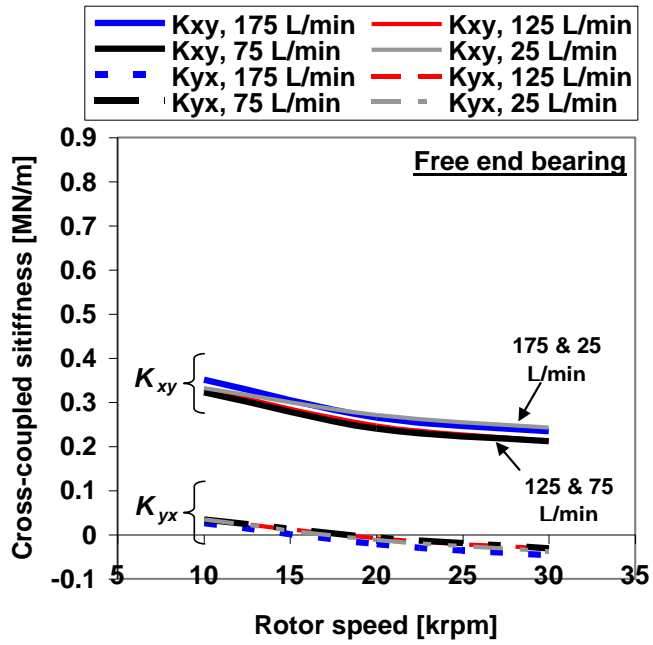

(d) Cross-coupled stiffness: Free end bearing

Fig. 43 Prediction: $T_{h s}=100^{\circ} \mathrm{C}$. Drive end and free end foil bearing direct and cross-coupled stiffness versus rotor speed and increasing air cooling flow rates. 


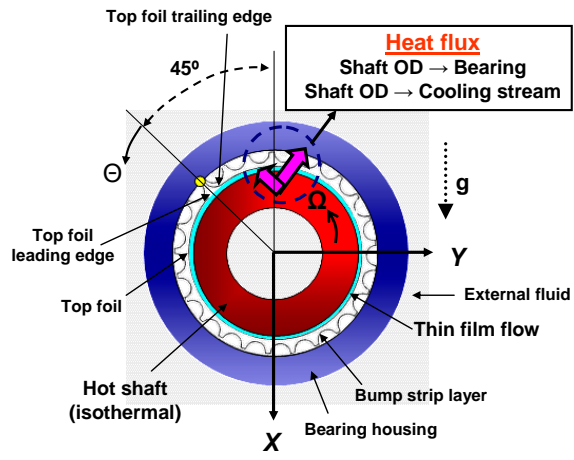

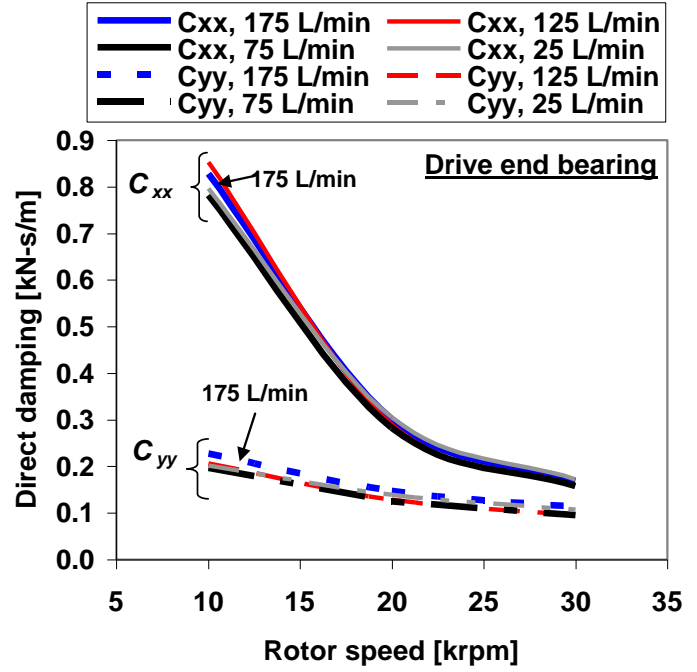

(a) Direct damping. Drive end bearing

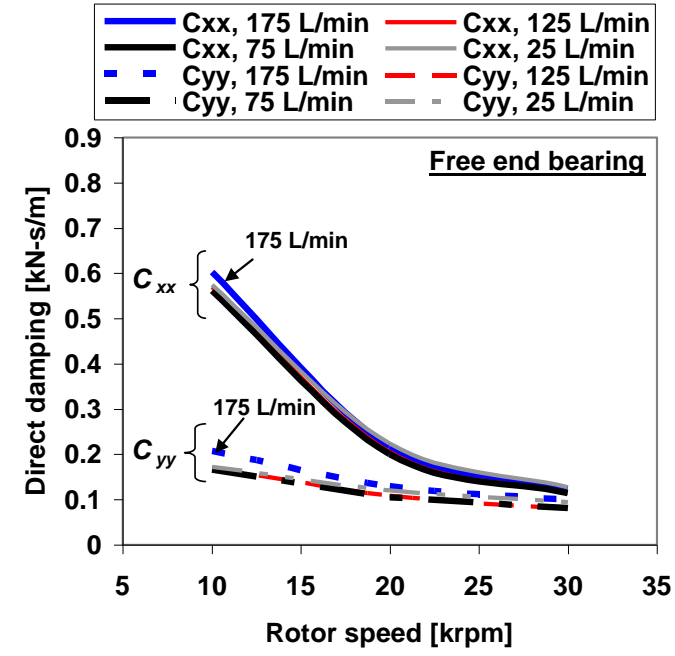

(c) Direct damping. Free end bearing

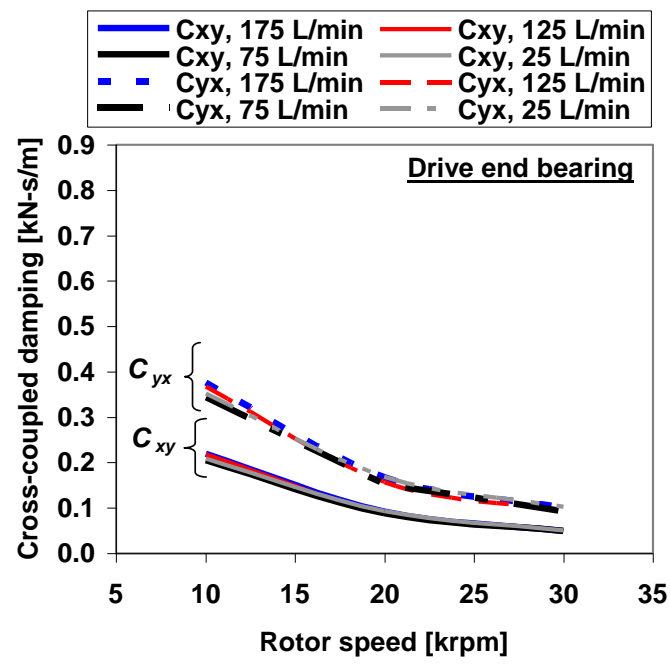

(b) Cross-coupled damping: Drive end bearing

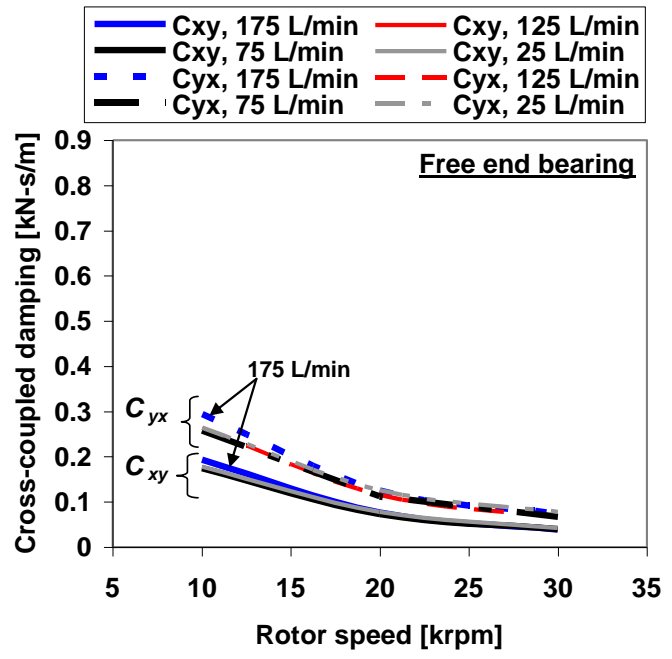

(d) Cross-coupled damping: Free end bearing

Fig. 44 Prediction: $T_{h s}=100^{\circ} \mathrm{C}$. Drive end and free end foil bearing direct and cross-coupled damping coefficients versus rotor speed and increasing air cooling flow rates. 
Figure 45 shows the 15 finite element structural model of the test rotor. The lateral stiffness of the flexible coupling is $\sim 4 \mathrm{~N} / \mathrm{mm}[14]$.

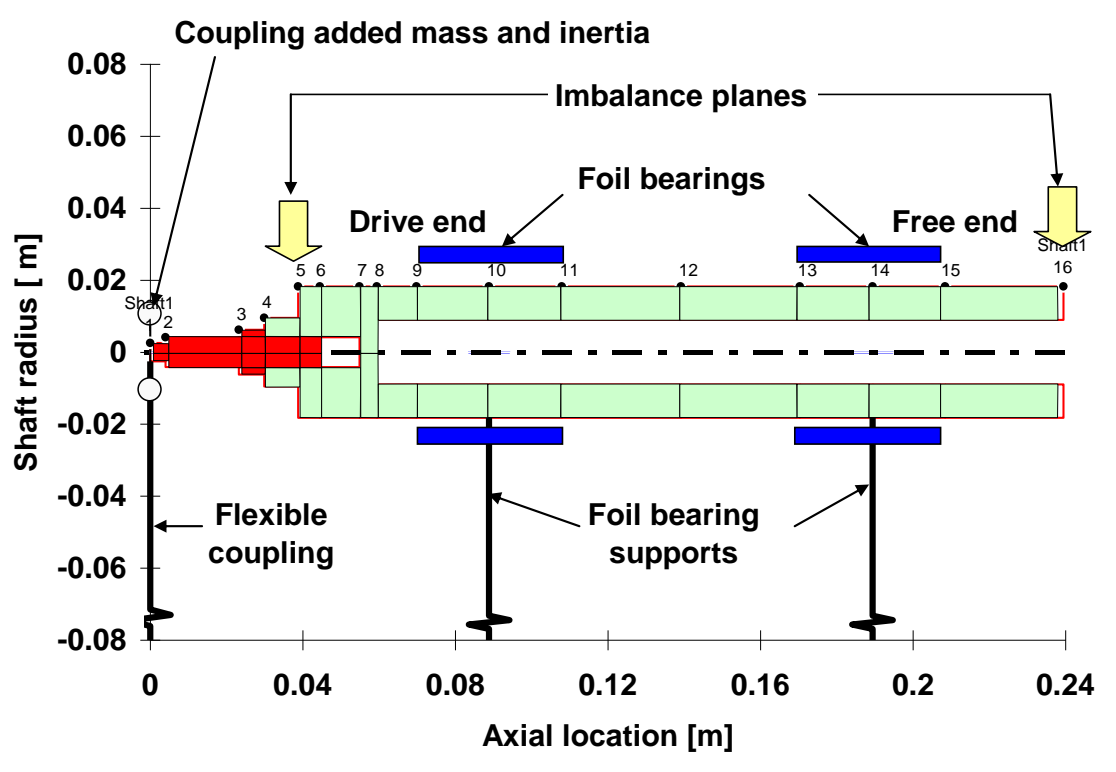

Fig. 45 Finite element model of test rotor supported on GFBs. Connecting rod and flexible coupling locate at drive end.

The predicted synchronous force coefficients of the bearings are incorporated into $\mathrm{XLTRC}^{2}{ }^{\circledR}$ for prediction of the rotor imbalance response. The eigenvalue analysis of the rotor-GFB system renders the natural frequencies and modal damping ratios, depicted in Figs. 46 and 47. Figure 46 depicts the predicted damped natural frequencies of the test rotor-bearing system for test case $\# 9\left(T_{h s}=100^{\circ} \mathrm{C}\right)$. The figure also shows the four rigid body modes (forward conical and cylindrical modes and backward conical and cylindrical modes) and predicted forward mode critical speeds at 3.2 and $3.8 \mathrm{krpm}$ and backward mode critical speeds at 4.3, 6.8, and $7.6 \mathrm{krpm}$. Note that the test results show 
two distinctive critical speeds $\sim 4 \mathrm{kprm}$ and $\sim 8 \mathrm{krpm}$ as shown in Fig. 34 . For the same test case, Fig. 47 depicts the predicted modal damping ratio versus rotor speed. The $3^{\text {rd }}$ and $4^{\text {th }}$ mode critical speeds are well-damped, damping ratio $0.65-0.89$, while the $1^{\text {st }}$ and $2^{\text {nd }}$ mode shows a lower damping ratio $\sim 0.1$. The $2^{\text {nd }}$ system natural mode renders a negative damping ratio for rotor speeds above $\sim 12 \mathrm{krpm}$. This implies an unstable system. However, in the experiments, no rotordynamic instability ever occurred over for the entire speed range. Table 5 lists the predicted system critical speeds and damping ratios.

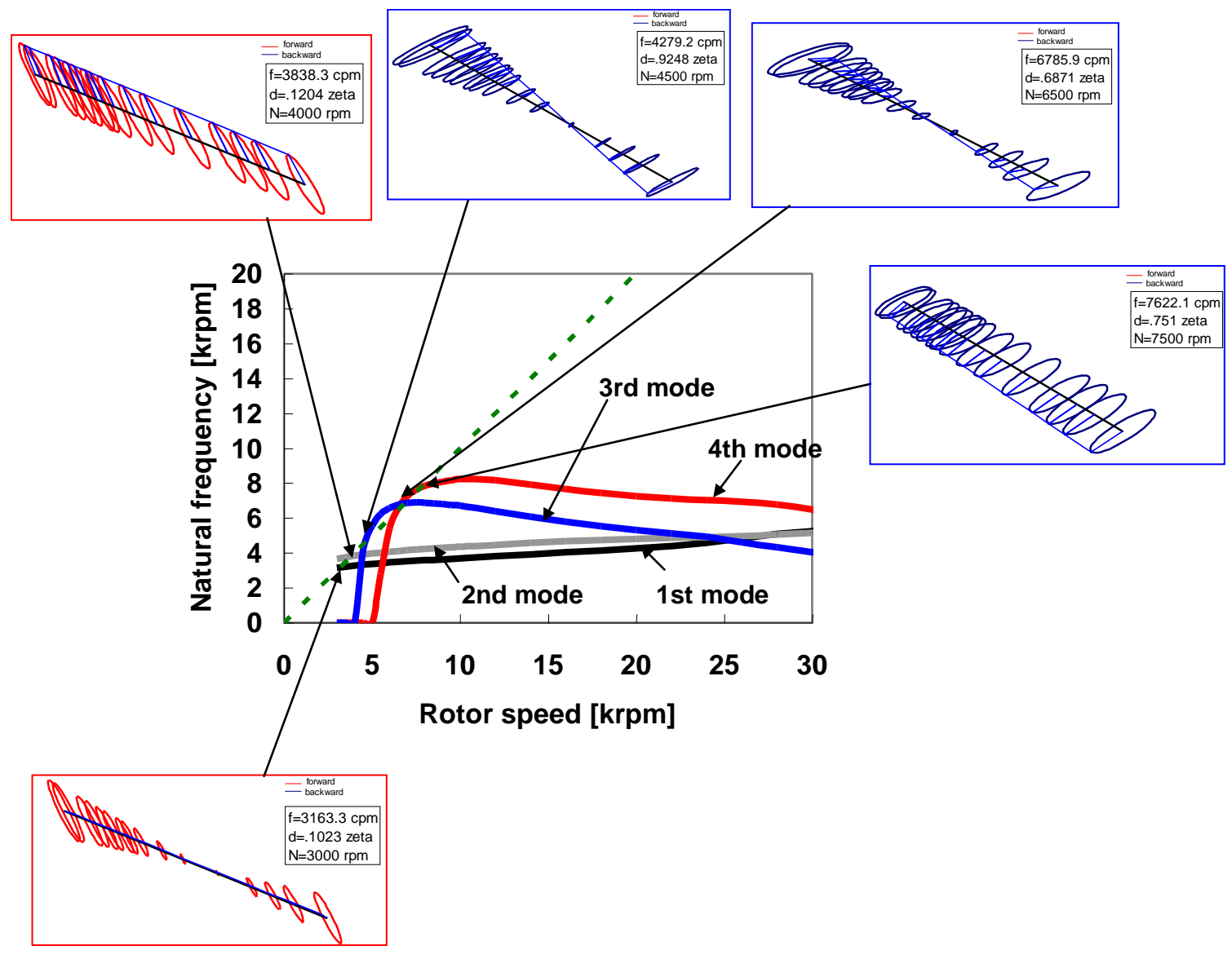

Fig. 46 Predicted damped natural frequency map of test rotor-GFB system. Mode shapes denoted. Test cases \#5 and \#9 $\left(T_{h s}=100^{\circ} \mathrm{C}\right)$. 


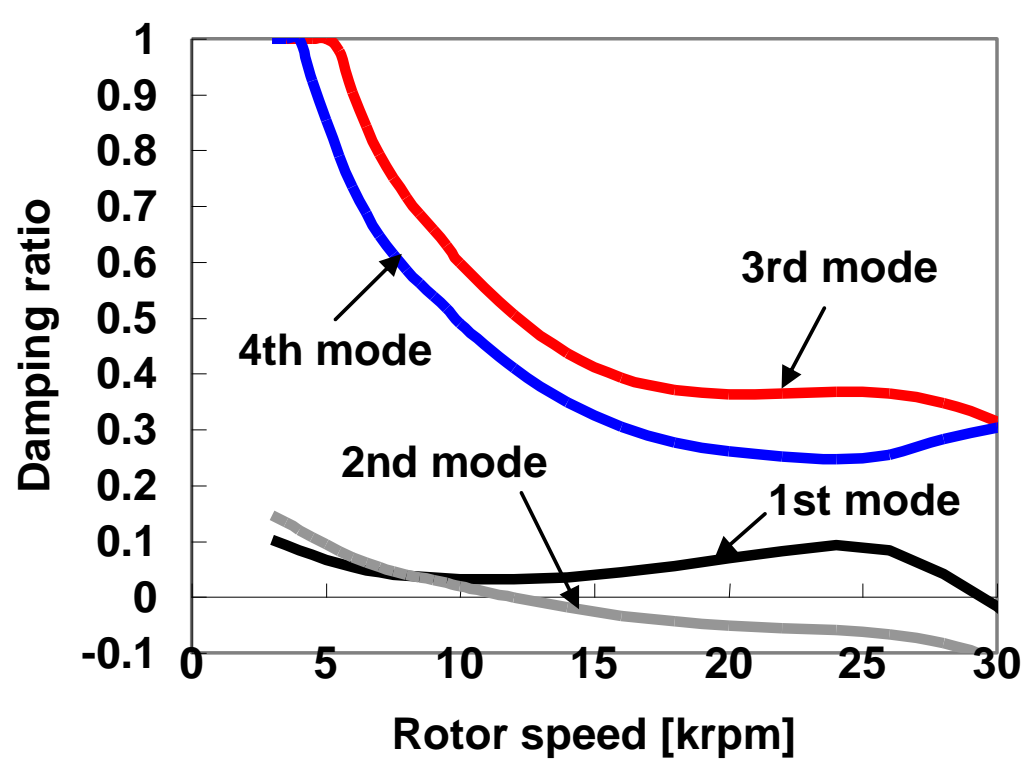

Fig. 47 Predicted damping ratio of test rotor-GFB system. Test cases \#5 and \#9 $\left(T_{h s}=100^{\circ} \mathrm{C}\right)$.

Table 5 Predicted natural frequencies and damping ratios of rotor-GFB system for test cases \#4,5, and 7-9

\begin{tabular}{|c|c|c|c|c|c|c|c|c|c|c|c|c|}
\hline \multirow{3}{*}{$\begin{array}{c}\text { Test } \\
\text { case } \\
\#\end{array}$} & \multicolumn{3}{|c|}{ Temperature $\left[{ }^{\circ} \mathrm{C}\right]$} & \multirow{3}{*}{$\begin{array}{c}\text { Cooling } \\
\text { flow } \\
\text { rate } \\
\text { (per } \\
\text { bearing) } \\
\text { [L/min] }\end{array}$} & \multicolumn{8}{|c|}{ Predicted natural mode } \\
\hline & \multirow[t]{2}{*}{$T_{h s}$} & \multicolumn{2}{|c|}{$\begin{array}{l}\text { Rotor OD at } \\
30 \mathrm{krpm}\end{array}$} & & \multicolumn{2}{|c|}{$\begin{array}{l}1^{\text {st }} \text { mode } \\
\text { (Conical } \\
\text { forward) }\end{array}$} & \multicolumn{2}{|c|}{$\begin{array}{c}2^{\text {nd }} \text { mode } \\
\text { (Cylindrical } \\
\text { forward) }\end{array}$} & \multicolumn{2}{|c|}{$\begin{array}{c}3^{\text {rd }} \text { mode } \\
\text { (Conical } \\
\text { backward) }\end{array}$} & \multicolumn{2}{|c|}{$\begin{array}{c}4^{\text {th }} \text { mode } \\
\text { (Cylindrical } \\
\text { backward) }\end{array}$} \\
\hline & & $\begin{array}{c}\text { Drive } \\
\text { end }\end{array}$ & $\begin{array}{l}\text { Free } \\
\text { end }\end{array}$ & & $\begin{array}{l}\text { N.F. }{ }^{(2)} \\
{[\mathrm{krpm}]}\end{array}$ & $\zeta^{(3)}$ & $\begin{array}{l}\text { N.F. }^{(2)} \\
{[\mathrm{krpm}]}\end{array}$ & $\zeta^{(3)}$ & $\begin{array}{l}\text { N.F. }^{(2)} \\
{[\mathrm{krpm}]}\end{array}$ & $\zeta^{(3)}$ & $\begin{array}{l}\text { N.F. }^{(2)} \\
{[\mathrm{krpm}]}\end{array}$ & $\zeta^{(3)}$ \\
\hline \multirow[t]{2}{*}{7} & \multirow{2}{*}{ Off } & \multirow{2}{*}{$\begin{array}{c}32 \\
(33)^{(1)}\end{array}$} & \multirow{2}{*}{$\begin{array}{c}33 \\
(33)^{(1)}\end{array}$} & \multirow{2}{*}{175} & \multirow{2}{*}{3.3} & \multirow{2}{*}{0.10} & \multirow{2}{*}{3.9} & \multirow{2}{*}{0.12} & 5.2 & 0.89 & \multirow{2}{*}{7.5} & \multirow{2}{*}{0.77} \\
\hline & & & & & & & & & 6.9 & 0.70 & & \\
\hline \multirow{2}{*}{4,8} & \multirow{2}{*}{65} & \multirow{2}{*}{$\begin{array}{c}49 \\
(53)^{(1)}\end{array}$} & \multirow{2}{*}{$\begin{array}{c}71 \\
(67)^{(1)}\end{array}$} & \multirow{2}{*}{175} & \multirow{2}{*}{3.2} & \multirow{2}{*}{0.11} & \multirow{2}{*}{3.9} & \multirow{2}{*}{0.13} & 5.4 & 0.86 & \multirow{2}{*}{7.1} & \multirow{2}{*}{0.81} \\
\hline & & & & & & & & & 6.8 & 0.65 & & \\
\hline \multirow{2}{*}{5,9} & \multirow{2}{*}{100} & \multirow{2}{*}{$\begin{array}{c}54 \\
(61)^{(1)}\end{array}$} & \multirow{2}{*}{$\begin{array}{c}87 \\
(80)^{(1)}\end{array}$} & \multirow{2}{*}{175} & \multirow{2}{*}{3.2} & 10 & 38 & 017 & 5.6 & 0.85 & & $\Omega$ \\
\hline & & & & & & & & & 6.9 & 0.65 & & \\
\hline
\end{tabular}

(1) The numbers in parentheses refer to the estimated rotor OD temperature at the bearing locations.

(2) N.F.= Natural frequency.

(3) $\zeta=$ Damping ratio. 
Figure 48 presents the predicted and measured synchronous rotor responses for test cases \#7 though \#9. In the figure, the rotor motion measurements are along the horizontal planes near the rotor free end $(\mathrm{FH})$ and drive end $(\mathrm{DH})$. In the predictions, estimated imbalance masses are $0.01 \mathrm{gram} \cdot \mathrm{mm}$ at the rotor drive end and $0.3 \mathrm{gram} \cdot \mathrm{mm}$ at the rotor free end (see Fig. 45), with $180^{\circ}$ out of phase ${ }^{29}$. The comparison between predicted and recorded rotor responses is less favorable at $\sim 8 \mathrm{krpm}$; the experiments show a narrow peak at this speed, while the predicted rotor motion does not show a peak amplitude because of the large damping ratio (see Table 5). In addition, the predicted system critical speeds are well-damped, thereby rendering significantly lower rotor response amplitudes than those experimentally recorded. Note that large dynamic displacements near the system natural frequencies are typical of a mechanical system with dry-friction [48]. In FBs, Coulomb-type damping (dry friction) arises due to the relative motions between the bumps and the top foil, and between the bumps and the bearing cartridge ID, see Ref. [39].

\footnotetext{
${ }^{29}$ The actual mass imbalance distribution is unknown.
} 


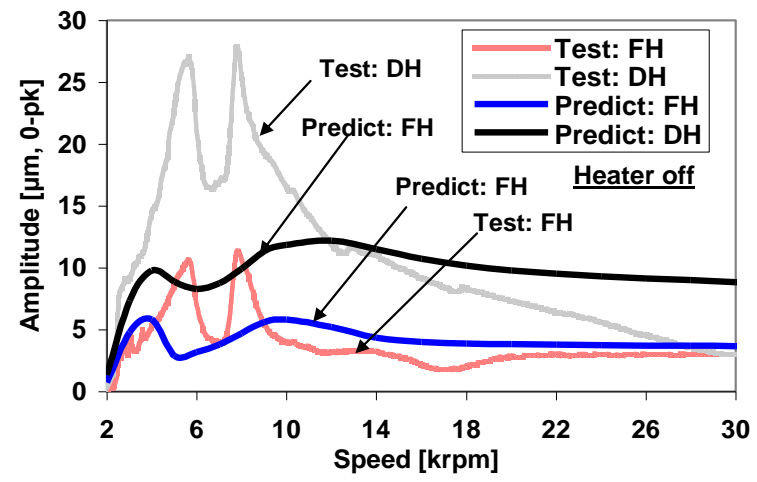

(a) Test case \#7

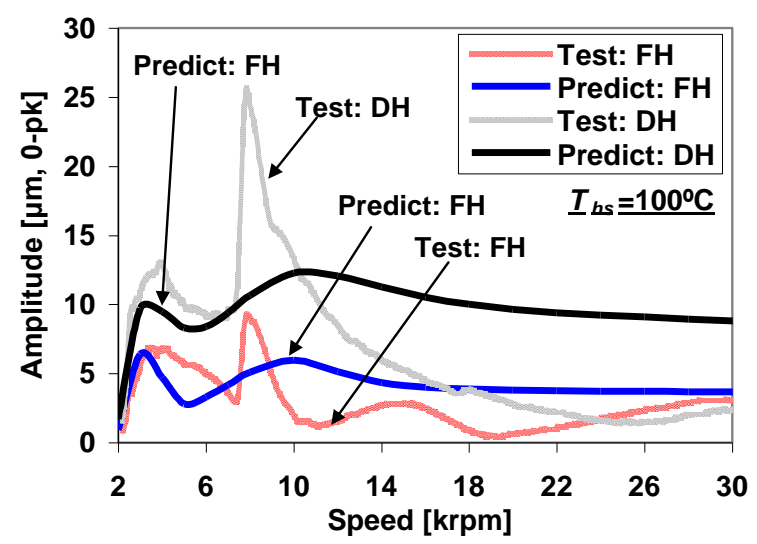

(c) Test case \#9

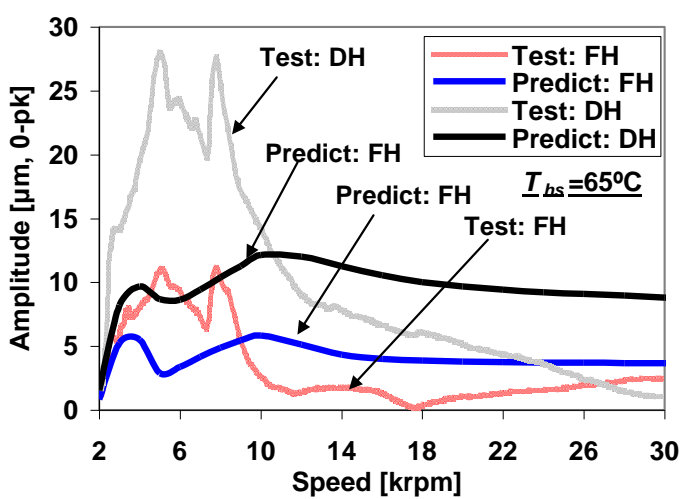

(b) Test case \#8

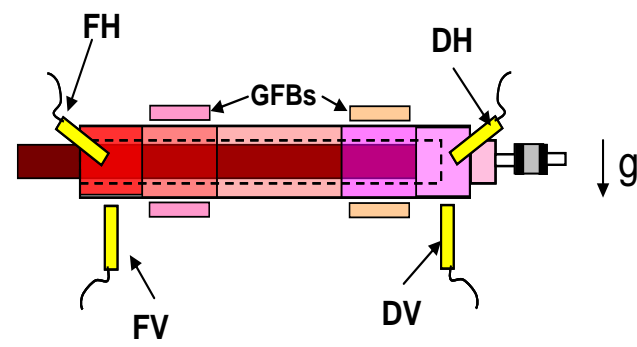

\begin{tabular}{|c|r|r|}
\hline $\begin{array}{c}\text { Imbalance } \\
\text { Station }\end{array}$ & $\begin{array}{c}\text { Imbalance } \\
\text { Amount }\end{array}$ & $\begin{array}{c}\text { Imbalance } \\
\text { Phase }\end{array}$ \\
\hline$\#$ & gm$^{*} \mathrm{~cm}$ & deg \\
\hline 5 & 0.01 & 0 \\
\hline 16 & 0.3 & 180 \\
\hline
\end{tabular}

Fig. 48 Comparison of predicted and measured imbalance responses of test rotor supported on foil bearings. Estimated mass imbalance distribution noted. 


\section{CHAPTER VIII}

\section{CONCLUSIONS AND RECOMMENDATIONS}

Successful implementation of gas foil bearings (GFBs) into high temperature rotating machinery rely on comprehensive and reliable performance measurements and accurate prediction models. An engineered thermal management in a hot rotor-GFB system is fundamental to avoid failure of a GFB thus increasing system reliability.

This dissertation presents measurements of temperatures in a laboratory rotor supported on gas foil bearings. The system operates at an elevated temperature (max. rotor OD temperature $\left.120^{\circ} \mathrm{C}\right)$. An Inconel 718 hollow rotor $(1.360 \mathrm{~kg}, 36.51 \mathrm{~mm}$ OD and $17.9 \mathrm{~mm}$ ID) is supported on two 1st generation GFBs. The rotor surface has a patented high temperature coating on its surface; the mating top foils have no surface coating. An electric cartridge heater inserted in the hollow rotor with a $1 \mathrm{~mm}$ radial gap warms the rotor unevenly. Thermocouples and non-contact infrared thermometers record the temperature of the bearing cartridges mid-plane and rotor surfaces, respectively. A forced air cooling stream (max. $420 \mathrm{~L} / \mathrm{min}$ ) is supplied axially on one side of the test bearings. The research focuses on evaluating the effectiveness of the cooling stream to reduce (control) the temperatures in the bearings and rotor.

When the rotor is stationary, the rotor and bearing temperatures steadily increase with cooling flow rate. At $T_{h s}=100^{\circ} \mathrm{C}$, for example, the free end rotor OD and FE bearing temperatures increase by $\sim 20 \%\left(50^{\circ} \mathrm{C} \rightarrow 60^{\circ} \mathrm{C}\right)$ and $\sim 200 \%\left(7^{\circ} \mathrm{C} \rightarrow 14^{\circ} \mathrm{C}\right)$, respectively, while decreasing cooling flow rate from $400 \mathrm{~L} / \mathrm{min}$ to $0 \mathrm{~L} / \mathrm{min}$. When the shaft rotates, 
temperature rises on the rotor and bearings are a strong function of shaft speed and the cooling flow rate into the bearings. The recorded temperatures on the bearings and rotor increase with rotor speed due to mechanical energy dissipation from viscous drag. The free end bearing temperature increases more than $200 \%\left(7^{\circ} \mathrm{C} \rightarrow 16^{\circ} \mathrm{C}\right)$ when the rotor speed increases from 0 to $30 \mathrm{krpm}$ at $400 \mathrm{~L} / \mathrm{min}$ of cooling flow rate and at $T_{h s}=100^{\circ} \mathrm{C}$.

The forced gas cooling stream plays a significant factor on the thermal management of the rotor-GFB system. As the cooling flow rate decreases, the gas flowing through a feed enclosure has a longer residence time, thus increasing its temperature. For example, as the cooling flow rate decreases from $400 \mathrm{~L} / \mathrm{min}$ to 50 $\mathrm{L} / \mathrm{min}$ at $T_{h s}=100^{\circ} \mathrm{C}$ and $30 \mathrm{krpm},\left(T_{e}-T_{a m b}\right)$ increases from $9^{\circ} \mathrm{C}$ to $18^{\circ} \mathrm{C}$. The bearings sleeve temperature increases with the air temperature inside the feed enclosure. The rate of decrement in the recorded bearing temperature, calculated as the temperature rise per unit cooling flow rate, increases significantly as the strength of the cooling flow rate decreases. The temperature rises per unit cooling flow rate for the FE bearing and FE rotor temperatures increase by $\sim 660 \%\left(\sim 0.05^{\circ} \mathrm{C} / \mathrm{L} / \mathrm{min} \rightarrow \sim 0.35^{\circ} \mathrm{C} / \mathrm{L} / \mathrm{min}\right)$ and $\sim 300 \%$ $\left(\sim 0.2^{\circ} \mathrm{C} / \mathrm{L} / \mathrm{min} \rightarrow \sim 0.8^{\circ} \mathrm{C} / \mathrm{L} / \mathrm{min}\right)$, respectively, when the cooling flow rate decreases from $\sim 400 \mathrm{~L} / \mathrm{min}$ to $\sim 50 \mathrm{~L} / \mathrm{min}$ at $T_{h s}=100^{\circ} \mathrm{C}$. Thus adequate thermal management using a cooling flow carries away heat from the foil bearings and controls the bearing temperatures. When the cooling air flow rates increases, the flow speed increases and there is not enough residence time for the passing air to remove heat more effectively.

Rotor speed-down tests for various rotor OD temperatures and strengths of cooling flow rate show an insignificant effect on the rotordynamic response of the test 
system. Waterfall of rotor vibration show that there is no marked differences in the amplitude and frequency content of the rotor dynamic response while the rotor temperature and cooling flow increase.

Model predictions are benchmarked against the test data. The predicted bearing temperatures are in remarkable agreement with those measured. A rotor FE structural model and GFBs force coefficients from the TEHD model are used to predict the test system critical speeds and damping ratios for operation at increasing shaft temperatures. The predicted rotor responses agree reasonably with the measurements.

A thermal model for shaft temperature prediction along its axial length is necessary for more accurate estimation of the bearing performance characteristics. This is because the shaft surface temperature determines the film temperature and the gas viscosity and density, and the operating clearances which change due to thermal expansion of the components.

The quantitative assessment for the thermal management in a rotor-GFB system requires considerable empirical experience. Thermal runaway can easily occur when very low cooling flows are supplied. Cooling flow into GFBs diminishes the severity of thermal gradients and prevents hot-spots in the bearings, thereby extending their life, for example. The present work continues to extend the GFB knowledge database and provides guidance on system component integration for foil bearing application at high temperature. Most importantly, the present work provides to date the most complete measurements (rotordynamic response and temperature) on a rotor-gas foil bearing system operating hot. 


\section{REFERENCES}

[1] Bruckner, R. J., 2004, “A Propulsion System Analysis of Oil Free Turbomachinery for Aviation Turbofan Engines,” AIAA Paper No. 2004-4189.

[2] DellaCorte, C., and Valco, M. J., 2003, “Oil-Free Turbomachinery Technology for Regional Jet, Rotorcraft and Supersonic Business Jet Propulsion Engines,” AIAA Paper No. ISABE-2003-1182.

[3] DellaCorte, C., Zaldana, A., Radil, K., 2003, "A System Approach to the Solid Lubrication of Foil Air Bearing for Oil-Free Turbomachinery," ASME J. Tribol., 126(1), pp. 200-207.

[4] DellaCorte, C., and Pinkus, O., 2000, “Tribological Limitations in Gas Turbine Engines: A Workshop to Identify the Challenges and Set Future Directions," National Aeronautics and Space Administration, Report No. NASA/TM 2000-210059, Cleveland, $\mathrm{OH}$.

[5] Heshmat, H., and Walton, J. F., 2000, “Oil-Free Turbocharger Demonstration Paves Way to Gas Turbine Engine Applications,” ASME Paper No. 2000-GT-620.

[6] DellaCorte, C., and Edmonds, B. J., 2009, "NASA PS400: A New High Temperature Solid Lubricant Coating for High Temperature Wear Applications," National Aeronautics and Space Administration, Report No. NASA/TM-2009-215678, Cleveland, $\mathrm{OH}$. 
[7] DellaCorte, C., and Valco, M., 2000, "Load Capacity Estimation of Foil Air Journal Bearing for Oil-Free Turbomachinery Applications," STLE Tribol. Trans., 43(4), pp. $795-801$.

[8] Ku, C.-P. R., and Heshmat, H., 1993, “Compliant Foil Bearing Structural Stiffness Analysis-Part II: Experimental Investigation,” ASME J. Tribol., 115(3), pp. 364-369.

[9] Rubio, D., and San Andrés, L., 2006, "Bump-Type Foil Bearing Structural Stiffness: Experiments and Predictions," ASME J. Eng. Gas Turbines Power, 128(3), pp. 653-660. [10] Rubio, D., and San Andrés, L., 2007, "Structural Stiffness, Dry Friction Coefficient, and Equivalent Viscous Damping in a Bump-Type Foil Gas Bearing," ASME J. Eng. Gas Turbines Power, 129(2), pp. 494-502.

[11] Valco, M. J., and DellaCorte, C., 2002, "Emerging Oil-Free Turbomachinery Technology for Military Propulsion and Power Applications," Proceedings of the 23rd U.S. Army Science Conference, Orlando, FL, Dec. 2-5.

[12] Dykas, B. D., 2006, "Factors Influencing the Performance of Foil Gas Thrust Bearings for Oil-Free Turbomachinery Applications," Ph.D. Dissertation, Case Western Reserve University, Cleveland, $\mathrm{OH}$.

[13] Dykas, B. D., 2003, "Investigation of Thermal and Rotational Contributions to the Catastrophic Failure Mechanism of a Thin-Walled Journal Operating with Foil Air Bearings," MS Thesis, Case Western Reserve University, Cleveland, OH.

[14] San Andrés, L. Kim, T.H., and Ryu, K., 2009, “Thermohydrodynamic Analysis of Bump Type Gas Foil Bearings: A Model Anchored to Test Data," Final Project Report to NASA SSRW2-1.3 Oil Free Engine Technology Program. 
[15] Blok, H. and van Rossum, J. J., 1953, “The Foil Bearing - A New Departure in Hydrodynamic Lubrication,” ASLE J. Lubr. Eng., 9(6), pp. 316-320.

[16] Heshmat, H, 1994, "Advancements in the Performance of Aerodynamic Foil Journal Bearings High Speed and Load Capability,” ASME J. Tribol., 116(2), pp. 284295.

[17] Klaass, R. M., and DellaCorte, C., 2006, “The Quest for Oil-Free Gas Turbine Engines," SAE Technical Papers, No. 2006-01-3055.

[18] Koepsel, W. F., 1977, “Gas Lubricated Foil Bearing Development for Advanced Turbomachines," Technical report No. AFAPL-TR-76-114, AiResearch Manufacturing Company of Arizona, Phoenix, AR.

[19] Suriano, F. J., 1981, “Gas Foil Bearing Development Program,” Technical Report No. AFWAL-TR-81-2095, Garrett Turbine Engine Company, Phoenix, AR.

[20] Ruscitto, D., McCormick, J., and Gray, S., 1978, "Hydrodynamic Air Lubricated Compliant Surface Bearing for an Automobile Gas Turbine Engine I-Journal Bearing Performance," National Aeronautics and Space Administration, Report No. NASA CR135368.

[21] DellaCorte, C., 1998, “A New Foil Air Bearing Test Rig for Use to $700^{\circ} \mathrm{C}$ and 70,000 rpm," STLE Tribol. Trans., 41(3), pp. 335-340.

[22] Radil, K.C., and DellaCorte, C., 2010, "A Three-Dimensional Foil Bearing Performance Map Applied to Oil-Free Turbomachinery," STLE Tribol. Trans., 53(5), pp. $771-778$. 
[23] Radil, K.C., DellaCorte, C., and Zeszotek, M. 2007, "Thermal Management Techniques for Oil-Free Turbomachinery Systems," STLE Tribol. Trans., 50(3), pp. $319-327$.

[24] Lee, D., Kim, D., and Sadashiva, R. P., 2011, "Transient Thermal Behavior of Preloaded Three-Pad Foil Bearings: Modeling and Experiments," ASME J. Tribol., 133(2), p. 021703

[25] Lee, D., and Kim, D., 2010, “Thermohydrodynamic Analyses of Bump Air Foil Bearings with Detailed Thermal Model of Foil Structure and Rotor," ASME J. Tribol., 132(2), p. 021704.

[26] Kirschmann, A. E., and Agrawal . G. L., 1998, "High Temperature Foil Air Bearing Development for a Missile/UAV Engine Application," Proceedings of the 35th JANNAF Propulsion Meeting, 1, pp. 101-108, Tucson, AZ, Dec. 7-11.

[27] Walton, J. F., Heshmat, H., and Tomaszewki, M. J., 2004, “Testing of a Small Turbocharger/Turbojet Sized Simulator Rotor Supported on Foil Bearings," ASME Paper No. GT2004-53647.

[28] Heshmat, H., Walton J. F., and Tomaszewski, M. J., 2005, "Demonstration of a Turbojet Engine Using an Air Foil Bearing," ASME Paper No. GT2005-6804.

[29] Larue, G. D., Kang, S. G., and Wick, W., 2006, “Turbocharger with Hydrodynamic Foil Bearings,” U.S. Patent No. 7,108,488 B2.

[30] Lubell, D., and Weissert, D., 2006, "Rotor and Bearing System for a Turbomachine," U.S. Patent No. 7,112,036 B2. 
[31] Lubell, D., DellaCorte, C., and Stanford, M.K., 2006, "Test Evolution and Oil-Free Engine Experience of a High Temperature Foil Air Bearing Coating," ASME Paper No. GT2006-90572.

[32] Lee, Y. B., Kim, C. H., Park, D. J., and Jo, J. H., 2008, "Medium Temperature Coating Material for High Speed Turbomachinery and Method of Coating Same," US Patent Application Publication No. US 2008/0057223 A1.

[33] DellaCorte, C., and Edmonds, B. J., 1999, "Self-Lubricating Composite Containing Chromium Oxide," U.S. Patent No. 5,866,518.

[34] Radil, K. C., and DellCorte, C., 2002, "The Effect of Journal Roughness and Foil Coatings on the Performance of Heavily Loaded Foil Air Bearings," STLE Tribol. Trans., 45(2), pp. 199-204.

[35] OMEGA Engineering, 2010, "User's Guide: OS550A/OS550AM/OS550A," Industrial Infrared Thermometer/Transmitter, Stamford, CT, http://www.omega.com/pptst/OS550A.html (accessed Oct. 2011).

[36] Y. B. Lee; T. H. Kim; C. H. Kim; N. S. Lee, 2003, "Suppression of Subsynchronous Vibrations due to Aerodynamic Response to Surge in a Two-Stage Centrifugal Compressor with Air Foil Bearings," STLE Tribol. Trans., 46(3), pp. $428-434$.

[37] San Andrés, L. Kim, T.H., and Ryu, K., 2009, "Thermohydrodynamic Analysis of Bump Type Gas Foil Bearings: A Model Anchored to Test Data, Appendix M. Structural Load Capacity of KIST Foil Bearings," $7^{\text {th }}$ Quarter Research Progress Report to NASA SSRW2-1.3 Oil Free Engine Technology Program, May 31. 
[38] San Andrés, L., and Kim, T.H., 2008, "Forced Nonlinear Response of Gas Foil Bearing Supported Rotors,” Tribol. Int., 41(8), pp. 704-715.

[39] San Andrés, L., Ryu, K., and Kim, T.H., 2011, "Identification of Structural Stiffness and Energy Dissipation Parameters in a Second Generation Foil Bearing Effect of Shaft Temperature,” ASME J. Eng. Gas Turbines Power, 133(3), p. 032501.

[40] Mott, R. L., 1999, Machine Elements in Mechanical Design, Third Edition, Prentice-Hall, Inc., Upper Saddle River, NJ, pp. 529-532.

[41] Heshmat, H., Tomaszewski, M., and Walton, J.F., 2006 "Small Gas Turbine Engine Operating with High Temperature Foil Bearings,” ASME Paper No. GT2006-90791.

[42] Swain, R., and Preater, R., 1997, "Investigation of Windage Heating Effects on Rotating Components Using Pulsed ESPI,” Opt. Laser. Eng., 26, pp. 377-394.

[43] Millward, J. A. and Edwards, M. F., 1996, "Windage Heating of Air Passing Through Labyrinth Seals,” ASME J. Turbomach., 118(2), pp. 414-419.

[44] Bruckner, R. J., 2009, "Windage Power Loss in Gas Foil Bearings and the RotorStator Clearance of High Speed Generators Operating in High Pressure Environments," ASME Paper No. GT2009-60118.

[45] San Andrés, L., and Kim, T.H., 2010, “Thermohydrodynamic Analysis of Bump Type Gas Foil Bearings: A Model Anchored to Test Data,” ASME J. Eng. Gas Turbines Power, 132(4), p. 042504.

[46] Kim, T.H. and San Andrés, L., 2010, “Thermohydrodynamic Model Predictions and Performance Measurements of Bump-Type Foil Bearing for Oil-Free Turboshaft Engines in Rotorcraft Propulsion Systems,” ASME J. Tribol., 132(1), p. 011701. 
[47] San Andrés, L., and Kim, T.H., 2008, "Numerical Solution of Transport Equations for Gas Film Pressure and Temperature in a Foil Bearing," 2nd Quarter Research Progress Report to NASA SSRW2-1.3 Oil Free Engine Technology Program, Mar. 31.

[48] Ginsberg, J. H., 2001, Mechanical and Structural Vibrations, Theory and Applications, 1st edition, John Wiley \& Sons, Inc., New York, pp. 135-139.

[49] Special Metals Corporation, 2007, “Inconel® Alloy 718,” Publication No. SMC045, Huntington, WV, http://www.specialmetals.com/products/inconelalloy718.php, (accessed Oct. 2011).

[50] Special Metals Corporation, 2004, “Inconel® Alloy X-750,” Publication No. SMC067, Huntington, WV, http://www.specialmetals.com/products/inconelalloyx750.php, (accessed Oct. 2011).

[51] Kipp, D. O., 2010, “AISI 4140 Steel, Oil Quenched, $315^{\circ} \mathrm{C}\left(600^{\circ} \mathrm{F}\right)$ Temper, $25 \mathrm{~mm}$ (1 in.) Round," Metal Material Data Sheets, MatWeb-Division of Automation Creation, Inc., Blacksburg, VA, http://www.matweb.com (accessed on Oct. 2011) [52] ASM International, 1988, “AISI 4140, Oil-Hardening Cr-Mo Steel,” Alloy Digest Data on World Wide Metals and Alloys, Filing Code SA-18, Materials Park, OH, http://products.asminternational.org/datasheets/index.jsp (accessed Oct. 2011).

[53] Fox, R. W., McDonald, A. T., and Pritchard, P. J., 2004, Introduction to Fluid Mechanics, Sixth Edition, John Wiley \& Sons, Inc., Hoboken, NJ, pp. 720-722.

[54] Hirs, G.G., 1973, “A Bulk-Flow Theory for Turbulence in Lubricant Films,” ASME J. Lub. Tech., 95(2), pp. 137-146. 
[55] Zirkelback, N., and San Andrés, L., 1996, "Bulk-Flow Model for the Transition to Turbulent Regime in Annular Pressure Seals," STLE Tribol. Trans., 39(4), pp. 835-842. [56] Yamada, Y., 1962, "Resistance of Flow through an Annulus with an Inner Rotating Cylinder,” Bull. JSME, 5(18), pp. 302-310.

[57] Childs, D. W., and Kim, C-H., 1985, "Analysis and Testing for Rotordynamic Coefficients of Turbulent Annular Seals with Different, Directionally-Homogeneous Surface-Roughness Treatment for Rotor and Stator Elements," ASME J. Tribol., 107(3), pp. 296-305.

[58] Ha, T. W., Childs, D. W., 1992, "Friction-Factor Data for Flat-Plat Tests of Smooth and Honeycomb Surfaces,” ASME J. Tribol., 114(4), pp. 722-730.

[59] Nelson, C. C. and Nguyen, D. T., 1987, "Comparison of Hirs' Equation With Moody's Equation for Determining Rotordynamic Coefficients of Annular Pressure Seals," ASME J. Tribol., 109(1), pp. 144-148.

[60] Black, H. F., Allaire, P. E., and Barrett, L. E., 1981, "Inlet Flow Swirl in Short Turbulent Annular Seal Dynamics," Proceedings of the Ninth International Conference in Fluid Sealing, BHRA Fluid Engineering, Leeuwenborst, The Netherlands, Apr. 1-3, pp. 141-152. 


\section{APPENDIX A}

MATERIAL PROPERTIES OF INCONEL 718, INCONEL X-750, AND AISI 4140

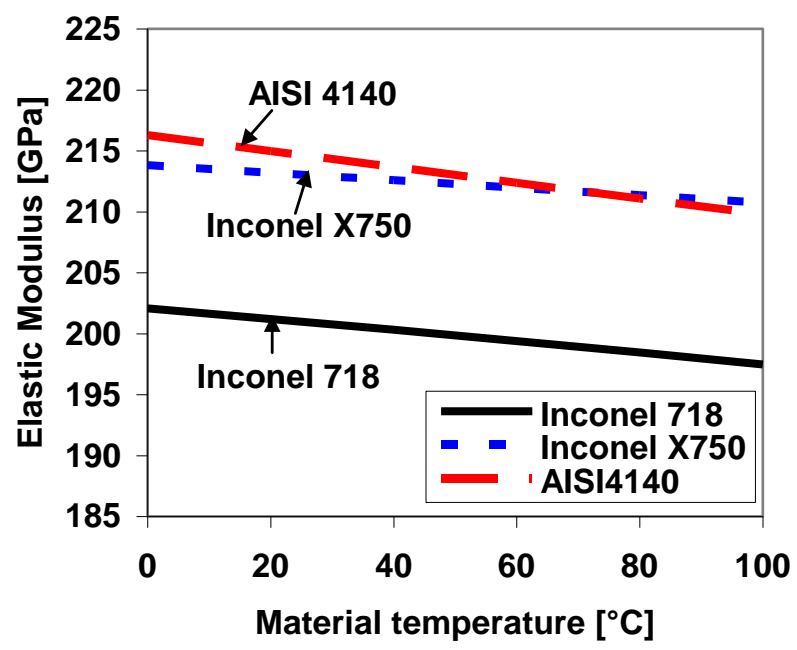

Fig. A.1 Elastic modulus versus material temperature for Inconel 718 , Inconel X750, and AISI4140. Taken from [49-52].

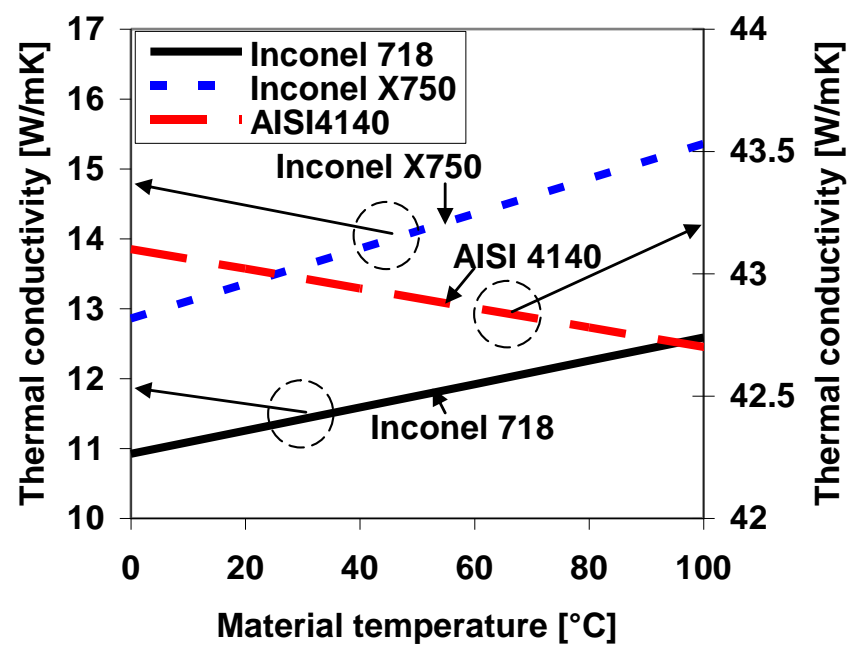

Fig. A.2 Thermal conductivity versus material temperature for Inconel 718, Inconel X750, and AISI4140. Taken from [49-52]. 


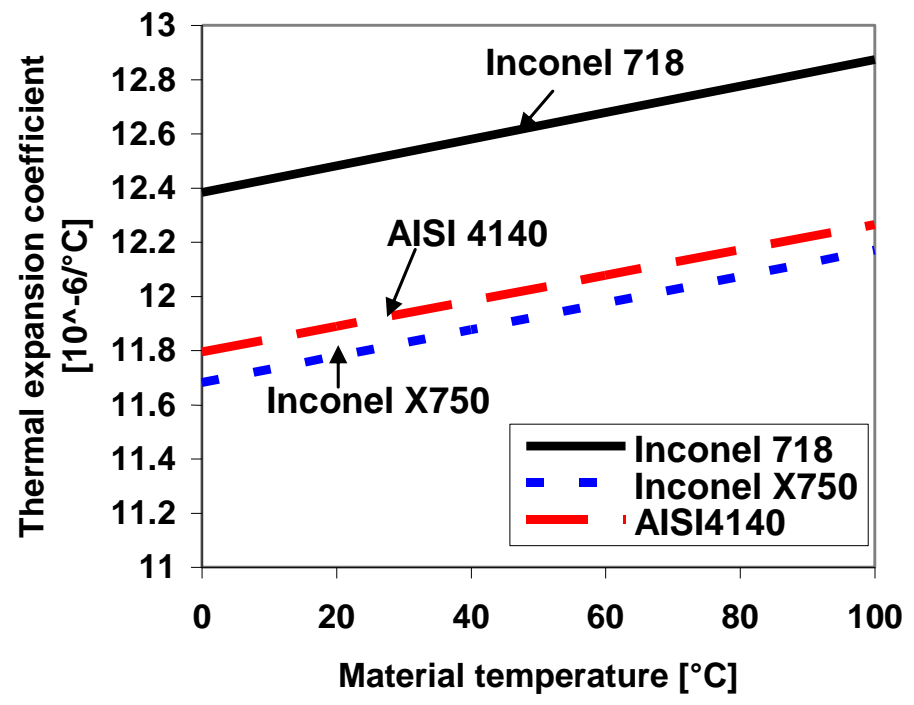

Fig. A.3 Thermal expansion coefficient versus material temperature for Inconel 718, Inconel X750, and AISI4140. Taken from [49-52].

Table A.1 Poisson's ratio, density, specific heat, and melting temperature of Inconel 718, Inconel X750, and AISI4140. Taken from [49-52]

\begin{tabular}{|c|c|c|c|}
\hline \hline & Inconel 718 & Inconel X750 & AISI 4140 \\
\hline Poisson's ratio [-] & 0.284 & 0.29 & 0.3 \\
\hline Density $\left[\mathrm{kg} / \mathrm{m}^{3}\right]$ & 8220 & 8303 & 7833 \\
\hline Specific heat $[\mathrm{J} / \mathrm{kg}-\mathrm{K}]$ & 473 & 440 & 473 \\
\hline Melting temperature $\left[{ }^{\circ} \mathrm{C}\right]$ & 1210 & 1393 & 1400 \\
\hline \hline
\end{tabular}




\section{APPENDIX B}

\section{SPECIFICATIONS OF EQUIPMENT AND INSTRUMENTATION}

\section{Table B. 1 Specifications of major equipment and instrumentation for high temperature rotor-GFB test rig ${ }^{30}$}

\begin{tabular}{|c|c|c|c|c|}
\hline Item & $\begin{array}{l}\text { Location in } \\
\text { test rig }\end{array}$ & Specification & Vendor & Model \# \\
\hline High speed motor & & $9.5 \mathrm{~kW}$ at $65 \mathrm{krpm}$ & KAES & MOO1C80905 \\
\hline Spindle drive & $\begin{array}{l}\text { Motor } \\
\text { controller }\end{array}$ & $\begin{array}{l}\text { Power source for motor, input } \\
380-480 \mathrm{~V}, 3 \text { phase, } 50 / 60 \mathrm{~Hz}\end{array}$ & GMN & $\begin{array}{c}\text { 90-00124-8048- } \\
0000\end{array}$ \\
\hline $\begin{array}{l}\text { Flexible } \\
\text { Coupling }\end{array}$ & & $\begin{array}{l}\text { Rated torque } 1.0 \mathrm{~N}-\mathrm{m} \text {, } \\
\text { torsional stiffness } 320 \mathrm{~N}-\mathrm{m} / \mathrm{rad}\end{array}$ & $\begin{array}{c}\mathrm{R}+\mathrm{W} \\
\text { coupling } \\
\text { technology }\end{array}$ & MK2/10/33 \\
\hline $\begin{array}{l}\text { Water jet well } \\
\text { pump }\end{array}$ & $\begin{array}{l}\text { Water pump } \\
\text { for motor } \\
\text { cooling }\end{array}$ & 3/4 HP, $78 \mathrm{psi}, 57 \mathrm{~L} / \mathrm{min}$ & Flotec & FP4022 \\
\hline $\begin{array}{l}\text { Digital gas mass } \\
\text { flow meter }\end{array}$ & $\begin{array}{l}\text { Cooling flow } \\
\text { rate into } \\
\text { bearings }\end{array}$ & $\begin{array}{l}\text { Max. } 500 \mathrm{~L} / \mathrm{min} \text {, accuracy } \\
\pm 1.5 \% \text { of full scale }\end{array}$ & OMEGA & $\begin{array}{l}\text { FMA1844, } \\
\text { FMA178PW }\end{array}$ \\
\hline Cartridge heater & $T_{h}$ & Max. $1.6 \mathrm{~kW}$ with $240 \mathrm{~V}$ & OMEGA & $\begin{array}{c}\text { CSH- } \\
4101600 / 240\end{array}$ \\
\hline Heater controller & $T_{h}$ & $\begin{array}{l}\text { Programmable } 1 / 8 \text { DIN digital } \\
\text { panel meter }\end{array}$ & OMEGA & $\mathrm{CNi} 853$ \\
\hline $\begin{array}{l}\text { Thermocouple } \\
\text { (K type) }\end{array}$ & $\begin{array}{l}T_{1}-T_{10}, T_{e} \\
T_{\text {out }}, T_{\text {amb }}\end{array}$ & $\begin{array}{l}\text { Up to } 480^{\circ} \mathrm{C} \text {, glass braid } \\
\text { insulation }\end{array}$ & OMEGA & $\begin{array}{l}\text { 5SC-GG-K-30- } \\
36\end{array}$ \\
\hline $\begin{array}{l}\text { Insulated } \\
\text { thermocouple } \\
\text { wire }\end{array}$ & $\begin{array}{l}T_{1}-T_{10}, T_{e} \\
T_{o u t}, T_{a m b}\end{array}$ & $\begin{array}{l}\text { 30m type } \mathrm{K} \text { duplex insulated } \\
\text { wire }\end{array}$ & OMEGA & $\begin{array}{c}\text { PR-K-24-SLE- } \\
100\end{array}$ \\
\hline $\begin{array}{l}\text { Thermocouple } \\
\text { indicator }\end{array}$ & $T_{e}, T_{\text {out }}, T_{\text {amb }}$ & Up to $1090^{\circ} \mathrm{C}$, resolution $0.6^{\circ} \mathrm{C}$ & OMEGA & DP116-KF1 \\
\hline $\begin{array}{l}\text { Benchtop } \\
\text { thermometer }\end{array}$ & $T_{1}-T_{10}$ & $\begin{array}{l}\text { 10-channel benchtop } \\
\text { thermometer, } \\
\text { dedicated thermocouple input } \\
\text { with analog }\end{array}$ & OMEGA & MDSSi8A-TC \\
\hline $\begin{array}{l}\text { Infrared } \\
\text { thermometer }\end{array}$ & $\operatorname{Tr}_{F E}, \operatorname{Tr}_{D E}$ & $\begin{array}{l}\text { Up to } 1370^{\circ} \mathrm{C}, \mathrm{D} / \mathrm{S} \text { Ratio } 68: 1 \text {, } \\
\text { 5Vdc output, adjustable } \\
\text { emissivity }\end{array}$ & OMEGA & OS552-V1-1 \\
\hline
\end{tabular}

\footnotetext{
${ }^{30}$ Reference [14] fully lists the components of the test rig, including commercial designations and costs.
} 


\title{
APPENDIX C \\ REPEATABILITY OF RECORDED TEMPERATURES:
}

\author{
TEST CASES \#1 AND \#3
}

Measurements for test cases \#1 and \#3 were repeated thrice (namely, tests 1, 2 and 3$)^{31}$. Figures C.1 and C.2 depict the temperature rise of the free end rotor OD $\left(\operatorname{Tr}_{F E}\right.$ $\left.-T_{a m b}\right)$, free end bearing sleeve OD $\left(T_{1}-T_{a m b}\right)$, drive end rotor OD $\left(\operatorname{Tr}_{D E}-T_{a m b}\right)$, and air in the housing enclosure $\left(T_{e}-T_{a m b}\right)$ versus air cooling flow rate for test cases\#1 and \#3. The average variability is less than $5^{\circ} \mathrm{C}$ for each test condition.
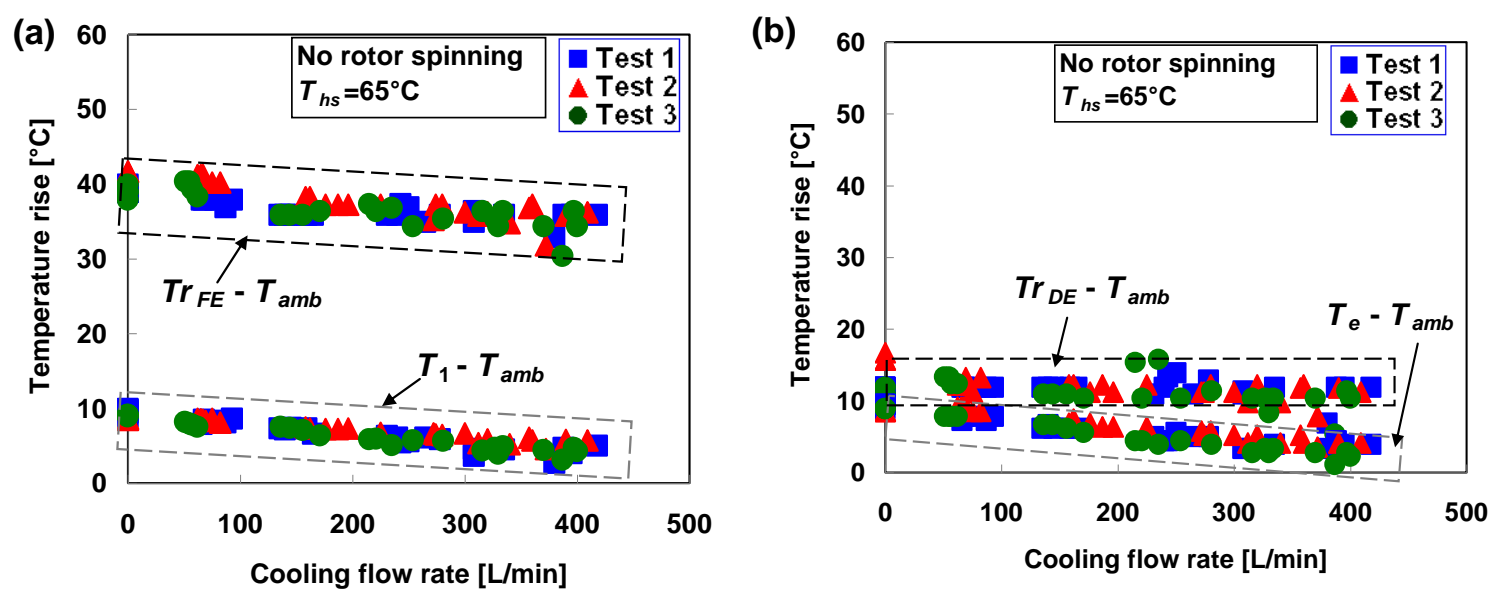

Fig. C. 1 Test case \#1. $T_{h s}=65^{\circ}$. No rotor spinning: Recorded test system component temperature rises $\left(T_{\Gamma} T_{a m b}\right.$; where ${ }_{i=\text { (a) }} r_{F E \text { and 1, (b) }} r_{D E \text { and e) }}$ ) versus cooling flow rate.

\footnotetext{
${ }^{31}$ In Figs. C.1 and C.2, temperatures for test 1 are taken from Figs. E.1 (shown later) and 17, respectively. The sets of tests 2 and 3 were conducted approximately seven months later after test 1 .
} 

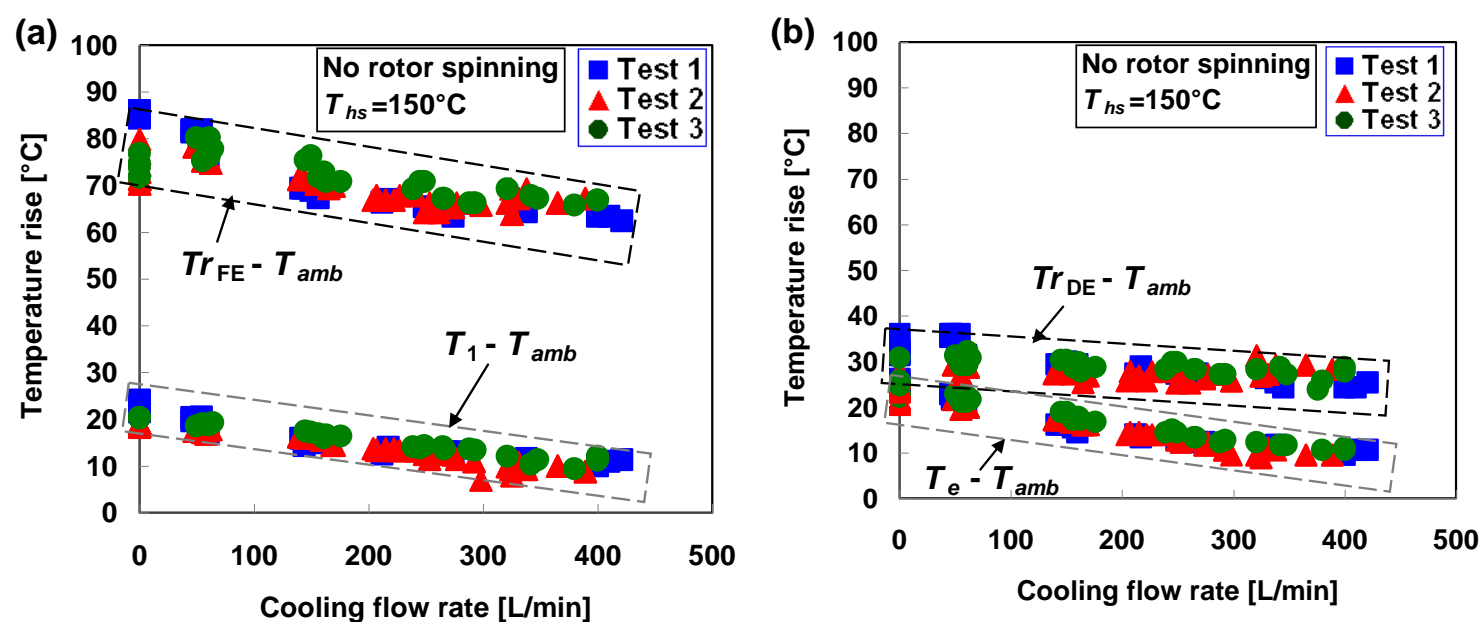

Fig. C. 2 Test case \#3. $T_{h s}=150^{\circ} \mathrm{C}$. No rotor spinning: Recorded test system component temperature rises ( $T_{\Gamma}-T_{a m b}$; where $\left.{ }_{i=\text { (a) }} r_{F E \text { and 1, (b) }} r_{D E \text { and e }}\right)$ versus cooling flow rate. 


\section{APPENDIX D}

\section{ELECTRIC POWER DELIVERED TO CARTRIDGE HEATER:}

\section{TEST CASE \#3}

Figure D.1 depicts the circuit diagram to measure the electric power delivered to the cartridge heater. Two multi-meters are connected in the heater controller circuit to measure voltage and current. The instruments displaying voltage and current digitally have uncertainties of $0.1 \mathrm{~V}$ and $0.001 \mathrm{~A}$, respectively. While the heater set temperature $T_{h s}$ is fixed at $150^{\circ} \mathrm{C}$ with a stationary shaft, measurements are conducted twice, namely tests 1 and 2. The test condition corresponds to test case \#3. Note that the heater temperature is automatically controlled using a mechanical relay in a temperature controller.

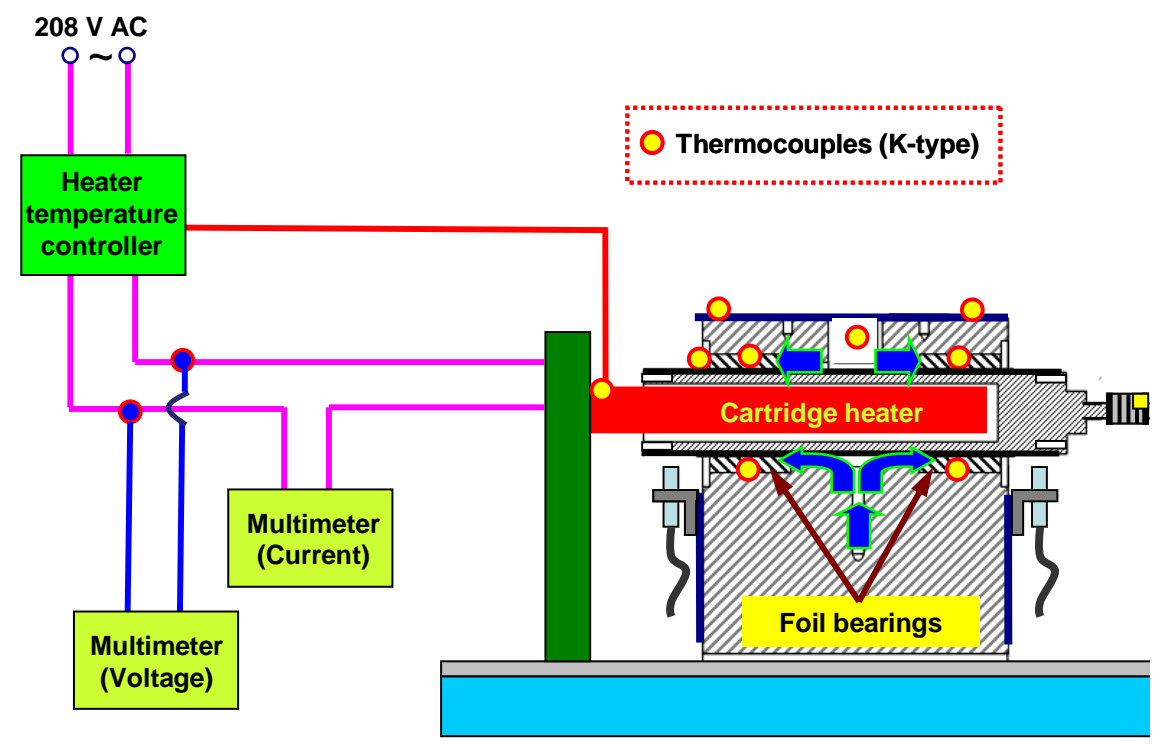

Fig. D.1 Schematic circuit diagram measuring voltage and current feeding the electrical heater. 
Electric power, the rate at which electrical energy is transferred by an electric circuit, is calculated using Joule's law $P(t)=I(t) \cdot V(t)$, where $P(t)$ is the instantaneous power, $V(t)$ is the voltage drop across the heater, and $I(t)$ is the current through it.

Figure D.2 depicts the measured voltage and current of the heater circuit while decreasing the cooling flow rate. The recorded voltage remains nearly invariant for decreasing cooling flow strength $(\sim 205 \mathrm{~V})$. As the cooling flow rate into the bearings decreases from $\sim 400 \mathrm{~L} / \mathrm{min}$ to $\sim 150 \mathrm{~L} / \mathrm{min}$, the current decreases linearly from 5.64 A to 5.56 A to maintain the set heater temperature $T_{h s}=150^{\circ} \mathrm{C}$. On the other hand, the current increases from 5.56 A to $5.64 \mathrm{~A}$ with decreasing cooling flow rate from $\sim 150$ to $0 \mathrm{~L} / \mathrm{min}$. The calculated electric power delivered to the heater follows a similar trend as with the recorded current, see Fig. D. 3.

Note that the heater does not only heats the rotor but also its surroundings; including the bearings and the enclosure. That is, the required power is also a function of the bounding solids and ambient conditions. As the cooling flow rate decreases, the air in the enclosure increases its temperature since it is not removed (quickly) by the cooling air stream. Something similar will happen with the bearing sleeves. Thus, the electric power increases at low flow rates. 


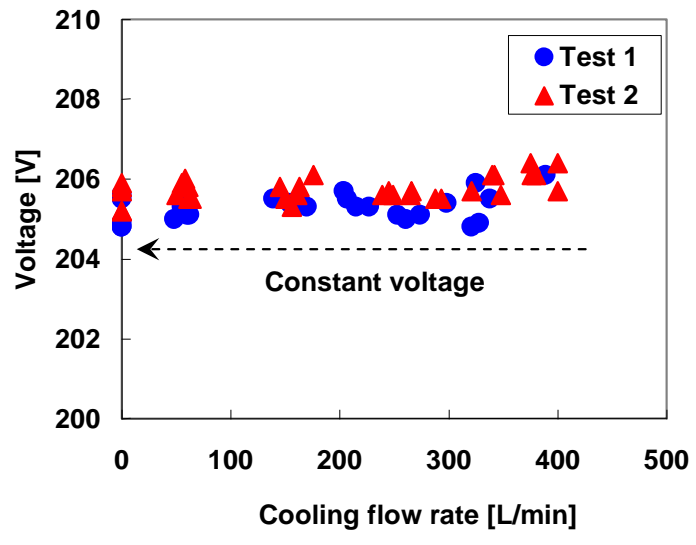

(a) Voltage

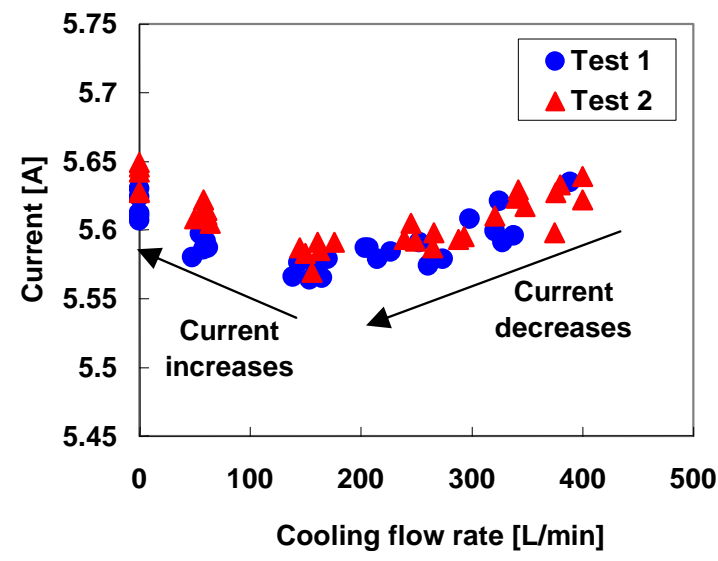

(b) Current

Fig. D.2 Test case \#3. $T_{h s}=150^{\circ} \mathrm{C}$. No rotor spinning: Recorded (a) voltage and (b) current of the heater circuit versus cooling flow rate.

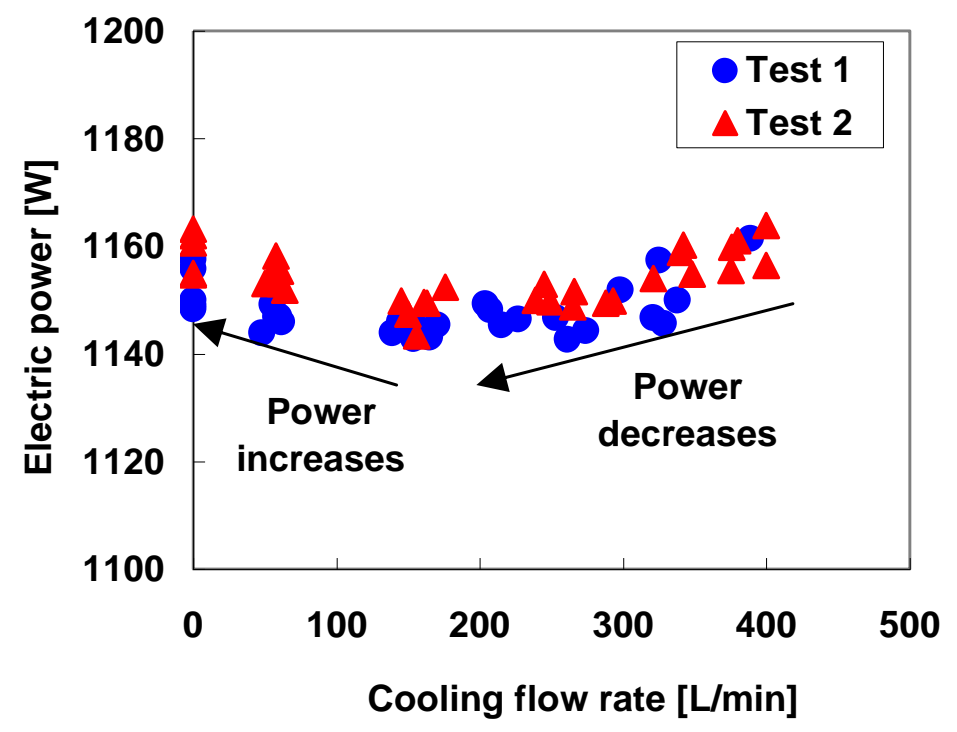

Fig. D.3 Test case \#3. $T_{h s}=150^{\circ} \mathrm{C}$. No rotor spinning: Measured electric power of the cartridge heater versus cooling flow rate. 


\section{APPENDIX E}

TEMPERATURE RISES OF SYSTEM COMPONENTS VERSUS ELAPSED TIME:

TEST CASES \#1, \#2, \#4, AND \#5

Figure E. 1 through E.4 depict the temperature rises $\left(T_{i}-T_{a m b}\right.$ where ${ }_{i}=$

$r_{F E}, r_{D E}, 1-10$, in, e, out $)$ of the test system components versus elapsed time for test cases\#1,\#2,\#4, and \#5. 


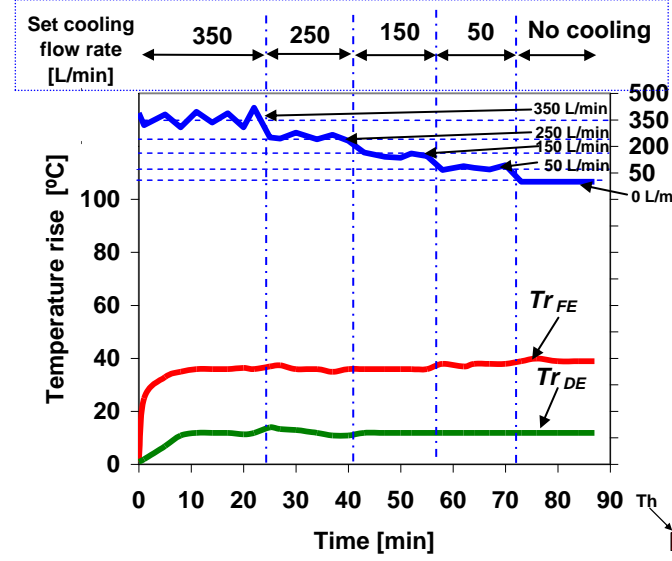

(a) Rotor OD:

Free end $\left(\operatorname{Tr}_{F E}\right)$ and drive end $\left(\operatorname{Tr}_{D E}\right)$

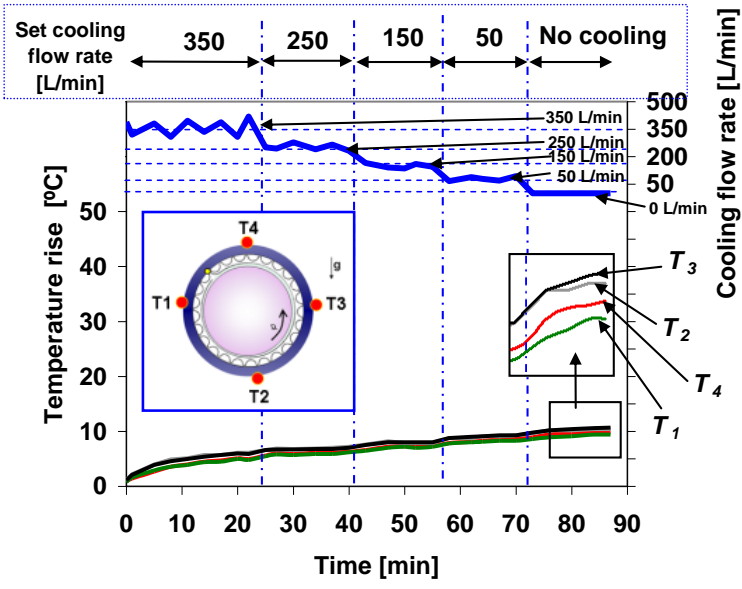

(c) FE bearing sleeve OD $\left(T_{1}-T_{4}\right)$

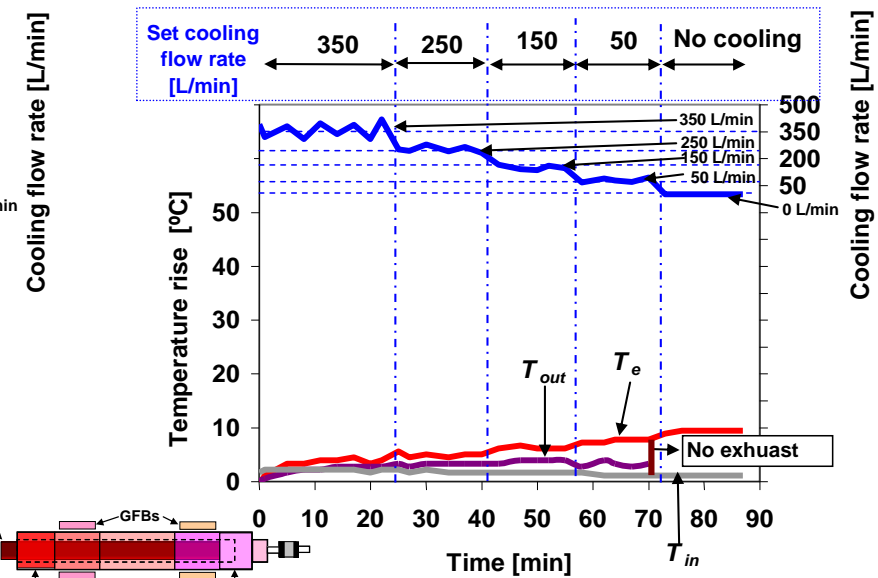

(b) Cooling air:

Upstream $\left(T_{\text {in }}\right)$, enclosure $\left(T_{e}\right)$, and exhaust $\left(T_{\text {out }}\right)$

\section{}



(d) DE bearing sleeve OD $\left(T_{6}-T_{9}\right)$

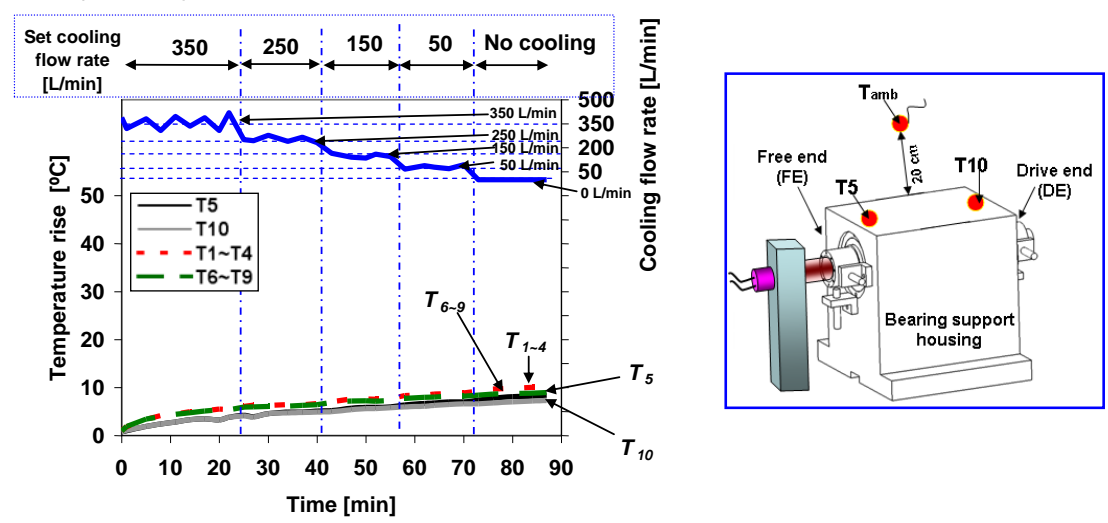

(e) Bearing housing surface ( $T_{5}$ and $\left.T_{10}\right)$ and bearing mean temperature (FE: $\left.T_{1-4}, \mathrm{DE}: T_{6-9}\right)$

Fig. E.1 Test case \#1. Heater set temperature at $65^{\circ} \mathrm{C}$. No rotor spinning: Recorded test

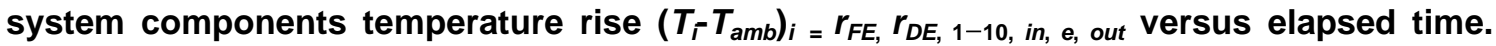

Axial cooling flow into bearings decreases from 420 to $0 \mathrm{~L} / \mathrm{min}$. Note different vertical scales. 


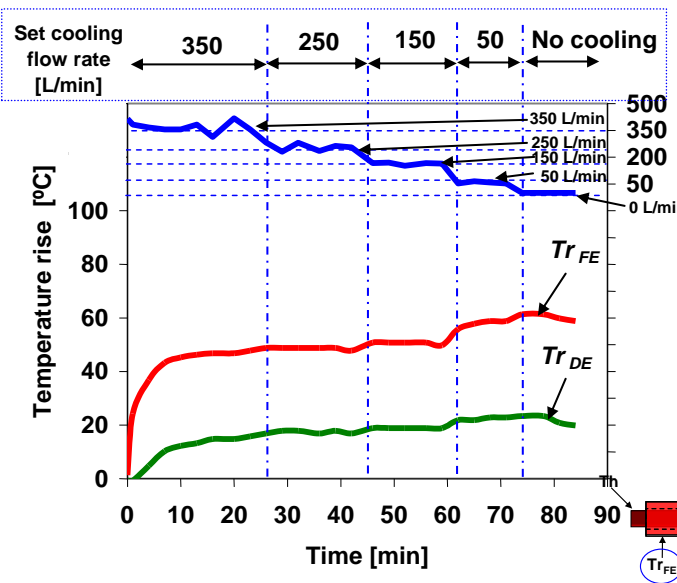

(a) Rotor OD:

Free end $\left(\operatorname{Tr}_{F E}\right)$ and drive end $\left(T r_{D E}\right)$

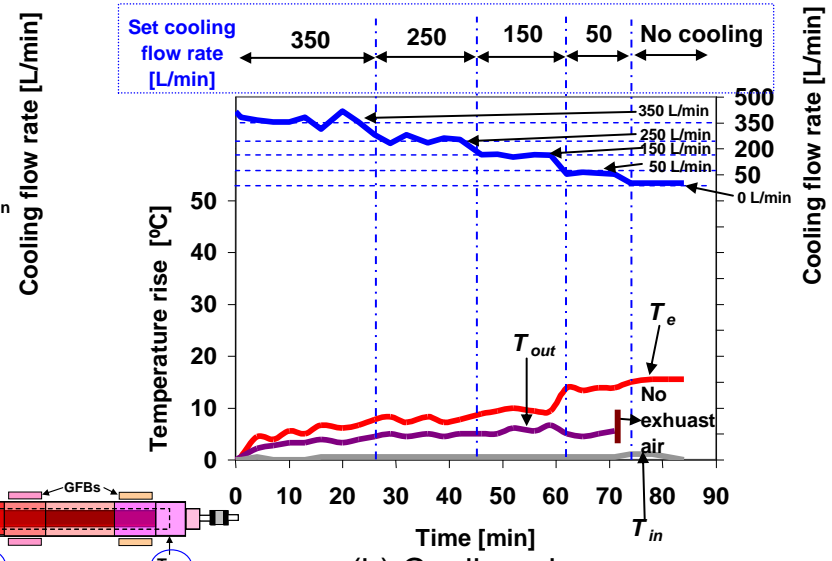

(b) Cooling air:

upstream $\left(T_{\text {in }}\right)$, enclosure $\left(T_{e}\right)$, and exhaust $\left(T_{\text {out }}\right)$

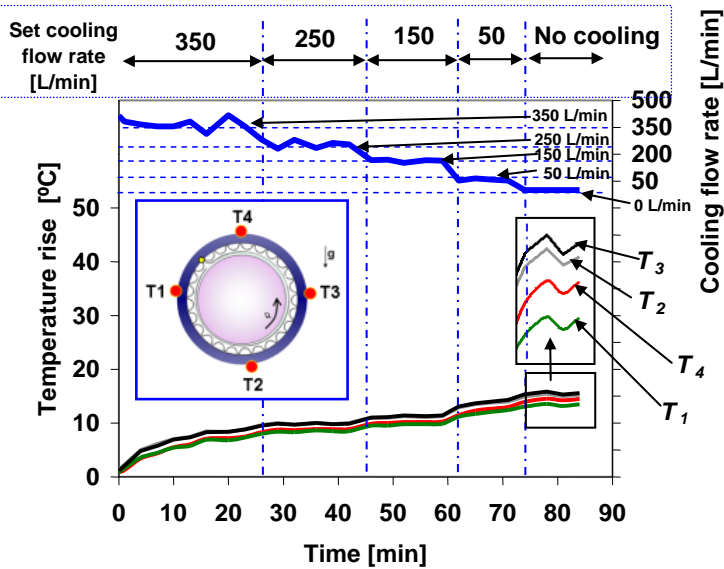

(c) FE bearing sleeve OD $\left(T_{1}-T_{4}\right)$

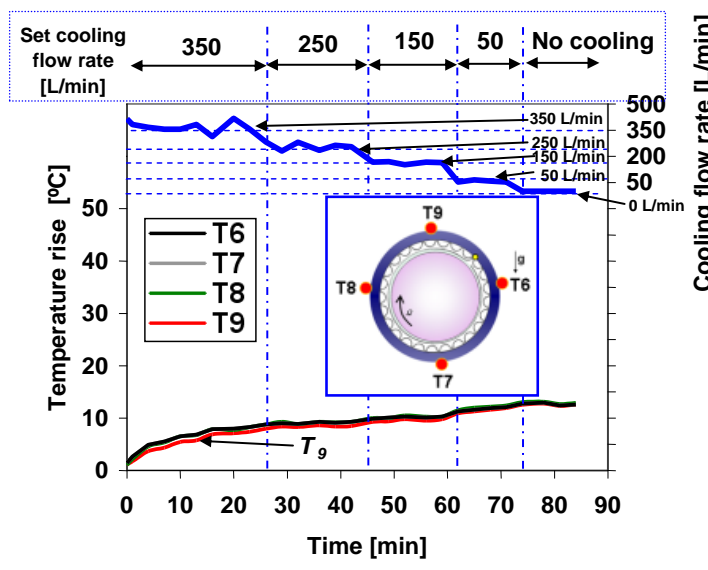

(d) DE bearing sleeve OD $\left(T_{6}-T_{9}\right)$
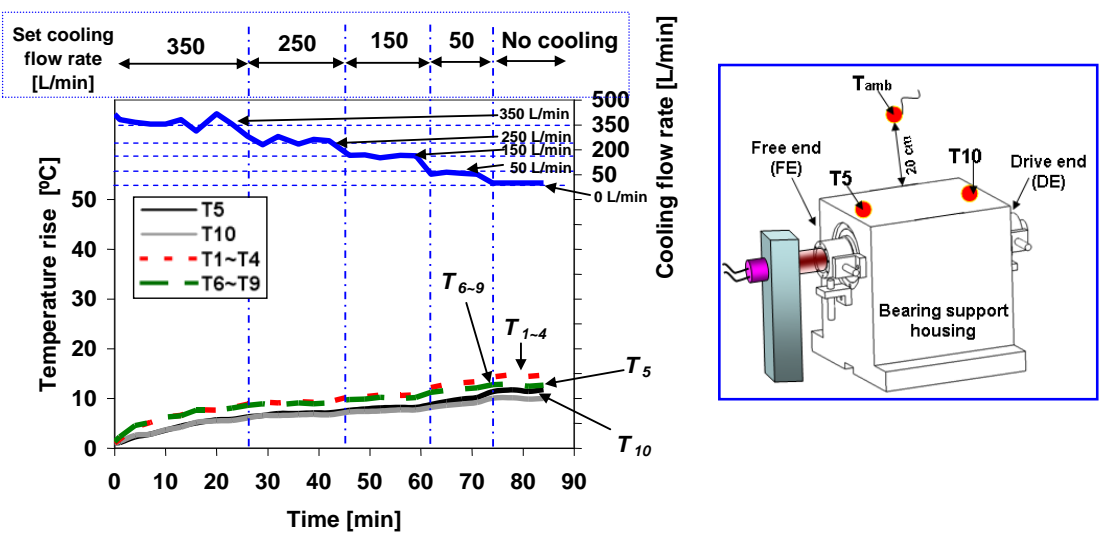

(e) Bearing housing surface $\left(T_{5}\right.$ and $\left.T_{10}\right)$ and bearing mean temperature (FE: $\left.T_{1-4}, \mathrm{DE}: T_{6-9}\right)$

Fig. E.2 Test case \#2. Heater set temperature at $10^{\circ} \mathrm{C}$. No rotor spinning: Recorded test

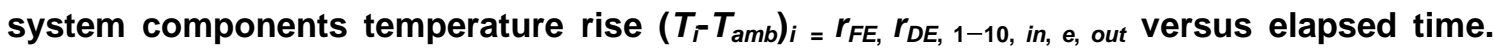
Axial cooling flow into bearings decreases from 420 to $0 \mathrm{~L} / \mathrm{min}$. Note different vertical scales. 


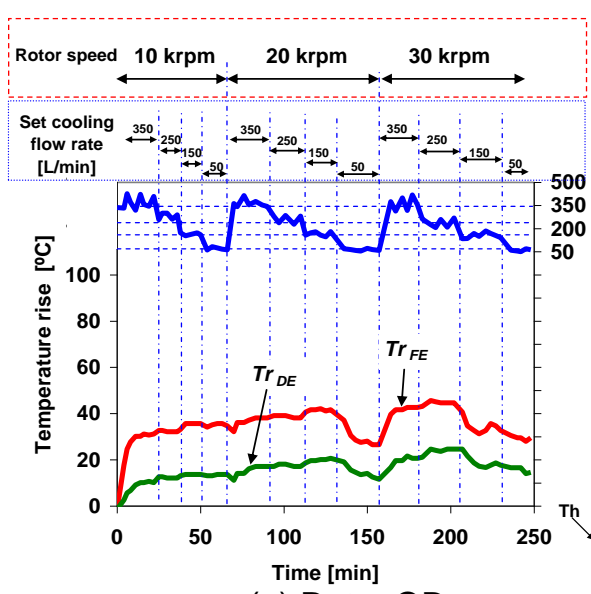

(a) Rotor OD:

Free end $\left(\operatorname{Tr}_{F E}\right)$ and drive end $\left(\operatorname{Tr}_{D E}\right)$

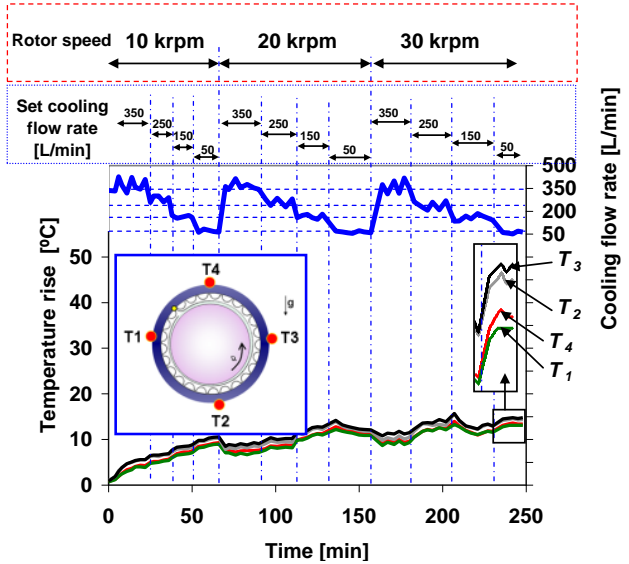

(c) FE bearing sleeve OD $\left(T_{1}-T_{4}\right)$

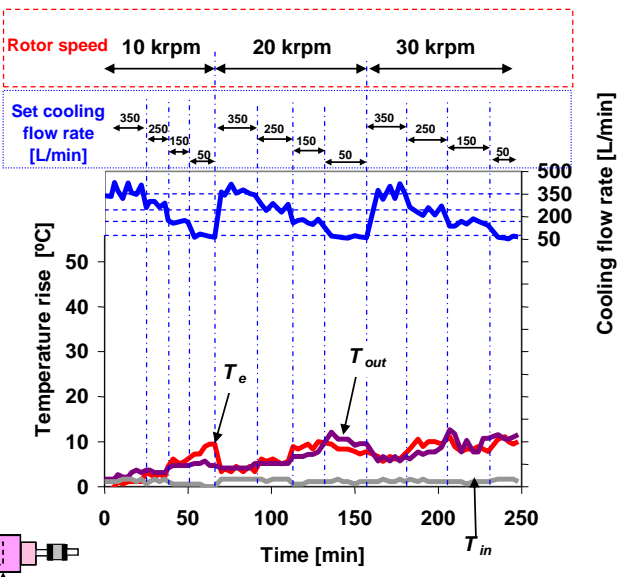

(b) Cooling air:

upstream $\left(T_{\text {in }}\right)$, enclosure $\left(T_{e}\right)$, and exhaust $\left(T_{\text {out }}\right)$
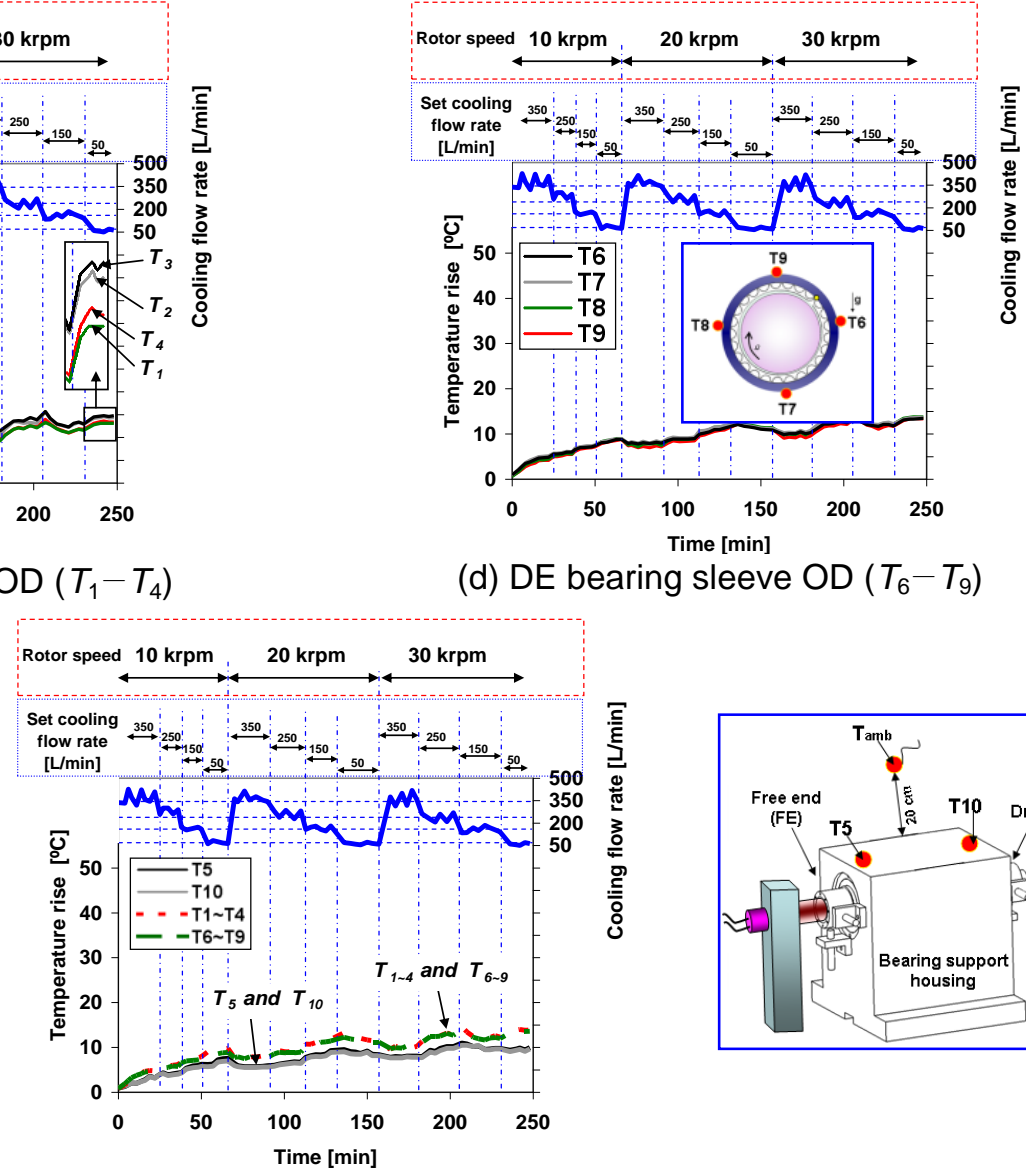

(d) DE bearing sleeve OD $\left(T_{6}-T_{9}\right)$

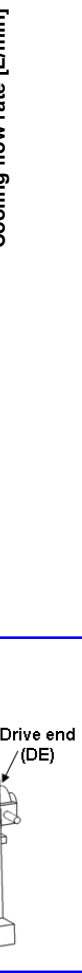

(e) Bearing housing surface $\left(T_{5}\right.$ and $\left.T_{10}\right)$ and bearing mean temperature (FE: $\left.T_{1-4}, \mathrm{DE}: T_{6-9}\right)$ Fig. E.3 Test case \#4, Heater set temperature at $65^{\circ} \mathrm{C}$. Rotor speed of 10, 20, and $30 \mathrm{krpm}$ :

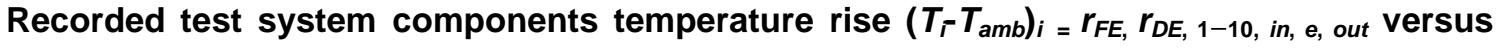
elapsed time. Axial cooling flow into bearings decreases from 420 to $50 \mathrm{~L} / \mathrm{min}$. Note different vertical scales. 


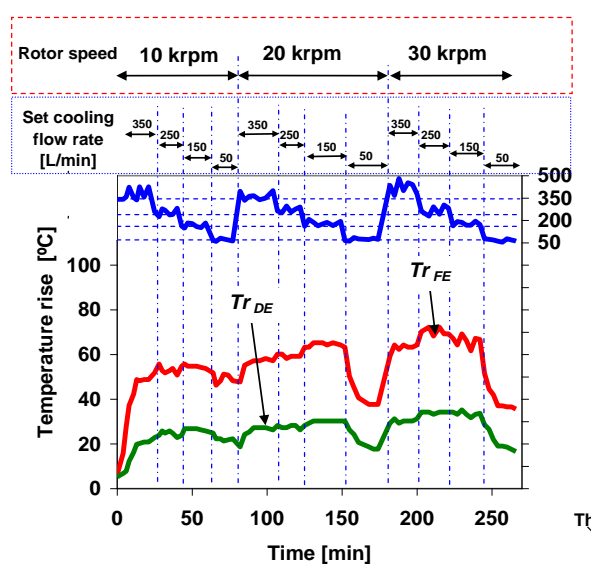

(a) Rotor OD:

Free end $\left(\operatorname{Tr}_{F E}\right)$ and drive end $\left(\operatorname{Tr}_{D E}\right) \mathrm{TrFE}^{\mathrm{Tr}_{\mathrm{F}}}$

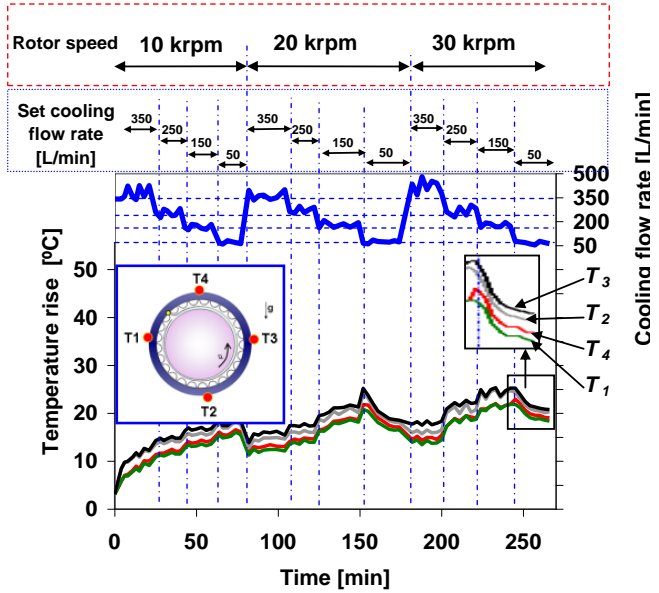

(c) FE bearing sleeve OD $\left(T_{1}-T_{4}\right)$

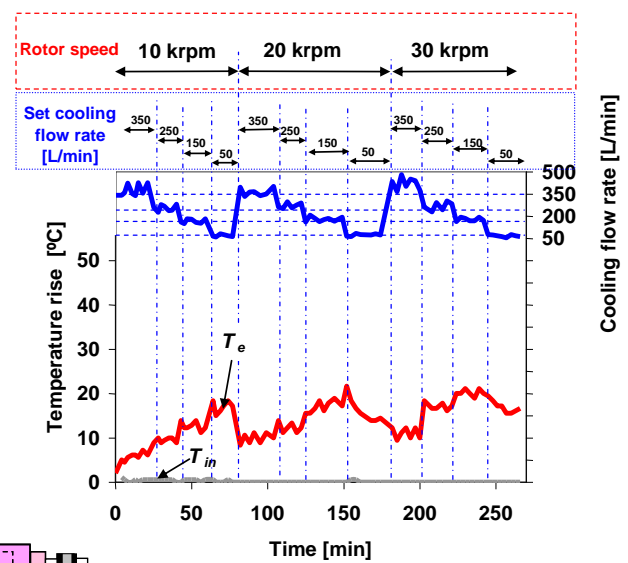

(b) Cooling air:

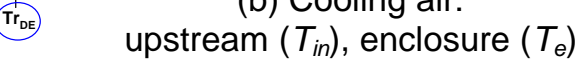

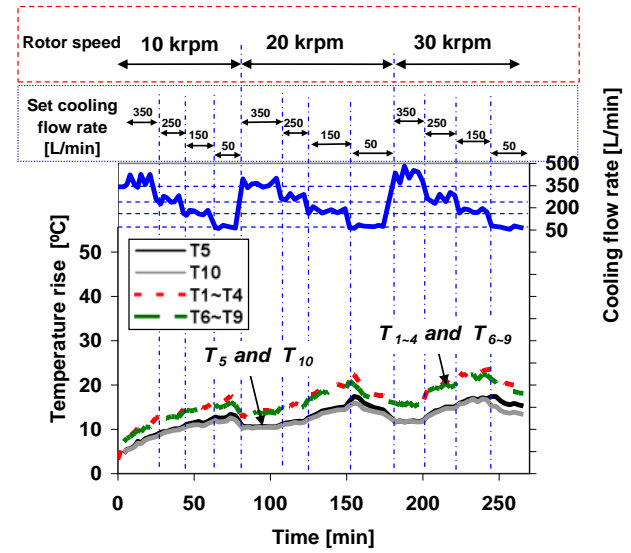

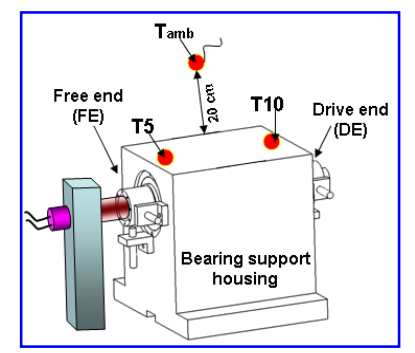

(e) Bearing housing surface ( $T_{5}$ and $\left.T_{10}\right)$ and bearing mean temperature (FE: $\left.T_{1-4}, \mathrm{DE}: T_{6-9}\right)$ Fig. E.4 Test case \#5, Heater set temperature at $100^{\circ} \mathrm{C}$. Rotor speed of 10,20 , and 30 krpm: Recorded test system components temperature rise $\left(T_{\Gamma} T_{a m b}\right)_{i}=r_{F E}, r_{D E, 1-10}$, in, e, out versus elapsed time. Axial cooling flow into bearings decreases from 420 to $50 \mathrm{~L} / \mathrm{min}$. Note different vertical scales. 


\section{APPENDIX F}

COMPLETE EXPERIMENTAL DATA

Table F.1 Complete recorded data of temperature rises for test case \#1

\begin{tabular}{|c|c|c|c|c|c|c|c|c|c|c|c|c|c|c|c|c|}
\hline $\begin{array}{l}\text { Time } \\
\text { [min] }\end{array}$ & $\begin{array}{c}\text { Cooling } \\
\text { flow } \\
\text { rate } \\
\text { [L/min] }\end{array}$ & $\begin{array}{l}\text { Rotor } \\
\text { Speed } \\
{[\mathrm{krpm}]}\end{array}$ & $\begin{array}{c}\operatorname{Tr}_{F E} \\
- \\
T_{a m b}\end{array}$ & $\begin{array}{c}\operatorname{Tr}_{D E} \\
- \\
T_{a m b}\end{array}$ & $\begin{array}{c}T_{1} \\
- \\
T_{a m b}\end{array}$ & $\begin{array}{c}T_{2} \\
- \\
T_{a m b}\end{array}$ & $\begin{array}{c}T_{3} \\
- \\
T_{a m b}\end{array}$ & $\begin{array}{c}T_{4} \\
- \\
T_{a m b}\end{array}$ & $\begin{array}{c}T_{5} \\
- \\
T_{a m b}\end{array}$ & $\begin{array}{c}T_{6} \\
- \\
T_{a m b}\end{array}$ & $\begin{array}{c}T_{7} \\
- \\
T_{a m b}\end{array}$ & $\begin{array}{c}T_{8} \\
- \\
T_{a m b}\end{array}$ & $\begin{array}{c}T_{9} \\
- \\
T_{a m b}\end{array}$ & $\begin{array}{c}T_{10} \\
- \\
T_{a m b}\end{array}$ & $\begin{array}{c}T_{\mathrm{e}} \\
- \\
T_{a m b}\end{array}$ & $\begin{array}{c}T_{\text {out }} \\
- \\
T_{a m b}\end{array}$ \\
\hline 1 & 320 & 0 & 25 & 2 & 1 & 2 & 2 & 2 & 1 & 2 & 2 & 2 & 2 & 1 & 1 & 1 \\
\hline 5 & 380 & 0 & 33 & 7 & 3 & 3 & 4 & 4 & 2 & 3 & 4 & 4 & 3 & 2 & 3 & 2 \\
\hline 8 & 308 & 0 & 35 & 11 & 4 & 4 & 5 & 5 & 2 & 3 & 4 & 4 & 4 & 2 & 3 & 2 \\
\hline 11 & 395 & 0 & 36 & 12 & 4 & 4 & 5 & 5 & 3 & 4 & 5 & 5 & 4 & 3 & 4 & 2 \\
\hline 14 & 335 & 0 & 36 & 12 & 4 & 4 & 6 & 5 & 3 & 4 & 5 & 5 & 5 & 3 & 4 & 3 \\
\hline 17 & 388 & 0 & 36 & 12 & 5 & 4 & 6 & 6 & 3 & 5 & 5 & 5 & 5 & 3 & 4 & 3 \\
\hline 20 & 308 & 0 & 36 & 11 & 5 & 5 & 6 & 6 & 3 & 5 & 5 & 6 & 5 & 3 & 3 & 3 \\
\hline 22 & 418 & 0 & 36 & 12 & 5 & 5 & 6 & 6 & 4 & 5 & 5 & 6 & 5 & 4 & 4 & 3 \\
\hline 25 & 250 & 0 & 37 & 14 & 6 & 5 & 7 & 7 & 4 & 5 & 6 & 6 & 6 & 4 & 6 & 3 \\
\hline 27 & 243 & 0 & 37 & 13 & 6 & 6 & 7 & 7 & 4 & 6 & 6 & 6 & 6 & 4 & 4 & 3 \\
\hline 30 & 278 & 0 & 36 & 13 & 6 & 6 & 7 & 7 & 5 & 6 & 6 & 6 & 6 & 5 & 5 & 3 \\
\hline 34 & 240 & 0 & 36 & 12 & 6 & 6 & 7 & 7 & 5 & 6 & 6 & 6 & 6 & 5 & 4 & 3 \\
\hline 37 & 265 & 0 & 35 & 11 & 6 & 6 & 7 & 7 & 5 & 6 & 6 & 6 & 6 & 5 & 5 & 3 \\
\hline 40 & 231 & 0 & 36 & 11 & 6 & 6 & 7 & 7 & 5 & 6 & 7 & 7 & 6 & 5 & 5 & 3 \\
\hline 43 & 165 & 0 & 36 & 12 & 7 & 6 & 8 & 7 & 5 & 6 & 7 & 7 & 7 & 5 & 6 & 3 \\
\hline 47 & 140 & 0 & 36 & 12 & 7 & 7 & 8 & 8 & 6 & 7 & 7 & 7 & 7 & 5 & 7 & 4 \\
\hline 50 & 135 & 0 & 36 & 12 & 7 & 7 & 8 & 8 & 6 & 7 & 7 & 7 & 7 & 6 & 6 & 4 \\
\hline 52 & 159 & 0 & 36 & 12 & 7 & 7 & 8 & 8 & 6 & 7 & 7 & 7 & 7 & 6 & 6 & 4 \\
\hline 55 & 145 & 0 & 36 & 12 & 7 & 7 & 8 & 8 & 6 & 7 & 7 & 7 & 7 & 6 & 6 & 4 \\
\hline 58 & 66 & 0 & 38 & 12 & 8 & 8 & 9 & 9 & 6 & 7 & 8 & 8 & 8 & 6 & 7 & 3 \\
\hline 62 & 87 & 0 & 37 & 12 & 8 & 8 & 9 & 9 & 7 & 8 & 8 & 8 & 8 & 6 & 7 & 4 \\
\hline 64 & 78 & 0 & 38 & 12 & 8 & 8 & 9 & 9 & 7 & 8 & 8 & 8 & 8 & 6 & 8 & 3 \\
\hline 67 & 68 & 0 & 38 & 12 & 8 & 8 & 9 & 9 & 7 & 8 & 8 & 8 & 8 & 6 & 8 & 3 \\
\hline 70 & 93 & 0 & 38 & 12 & 9 & 8 & 9 & 9 & 7 & 8 & 8 & 8 & 8 & 7 & 8 & 3 \\
\hline 73 & 0 & 0 & 39 & 12 & 9 & 9 & 10 & 10 & 7 & 8 & 8 & 9 & 8 & 7 & 9 & 16 \\
\hline 76 & 0 & 0 & 40 & 12 & 9 & 9 & 10 & 10 & 8 & 8 & 9 & 9 & 9 & 7 & 9 & 15 \\
\hline 80 & 0 & 0 & 39 & 12 & 10 & 9 & 10 & 10 & 8 & 8 & 9 & 9 & 9 & 7 & 9 & 16 \\
\hline 84 & 0 & 0 & 39 & 12 & 10 & 9 & 10 & 11 & 8 & 9 & 9 & 9 & 9 & 7 & 9 & 16 \\
\hline 87 & 0 & 0 & 39 & 12 & 10 & 9 & 10 & 11 & 8 & 9 & 9 & 9 & 9 & 7 & 9 & 14 \\
\hline
\end{tabular}


Table F.2 Complete recorded data of temperature rises for test case \#2

\begin{tabular}{|c|c|c|c|c|c|c|c|c|c|c|c|c|c|c|c|c|}
\hline $\begin{array}{l}\text { Time } \\
{[\mathrm{min}]}\end{array}$ & $\begin{array}{c}\text { Cooling } \\
\text { flow } \\
\text { rate } \\
{[\mathrm{L} / \mathrm{min}]}\end{array}$ & $\begin{array}{l}\text { Rotor } \\
\text { Speed } \\
{[\mathrm{krpm}]}\end{array}$ & $\begin{array}{c}\operatorname{Tr}_{F E} \\
- \\
T_{a m b}\end{array}$ & $\begin{array}{c}T r_{D E} \\
- \\
T_{a m b}\end{array}$ & $\begin{array}{c}T_{1} \\
- \\
T_{a m b}\end{array}$ & $\begin{array}{c}T_{2} \\
- \\
T_{a m b}\end{array}$ & $\begin{array}{c}T_{3} \\
- \\
T_{a m b}\end{array}$ & $\begin{array}{c}T_{4} \\
- \\
T_{a m b}\end{array}$ & $\begin{array}{c}T_{5} \\
- \\
T_{a m b}\end{array}$ & $\begin{array}{c}T_{6} \\
- \\
T_{a m b}\end{array}$ & $\begin{array}{c}T_{7} \\
- \\
T_{a m b}\end{array}$ & $\begin{array}{c}T_{8} \\
- \\
T_{a m b}\end{array}$ & $\begin{array}{c}T_{9} \\
- \\
T_{a m b}\end{array}$ & $\begin{array}{c}T_{10} \\
- \\
T_{a m b}\end{array}$ & $\begin{array}{c}T_{\mathrm{e}} \\
- \\
T_{a m b}\end{array}$ & $\begin{array}{c}T_{\text {out }} \\
- \\
T_{a m b}\end{array}$ \\
\hline 1 & 382 & 0 & 24 & 1 & 1 & 2 & 2 & 2 & 1 & 2 & 2 & 3 & 3 & 1 & 1 & 1 \\
\hline 4 & 366 & 0 & 37 & 5 & 3 & 4 & 5 & 5 & 2 & 4 & 5 & 5 & 5 & 3 & 4 & 2 \\
\hline 7 & 355 & 0 & 43 & 10 & 4 & 4 & 6 & 6 & 3 & 4 & 5 & 6 & 6 & 3 & 4 & 3 \\
\hline 10 & 355 & 0 & 45 & 12 & 6 & 5 & 7 & 7 & 4 & 5 & 7 & 7 & 7 & 4 & 6 & 3 \\
\hline 13 & 382 & 0 & 46 & 13 & 6 & 6 & 7 & 7 & 4 & 6 & 7 & 7 & 7 & 4 & 5 & 3 \\
\hline 16 & 313 & 0 & 47 & 15 & 7 & 7 & 8 & 8 & 5 & 7 & 8 & 8 & 8 & 5 & 7 & 4 \\
\hline 20 & 417 & 0 & 47 & 15 & 7 & 7 & 8 & 8 & 6 & 7 & 8 & 8 & 8 & 5 & 6 & 3 \\
\hline 23 & 355 & 0 & 48 & 16 & 7 & 7 & 9 & 9 & 6 & 7 & 8 & 8 & 8 & 6 & 7 & 4 \\
\hline 26 & 282 & 0 & 49 & 17 & 8 & 8 & 10 & 9 & 6 & 8 & 9 & 9 & 9 & 6 & 8 & 4 \\
\hline 29 & 230 & 0 & 49 & 18 & 9 & 8 & 10 & 10 & 7 & 8 & 9 & 9 & 9 & 7 & 8 & 5 \\
\hline 32 & 280 & 0 & 49 & 18 & 9 & 8 & 10 & 10 & 7 & 8 & 9 & 9 & 9 & 7 & 7 & 4 \\
\hline 36 & 234 & 0 & 49 & 17 & 9 & 9 & 10 & 10 & 7 & 9 & 9 & 9 & 9 & 7 & 8 & 5 \\
\hline 39 & 262 & 0 & 49 & 18 & 9 & 8 & 10 & 10 & 7 & 8 & 9 & 9 & 9 & 7 & 7 & 4 \\
\hline 42 & 254 & 0 & 48 & 17 & 9 & 8 & 10 & 10 & 7 & 8 & 9 & 9 & 9 & 7 & 8 & 5 \\
\hline 46 & 166 & 0 & 51 & 19 & 10 & 9 & 11 & 11 & 8 & 9 & 10 & 10 & 10 & 7 & 9 & 5 \\
\hline 49 & 169 & 0 & 51 & 19 & 10 & 9 & 11 & 11 & 8 & 9 & 10 & 10 & 10 & 7 & 9 & 5 \\
\hline 52 & 152 & 0 & 51 & 19 & 10 & 10 & 11 & 11 & 8 & 10 & 10 & 10 & 10 & 7 & 10 & 6 \\
\hline 56 & 166 & 0 & 51 & 19 & 10 & 10 & 11 & 11 & 8 & 9 & 10 & 10 & 10 & 8 & 9 & 6 \\
\hline 59 & 164 & 0 & 50 & 19 & 10 & 10 & 11 & 11 & 8 & 10 & 10 & 10 & 10 & 8 & 9 & 7 \\
\hline 62 & 52 & 0 & 56 & 22 & 11 & 11 & 13 & 13 & 9 & 11 & 11 & 11 & 11 & 8 & 14 & 5 \\
\hline 65 & 64 & 0 & 58 & 22 & 12 & 12 & 13 & 14 & 9 & 11 & 12 & 12 & 12 & 9 & 13 & 4 \\
\hline 68 & 58 & 0 & 59 & 23 & 13 & 12 & 14 & 14 & 10 & 12 & 12 & 12 & 12 & 9 & 14 & 5 \\
\hline 71 & 52 & 0 & 59 & 23 & 13 & 12 & 14 & 14 & 10 & 12 & 12 & 12 & 12 & 9 & 14 & 6 \\
\hline 74 & 0 & 0 & 61 & 23 & 14 & 13 & 15 & 15 & 11 & 13 & 13 & 13 & 13 & 10 & 15 & 26 \\
\hline 78 & 0 & 0 & 61 & 23 & 15 & 14 & 15 & 16 & 12 & 13 & 13 & 13 & 13 & 10 & 16 & 29 \\
\hline 81 & 0 & 0 & 60 & 21 & 14 & 13 & 15 & 15 & 11 & 12 & 13 & 12 & 12 & 10 & 16 & 28 \\
\hline 84 & 0 & 0 & 59 & 20 & 14 & 13 & 15 & 16 & 12 & 13 & 13 & 13 & 13 & 10 & 16 & 27 \\
\hline
\end{tabular}


Table F.3 Complete recorded data of temperature rises for test case \#3

\begin{tabular}{|c|c|c|c|c|c|c|c|c|c|c|c|c|c|c|c|c|}
\hline $\begin{array}{l}\text { Time } \\
{[\mathrm{min}]}\end{array}$ & $\begin{array}{c}\text { Cooling } \\
\text { flow } \\
\text { rate } \\
{[\mathrm{L} / \mathrm{min}]}\end{array}$ & $\begin{array}{l}\text { Rotor } \\
\text { Speed } \\
{[\mathrm{krpm}]}\end{array}$ & $\begin{array}{c}\operatorname{Tr}_{F E} \\
- \\
T_{a m b}\end{array}$ & $\begin{array}{c}T_{D E} \\
- \\
T_{a m b}\end{array}$ & $\begin{array}{c}T_{1} \\
- \\
T_{a m b}\end{array}$ & $\begin{array}{c}T_{2} \\
- \\
T_{a m b}\end{array}$ & $\begin{array}{c}T_{3} \\
- \\
T_{a m b}\end{array}$ & $\begin{array}{c}T_{4} \\
- \\
T_{a m b}\end{array}$ & $\begin{array}{c}T_{5} \\
- \\
T_{a m b}\end{array}$ & $\begin{array}{c}T_{6} \\
- \\
T_{a m b}\end{array}$ & $\begin{array}{c}T_{7} \\
- \\
T_{a m b}\end{array}$ & $\begin{array}{c}T_{8} \\
- \\
T_{a m b}\end{array}$ & $\begin{array}{c}T_{9} \\
- \\
T_{a m b}\end{array}$ & $\begin{array}{c}T_{10} \\
- \\
T_{a m b}\end{array}$ & $\begin{array}{c}T_{\mathrm{e}} \\
- \\
T_{a m b}\end{array}$ & $\begin{array}{c}T_{\text {out }} \\
- \\
T_{a m b}\end{array}$ \\
\hline 1 & 381 & 0 & 8 & 6 & 4 & 3 & 3 & 4 & 4 & 4 & 4 & 4 & 4 & 4 & 1 & 1 \\
\hline 2 & 412 & 0 & 44 & 10 & 4 & 4 & 6 & 5 & 3 & 5 & 6 & 6 & 6 & 4 & 6 & 2 \\
\hline 5 & 336 & 0 & 56 & 18 & 7 & 7 & 9 & 8 & 4 & 7 & 8 & 8 & 8 & 4 & 8 & 4 \\
\hline 8 & 400 & 0 & 60 & 21 & 8 & 8 & 10 & 10 & 5 & 8 & 9 & 9 & 9 & 5 & 8 & 4 \\
\hline 11 & 345 & 0 & 63 & 24 & 9 & 9 & 11 & 11 & 7 & 9 & 11 & 10 & 10 & 6 & 11 & 6 \\
\hline 14 & 400 & 0 & 63 & 24 & 10 & 9 & 12 & 11 & 7 & 9 & 11 & 10 & 10 & 7 & 9 & 6 \\
\hline 17 & 329 & 0 & 65 & 26 & 11 & 11 & 13 & 13 & 8 & 11 & 12 & 12 & 12 & 8 & 11 & 6 \\
\hline 20 & 410 & 0 & 63 & 24 & 11 & 10 & 12 & 12 & 8 & 11 & 12 & 12 & 12 & 8 & 11 & 6 \\
\hline 23 & 338 & 0 & 64 & 25 & 12 & 11 & 13 & 13 & 9 & 11 & 13 & 12 & 12 & 8 & 12 & 7 \\
\hline 26 & 421 & 0 & 62 & 25 & 11 & 11 & 13 & 13 & 9 & 11 & 12 & 12 & 12 & 9 & 11 & 6 \\
\hline 29 & 212 & 0 & 66 & 27 & 13 & 12 & 14 & 14 & 9 & 12 & 14 & 13 & 13 & 9 & 14 & 7 \\
\hline 32 & 268 & 0 & 65 & 27 & 13 & 12 & 14 & 14 & 10 & 12 & 13 & 13 & 13 & 9 & 12 & 7 \\
\hline 35 & 249 & 0 & 65 & 27 & 13 & 13 & 14 & 14 & 10 & 12 & 14 & 13 & 13 & 10 & 13 & 7 \\
\hline 38 & 217 & 0 & 67 & 29 & 14 & 13 & 15 & 15 & 11 & 13 & 14 & 14 & 14 & 10 & 13 & 8 \\
\hline 41 & 274 & 0 & 63 & 26 & 13 & 13 & 14 & 14 & 10 & 12 & 13 & 13 & 13 & 10 & 12 & 7 \\
\hline 44 & 144 & 0 & 69 & 29 & 14 & 14 & 16 & 16 & 11 & 14 & 15 & 14 & 14 & 10 & 16 & 8 \\
\hline 47 & 160 & 0 & 69 & 29 & 15 & 14 & 16 & 16 & 11 & 14 & 15 & 14 & 14 & 11 & 14 & 8 \\
\hline 51 & 150 & 0 & 69 & 30 & 16 & 15 & 17 & 17 & 12 & 15 & 16 & 15 & 15 & 12 & 16 & 9 \\
\hline 58 & 156 & 0 & 67 & 29 & 15 & 15 & 17 & 17 & 12 & 14 & 15 & 15 & 15 & 12 & 16 & 8 \\
\hline 61 & 141 & 0 & 69 & 29 & 16 & 15 & 17 & 17 & 12 & 15 & 16 & 15 & 15 & 12 & 16 & 8 \\
\hline 64 & 60 & 0 & 75 & 31 & 17 & 17 & 19 & 19 & 13 & 16 & 17 & 17 & 17 & 12 & 21 & 6 \\
\hline 67 & 52 & 0 & 80 & 34 & 19 & 18 & 20 & 21 & 14 & 17 & 18 & 18 & 18 & 13 & 22 & 8 \\
\hline 70 & 46 & 0 & 82 & 36 & 20 & 19 & 21 & 22 & 15 & 18 & 19 & 18 & 18 & 14 & 23 & 9 \\
\hline 73 & 47 & 0 & 82 & 36 & 20 & 19 & 22 & 22 & 16 & 18 & 19 & 18 & 18 & 14 & 22 & 9 \\
\hline 76 & 54 & 0 & 82 & 36 & 20 & 19 & 21 & 22 & 16 & 18 & 19 & 19 & 19 & 14 & 22 & 8 \\
\hline 81 & 46 & 0 & 81 & 35 & 20 & 19 & 22 & 22 & 16 & 18 & 19 & 18 & 18 & 14 & 23 & 9 \\
\hline 84 & 0 & 0 & 86 & 36 & 21 & 20 & 23 & 24 & 18 & 19 & 20 & 19 & 19 & 15 & 24 & 47 \\
\hline 88 & 0 & 0 & 85 & 34 & 22 & 20 & 23 & 24 & 17 & 19 & 19 & 19 & 19 & 15 & 24 & 47 \\
\hline 92 & 0 & 0 & 85 & 32 & 22 & 21 & 23 & 24 & 18 & 19 & 20 & 19 & 19 & 15 & 24 & 48 \\
\hline 97 & 0 & 0 & 84 & 31 & 23 & 21 & 24 & 25 & 19 & 20 & 20 & 20 & 20 & 16 & 25 & 42 \\
\hline 101 & 0 & 0 & 84 & 31 & 23 & 21 & 24 & 25 & 19 & 20 & 20 & 20 & 20 & 16 & 25 & 47 \\
\hline 105 & 0 & 0 & 85 & 32 & 24 & 22 & 25 & 26 & 20 & 21 & 21 & 21 & 21 & 17 & 26 & 45 \\
\hline 108 & 0 & 0 & 86 & 32 & 24 & 22 & 25 & 26 & 20 & 21 & 21 & 21 & 21 & 17 & 26 & 46 \\
\hline
\end{tabular}


Table F.4 Complete recorded data of temperature rises for test case \#4

\begin{tabular}{|c|c|c|c|c|c|c|c|c|c|c|c|c|c|c|c|c|}
\hline $\begin{array}{l}\text { Time } \\
{[\mathrm{min}]}\end{array}$ & $\begin{array}{c}\text { Cooling } \\
\text { flow } \\
\text { rate } \\
\text { [L/min] }\end{array}$ & $\begin{array}{l}\text { Rotor } \\
\text { Speed } \\
{[\mathrm{krpm}]}\end{array}$ & $\begin{array}{c}\operatorname{Tr}_{F E} \\
- \\
T_{a m b}\end{array}$ & $\begin{array}{c}T_{D E} \\
- \\
T_{a m b}\end{array}$ & $\begin{array}{c}T_{1} \\
- \\
T_{a m b}\end{array}$ & $\begin{array}{c}T_{2} \\
- \\
T_{a m b}\end{array}$ & $\begin{array}{c}T_{3} \\
- \\
T_{a m b}\end{array}$ & $\begin{array}{c}T_{4} \\
- \\
T_{a m b}\end{array}$ & $\begin{array}{c}T_{5} \\
- \\
T_{a m b}\end{array}$ & $\begin{array}{c}T_{6} \\
- \\
T_{a m b}\end{array}$ & $\begin{array}{c}T_{7} \\
- \\
T_{a m b}\end{array}$ & $\begin{array}{c}T_{8} \\
- \\
T_{a m b}\end{array}$ & $\begin{array}{c}T_{9} \\
- \\
T_{a m b}\end{array}$ & $\begin{array}{c}T_{10} \\
- \\
T_{a m b}\end{array}$ & $\begin{array}{c}T_{\mathrm{e}} \\
- \\
T_{a m b}\end{array}$ & $\begin{array}{c}T_{\text {out }} \\
- \\
T_{a m b}\end{array}$ \\
\hline 1 & 337 & 10 & 0 & 0 & 1 & 1 & 1 & 1 & 1 & 1 & 1 & 1 & 1 & 1 & 0 & 2 \\
\hline 4 & 333 & 10 & 18 & 3 & 1 & 1 & 2 & 2 & 1 & 2 & 2 & 2 & 2 & 1 & 0 & 2 \\
\hline 6 & 426 & 10 & 25 & 6 & 2 & 2 & 3 & 3 & 2 & 2 & 2 & 3 & 3 & 2 & 0 & 2 \\
\hline 8 & 371 & 10 & 28 & 7 & 3 & 2 & 4 & 4 & 2 & 3 & 3 & 4 & 3 & 2 & 1 & 3 \\
\hline 11 & 319 & 10 & 30 & 9 & 3 & 3 & 5 & 5 & 2 & 3 & 4 & 4 & 4 & 2 & 1 & 2 \\
\hline 14 & 423 & 10 & 30 & 10 & 4 & 3 & 5 & 5 & 3 & 4 & 4 & 5 & 4 & 2 & 1 & 2 \\
\hline 16 & 358 & 10 & 31 & 10 & 4 & 4 & 5 & 5 & 3 & 4 & 4 & 5 & 5 & 3 & 1 & 3 \\
\hline 19 & 345 & 10 & 31 & 11 & 4 & 4 & 6 & 6 & 4 & 4 & 4 & 5 & 5 & 3 & 1 & 4 \\
\hline 22 & 409 & 10 & 31 & 10 & 4 & 4 & 6 & 6 & 3 & 4 & 4 & 5 & 5 & 3 & 1 & 3 \\
\hline 25 & 258 & 10 & 33 & 13 & 5 & 5 & 6 & 6 & 4 & 5 & 5 & 6 & 6 & 4 & 3 & 4 \\
\hline 27 & 300 & 10 & 33 & 13 & 5 & 5 & 6 & 7 & 4 & 5 & 5 & 6 & 6 & 4 & 3 & 4 \\
\hline 30 & 300 & 10 & 32 & 12 & 5 & 5 & 6 & 7 & 4 & 5 & 5 & 6 & 6 & 4 & 2 & 3 \\
\hline 33 & 261 & 10 & 32 & 12 & 5 & 5 & 7 & 7 & 4 & 5 & 6 & 6 & 6 & 4 & 3 & 3 \\
\hline 36 & 290 & 10 & 32 & 12 & 6 & 5 & 7 & 7 & 4 & 5 & 6 & 6 & 6 & 4 & 2 & 3 \\
\hline 38 & 173 & 10 & 33 & 13 & 6 & 6 & 7 & 8 & 4 & 6 & 7 & 7 & 7 & 4 & 4 & 4 \\
\hline 41 & 153 & 10 & 36 & 14 & 7 & 7 & 8 & 8 & 5 & 7 & 7 & 7 & 7 & 5 & 6 & 5 \\
\hline 45 & 164 & 10 & 36 & 14 & 7 & 7 & 8 & 8 & 6 & 7 & 7 & 7 & 7 & 5 & 5 & 5 \\
\hline 48 & 173 & 10 & 36 & 14 & 7 & 7 & 8 & 9 & 6 & 7 & 7 & 7 & 7 & 6 & 6 & 5 \\
\hline 50 & 161 & 10 & 36 & 14 & 7 & 7 & 8 & 9 & 6 & 7 & 7 & 8 & 7 & 6 & 6 & 5 \\
\hline 54 & 61 & 10 & 34 & 13 & 8 & 8 & 10 & 10 & 6 & 8 & 8 & 8 & 8 & 6 & 7 & 5 \\
\hline 57 & 83 & 10 & 35 & 13 & 9 & 8 & 10 & 10 & 6 & 8 & 9 & 8 & 8 & 6 & 7 & 5 \\
\hline 60 & 75 & 10 & 36 & 14 & 9 & 9 & 10 & 10 & 7 & 8 & 9 & 9 & 8 & 7 & 9 & 6 \\
\hline 63 & 67 & 10 & 36 & 14 & 9 & 9 & 10 & 10 & 7 & 9 & 9 & 9 & 9 & 7 & 9 & 5 \\
\hline 66 & 62 & 10 & 35 & 14 & 9 & 9 & 10 & 11 & 8 & 9 & 9 & 9 & 9 & 7 & 9 & 5 \\
\hline 70 & 363 & 20 & 32 & 11 & 8 & 7 & 8 & 8 & 6 & 7 & 8 & 8 & 8 & 6 & 3 & 4 \\
\hline 72 & 342 & 20 & 36 & 14 & 8 & 7 & 8 & 9 & 6 & 7 & 8 & 8 & 8 & 6 & 4 & 4 \\
\hline 76 & 414 & 20 & 36 & 14 & 7 & 7 & 8 & 9 & 6 & 7 & 7 & 8 & 8 & 6 & 3 & 4 \\
\hline 79 & 354 & 20 & 37 & 16 & 7 & 7 & 8 & 9 & 6 & 7 & 8 & 8 & 8 & 6 & 4 & 4 \\
\hline 83 & 377 & 20 & 38 & 17 & 8 & 7 & 8 & 9 & 6 & 7 & 8 & 8 & 8 & 6 & 3 & 4 \\
\hline 87 & 353 & 20 & 38 & 17 & 8 & 7 & 9 & 9 & 6 & 7 & 8 & 8 & 8 & 6 & 4 & 4 \\
\hline 90 & 344 & 20 & 38 & 17 & 8 & 7 & 8 & 9 & 6 & 7 & 7 & 8 & 8 & 6 & 3 & 5 \\
\hline 94 & 280 & 20 & 39 & 17 & 8 & 8 & 9 & 10 & 6 & 8 & 8 & 9 & 9 & 6 & 6 & 5 \\
\hline 97 & 238 & 20 & 39 & 18 & 9 & 8 & 10 & 10 & 6 & 8 & 9 & 9 & 9 & 6 & 6 & 5 \\
\hline 101 & 285 & 20 & 39 & 18 & 8 & 8 & 9 & 10 & 7 & 8 & 9 & 9 & 9 & 6 & 6 & 5 \\
\hline 106 & 228 & 20 & 38 & 17 & 9 & 8 & 9 & 10 & 7 & 8 & 9 & 9 & 9 & 7 & 5 & 5 \\
\hline 110 & 281 & 20 & 38 & 17 & 9 & 8 & 9 & 10 & 7 & 8 & 9 & 9 & 9 & 6 & 6 & 5 \\
\hline 113 & 158 & 20 & 41 & 19 & 10 & 10 & 12 & 12 & 8 & 10 & 10 & 11 & 10 & 7 & 9 & 7 \\
\hline
\end{tabular}


Table F.4 Continued

\begin{tabular}{|c|c|c|c|c|c|c|c|c|c|c|c|c|c|c|c|c|}
\hline $\begin{array}{l}\text { Time } \\
{[\mathrm{min}]}\end{array}$ & $\begin{array}{c}\text { Cooling } \\
\text { flow } \\
\text { rate } \\
\text { [L/min }]\end{array}$ & $\begin{array}{l}\text { Rotor } \\
\text { Speed } \\
{[\mathrm{krpm}]}\end{array}$ & $\begin{array}{c}\operatorname{Tr}_{F E} \\
- \\
T_{a m b}\end{array}$ & $\begin{array}{c}T r_{D E} \\
- \\
T_{a m b}\end{array}$ & $\begin{array}{c}T_{1} \\
- \\
T_{a m b}\end{array}$ & $\begin{array}{c}T_{2} \\
- \\
T_{a m b}\end{array}$ & $\begin{array}{c}T_{3} \\
- \\
T_{a m b}\end{array}$ & $\begin{array}{c}T_{4} \\
- \\
T_{a m b}\end{array}$ & $\begin{array}{c}T_{5} \\
- \\
T_{a m b}\end{array}$ & $\begin{array}{c}T_{6} \\
- \\
T_{a m b}\end{array}$ & $\begin{array}{c}T_{7} \\
- \\
T_{a m b}\end{array}$ & $\begin{array}{c}T_{8} \\
- \\
T_{a m b}\end{array}$ & $\begin{array}{c}T_{9} \\
- \\
T_{a m b}\end{array}$ & $\begin{array}{c}T_{10} \\
- \\
T_{a m b}\end{array}$ & $\begin{array}{c}T_{\mathrm{e}} \\
- \\
T_{a m b}\end{array}$ & $\begin{array}{c}T_{\text {out }} \\
- \\
T_{a m b}\end{array}$ \\
\hline 116 & 172 & 20 & 42 & 20 & 10 & 10 & 11 & 12 & 8 & 10 & 11 & 11 & 10 & 8 & 8 & 7 \\
\hline 119 & 179 & 20 & 42 & 20 & 10 & 10 & 12 & 12 & 8 & 10 & 11 & 11 & 10 & 8 & 9 & 7 \\
\hline 122 & 158 & 20 & 42 & 20 & 11 & 11 & 12 & 13 & 8 & 11 & 11 & 12 & 11 & 8 & 9 & 7 \\
\hline 125 & 147 & 20 & 41 & 20 & 11 & 11 & 12 & 13 & 9 & 11 & 12 & 12 & 11 & 8 & 8 & 7 \\
\hline 128 & 181 & 20 & 42 & 21 & 11 & 11 & 12 & 13 & 9 & 11 & 12 & 12 & 11 & 9 & 10 & 8 \\
\hline 136 & 69 & 20 & 37 & 19 & 13 & 12 & 14 & 14 & 10 & 12 & 12 & 12 & 12 & 9 & 9 & 12 \\
\hline 140 & 64 & 20 & 31 & 16 & 12 & 12 & 13 & 13 & 9 & 12 & 12 & 12 & 12 & 9 & 8 & 11 \\
\hline 143 & 59 & 20 & 29 & 15 & 12 & 12 & 12 & 13 & 9 & 12 & 12 & 12 & 12 & 8 & 8 & 11 \\
\hline 146 & 54 & 20 & 28 & 14 & 12 & 11 & 12 & 13 & 9 & 12 & 12 & 12 & 11 & 8 & 8 & 11 \\
\hline 150 & 72 & 20 & 28 & 14 & 11 & 11 & 12 & 12 & 9 & 11 & 11 & 11 & 11 & 9 & 8 & 9 \\
\hline 153 & 64 & 20 & 27 & 13 & 11 & 11 & 12 & 12 & 8 & 11 & 11 & 11 & 11 & 8 & 7 & 10 \\
\hline 157 & 58 & 20 & 27 & 12 & 11 & 11 & 12 & 12 & 8 & 11 & 11 & 11 & 11 & 8 & 8 & 10 \\
\hline 164 & 375 & 30 & 40 & 17 & 9 & 9 & 10 & 11 & 8 & 9 & 10 & 10 & 10 & 8 & 7 & 6 \\
\hline 167 & 314 & 30 & 42 & 20 & 10 & 9 & 10 & 11 & 8 & 9 & 10 & 10 & 10 & 8 & 6 & 7 \\
\hline 171 & 400 & 30 & 42 & 20 & 9 & 9 & 10 & 11 & 8 & 9 & 10 & 10 & 10 & 8 & 7 & 6 \\
\hline 174 & 318 & 30 & 43 & 22 & 10 & 10 & 11 & 12 & 8 & 10 & 10 & 11 & 10 & 8 & 6 & 7 \\
\hline 177 & 419 & 30 & 43 & 21 & 9 & 9 & 10 & 11 & 8 & 9 & 10 & 10 & 10 & 8 & 6 & 6 \\
\hline 180 & 354 & 30 & 43 & 21 & 10 & 9 & 10 & 11 & 8 & 10 & 10 & 11 & 10 & 8 & 7 & 7 \\
\hline 183 & 262 & 30 & 43 & 21 & 11 & 10 & 12 & 12 & 8 & 10 & 11 & 12 & 11 & 8 & 8 & 6 \\
\hline 188 & 225 & 30 & 46 & 25 & 12 & 12 & 13 & 14 & 9 & 12 & 13 & 13 & 12 & 9 & 11 & 8 \\
\hline 191 & 206 & 30 & 45 & 24 & 12 & 12 & 13 & 14 & 9 & 12 & 13 & 13 & 12 & 9 & 9 & 7 \\
\hline 194 & 259 & 30 & 45 & 24 & 12 & 12 & 13 & 14 & 10 & 12 & 13 & 13 & 12 & 9 & 10 & 8 \\
\hline 198 & 209 & 30 & 45 & 25 & 13 & 13 & 13 & 14 & 10 & 12 & 14 & 14 & 13 & 10 & 10 & 8 \\
\hline 202 & 269 & 30 & 45 & 25 & 12 & 12 & 13 & 14 & 10 & 12 & 13 & 13 & 12 & 10 & 9 & 9 \\
\hline 207 & 134 & 30 & 41 & 25 & 14 & 13 & 16 & 16 & 11 & 14 & 14 & 14 & 14 & 10 & 11 & 13 \\
\hline 210 & 136 & 30 & 35 & 22 & 13 & 13 & 14 & 14 & 11 & 13 & 13 & 13 & 13 & 10 & 9 & 12 \\
\hline 214 & 168 & 30 & 33 & 19 & 12 & 12 & 13 & 13 & 10 & 12 & 12 & 12 & 12 & 10 & 8 & 8 \\
\hline 217 & 150 & 30 & 31 & 17 & 12 & 11 & 13 & 13 & 10 & 12 & 12 & 12 & 12 & 10 & 8 & 10 \\
\hline 221 & 185 & 30 & 33 & 17 & 11 & 11 & 12 & 12 & 10 & 11 & 12 & 12 & 12 & 9 & 8 & 8 \\
\hline 224 & 168 & 30 & 36 & 18 & 11 & 11 & 13 & 13 & 10 & 12 & 12 & 12 & 12 & 9 & 9 & 8 \\
\hline 227 & 155 & 30 & 35 & 19 & 12 & 12 & 13 & 13 & 10 & 12 & 12 & 13 & 12 & 10 & 8 & 11 \\
\hline 230 & 141 & 30 & 33 & 18 & 12 & 12 & 13 & 13 & 10 & 12 & 12 & 12 & 12 & 10 & 8 & 11 \\
\hline 236 & 60 & 30 & 31 & 17 & 13 & 13 & 14 & 14 & 9 & 13 & 13 & 13 & 13 & 9 & 11 & 12 \\
\hline 240 & 54 & 30 & 30 & 17 & 13 & 13 & 14 & 15 & 10 & 13 & 14 & 14 & 13 & 9 & 11 & 11 \\
\hline 242 & 50 & 30 & 30 & 17 & 14 & 13 & 15 & 15 & 10 & 13 & 14 & 14 & 13 & 10 & 10 & 11 \\
\hline 245 & 69 & 30 & 28 & 14 & 13 & 13 & 14 & 15 & 9 & 13 & 14 & 14 & 13 & 9 & 9 & 11 \\
\hline 248 & 63 & 30 & 30 & 15 & 13 & 13 & 14 & 15 & 10 & 13 & 14 & 14 & 13 & 10 & 10 & 12 \\
\hline
\end{tabular}


Table F.5 Complete recorded data of temperature rises for test case \#5

\begin{tabular}{|c|c|c|c|c|c|c|c|c|c|c|c|c|c|c|c|}
\hline $\begin{array}{l}\text { Time } \\
\text { [min] }\end{array}$ & $\begin{array}{c}\text { Cooling } \\
\text { flow } \\
\text { rate } \\
\text { [L/min }]\end{array}$ & $\begin{array}{l}\text { Rotor } \\
\text { Speed } \\
{[\mathrm{krpm}]}\end{array}$ & $\begin{array}{c}\operatorname{Tr}_{F E} \\
- \\
T_{a m b}\end{array}$ & $\begin{array}{c}T_{D E} \\
- \\
T_{a m b}\end{array}$ & $\begin{array}{c}T_{1} \\
- \\
T_{a m b}\end{array}$ & $\begin{array}{c}T_{2} \\
- \\
T_{a m b}\end{array}$ & $\begin{array}{c}T_{3} \\
- \\
T_{a m b}\end{array}$ & $\begin{array}{c}T_{4} \\
- \\
T_{a m b}\end{array}$ & $\begin{array}{c}T_{5} \\
- \\
T_{a m b}\end{array}$ & $\begin{array}{c}T_{6} \\
- \\
T_{a m b}\end{array}$ & $\begin{array}{c}T_{7} \\
- \\
T_{a m b}\end{array}$ & $\begin{array}{c}T_{8} \\
- \\
T_{a m b}\end{array}$ & $\begin{array}{c}T_{9} \\
- \\
T_{a m b}\end{array}$ & $\begin{array}{c}T_{10} \\
- \\
T_{a m b}\end{array}$ & $\begin{array}{c}T_{\mathrm{e}} \\
- \\
T_{a m b}\end{array}$ \\
\hline 1 & 341 & 10 & 4 & 3 & 2 & 2 & 2 & 2 & 1 & 2 & 2 & 2 & 2 & 1 & 2 \\
\hline 4 & 341 & 10 & 16 & 7 & 6 & 6 & 8 & 8 & 5 & 6 & 7 & 8 & 7 & 5 & 5 \\
\hline 6 & 357 & 10 & 28 & 8 & 7 & 7 & 10 & 10 & 5 & 7 & 8 & 9 & 8 & 5 & 4 \\
\hline 8 & 422 & 10 & 37 & 12 & 7 & 7 & 10 & 10 & 6 & 7 & 8 & 9 & 9 & 6 & 6 \\
\hline 11 & 353 & 10 & 42 & 16 & 8 & 8 & 11 & 11 & 6 & 8 & 9 & 10 & 9 & 6 & 6 \\
\hline 13 & 337 & 10 & 49 & 20 & 9 & 8 & 11 & 12 & 7 & 9 & 9 & 11 & 10 & 7 & 6 \\
\hline 15 & 426 & 10 & 48 & 20 & 9 & 8 & 11 & 11 & 7 & 8 & 9 & 11 & 10 & 7 & 6 \\
\hline 18 & 356 & 10 & 49 & 21 & 10 & 10 & 12 & 13 & 8 & 9 & 10 & 12 & 11 & 8 & 7 \\
\hline 21 & 426 & 10 & 49 & 21 & 10 & 9 & 12 & 12 & 8 & 9 & 10 & 12 & 11 & 8 & 6 \\
\hline 25 & 259 & 10 & 52 & 23 & 11 & 11 & 14 & 14 & 9 & 11 & 12 & 13 & 12 & 8 & 9 \\
\hline 28 & 225 & 10 & 56 & 24 & 12 & 11 & 14 & 15 & 9 & 11 & 12 & 13 & 13 & 9 & 10 \\
\hline 30 & 278 & 10 & 53 & 26 & 12 & 11 & 14 & 14 & 9 & 11 & 12 & 13 & 13 & 9 & 9 \\
\hline 32 & 268 & 10 & 52 & 25 & 12 & 11 & 14 & 15 & 9 & 12 & 12 & 13 & 13 & 9 & 9 \\
\hline 35 & 237 & 10 & 53 & 26 & 12 & 12 & 14 & 15 & 10 & 12 & 13 & 14 & 13 & 10 & 10 \\
\hline 37 & 240 & 10 & 54 & 25 & 12 & 11 & 14 & 15 & 10 & 12 & 13 & 14 & 13 & 10 & 10 \\
\hline 40 & 281 & 10 & 51 & 23 & 12 & 11 & 14 & 15 & 10 & 12 & 12 & 13 & 13 & 10 & 9 \\
\hline 43 & 161 & 10 & 55 & 24 & 13 & 13 & 15 & 16 & 11 & 13 & 14 & 15 & 14 & 10 & 14 \\
\hline 45 & 148 & 10 & 56 & 27 & 14 & 13 & 16 & 17 & 11 & 14 & 14 & 15 & 14 & 11 & 12 \\
\hline 47 & 183 & 10 & 55 & 27 & 14 & 13 & 15 & 16 & 11 & 13 & 14 & 15 & 14 & 11 & 12 \\
\hline 50 & 178 & 10 & 55 & 27 & 14 & 13 & 16 & 17 & 11 & 13 & 14 & 15 & 14 & 11 & 13 \\
\hline 53 & 158 & 10 & 55 & 27 & 14 & 14 & 16 & 17 & 12 & 14 & 15 & 15 & 15 & 11 & 14 \\
\hline 56 & 151 & 10 & 54 & 26 & 14 & 13 & 15 & 16 & 11 & 13 & 14 & 14 & 14 & 11 & 11 \\
\hline 59 & 182 & 10 & 54 & 26 & 14 & 14 & 16 & 17 & 12 & 14 & 14 & 15 & 14 & 11 & 12 \\
\hline 64 & 65 & 10 & 52 & 25 & 16 & 15 & 18 & 19 & 13 & 15 & 16 & 16 & 16 & 12 & 18 \\
\hline 66 & 59 & 10 & 46 & 22 & 16 & 15 & 17 & 17 & 13 & 15 & 15 & 15 & 15 & 12 & 15 \\
\hline 69 & 81 & 10 & 48 & 22 & 15 & 15 & 17 & 17 & 13 & 15 & 15 & 15 & 15 & 12 & 16 \\
\hline 71 & 75 & 10 & 51 & 21 & 16 & 15 & 18 & 18 & 13 & 15 & 16 & 16 & 15 & 12 & 17 \\
\hline 74 & 68 & 10 & 51 & 22 & 17 & 16 & 18 & 19 & 13 & 16 & 16 & 16 & 16 & 13 & 18 \\
\hline 77 & 62 & 10 & 48 & 22 & 16 & 16 & 18 & 18 & 13 & 15 & 16 & 16 & 15 & 12 & 17 \\
\hline 82 & 395 & 20 & 48 & 19 & 12 & 11 & 13 & 14 & 11 & 12 & 12 & 13 & 13 & 10 & 8 \\
\hline 85 & 334 & 20 & 55 & 24 & 13 & 13 & 14 & 16 & 11 & 13 & 14 & 15 & 14 & 11 & 11 \\
\hline 88 & 362 & 20 & 56 & 25 & 13 & 12 & 14 & 15 & 11 & 12 & 13 & 14 & 14 & 10 & 9 \\
\hline 91 & 365 & 20 & 57 & 27 & 13 & 12 & 15 & 16 & 11 & 13 & 14 & 15 & 14 & 10 & 11 \\
\hline 95 & 339 & 20 & 57 & 27 & 13 & 12 & 15 & 16 & 11 & 12 & 13 & 14 & 14 & 10 & 9 \\
\hline 99 & 349 & 20 & 58 & 27 & 13 & 12 & 15 & 16 & 11 & 13 & 14 & 15 & 14 & 10 & 11 \\
\hline 104 & 400 & 20 & 57 & 26 & 13 & 12 & 15 & 15 & 11 & 12 & 13 & 15 & 14 & 10 & 10 \\
\hline 107 & 262 & 20 & 60 & 28 & 14 & 14 & 16 & 17 & 11 & 14 & 15 & 16 & 15 & 11 & 14 \\
\hline
\end{tabular}


Table F.5 Continued

\begin{tabular}{|c|c|c|c|c|c|c|c|c|c|c|c|c|c|c|c|}
\hline $\begin{array}{l}\text { Time } \\
\text { [min] }\end{array}$ & $\begin{array}{c}\text { Cooling } \\
\text { flow } \\
\text { rate } \\
\text { [L/min }]\end{array}$ & $\begin{array}{l}\text { Rotor } \\
\text { Speed } \\
{[\mathrm{krpm}]}\end{array}$ & $\begin{array}{c}\operatorname{Tr}_{F E} \\
- \\
T_{a m b}\end{array}$ & $\begin{array}{c}T r_{D E} \\
- \\
T_{a m b}\end{array}$ & $\begin{array}{c}T_{1} \\
- \\
T_{a m b}\end{array}$ & $\begin{array}{c}T_{2} \\
- \\
T_{a m b}\end{array}$ & $\begin{array}{c}T_{3} \\
- \\
T_{a m b}\end{array}$ & $\begin{array}{c}T_{4} \\
- \\
T_{a m b}\end{array}$ & $\begin{array}{c}T_{5} \\
- \\
T_{a m b}\end{array}$ & $\begin{array}{c}T_{6} \\
- \\
T_{a m b}\end{array}$ & $\begin{array}{c}T_{7} \\
- \\
T_{a m b}\end{array}$ & $\begin{array}{c}T_{8} \\
- \\
T_{a m b}\end{array}$ & $\begin{array}{c}T_{9} \\
- \\
T_{a m b}\end{array}$ & $\begin{array}{c}T_{10} \\
- \\
T_{a m b}\end{array}$ & $\begin{array}{c}T_{\mathrm{e}} \\
- \\
T_{a m b}\end{array}$ \\
\hline 110 & 251 & 20 & 60 & 27 & 15 & 14 & 16 & 17 & 11 & 14 & 15 & 15 & 15 & 11 & 11 \\
\hline 113 & 296 & 20 & 58 & 27 & 14 & 14 & 16 & 17 & 12 & 14 & 15 & 16 & 15 & 11 & 12 \\
\hline 116 & 255 & 20 & 59 & 28 & 15 & 14 & 16 & 18 & 12 & 14 & 15 & 16 & 15 & 12 & 13 \\
\hline 119 & 276 & 20 & 59 & 28 & 15 & 14 & 16 & 17 & 12 & 14 & 15 & 16 & 15 & 11 & 11 \\
\hline 122 & 289 & 20 & 59 & 26 & 15 & 14 & 16 & 17 & 12 & 14 & 15 & 16 & 15 & 12 & 12 \\
\hline 125 & 160 & 20 & 63 & 28 & 17 & 16 & 19 & 20 & 13 & 16 & 17 & 18 & 17 & 12 & 16 \\
\hline 128 & 207 & 20 & 63 & 29 & 17 & 16 & 18 & 20 & 13 & 16 & 17 & 18 & 17 & 13 & 16 \\
\hline 131 & 186 & 20 & 65 & 30 & 17 & 17 & 19 & 20 & 14 & 17 & 18 & 18 & 18 & 13 & 17 \\
\hline 134 & 164 & 20 & 65 & 30 & 18 & 18 & 20 & 21 & 14 & 18 & 19 & 19 & 18 & 14 & 18 \\
\hline 137 & 176 & 20 & 65 & 30 & 18 & 18 & 20 & 21 & 14 & 17 & 19 & 19 & 18 & 14 & 16 \\
\hline 140 & 186 & 20 & 64 & 30 & 19 & 18 & 20 & 21 & 15 & 18 & 19 & 20 & 19 & 14 & 18 \\
\hline 144 & 165 & 20 & 65 & 30 & 19 & 19 & 21 & 22 & 15 & 18 & 20 & 20 & 19 & 14 & 19 \\
\hline 149 & 193 & 20 & 64 & 30 & 19 & 18 & 20 & 21 & 15 & 18 & 19 & 20 & 19 & 14 & 17 \\
\hline 152 & 64 & 20 & 63 & 30 & 22 & 21 & 24 & 25 & 16 & 21 & 21 & 21 & 21 & 15 & 22 \\
\hline 155 & 60 & 20 & 50 & 26 & 22 & 20 & 23 & 24 & 17 & 20 & 20 & 20 & 20 & 16 & 18 \\
\hline 158 & 84 & 20 & 45 & 24 & 20 & 19 & 21 & 22 & 17 & 19 & 19 & 19 & 19 & 16 & 17 \\
\hline 161 & 75 & 20 & 41 & 21 & 19 & 18 & 20 & 20 & 16 & 18 & 18 & 17 & 17 & 15 & 16 \\
\hline 168 & 71 & 20 & 38 & 19 & 17 & 17 & 18 & 19 & 15 & 17 & 17 & 17 & 17 & 14 & 14 \\
\hline 171 & 80 & 20 & 38 & 18 & 17 & 16 & 18 & 19 & 15 & 17 & 17 & 17 & 16 & 14 & 14 \\
\hline 174 & 73 & 20 & 38 & $\begin{array}{l}18 \\
\end{array}$ & 17 & 17 & 18 & 19 & 14 & 16 & 17 & 17 & 16 & 14 & 14 \\
\hline 182 & 435 & 30 & 59 & 29 & 15 & 14 & 16 & 18 & 12 & 14 & 16 & 17 & 16 & 12 & 12 \\
\hline 185 & 367 & 30 & 64 & 31 & 15 & 14 & 16 & 18 & 12 & 14 & 15 & 17 & 16 & 12 & 9 \\
\hline 188 & 481 & 30 & 62 & 29 & 14 & 13 & 16 & 18 & 12 & 14 & 15 & 17 & 16 & 12 & 11 \\
\hline 191 & 400 & 30 & 64 & 30 & 15 & 14 & 17 & 18 & 12 & 15 & 16 & 17 & 17 & 12 & 12 \\
\hline 194 & 452 & 30 & 63 & 30 & 15 & 14 & 16 & 18 & 12 & 14 & 15 & 16 & 16 & 12 & 10 \\
\hline 197 & 440 & 30 & 63 & 30 & 15 & 14 & 16 & 18 & 12 & 14 & 15 & 17 & 16 & 12 & 12 \\
\hline 200 & 377 & 30 & 64 & 31 & 15 & 14 & 17 & 18 & 12 & 14 & 15 & 17 & 16 & 12 & 10 \\
\hline 203 & 261 & 30 & 70 & 34 & 17 & 17 & 20 & 21 & 13 & 17 & 19 & 20 & 18 & 13 & 18 \\
\hline 208 & 229 & 30 & 72 & 34 & 19 & 19 & 21 & 22 & 14 & 18 & 20 & 20 & 19 & 14 & 17 \\
\hline 211 & 291 & 30 & 68 & 33 & 18 & 18 & 20 & 22 & 14 & 18 & 20 & 20 & 19 & 14 & 17 \\
\hline 215 & 241 & 30 & 72 & 34 & 20 & 20 & 22 & 23 & 15 & 19 & 21 & 21 & 20 & 15 & 18 \\
\hline 218 & 303 & 30 & 69 & 34 & 19 & 19 & 20 & 22 & 15 & 18 & 20 & 20 & 19 & 15 & 16 \\
\hline 221 & 283 & 30 & 69 & 34 & 19 & 19 & 21 & 22 & 15 & 19 & 20 & 21 & 20 & 15 & 17 \\
\hline 224 & 164 & 30 & 67 & 34 & 21 & 21 & 25 & 25 & 16 & 21 & 22 & 22 & 21 & 16 & 20 \\
\hline 227 & 192 & 30 & 64 & 33 & 21 & 21 & 23 & 23 & 16 & 20 & 22 & 22 & 21 & 16 & 20 \\
\hline 230 & 186 & 30 & 69 & 35 & 21 & 22 & 25 & 25 & 17 & 21 & 23 & 23 & 22 & 16 & 21 \\
\hline 233 & 167 & 30 & 66 & 33 & 22 & 22 & 25 & 25 & 17 & 22 & 23 & 23 & 22 & 17 & 20 \\
\hline
\end{tabular}


Table F.5 Continued

\begin{tabular}{|c|c|c|c|c|c|c|c|c|c|c|c|c|c|c|c|}
\hline $\begin{array}{l}\text { Time } \\
\text { [min] }\end{array}$ & $\begin{array}{c}\text { Cooling } \\
\text { flow } \\
\text { rate } \\
\text { [L/min] }\end{array}$ & $\begin{array}{l}\text { Rotor } \\
\text { Speed } \\
{[\mathrm{krpm}]}\end{array}$ & $\begin{array}{c}\operatorname{Tr}_{F E} \\
- \\
T_{a m b}\end{array}$ & $\begin{array}{c}T_{D E} \\
- \\
T_{a m b}\end{array}$ & $\begin{array}{c}T_{1} \\
- \\
T_{a m b}\end{array}$ & $\begin{array}{c}T_{2} \\
- \\
T_{a m b}\end{array}$ & $\begin{array}{c}T_{3} \\
- \\
T_{a m b}\end{array}$ & $\begin{array}{c}T_{4} \\
- \\
T_{a m b}\end{array}$ & $\begin{array}{c}T_{5} \\
- \\
T_{a m b}\end{array}$ & $\begin{array}{c}T_{6} \\
- \\
T_{a m b}\end{array}$ & $\begin{array}{c}T_{7} \\
- \\
T_{a m b}\end{array}$ & $\begin{array}{c}T_{8} \\
- \\
T_{a m b}\end{array}$ & $\begin{array}{c}T_{9} \\
- \\
T_{a m b}\end{array}$ & $\begin{array}{c}T_{10} \\
- \\
T_{a m b}\end{array}$ & $\begin{array}{c}T_{\mathrm{e}} \\
- \\
T_{a m b}\end{array}$ \\
\hline 236 & 167 & 30 & 62 & 32 & 21 & 21 & 23 & 24 & 17 & 20 & 22 & 22 & 21 & 16 & 19 \\
\hline 239 & 194 & 30 & 67 & 33 & 22 & 22 & 24 & 25 & 17 & 21 & 23 & 23 & 22 & 17 & 21 \\
\hline 242 & 172 & 30 & 67 & 34 & 22 & 22 & 25 & 25 & 17 & 21 & 23 & 23 & 22 & 17 & 20 \\
\hline 245 & 76 & 30 & 52 & 29 & 23 & 22 & 24 & 25 & 17 & 21 & 22 & 21 & 21 & 15 & 19 \\
\hline 248 & 73 & 30 & 45 & 27 & 22 & 21 & 23 & 24 & 17 & 20 & 21 & 20 & 20 & 15 & 18 \\
\hline 251 & 68 & 30 & 42 & 22 & 21 & 20 & 22 & 23 & 16 & 19 & 20 & 19 & 19 & 14 & 17 \\
\hline 254 & 60 & 30 & 37 & 19 & 20 & 19 & 21 & 22 & 16 & 19 & 19 & 19 & 19 & 14 & 17 \\
\hline 257 & 54 & 30 & 37 & 19 & 20 & 19 & 21 & 21 & 16 & 18 & 19 & 18 & 18 & 14 & 16 \\
\hline 260 & 76 & 30 & 37 & 19 & 20 & 19 & 20 & 21 & 16 & 18 & 19 & 19 & 18 & 14 & 16 \\
\hline 263 & 68 & 30 & 37 & 18 & 19 & 19 & 20 & 21 & 15 & 18 & 19 & 18 & 18 & 14 & 16 \\
\hline 266 & 61 & 30 & 36 & 17 & 19 & 18 & 20 & 21 & 15 & 18 & 18 & 18 & 18 & 13 & 17 \\
\hline
\end{tabular}


Table F. 6 Complete recorded data of temperature rises for test case \#6

\begin{tabular}{|c|c|c|c|c|c|c|c|c|c|c|c|c|c|c|c|c|}
\hline $\begin{array}{l}\text { Time } \\
{[\mathrm{min}]}\end{array}$ & $\begin{array}{c}\text { Cooling } \\
\text { flow } \\
\text { rate } \\
\text { [L/min }]\end{array}$ & $\begin{array}{l}\text { Rotor } \\
\text { Speed } \\
{[\mathrm{krpm}]}\end{array}$ & $\begin{array}{c}\operatorname{Tr}_{F E} \\
- \\
T_{a m b}\end{array}$ & $\begin{array}{c}T_{D E} \\
- \\
T_{a m b}\end{array}$ & $\begin{array}{c}T_{1} \\
- \\
T_{a m b}\end{array}$ & $\begin{array}{c}T_{2} \\
- \\
T_{a m b}\end{array}$ & $\begin{array}{c}T_{3} \\
- \\
T_{a m b}\end{array}$ & $\begin{array}{c}T_{4} \\
- \\
T_{a m b}\end{array}$ & $\begin{array}{c}T_{5} \\
- \\
T_{a m b}\end{array}$ & $\begin{array}{c}T_{6} \\
- \\
T_{a m b}\end{array}$ & $\begin{array}{c}T_{7} \\
- \\
T_{a m b}\end{array}$ & $\begin{array}{c}T_{8} \\
- \\
T_{a m b}\end{array}$ & $\begin{array}{c}T_{9} \\
- \\
T_{a m b}\end{array}$ & $\begin{array}{c}T_{10} \\
- \\
T_{a m b}\end{array}$ & $\begin{array}{c}T_{\mathrm{e}} \\
- \\
T_{a m b}\end{array}$ & $\begin{array}{c}T_{\text {out }} \\
- \\
T_{a m b}\end{array}$ \\
\hline 1 & 371 & 10 & 1 & 1 & 1 & 1 & 1 & 1 & 1 & 1 & 1 & 1 & 1 & 1 & 1 & 2 \\
\hline 5 & 342 & 10 & 14 & 5 & 2 & 1 & 2 & 2 & 2 & 2 & 1 & 2 & 2 & 2 & 0 & 2 \\
\hline 8 & 350 & 10 & 36 & 9 & 3 & 3 & 5 & 5 & 2 & 3 & 4 & 5 & 5 & 3 & 4 & 2 \\
\hline 11 & 290 & 10 & 69 & 19 & 6 & 7 & 10 & 11 & 4 & 7 & 9 & 10 & 9 & 4 & 7 & 5 \\
\hline 14 & 384 & 10 & 77 & 29 & 9 & 9 & 13 & 13 & 6 & 9 & 11 & 13 & 11 & 6 & 9 & 6 \\
\hline 16 & 335 & 10 & 82 & 32 & 11 & 10 & 15 & 16 & 7 & 11 & 12 & 14 & 13 & 7 & 11 & 7 \\
\hline 19 & 295 & 10 & 85 & 35 & 12 & 11 & 16 & 17 & 9 & 12 & 13 & 14 & 13 & 8 & 9 & 8 \\
\hline 22 & 367 & 10 & 81 & 33 & 12 & 12 & 16 & 17 & 9 & 12 & 13 & 15 & 14 & 9 & 11 & 8 \\
\hline 25 & 323 & 10 & 83 & 35 & 13 & 13 & 17 & 18 & 10 & 13 & 14 & 16 & 15 & 10 & 12 & 8 \\
\hline 28 & 389 & 10 & 81 & 34 & 14 & 13 & 17 & 17 & 11 & 13 & 14 & 16 & 15 & 10 & 11 & 8 \\
\hline 31 & 339 & 10 & 82 & 33 & 14 & 13 & 17 & 18 & 10 & 14 & 15 & 17 & 16 & 10 & 12 & 8 \\
\hline 34 & 287 & 10 & 86 & 36 & 15 & 14 & 18 & 19 & 11 & 14 & 15 & 17 & 16 & 11 & 11 & 9 \\
\hline 38 & 358 & 10 & 81 & 34 & 14 & 13 & 17 & 18 & 11 & 14 & 15 & 17 & 16 & 11 & 12 & 9 \\
\hline 41 & 305 & 10 & 84 & 35 & 15 & 14 & 18 & 19 & 12 & 15 & 16 & 17 & 16 & 11 & 12 & 9 \\
\hline 44 & 380 & 10 & 81 & 34 & 15 & 13 & 18 & 18 & 12 & 14 & 15 & 17 & 16 & 11 & 11 & 9 \\
\hline 47 & 247 & 10 & 87 & 35 & 16 & 15 & 20 & 21 & 12 & 16 & 17 & 18 & 17 & 11 & 15 & 9 \\
\hline 50 & 245 & 10 & 89 & 36 & 17 & 16 & 20 & 21 & 13 & 16 & 17 & 18 & 17 & 12 & 13 & 10 \\
\hline 53 & 300 & 10 & 85 & 34 & 16 & 15 & 19 & 20 & 13 & 16 & 17 & 18 & 17 & 12 & 13 & 10 \\
\hline 56 & 238 & 10 & 88 & 36 & 17 & 16 & 20 & 22 & 13 & 17 & 18 & 19 & 18 & 13 & 16 & 11 \\
\hline 58 & 209 & 10 & 90 & 37 & 18 & 17 & 21 & 23 & 14 & 17 & 18 & 19 & 18 & 13 & 16 & 10 \\
\hline 61 & 270 & 10 & 85 & 35 & 18 & 16 & 20 & 22 & 14 & 17 & 18 & 19 & 18 & 13 & 14 & 10 \\
\hline 64 & 237 & 10 & 87 & 35 & 18 & 17 & 21 & 22 & 14 & 17 & 18 & 19 & 19 & 13 & 16 & 11 \\
\hline 67 & 210 & 10 & 90 & 37 & 19 & 18 & 21 & 23 & 14 & 18 & 19 & 20 & 19 & 13 & 15 & 11 \\
\hline 70 & 263 & 10 & 85 & 35 & 18 & 17 & 21 & 22 & 14 & 17 & 18 & 19 & 19 & 13 & 15 & 10 \\
\hline 74 & 229 & 10 & 88 & 37 & 19 & 17 & 21 & 23 & 14 & 18 & 19 & 20 & 19 & 14 & 16 & 10 \\
\hline 77 & 216 & 10 & 88 & 37 & 19 & 18 & 22 & 23 & 15 & 18 & 19 & 20 & 19 & 14 & 14 & 11 \\
\hline 80 & 252 & 10 & 86 & 35 & 18 & 17 & 21 & 22 & 14 & 18 & 19 & 20 & 19 & 14 & 16 & 10 \\
\hline 83 & 143 & 10 & 92 & 39 & 21 & 19 & 23 & 25 & 15 & 20 & 21 & 21 & 21 & 14 & 22 & 13 \\
\hline 87 & 153 & 10 & 92 & 39 & 21 & 20 & 23 & 25 & 16 & 20 & 20 & 21 & 20 & 15 & 19 & 12 \\
\hline 90 & 163 & 10 & 89 & 39 & 21 & 20 & 23 & 25 & 16 & 20 & 21 & 21 & 20 & 14 & 19 & 13 \\
\hline 93 & 150 & 10 & 89 & 39 & 21 & 20 & 23 & 25 & 16 & 20 & 21 & 21 & 21 & 15 & 21 & 13 \\
\hline 96 & 142 & 10 & 90 & 39 & 22 & 20 & 24 & 26 & 16 & 21 & 21 & 21 & 21 & 15 & 18 & 14 \\
\hline 99 & 168 & 10 & 88 & 38 & 21 & 20 & 23 & 25 & 17 & 20 & 21 & 22 & 21 & 15 & 20 & 13 \\
\hline 103 & 150 & 10 & 89 & 39 & 22 & 20 & 24 & 26 & 17 & 21 & 22 & 22 & 21 & 15 & 21 & 14 \\
\hline 107 & 139 & 10 & 90 & 39 & 23 & 21 & 24 & 26 & 17 & 21 & 22 & 22 & 21 & 15 & 18 & 14 \\
\hline 111 & 161 & 10 & 89 & 38 & 22 & 20 & 24 & 26 & 17 & 21 & 21 & 22 & 21 & 15 & 20 & 14 \\
\hline 114 & 151 & 10 & 89 & 38 & 22 & 21 & 24 & 26 & 17 & 21 & 22 & 22 & 22 & 15 & 21 & 13 \\
\hline
\end{tabular}


Table F.6 Continued

\begin{tabular}{|c|c|c|c|c|c|c|c|c|c|c|c|c|c|c|c|c|}
\hline $\begin{array}{l}\text { Time } \\
{[\mathrm{min}]}\end{array}$ & $\begin{array}{c}\text { Cooling } \\
\text { flow } \\
\text { rate } \\
{[\mathrm{L} / \mathrm{min}]}\end{array}$ & $\begin{array}{l}\text { Rotor } \\
\text { Speed } \\
{[\mathrm{krpm}]}\end{array}$ & $\begin{array}{c}\operatorname{Tr}_{F E} \\
- \\
T_{a m b}\end{array}$ & $\begin{array}{c}T r_{D E} \\
- \\
T_{a m b}\end{array}$ & $\begin{array}{c}T_{1} \\
- \\
T_{a m b}\end{array}$ & $\begin{array}{c}T_{2} \\
- \\
T_{a m b}\end{array}$ & $\begin{array}{c}T_{3} \\
- \\
T_{a m b}\end{array}$ & $\begin{array}{c}T_{4} \\
- \\
T_{a m b}\end{array}$ & $\begin{array}{c}T_{5} \\
- \\
T_{a m b}\end{array}$ & $\begin{array}{c}T_{6} \\
- \\
T_{a m b}\end{array}$ & $\begin{array}{c}T_{7} \\
- \\
T_{a m b}\end{array}$ & $\begin{array}{c}T_{8} \\
- \\
T_{a m b}\end{array}$ & $\begin{array}{c}T_{9} \\
- \\
T_{a m b}\end{array}$ & $\begin{array}{c}T_{10} \\
- \\
T_{a m b}\end{array}$ & $\begin{array}{c}T_{\mathrm{e}} \\
- \\
T_{a m b}\end{array}$ & $\begin{array}{c}T_{\text {out }} \\
- \\
T_{a m b}\end{array}$ \\
\hline 117 & 68 & 10 & 88 & 38 & 24 & 23 & 27 & 28 & 17 & 22 & 24 & 23 & 23 & 16 & 24 & 11 \\
\hline 120 & 91 & 10 & 92 & 39 & 25 & 24 & 27 & 29 & 18 & 23 & 24 & 24 & 24 & 16 & 27 & 14 \\
\hline 123 & 83 & 10 & 94 & 40 & 26 & 24 & 28 & 29 & 19 & 24 & 25 & 25 & 24 & 17 & 28 & 13 \\
\hline 127 & 67 & 10 & 87 & 37 & 26 & 25 & 29 & 30 & 19 & 24 & 25 & 25 & 24 & 17 & 27 & 13 \\
\hline 130 & 87 & 10 & 87 & 37 & 26 & 25 & 28 & 29 & 19 & 24 & 25 & 25 & 24 & 17 & 25 & 15 \\
\hline 133 & 85 & 10 & 92 & 39 & 27 & 25 & 29 & 30 & 20 & 25 & 26 & 26 & 25 & 18 & 28 & 14 \\
\hline 136 & 80 & 10 & 92 & 40 & 27 & 26 & 29 & 31 & 20 & 25 & 26 & 26 & 25 & 18 & 29 & 15 \\
\hline
\end{tabular}




\section{APPENDIX G}

\section{RECORDED COOLING FLOW RATE VERSUS SUPPLY AIR PRESSURE: TEST CASES \#1-\#6}

Figure G.1 depicts the air cooling flow rate versus the supply air pressure. Recall Fig. 11 for a layout of the flow path of the forced cooling air and measurement locations (i.e., mass flow meter and pressure gauge 2 in Fig. 11). The uncertainties of the flowmeter and pressure gauge are $\pm 7.5 \mathrm{~L} / \mathrm{min}$ and $\pm 1 \mathrm{psig}$, respectively. Cooling flow rates increase linearly with supplied pressure. The cooling flow rate and pressure do not change with increasing rotor speeds and heater set temperatures. 


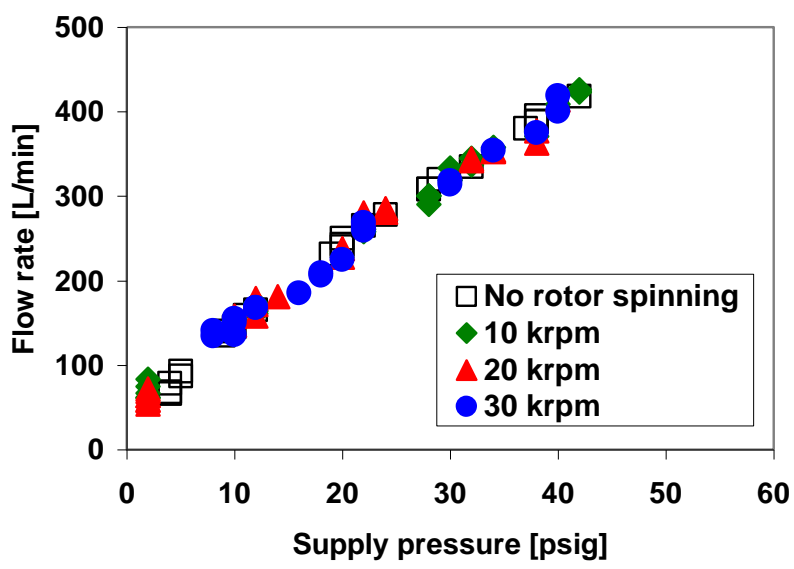

(a) Test cases 1 and 1: $T_{h s}=65^{\circ} \mathrm{C}$

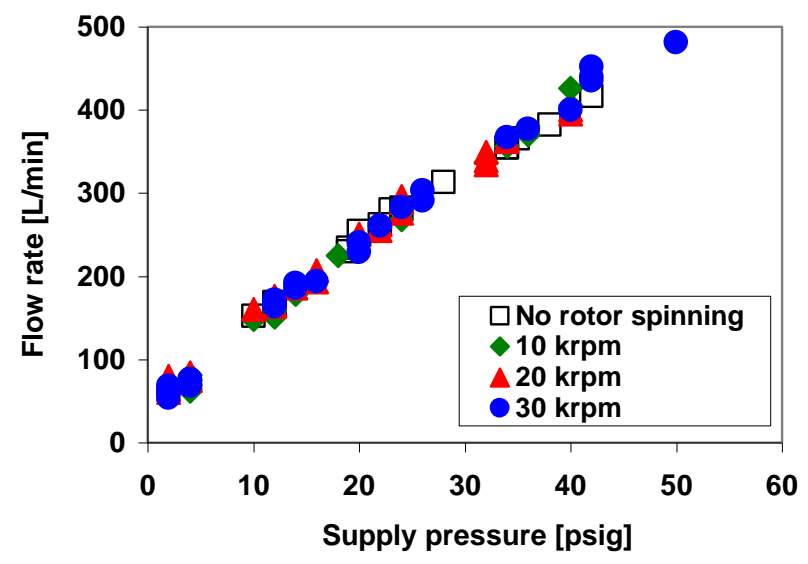

(b) Test cases 2 and 5: $T_{h s}=100^{\circ} \mathrm{C}$

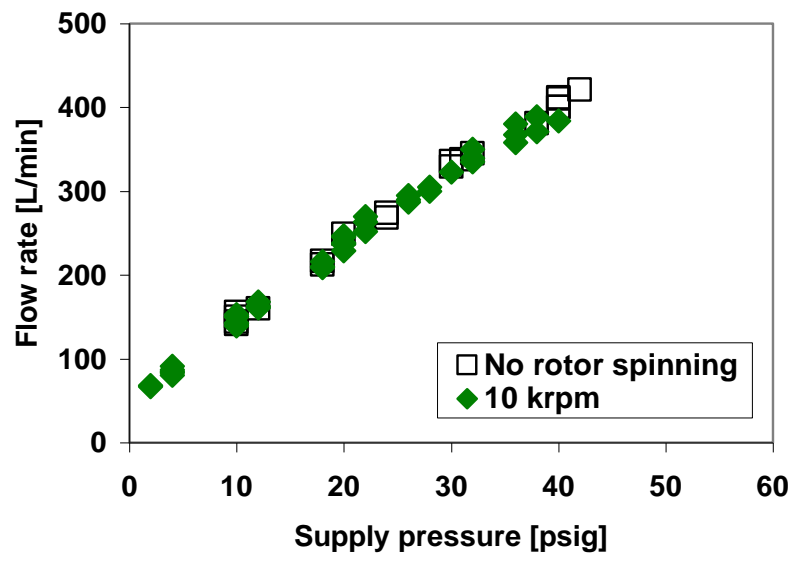

(c) Test cases 3 and 6: $T_{h s}=150^{\circ} \mathrm{C}$

Fig. G.1 Test cases \#1-\#6: recorded cooling flow rate versus supply air pressure. 


\section{APPENDIX H}

\section{TEMPERATURE RISE OF BEARING SLEEVE VERSUS TEMPERATURE RISE OF} AIR INSIDE HOUSING ENCLOSURE: TEST CASES \#1AND \#4, \#3 AND \#6

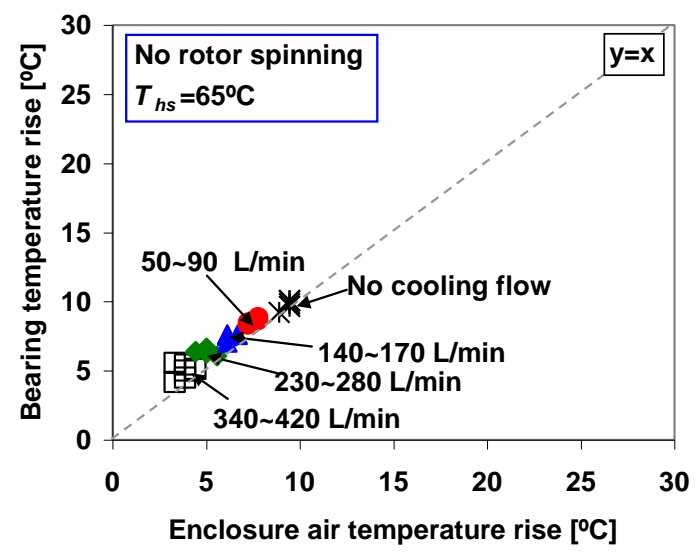

(a) No rotor spinning

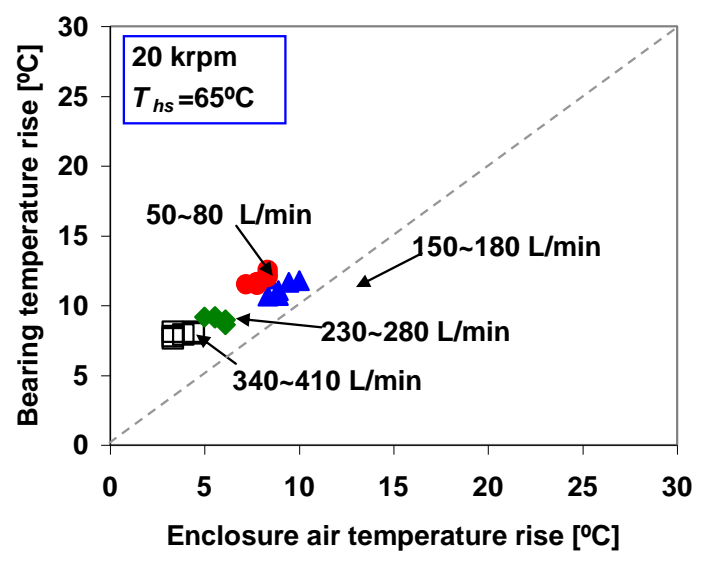

(a) $20 \mathrm{krpm}$

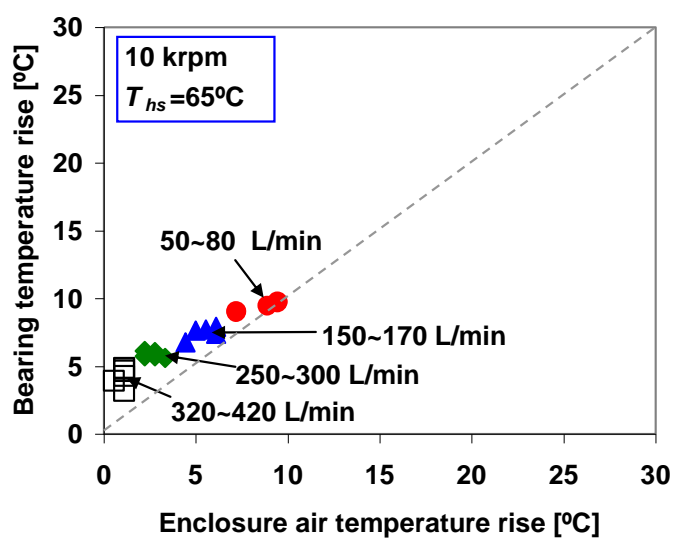

(a) $10 \mathrm{krpm}$

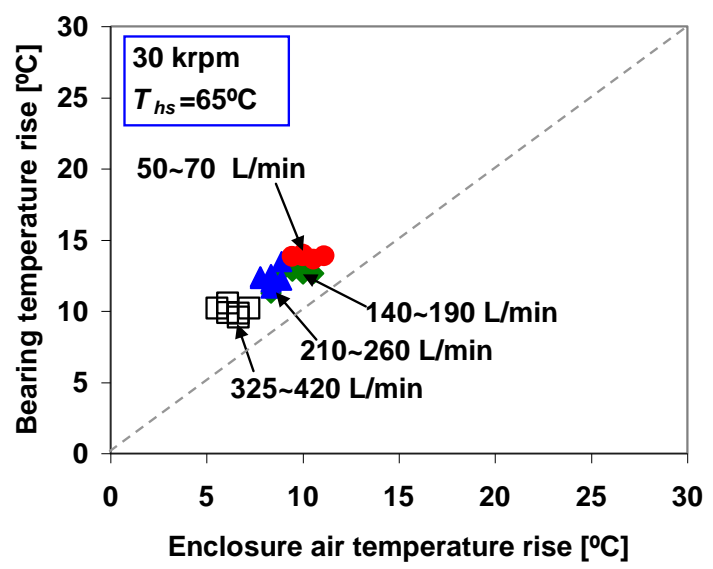

(c) $30 \mathrm{krpm}$

Fig. H.1 Test cases \#1 and \#4. $T_{h s}=65^{\circ} \mathrm{C}$ : Free end bearing temperature rise $\left(T_{1-4}-T_{a m b}\right)$ versus air temperature rise in the feed enclosure $\left(T_{e}-T_{a m b}\right)$. Arithmetic mean of $\left(T_{1}, T_{2}, T_{3}\right.$, and $T_{4}$ ) shown. 


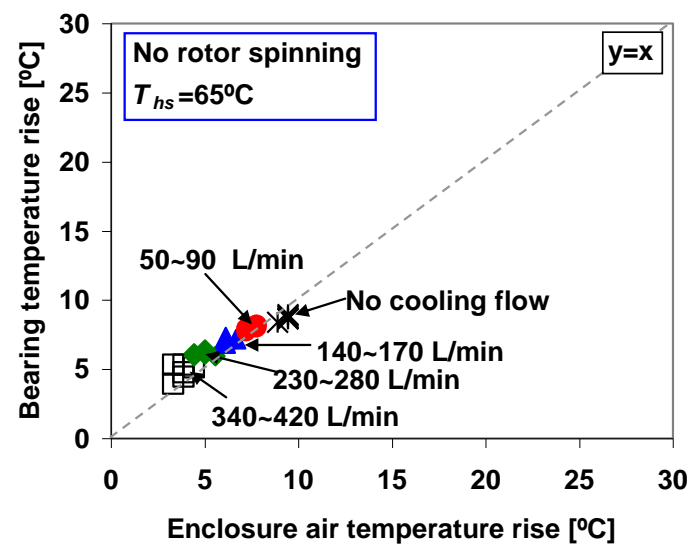

(a) No rotor spinning

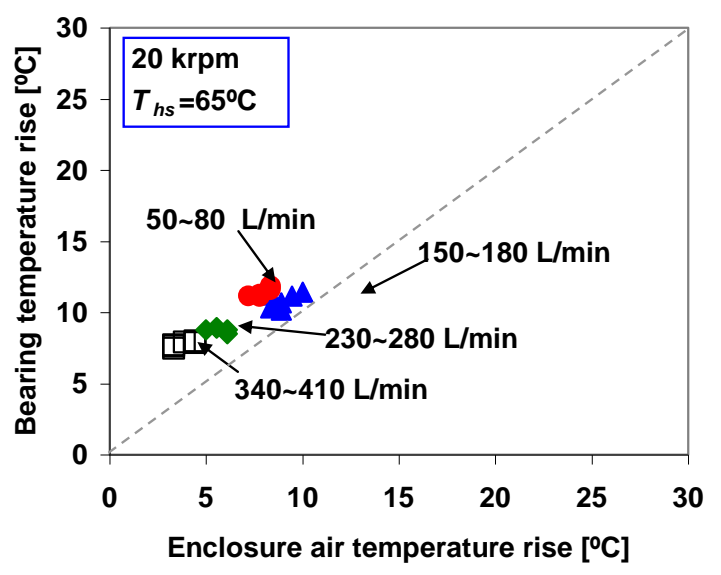

(c) $20 \mathrm{krpm}$

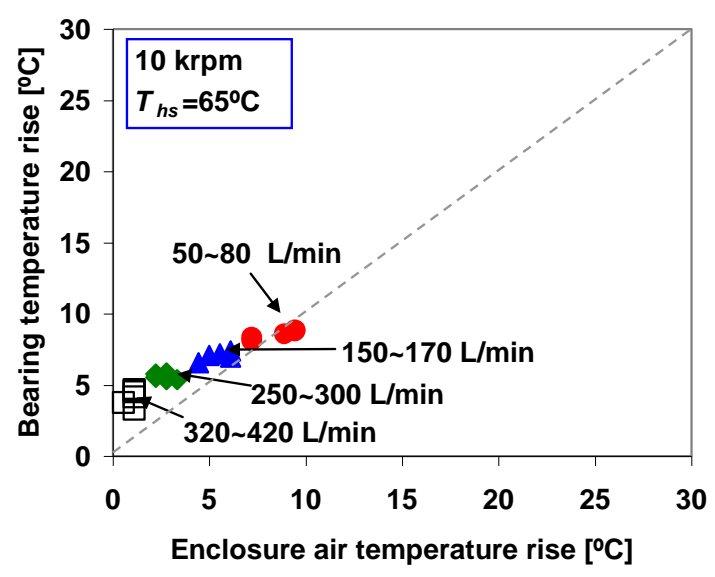

(b) $10 \mathrm{krpm}$

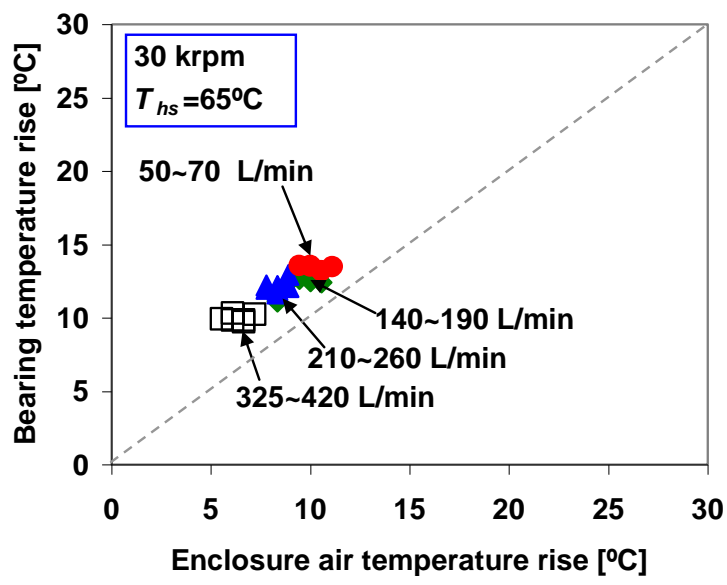

(d) $30 \mathrm{krpm}$

Fig. H.2 Test cases \#1 and \#4. $T_{h s}=65 \circ C$ : Drive end bearing temperature rise $\left(T_{6-9}-T_{a m b}\right)$ versus air temperature rise in the feed enclosure $\left(T_{e}-T_{a m b}\right)$. Arithmetic mean of $\left(T_{6}, T_{7}, T_{8}\right.$, and $T_{9}$ ) shown. 


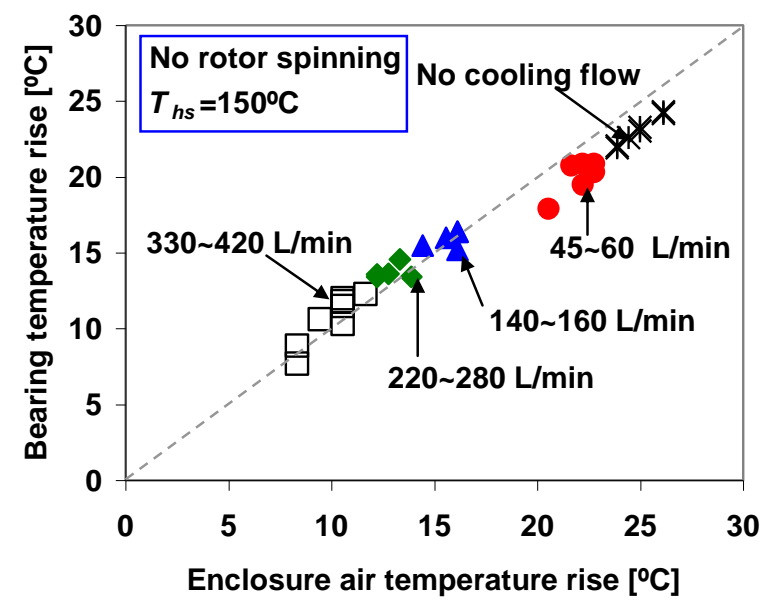

(a) No rotor spinning

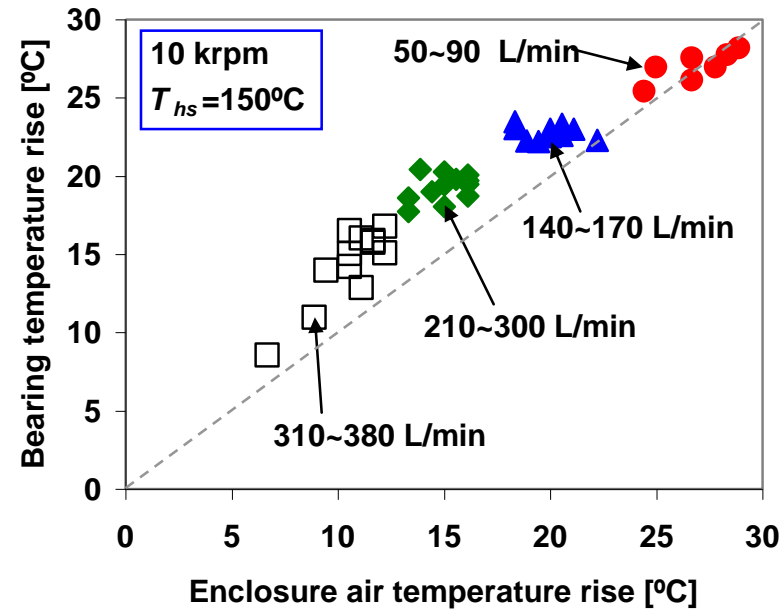

(a) $10 \mathrm{krpm}$

Fig. H.3 Test cases \#3 and \#6. $T_{h s}=150^{\circ} \mathrm{C}$ : Free end bearing temperature rise $\left(T_{1-4^{-}} T_{a m b}\right)$ versus air temperature rise in the feed enclosure $\left(T_{e}-T_{a m b}\right)$. Arithmetic mean of $\left(T_{1}, T_{2}, T_{3}\right.$, and $T_{4}$ ) shown.

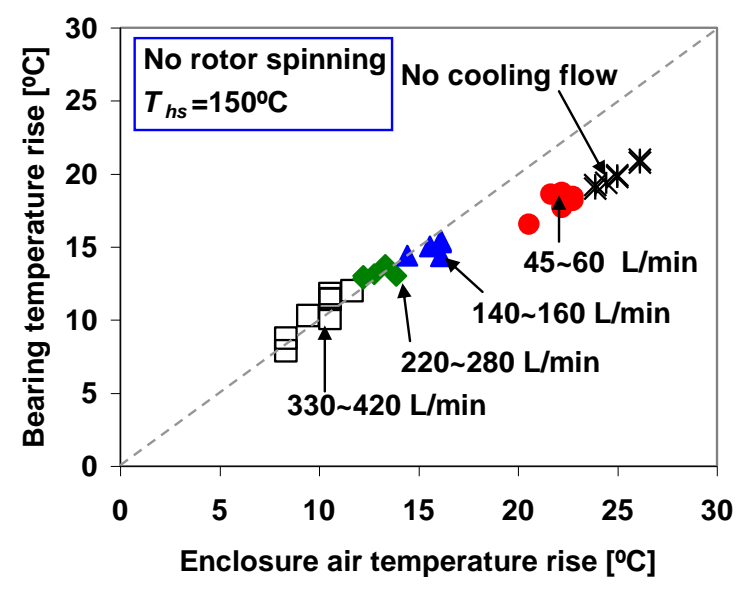

(a) No rotor spinning

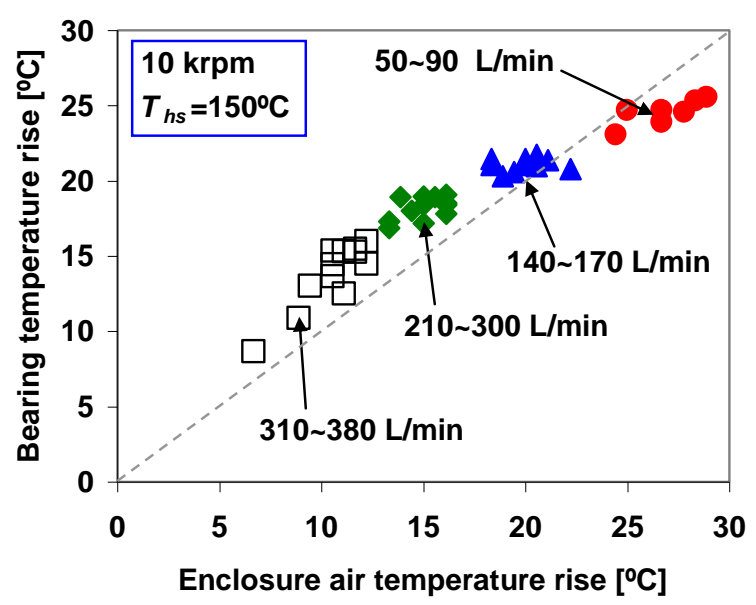

(a) $10 \mathrm{krpm}$

Fig. H.4 Test cases \#3 and \#6. $T_{h s}=150^{\circ} \mathrm{C}$ : Drive end bearing temperature rise $\left(T_{6-9}-T_{a m b}\right)$ versus air temperature rise in the feed enclosure $\left(T_{e}-T_{a m b}\right)$. Arithmetic mean of $\left(T_{6}, T_{7}, T_{8}\right.$, and $T_{9}$ ) shown. 


\section{APPENDIX I}

\section{PREDICTION OF AXIAL AND CIRCUMFERENTIAL FLOW CONDITIONS FOR THE INNER AND OUTER COOLING STREAMS}

Upon entering a foil bearing, the cooling gas stream splits into two streams; one flowing axially through the thin film gas region (inner stream) and the other flowing through the region underneath the top foil and the ID of the bearing sleeve (outer stream). The outer stream removes heat from the back surface of the top foil. Along the bearing axial length, the outer stream temperature increases as it removes heat, while its pressure decreases to ambient condition. This outer flow is eminently axial; hence, it is not disturbed by the rotating shaft. An outer stream with large flow rate takes away effectively most of the heat from the back of the top foil, with little heat conduction into the bearing cartridge [46]. Within the thin gas film, mechanical energy from viscous shear drag and heat convected from the shaft are removed and convected into the top foil. Note that the gas film thickness is very small compared to the rotor OD and bearing axial length. In this region, the hydrodynamic gas film pressure is generated while its temperature varies.

The rotor and bearing thermal expansion and centrifugal growth due to rotor spinning determine the actual bearing clearance $c_{+}$. Note that thermal expansion of the shaft and the bearing leads to a significant reduction in the operating clearance (see Appendix M). Presently, the rotor centrifugal growth, a function of rotor speed and material properties, is less than $1 \mu \mathrm{m}$ at the top rotor speed of $30 \mathrm{krpm}$. 
For concentric rotor operation, Fig. I.1 depicts a schematic view of a gas foil bearing with axially fed flow as in the current test rig. Forced cooling air flows through the mid-section of the bearing support housing, and then enters the test bearings. The flow is confined to the annular regions between the rotor OD and top foil ID, and between the top foil OD and bearing sleeve ID. For simplicity, the radial gaps for the outer and inner cooling flow streams equal the bump height $h_{B}$ and uniform bearing clearance $c_{+}$along the bearing axial length, respectively. Note that the outer gas flow through the outer gap region behind the top foil is only axial, not greatly restricted by the bump foils.

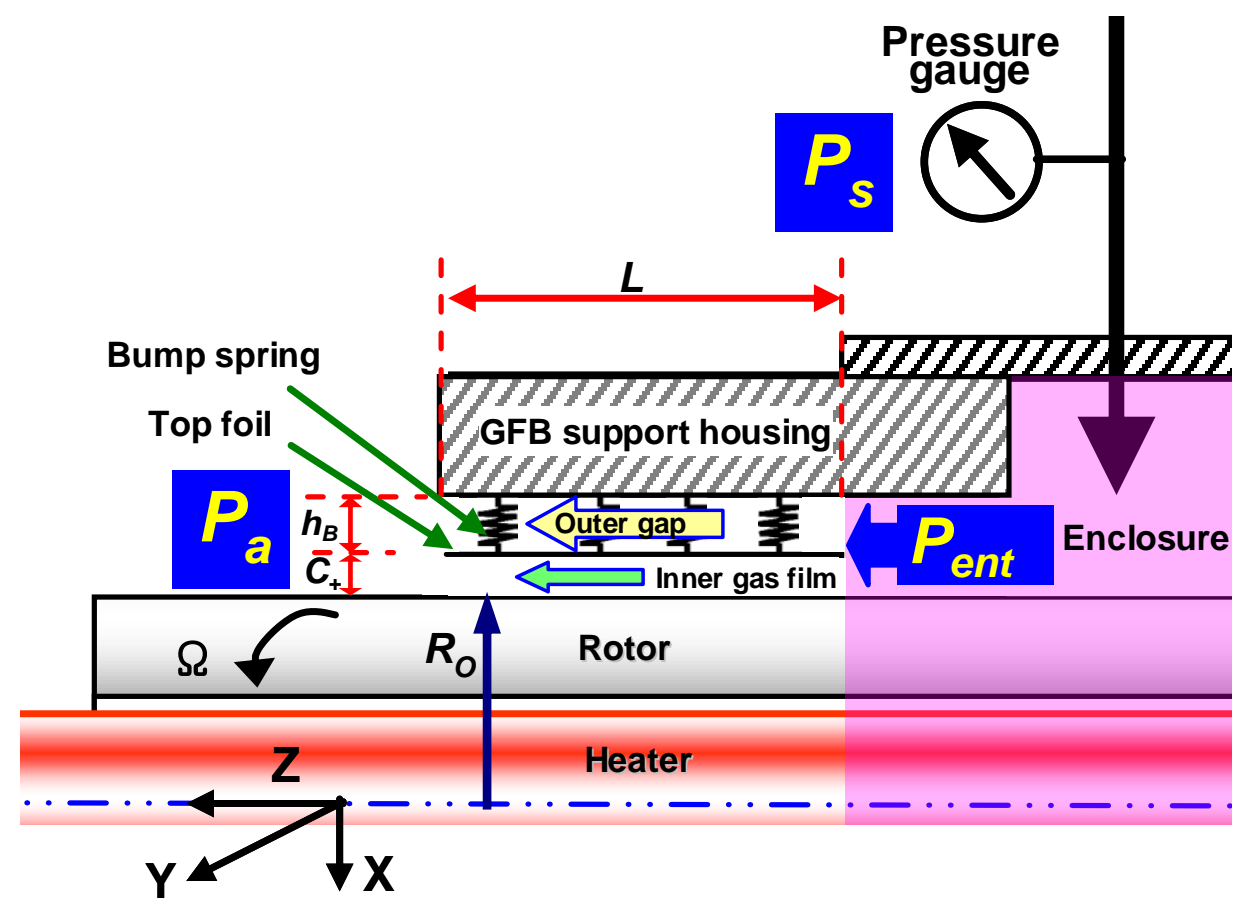

Fig. I.1 Schematic view (not to scale) of axial flows induced by forced cooling flow in the test foil bearing system. 
The present analysis regards the fluid as an ideal gas and neglects energy transport considerations for simplicity ${ }^{32}$. At the bearing exist plane $(z=L)$, the air pressure equals ambient pressure $P_{a}$ and no pressure recovery effect is assumed. The density of a perfect gas is $\rho={\frac{P}{Z_{c} R_{c} T}}^{33}$, while air viscosity is $\mu=\frac{1.458 \times 10^{-6} T^{\frac{3}{2}}}{110.4+T}$ [53].

For test case \#6 (the highest operating temperature condition $T_{h s}=150^{\circ} \mathrm{C}$ ), air viscosity increases by $8 \%$ relative to its ambient condition value.

The continuity and momentum equations for the bulk flows in the outer gap is

$$
\begin{gathered}
\frac{\partial\left(\rho \cdot h_{B} \cdot W_{\text {outer }}\right)}{\partial z}+\frac{\partial\left(\rho \cdot h_{B}\right)}{\partial t}=0 \\
-h_{B} \frac{\partial P}{\partial z}=-\left.\tau_{z y}\right|_{0} ^{h_{B}}+\frac{\partial\left(\rho \cdot h_{B} \cdot W_{\text {outer }}\right)}{\partial t}+\frac{\partial\left(\rho \cdot h_{B} \cdot W_{\text {outer }}^{2}\right)}{\partial z}
\end{gathered}
$$

, while for the inner gap

$$
\begin{gathered}
\frac{\partial\left(\rho \cdot c_{+} \cdot U\right)}{\partial x}+\frac{\partial\left(\rho \cdot c_{+} \cdot W_{\text {inner }}\right)}{\partial z}+\frac{\partial\left(\rho \cdot c_{+}\right)}{\partial t}=0 \\
-c_{+} \frac{\partial P}{\partial x}=-\tau_{x y}||_{0}^{c_{+}}+\frac{\partial\left(\rho \cdot c_{+} \cdot U\right)}{\partial t}+\frac{\partial\left(\rho \cdot c_{+} \cdot U^{2}\right)}{\partial x}+\frac{\partial\left(\rho \cdot c_{+} \cdot U \cdot W_{\text {inner }}\right)}{\partial z} \\
-c_{+} \frac{\partial P}{\partial z}=-\tau_{z y} \mid c_{0}^{c_{+}}+\frac{\partial\left(\rho \cdot c_{+} \cdot W_{\text {inner }}\right)}{\partial t}+\frac{\partial\left(\rho \cdot c_{+} \cdot U \cdot W_{\text {inner }}\right)}{\partial x}+\frac{\partial\left(\rho \cdot c_{+} \cdot W_{\text {inner }}{ }^{2}\right)}{\partial z}
\end{gathered}
$$

Above $U$ is the circumferential bulk-flow velocity in the inner gap, and $W_{\text {outer }}$ and $W_{\text {inner }}$ are the axial bulk-flow velocities in the outer and inner gaps, respectively; $x$ is the

\footnotetext{
${ }^{32}$ In practice, the rotor surface temperature is much higher than the temperatures of the top foil and the bearing housing, see Figs. 17-19 and Appendix E.

${ }^{33} Z_{c}(=1)$ is the compressibility factor, $R_{c}(=287 \mathrm{~J} / \mathrm{kg}-\mathrm{K})$ is the ideal gas constant, and $T$ is temperature in degrees Kelvin.
} 
circumferential coordinate along the bearing circumferential length, and $z$ is the axial coordinate system spanning the bearing length.

For steady-state operating conditions $(\partial / \partial t=0)$ and assuming $\partial U / \partial x=0$, substitution of the wall shear stress differences, $\left.\tau_{y z}\right|_{0} ^{h_{B}}=-\frac{\mu\left(k_{z_{\text {outer }}} \cdot W_{\text {outer }}\right)}{h_{B}}$ and $\tau_{y z}\left|c_{+}\right|_{+}=-\frac{\mu\left(k_{z_{\text {inner }}} \cdot W_{\text {inner }}\right)}{c_{+}}$into Eqs. (I.1) and (I.2), and neglecting fluid inertia effects obtain

$$
\begin{aligned}
& -h_{B} \frac{d P}{d z}=\frac{\mu\left(k_{z_{\text {outer }}} \cdot W_{\text {outer }}\right)}{h_{B}} \text { for the outer stream } \\
& -c_{+} \frac{d P}{d z}=\frac{\mu\left(k_{z_{\text {inner }}} \cdot W_{\text {inner }}\right)}{c_{+}} \text {for the inner stream }
\end{aligned}
$$

where $k_{z_{\text {outer }}}$ and $k_{z_{\text {inner }}}$ are shear flow parameters depending on the flow Reynolds number and friction factors based on Hirs' formula [54]. Presently, $k_{z_{i}}=12$ if Reynolds number $\leq 1000$, otherwise $k_{z_{i}}=f_{z_{i}} \operatorname{Re}_{a_{i}}$ [55]. For a turbulent flow condition, the friction factor is calculated using Hir's formulation [54],

$$
f_{z_{i}}=n \cdot \operatorname{Re}_{a_{i}}{ }^{m} ; i=\text { inner or outer }
$$

where $n=0.066$ and $m=-0.25$ for smooth surfaces ${ }^{34}$. Note that, for smooth surfaces, Hirs' and Moody's friction factors are nearly identical for most Reynolds numbers [59]. The

\footnotetext{
${ }^{34}$ For smooth surfaces, Yamada [56], Childs and Kim [57], and Ha and Childs [58] report the values to be $(n=0.079, m=-0.25),(n=0.0674, m=-0.217)$, and $(n=0.0586, m=-0.217)$, respectively.
} 
axial flow Reynolds numbers are defined as $\operatorname{Re}_{a_{\text {outer }}}=\dot{m}_{\text {outer }} /\left[\mu \cdot \pi \cdot 2\left(R_{O}+c_{+}\right)\right]$for the outer stream and $\operatorname{Re}_{a_{\text {inner }}}=\dot{m}_{\text {inner }} /\left(\mu \cdot \pi \cdot 2 R_{O}\right)$ for the inner stream.

$$
\begin{aligned}
& \text { Since } W_{\text {outer }}=\dot{M}_{\text {outer }} /\left(\rho h_{B}\right) \text { and } W_{\text {inner }}=\dot{M}_{\text {inner }} /\left(\rho c_{+}\right), \text {Eqs (I.3) and (I.4) become } \\
& \qquad \begin{aligned}
\frac{d}{d z}\left(\frac{\rho \cdot h_{B}{ }^{3}}{k_{z_{\text {outer }}} \cdot \mu} \frac{d P}{d z}\right)=\frac{d}{d z}\left(-\dot{M}_{\text {outer }}\right)=0 \text { for the outer stream } \\
\frac{d}{d z}\left(\frac{\rho \cdot c_{+}{ }^{3}}{k_{z_{\text {inner }}} \cdot \mu} \frac{d P}{d z}\right)=\frac{d}{d z}\left(-\dot{M}_{\text {inner }}\right)=0 \text { for the inner stream }
\end{aligned}
\end{aligned}
$$

Above, $\dot{M}_{\text {outer }}$ is the mass flow rate per circumferential length through the outer gap, and $\dot{M}_{\text {inner }}$ is the mass flow rate per circumferential length through the bearing clearance (i.e., inner gas film). Integrating equations (I.6) and (I.7) across the bearing axial length $(L)$, and using the ideal gas law leads to

$$
\begin{aligned}
& \dot{M}_{\text {outer }}=\frac{h_{B}{ }^{3}}{2 k_{z_{\text {outer }}} \mu R_{c} T L}\left(P_{\text {ent }}{ }^{2}-P_{a}^{2}\right) \text { for the outer stream } \\
& \dot{M}_{\text {inner }}=\frac{c_{+}{ }^{3}}{2 k_{z_{\text {inner }}} \mu R_{c} T L}\left(P_{\text {ent }}{ }^{2}-P_{a}^{2}\right) \text { for the inner stream }
\end{aligned}
$$

Then, the axial mass flow rates over the bearing circumference are

$$
\begin{gathered}
\dot{m}_{\text {outer }}=\dot{M}_{\text {outer }} \cdot \pi \cdot\left[2\left(R_{O}+c_{+}\right)\right] \text {for the outer stream } \\
\dot{m}_{\text {inner }}=\dot{M}_{\text {inner }} \cdot \pi \cdot 2 R_{O} \text { for the inner stream }
\end{gathered}
$$

Therefore, the overall cooling flow rate $\left(\dot{m}_{\text {overall }}=\dot{m}_{\text {outer }}+\dot{m}_{\text {inner }}\right)$ into a bearing equals 


$$
\dot{m}_{\text {overall }}=\frac{\left(P_{\text {ent }}{ }^{2}-P_{a}^{2}\right) \cdot \pi}{\mu \cdot R_{c} \cdot T \cdot L} \cdot\left(\frac{h_{B}^{3} \cdot\left(R_{O}+c_{+}\right)}{k_{z_{\text {outer }}}}+\frac{c_{+}{ }^{3} \cdot R_{O}}{k_{z_{\text {inner }}}}\right)
$$

From Eq. (I.12), the entrance pressure $P_{\text {ent }}$ is

$$
P_{\text {ent }}^{2}=\frac{\dot{m}_{\text {overall }} \cdot \mu \cdot R_{c} \cdot T \cdot L}{\left[\frac{h_{B}^{3} \cdot\left(R_{O}+c_{+}\right)}{k_{z_{\text {outer }}}}+\frac{c_{+}^{3} \cdot R_{O}}{k_{z_{\text {inner }}}}\right] \cdot \pi}+P_{a}^{2}
$$

Combination of equations (I.5) and (I.13) allows estimation of the entrance pressure $P_{\text {ent }}$. Since $\operatorname{Re}_{a_{\text {outer }}}=\frac{\dot{m}_{\text {outer }}}{\mu \cdot \pi \cdot 2\left(R_{O}+c_{+}\right)}=\frac{\dot{m}_{\text {overall }}-\dot{m}_{\text {inner }}}{\mu \cdot \pi \cdot 2\left(R_{O}+c_{+}\right)}$, the procedure to solve Eq. (I.13) is iterative. Recall the overall cooling flow rate $\left(\dot{m}_{\text {overall }}=Q \cdot \rho\right)$ is recorded using the flow meter as shown in Fig. 11. Hence, the current calculation uses the recorded flow rate of the cooling stream and measured bearing sleeve temperatures ${ }^{35}$.

The calculated shear factor for the bearing inner thin film region $k_{z_{\text {inner }}}$ is 12 for every test case since the axial flow Reynolds number for the inner stream is below 25 , see Fig. I.6 (a) later.

For test case \#5, Fig. I.2 depicts the shear factor $\left(k_{z_{\text {outer }}}\right)$ for the outer stream versus cooling flow rate. $k_{z_{\text {outer }}}=12$ at cooling flow rate $<115 \mathrm{~L} / \mathrm{min}$ (per bearing) and $k_{z_{\text {outer }}}=12-20$ at cooling flow rates between $115 \mathrm{~L} / \mathrm{min}$ and $250 \mathrm{~L} / \mathrm{min}$ (per bearing). For the outer cooling flow, transition from laminar flow to turbulent flow occurs when the cooling flow rate into the test bearings is larger than $\sim 115 \mathrm{~L} / \mathrm{min}$ (per bearing). The shear factor does not change with rotor speed.

\footnotetext{
${ }^{35}$ For simplicity, the gas film temperature is taken as equal to the recorded bearing sleeve temperatures.
} 


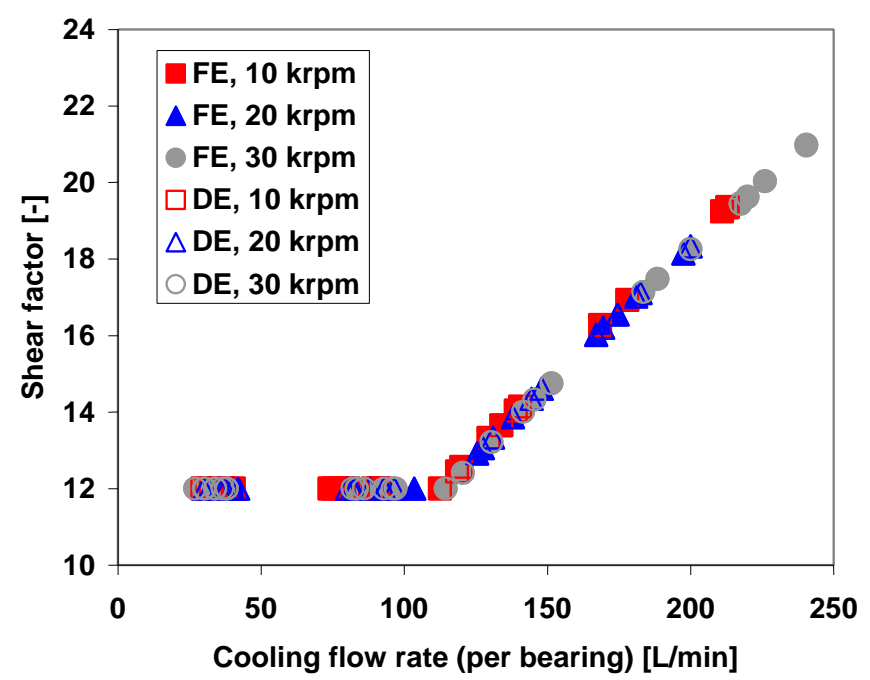

Fig. I.2 Test cases \#5. Heater set temperature $T_{h s}=100^{\circ} \mathrm{C}$. Rotor speed of 10, 20, and 30 krpm: Shear factor of outer gap flow versus cooling flow rate. FE: Free end bearing, DE: Drive end bearing.

Figure I.3 depicts the calculated bearing entrance pressure $P_{\text {ent }}$ versus cooling flow rate. The entrance pressures for the free end and drive end bearings are nearly identical. The entrance pressure steadily increases with cooling flow rate. $P_{\text {ent }}$ for cooling flow rate above $115 \mathrm{~L} / \mathrm{min}$ (per bearing) increases more rapidly than that for cooling flow rate below $115 \mathrm{~L} / \mathrm{min}$. This is because the shear factor at cooling flow rate above $115 \mathrm{~L} / \mathrm{min}$ (per bearing) increases with cooling flow rate from 12 up to 20 . Note that, at the largest cooling flow rate $\sim 250 \mathrm{~L} /$ min (per bearing), $P_{e n t}$ is just $\sim 4 \%$ higher than the ambient pressure $P_{a}$. This implies that the air inside the rig housing enclosure (mid-section) is not stagnant but flows quickly towards the bearing exit plane because of the very little flow resistance through the test FBs. 
$P_{\text {ent }} / P_{s}$, omitted for brevity, ranges $0.9-0.3$ and drops significantly with cooling flow rate. That is, the recorded gauge pressure $P_{s}$ (see Fig. 11, pressure gauge 2) is much higher than the actual pressure $\left(P_{e n t}\right)$ inside the bearing housing enclosure (i.e., upstream bearing region). Note that the gauge pressure is recorded about $1 \mathrm{~m}$ away from the rig housing (long hose line) ${ }^{36}$.

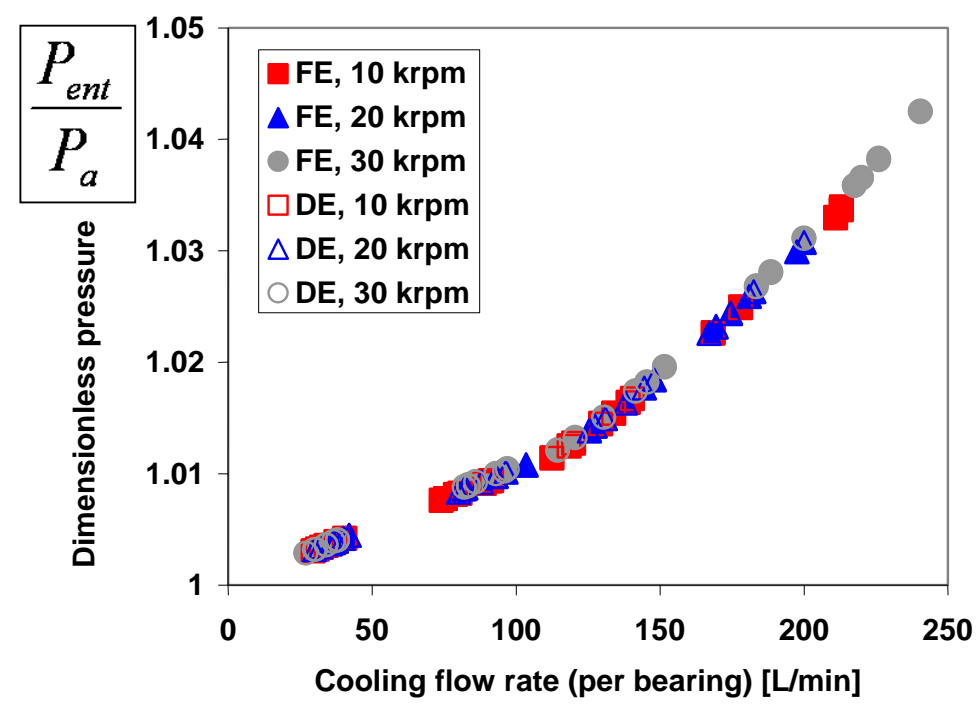

Fig. I.3 Test cases \#5. Heater set temperature $T_{h s}=10^{\circ} \mathrm{C}$. Rotor speed of 10, 20, and 30 krpm: Dimensionless pressure (entrance pressure $P_{\text {ent }}$ over ambient pressure $P_{\mathrm{a}}$ ) versus cooling flow rate. FE: Free end bearing, DE: Drive end bearing.

Through the outer gap underneath the top foil, the axial distribution of the gas pressure from the bearing entrance toward the bearing exit equals:

\footnotetext{
${ }^{36}$ Recent independent tests conducted by another student confirm the assertion. The static pressure in the rig enclosure cannot be distinguished from ambient pressure. Presently, a static pressure gauge located in the enclosure hardly records a change, a few tenths of a bar for a supply pressure of 4 bar.
} 


$$
P_{\text {outer }}(z)=\frac{\sqrt{P_{\text {ent }}{ }^{2}-\frac{2 \cdot k_{z_{\text {outer }}} \cdot \mu \cdot R_{c} \cdot T \cdot L \cdot z \cdot \dot{m}_{\text {outer }}}{h_{B}{ }^{3} \cdot \pi \cdot\left[2\left(R_{O}+c_{+}\right)\right]}}}{P_{a}} \text { for the outer stream }
$$

Figure I.4 depicts the calculated pressure field $\left(P / P_{a}\right)$ between the top foil OD and the bearing sleeve ID. As the cooling flow rate increases, the pressure along the bearing axial length decreases rapidly from the bearing entrance $P_{\text {ent }}$ toward the bearing exit $P_{\text {exi }}=P_{a}$.

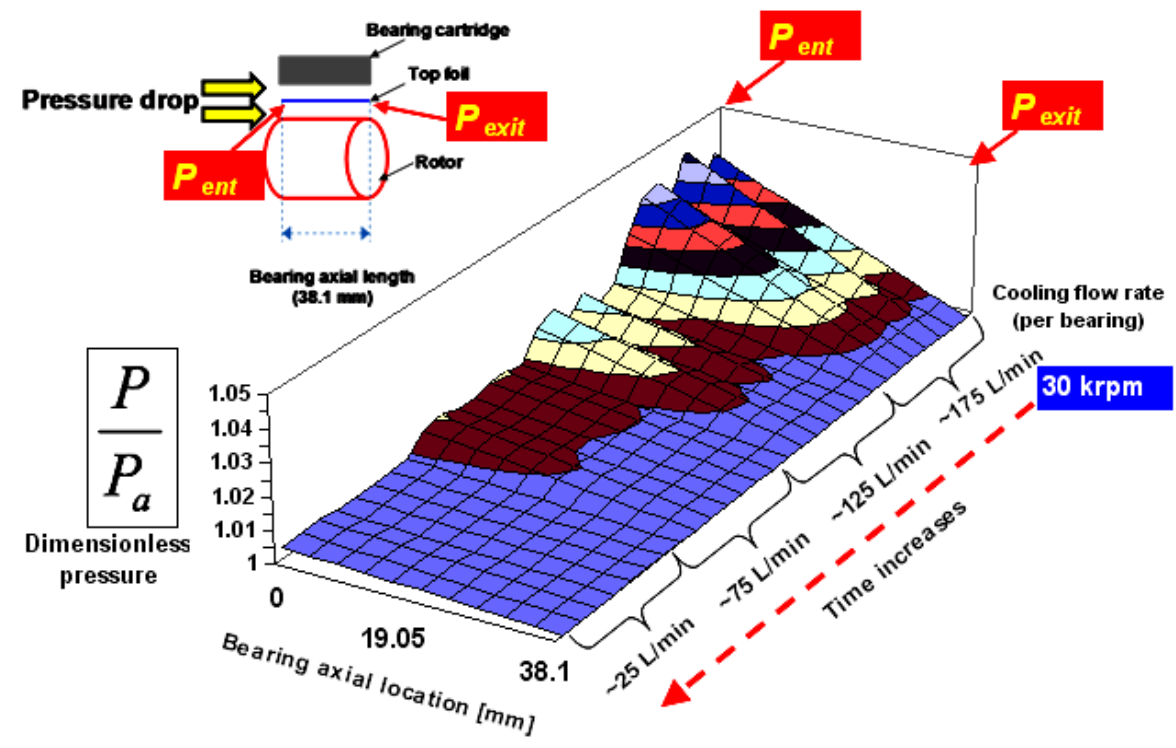

Fig. I.4 Test case \#5. Heater set temperature $T_{h s}=100 \stackrel{\circ}{ }{ }^{\circ}$. Rotor speed of $30 \mathrm{krpm}$. Free end bearing: Dimensionless axial pressure distribution within outer gap versus cooling flow rate. $P_{\text {exit }}=P_{a}$.

Figure I.5 shows the mass flow rate through the outer gap over mass flow rate through inner gap, i.e., $\frac{\dot{m}_{\text {inner }}}{\dot{m}_{\text {outer }}}$. The figure also depicts $\left(\frac{c_{+}}{h_{B}}\right)^{3}$ since $\frac{\dot{m}_{\text {inner }}}{\dot{m}_{\text {outer }}} \propto\left(\frac{c_{+}}{h_{B}}\right)^{3}$, see 
Eqs. (I.8) through (I.11). For cooling flow rates $<115 \mathrm{~L} / \mathrm{min}$ (per bearing), $\frac{\dot{m}_{\text {inner }}}{\dot{m}_{\text {outer }}} \approx\left(\frac{c_{+}}{h_{B}}\right)^{3}$ since $k_{z_{\text {inner }}}=k_{z_{\text {outer }}}=12$ when both flows are laminar. On the other hand, for cooling flow rates above $115 \mathrm{~L} / \mathrm{min}$ (per bearing), $\frac{\dot{m}_{\text {inner }}}{\dot{m}_{\text {outer }}}>\left(\frac{c_{+}}{h_{B}}\right)^{3}$ since the shear $k_{z_{\text {inner }}}=$ $12<k_{z_{\text {outer }}}$ (see Fig. I.2). Note that less than just $10 \%$ of the overall cooling mass flows through the inner thin film region.

Figure I.6 shows the calculated axial flow Reynolds numbers for the outer and inner streams $\left(\operatorname{Re}_{a_{\text {outer }}}\right.$ and $\operatorname{Re}_{a_{\text {inner }}}$ ) versus cooling flow rate. $\operatorname{Re}_{a_{\text {outer }}}$ and $\operatorname{Re}_{a_{\text {imner }}}$ range $200-2,000$ and $1-23$, respectively. The results indicate that laminar flow prevails in the inner film gap. For the outer gap, flow is laminar for cooling flow rates $<115 \mathrm{~L} / \mathrm{min}$. Presently, $\mathrm{Re}_{a_{\text {outer }}}$ increases linearly with cooling flow rate while $\mathrm{Re}_{a_{\text {inmer }}}$ increases nearly exponentially with cooling flow rate. This is because, for the present calculation, the inner and outer gap flows are determined by $c_{+}$(decreasing with rotor speed and increasing with cooling flow rate) and $h_{B}$ (constant regardless of the operating condition), respectively. $\operatorname{Re}_{a_{\text {inner }}}$ for the drive end bearing is slightly higher than that for the free end bearing because the operating clearance $c_{+}$is larger than that of the free end bearing. 


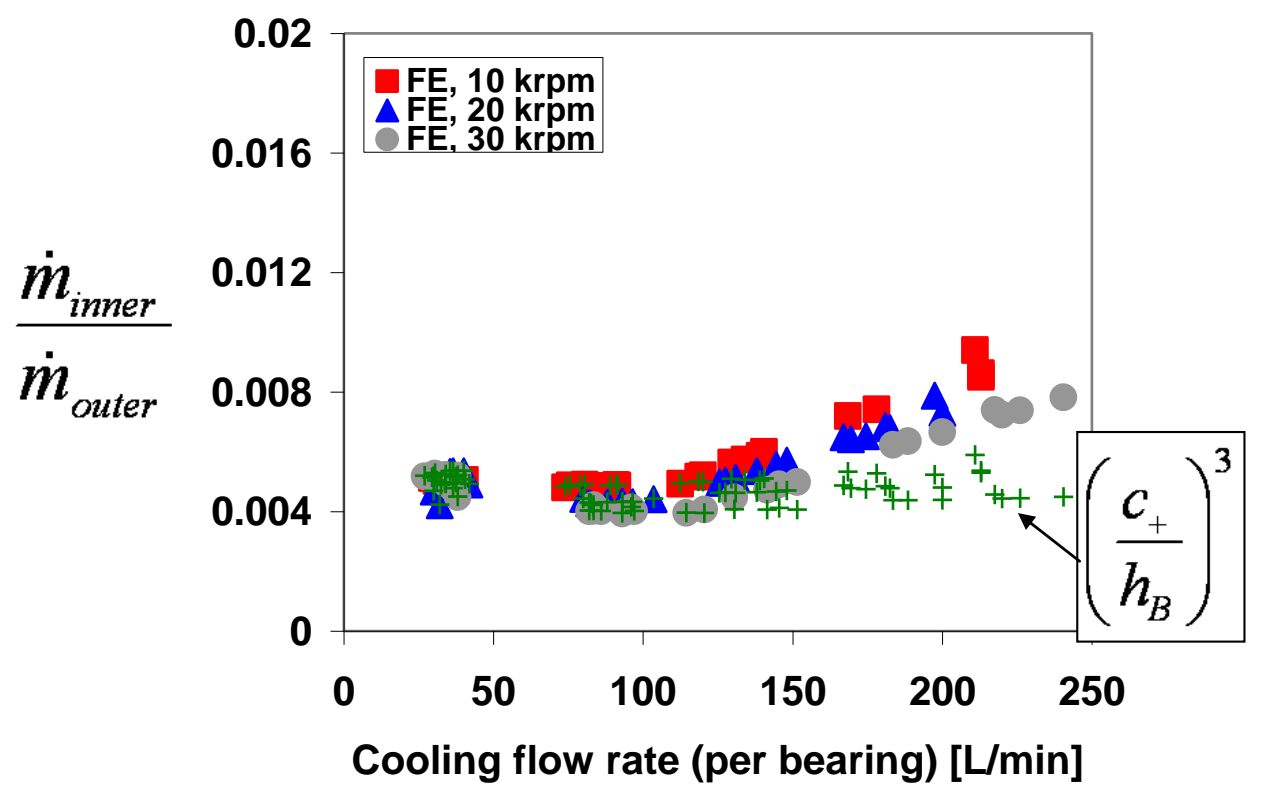

(a) Free end bearing

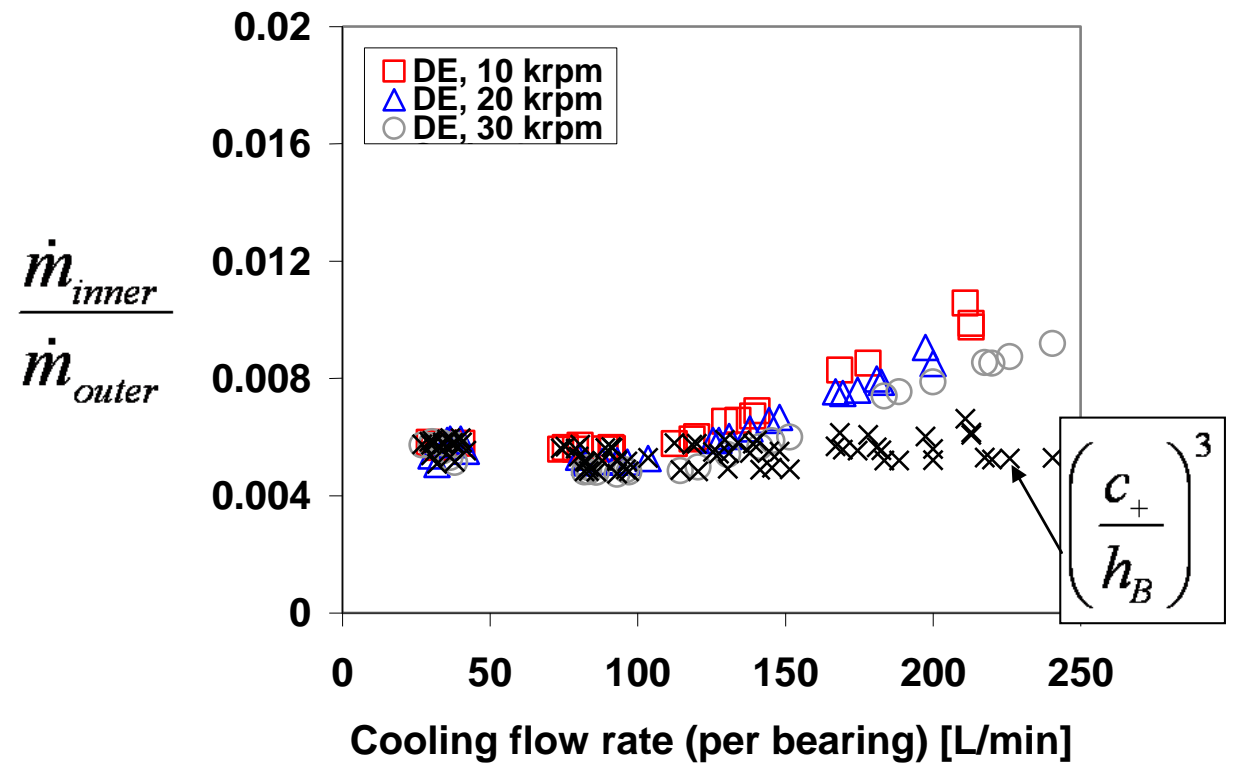

(b) Drive end bearing

Fig. I.5 Test cases \#5. Heater set temperature $T_{h s}=100 \stackrel{\circ}{ }=$. Rotor speed of 10,20 , and 30 krpm: Mass flow rate though outer gap over mass flow rate through inner gap versus cooling flow rate. $\left(c_{+} / h_{B}\right)^{3}$ also shown. FE: Free end bearing, DE: Drive end bearing. 


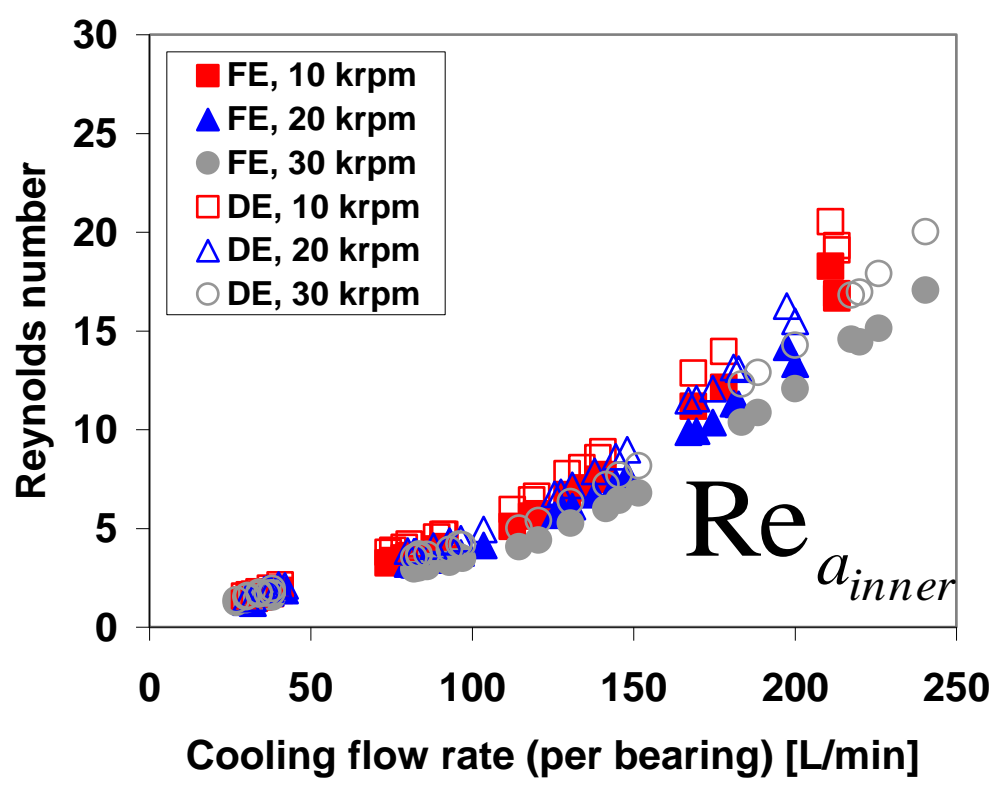

(a) Inner thin film region

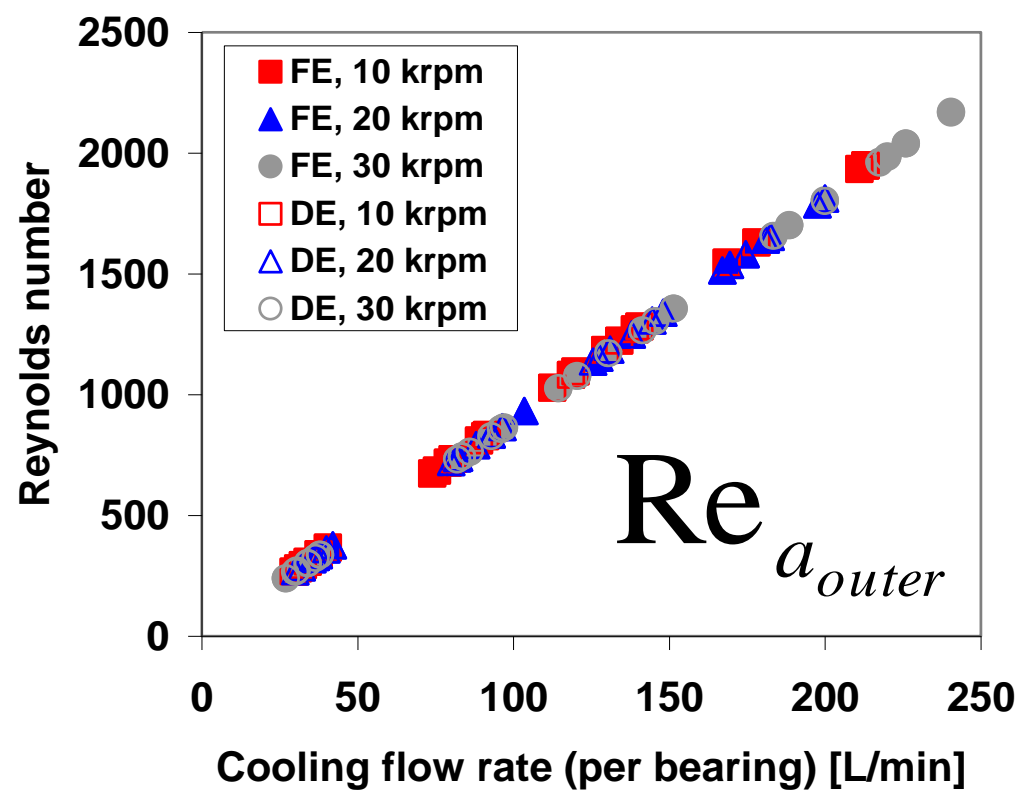

(b) Outer gap region

Fig. I.6 Test cases \#5. Heater set temperature $T_{h s}=100^{\circ} \mathrm{C}$. Rotor speed of 10,20 , and 30 krpm: Axial flow Reynolds numbers of (a) inner and (b) outer cooling streams versus cooling flow rate. Note different vertical scale. 
In a centered journal bearing, the circumferential flow Reynolds number is $\operatorname{Re}_{c}=\frac{\rho}{\mu} R_{O} \Omega c_{+}$, where $R_{O}$ is the rotor radius, $\Omega$ is the rotor speed, $c_{+}$is a operating radial clearance, and $\rho$ and $\mu$ are the gas density and viscosity, respectively. Figure I.7 depicts the predicted circumferential flow Reynolds number $\operatorname{Re}_{c_{\text {exist }}}$ in the thin film region at the bearing exit plane ${ }^{37} . \operatorname{Re}_{c_{\text {exist }}}$ at 10,20 , and $30 \mathrm{krpm}$ are $\sim 100, \sim 200, \sim 300$, respectively. $\operatorname{Re}_{c_{\text {exist }}}$ decreases as the operating temperature increases since $c_{+}$decreases with $T_{h s}$.

In the inner gap flow region, and for all test cases, i.e., $\operatorname{Re}_{c}>>\operatorname{Re}_{a_{\text {iner }}}$, compare Figs. I.6 (a) and I.7. Therefore, the forced axial cooling flow rate does not alter significantly the development of the circumferential velocity, see Fig. I.8 later.

${ }^{37}$ The circumferential flow Reynolds number at the entrance plane is similar with the circumferential flow Reynolds number at the exit plane, i.e., for all test cases, $\frac{\operatorname{Re}_{C_{e x i t}}}{\operatorname{Re}_{C_{e n t}}} \approx 0.96 \sim 0.99$, where $\operatorname{Re}_{C_{e n t}}=\frac{\rho_{e n t}}{\mu} R \Omega c_{+}$. 


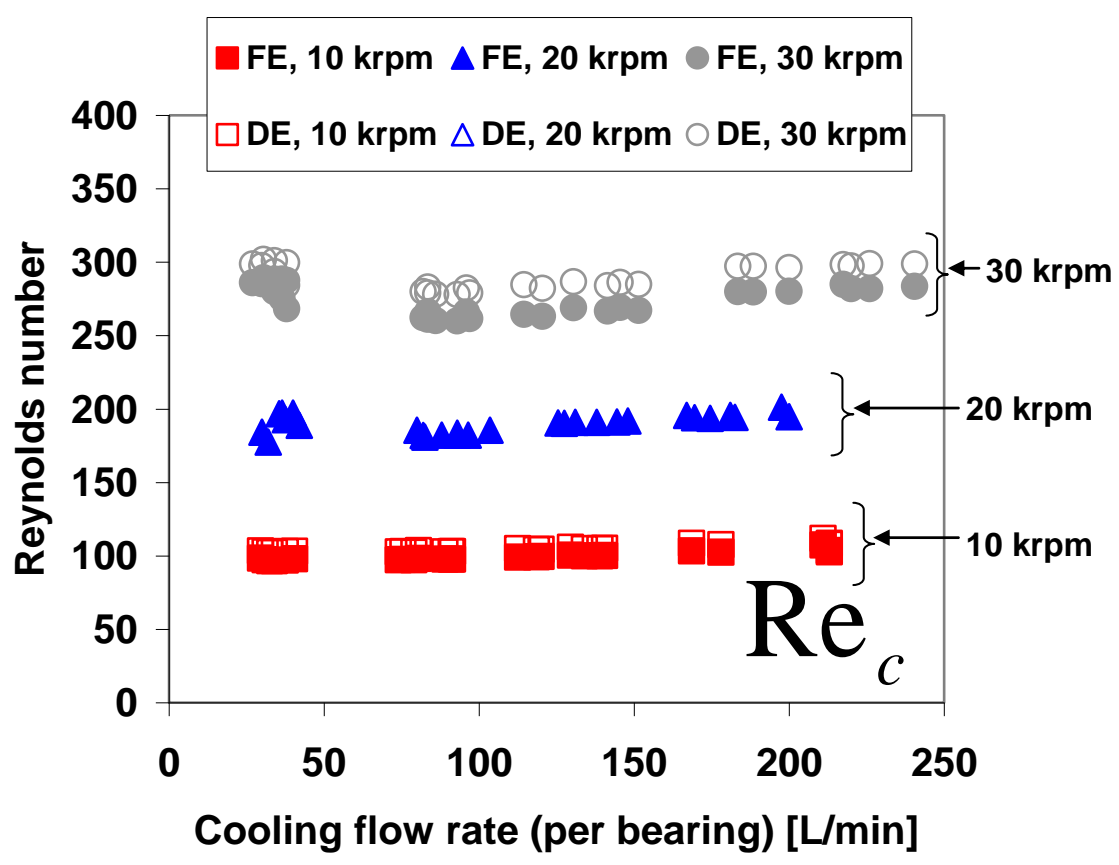

Fig. I.7 Test cases \#5. Heater set temperature $T_{h s}=100^{\circ} \mathrm{C}$. Rotor speed of 10, 20, and 30 krpm: Circumferential flow Reynolds number for thin film gas region at the bearing exit plane $\left(P=P_{a}\right)$ versus cooling flow rate. FE: Free end bearing, DE: Drive end bearing.

In the inner gap flow region (i.e., the thin film), the entrance circumferential velocity is

$$
U_{\text {ent }}=U(x, 0)=\alpha \Omega R_{O}
$$

where $\alpha$ is an inlet flow pre-swirl factor, $\Omega$ is rotor angular velocity, and $R_{O}$ is the rotor radius. The current analysis assumes $\alpha=0$, i.e., negligible fluid rotation at the bearing entrance plane since the cooling flow is imposed directly into the bearing entrance. The evolution of the gas circumferential velocity $\left(u_{c}\right)$ along the axial direction is ${ }^{38}[60]$

\footnotetext{
${ }^{38}$ This equation is valid for centered journal operation.
} 


$$
u_{c}=\frac{\Omega R_{O}}{2}\left(1-e^{-\sigma z}\right)+U_{e n t} e^{-\sigma z}
$$

where $\sigma=\frac{k_{z_{\text {inner }}}}{\frac{\dot{m}_{\text {inner }}}{2 R_{O} \pi \cdot \mu}} \frac{L}{c_{+}}$is a parameter relating drag friction to fluid inertia effects. Note that $u_{c}=0$ at the inlet plance and $u_{c} \rightarrow \frac{\Omega R_{O}}{2}$ as $z \rightarrow L$ (exit plane). For test case \#5 $\left(T_{h s}=100^{\circ} \mathrm{C}\right)$, Fig. I.8 depicts the dimensionless circumferential gas velocity $\frac{u_{c}}{\Omega R_{O}}$ versus dimensionless bearing axial length while increasing the cooling flow rate for rotor speeds of 10-30 krpm. The results are shown over $20 \%$ of the bearing axial length, i.e., from $z=0$ to $z=0.2 L$. As the cooling flow rate into the bearings increases, the axial location where $u_{c}=\frac{\Omega R_{O}}{2}$ shifts toward the bearing exit plane. That is, the gas film circumferential flow velocity decreases with an increasing cooling flow rate. For the present test configuration, $u_{c} / \Omega R_{O}$ reaches $1 / 2$ within $5 \%$ of the bearing axial length since $P_{e n t} \approx(1 \sim 1.05) \times P_{a}$, recall Fig. I.3. 


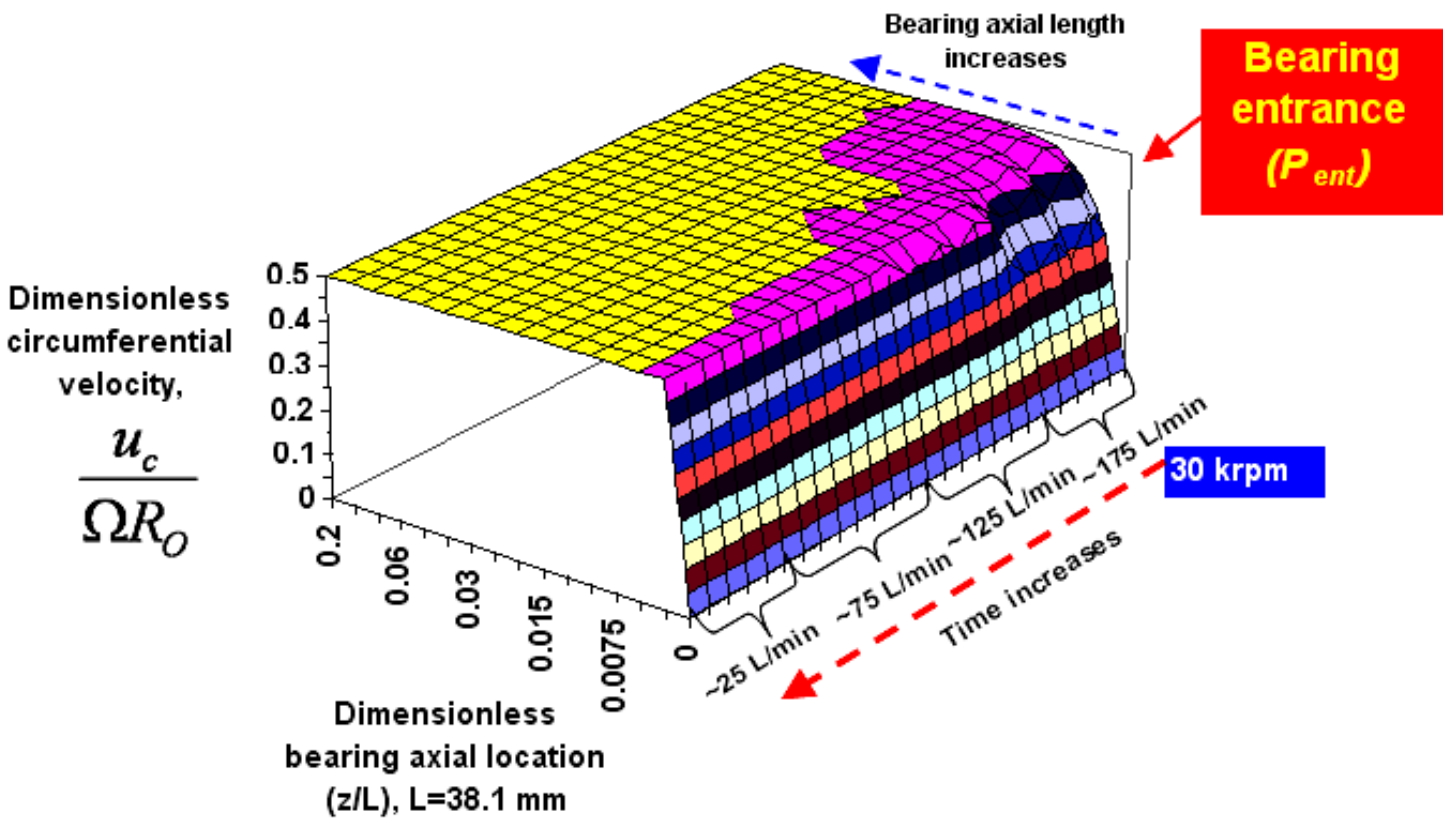

Fig. I.8 Test case \#5. Heater set temperature $T_{h s}=100 \stackrel{\circ}{ }$. Rotor speed of $30 \mathrm{krpm}$. Free end bearing: Dimensionless circumferential mean flow velocity versus dimensionless bearing axial length within bearing inner thin film region. 


\section{APPENDIX J}

\section{ROTORDYNAMIC RESPONSE DURING START-UP: COLD ROTOR CONDITION. TEST CASE \#7}

For test case \#4, Fig. J.1 depicts waterfall plots of vertical and horizontal motion recorded at the rotor drive and free ends for operation from rest to $30 \mathrm{krpm}$. The forced cooling flow rate into the bearings is $\sim 350 \mathrm{~L} / \mathrm{min}$. The ramp rate for rotor acceleration is 16.7 Hz/s. Note that the temperatures of the rotor and bearings are close to ambient temperature, i.e., cold rotor and bearings. Recall that the tests demand enough time to reach steady state thermal conditions. No subsynchronous rotor motions are recorded. The rotor responses along the rotor drive end are mainly synchronous. On the other hand, the $2 \mathrm{X}$ rotor whirl motions are dominant at the rotor free end. 

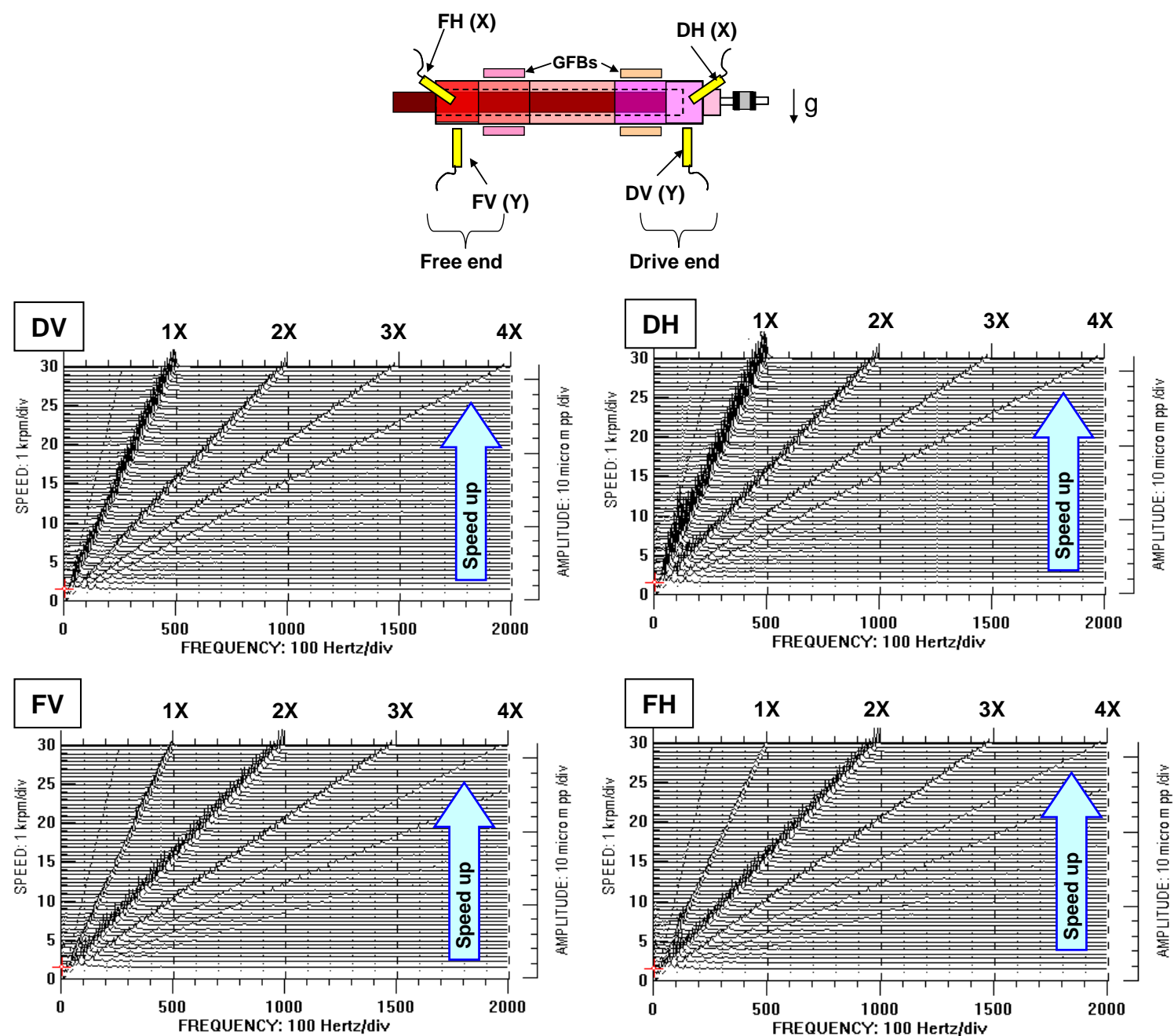

Fig. J.1 Test case \#7: Waterfalls of rotor motion during accelerating from rest to $30 \mathrm{krpm}$. Heater off, set cooling flow rate $350 \mathrm{~L} / \mathrm{min}$, acceleration= $16.7 \mathrm{~Hz} / \mathrm{s}$. Rotor drive end, vertical (DV) and horizontal (DH) planes and rotor free end, vertical (FV) and horizontal (FH) planes.

Figure J.2 shows synchronous speed (1X) and $2 \mathrm{X}$ response amplitude of rotor motions during the start up process from rest to $30 \mathrm{krpm}$. Slow roll compensation is at 4 $\mathrm{krpm}$. The rotor motion amplitude peaks at $\sim 7 \mathrm{krpm}$. The rotor response amplitudes at the system critical speed region are damped well. The $2 \mathrm{X}$ rotor response amplitudes are 
almost constant above the system critical speed. The measured rotor response does not show any evidence of nonlinearity in the rotor-bearing system ${ }^{39}$.

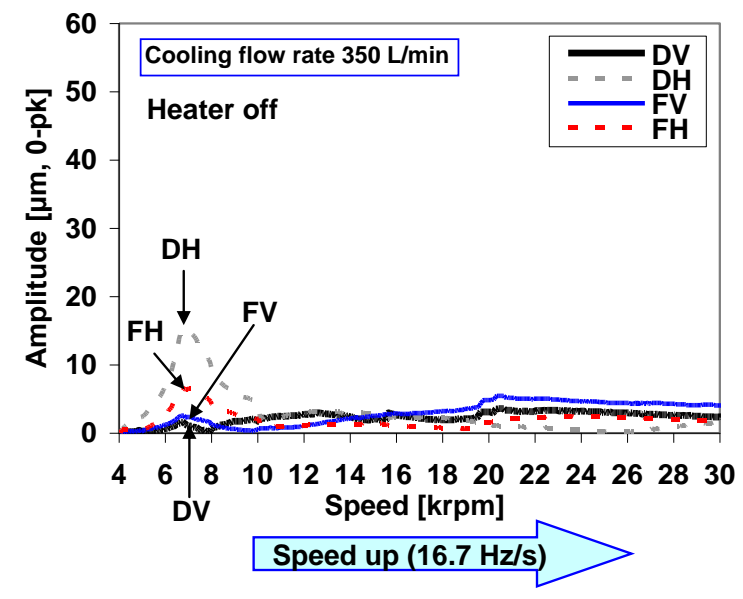

(a) Synchronous $(1 \mathrm{X})$ rotor motion

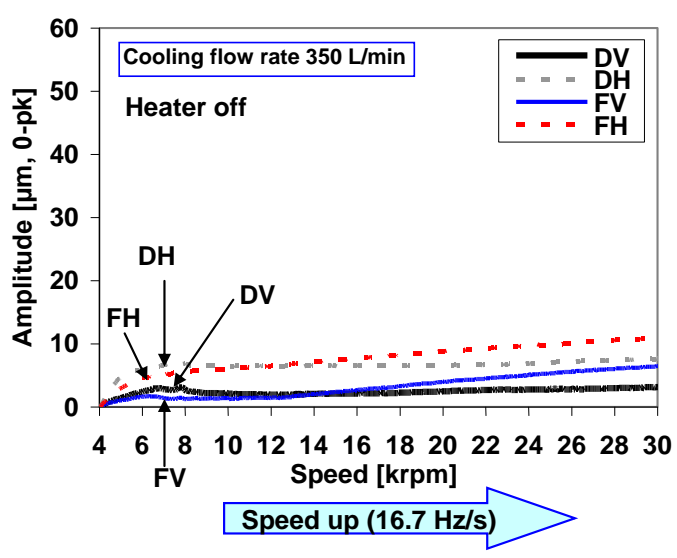

(b) $2 X$ rotor motion

Fig. J.2 Test case \#7: Amplitude of rotor synchronous response versus rotor speed. Speed up from rest to $30 \mathrm{krpm}$ with ramp rate of $16.7 \mathrm{~Hz} / \mathrm{s}$ Slow roll compensation 4100 rpm.

Figure J.3 depicts a phase difference of $180 \mathrm{deg}$ while traversing the speeds with largest response amplitudes. Figure J.4 shows the ratio of amplitudes between the rotor responses at the drive and free ends.

\footnotetext{
${ }^{39}$ Reference [46] shows the nonlinear rotor dynamic response characterized as a sudden drop in rotor motion amplitudes at rotor speed just above the system critical speed due to large rotor imbalances.
} 


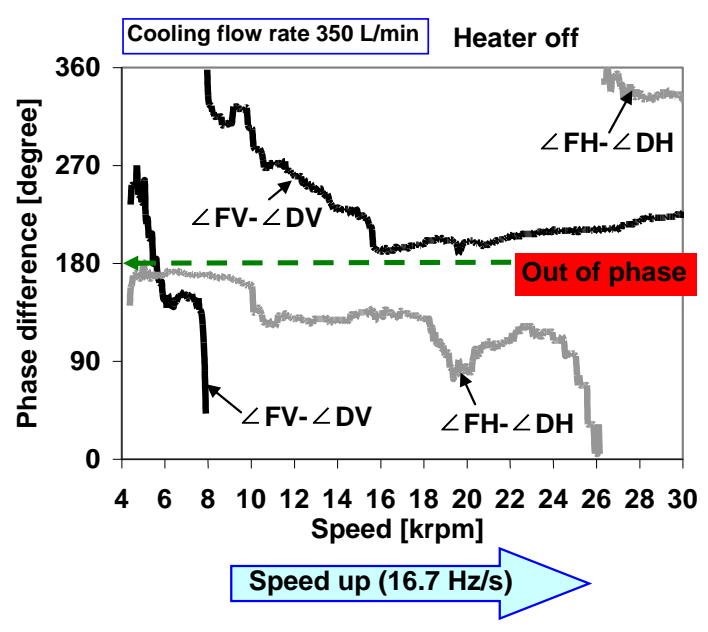

(a) Synchronous (1X) rotor motion

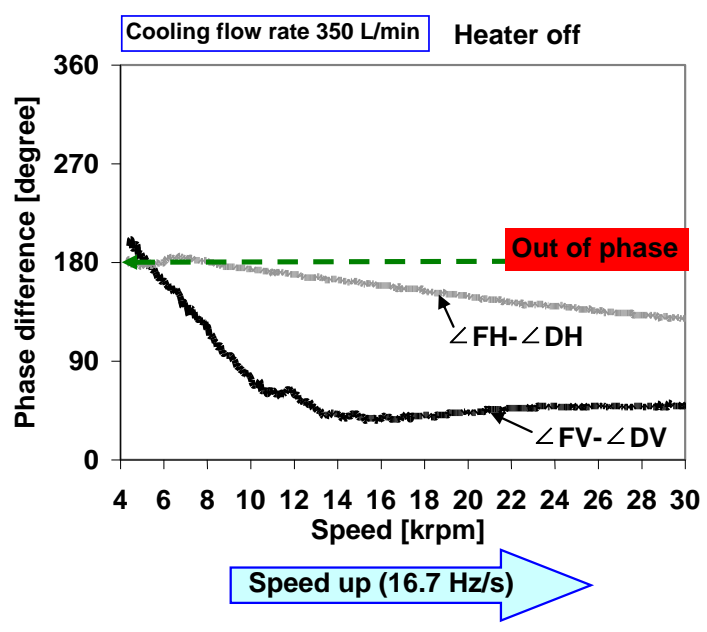

(b) $2 X$ rotor motion

Fig. J.3 Test case \#7: Phase differences of recorded imbalance response. $T_{h s}=65^{\circ} \mathrm{C}$. Speed up from rest to $30 \mathrm{krpm}$ with ramp rate of $16.7 \mathrm{~Hz} / \mathrm{s}$ Cooling flow rate $350 \mathrm{~L} / \mathrm{min}$.

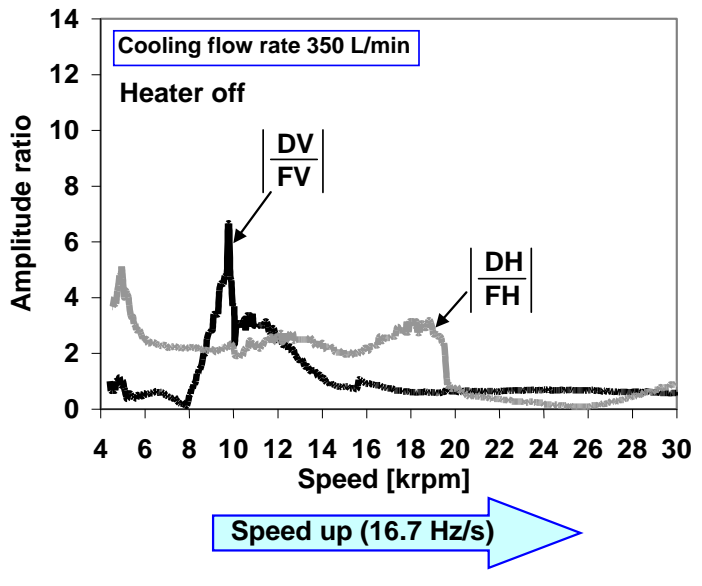

(a) Synchronous (1X) rotor motion

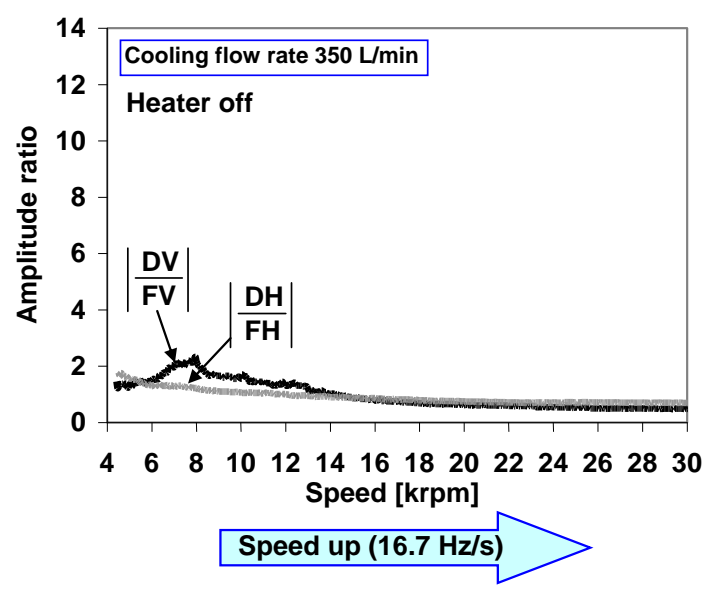

(b) $2 X$ rotor motion

Fig. J.4 Test case \#7: Amplitude ratio of recorded imbalance response. $T_{h s}=65^{\circ} \mathrm{C}$. Cooling flow rate $350 \mathrm{~L} / \mathrm{min}$. 


\section{APPENDIX K}

\section{NATURAL FREQUENCIES OF TEST ROTOR-BEARING SYSTEM}

A miniature accelerometer (PCB352C23, sensitivity $5.11 \mathrm{mV} / \mathrm{g}$ ) measures the natural frequency of the test rotor-bearing system. The accelerometer is affixed on (a) the flexible coupling, or (b) connecting rod, or (c) rotor drive end, or (d) rotor free end, refer the insets in Fig. G.1.

Figure K.1 depicts the FFT of the recorded accelerations. A thin steel rod impacts the indicated location in the inset figure for each measurement. The flexure mode of the thin connecting rod and coupling (namely, a dog tail wagging mode, $1.50 \mathrm{kHz}=90 \mathrm{krpm}$ ) exists beyond the present operating speed (up to $30 \mathrm{krpm}$ ) and is lower than the first bending natural frequency $(3.74 \mathrm{kHz}=224 \mathrm{krpm})$ of the test rotor. 

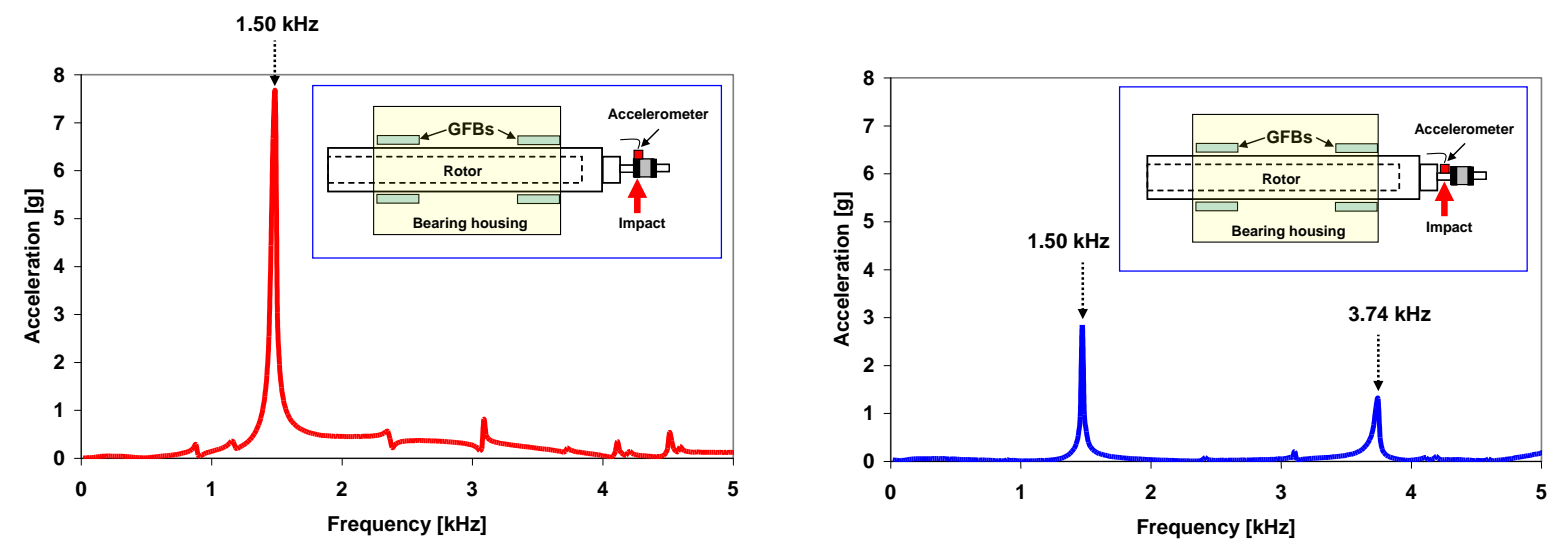

(a) Impact and sensor location: flexible

(b) Impact and sensor location: connecting rod coupling

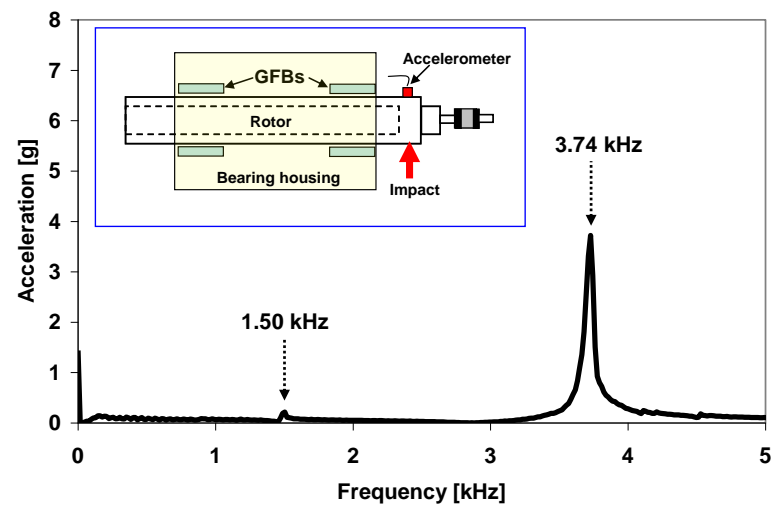

(c) Impact and sensor location: rotor drive end

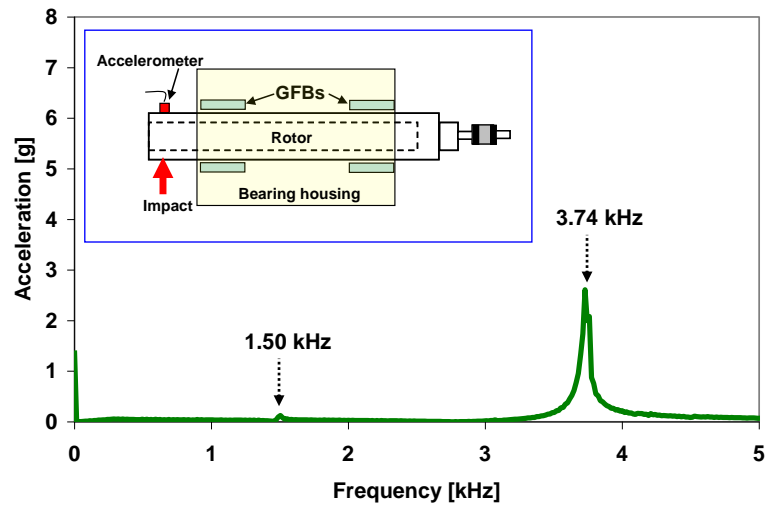

(d) Impact and sensor location: rotor free end

Fig. K.1 Acceleration spectra at (a) flexible coupling, (b) connecting rod, (c) rotor drive and (d) free ends. Uncertainty in frequency $16 \mathrm{~Hz}$. No shaft rotation. Ambient temperature 22으. 


\section{APPENDIX L}

\section{ROTOR WHIRL ORBITS: TEST CASES \#7 AND \#9}

Figures L.1 through L.4 show rotor whirl orbits for test cases \#7 (heater off) and $\# 9\left(T_{h s}=100^{\circ} \mathrm{C}\right)$. There is no major difference in rotor response amplitude and phase angles while increasing the rotor OD temperature. 


\section{Heater off, $30 \mathrm{krpm}, 350 \mathrm{~L} / \mathrm{min}$}
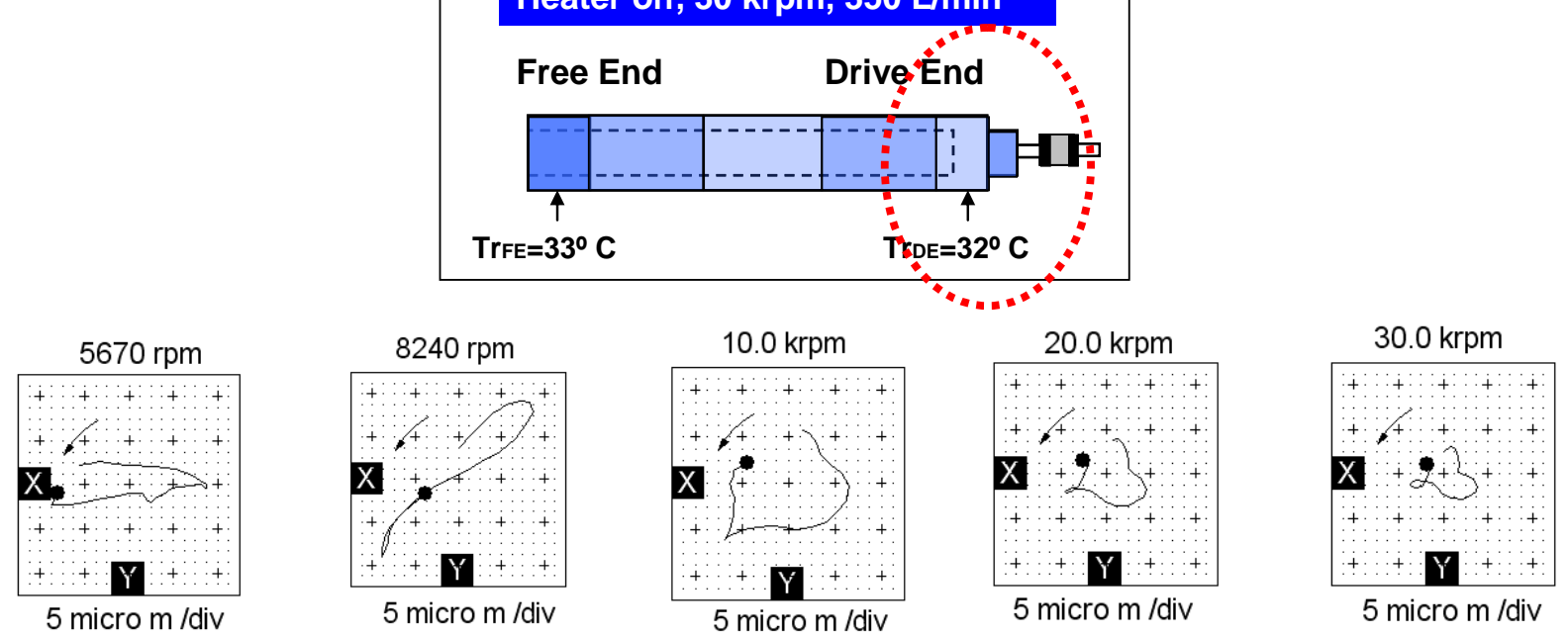

\section{Speed down. Ramp rate $16.7 \mathrm{~Hz} / \mathrm{s}$}

(a) Unfiltered rotor orbits
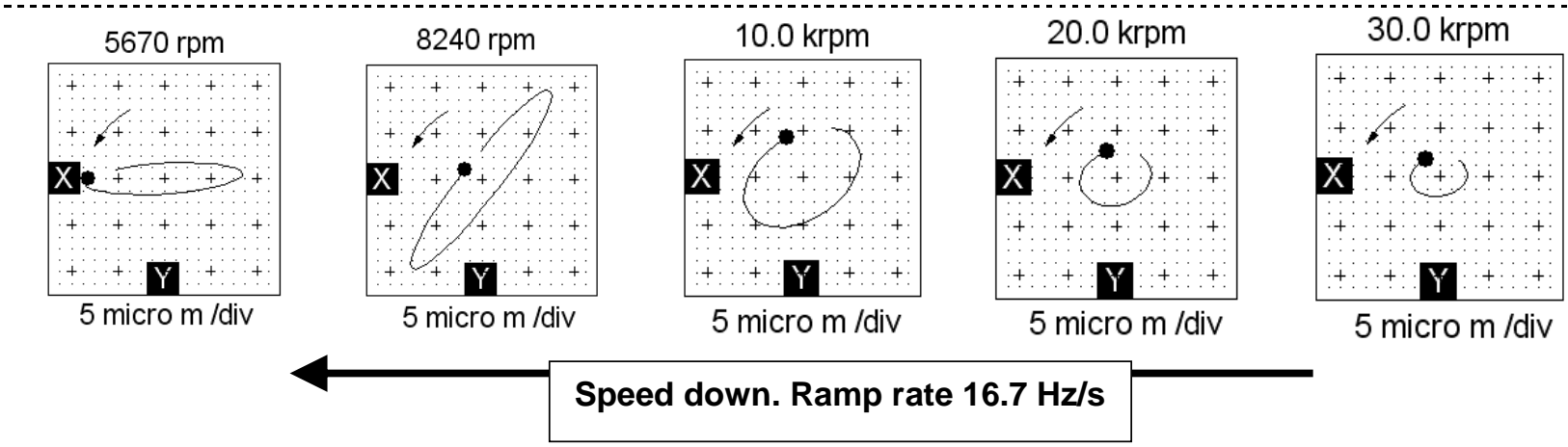

(b) Synchronous (1X) rotor orbits
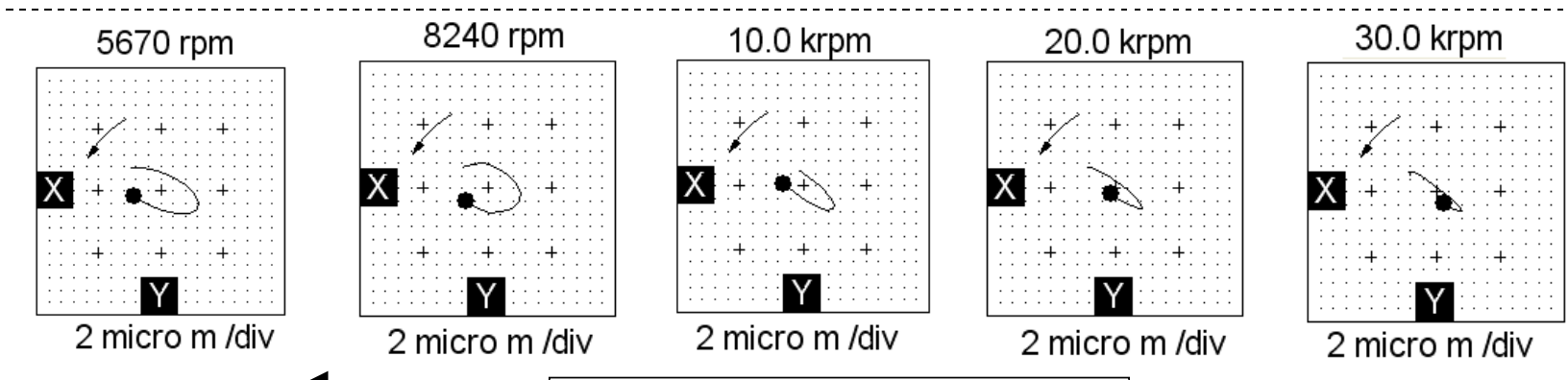

Speed down. Ramp rate $16.7 \mathrm{~Hz} / \mathrm{s}$

(c) $2 \mathrm{X}$ rotor orbits

Fig. L.1 Test case \#7. Drive end rotor orbits. Heater off. Speed down from $30 \mathrm{krpm}$ to rest with ramp rate of $16.7 \mathrm{~Hz} / \mathrm{s}$. Cooling flow rate $\sim 350 \mathrm{~L} / \mathrm{min}$. No slow roll compensation. Note different scale. 

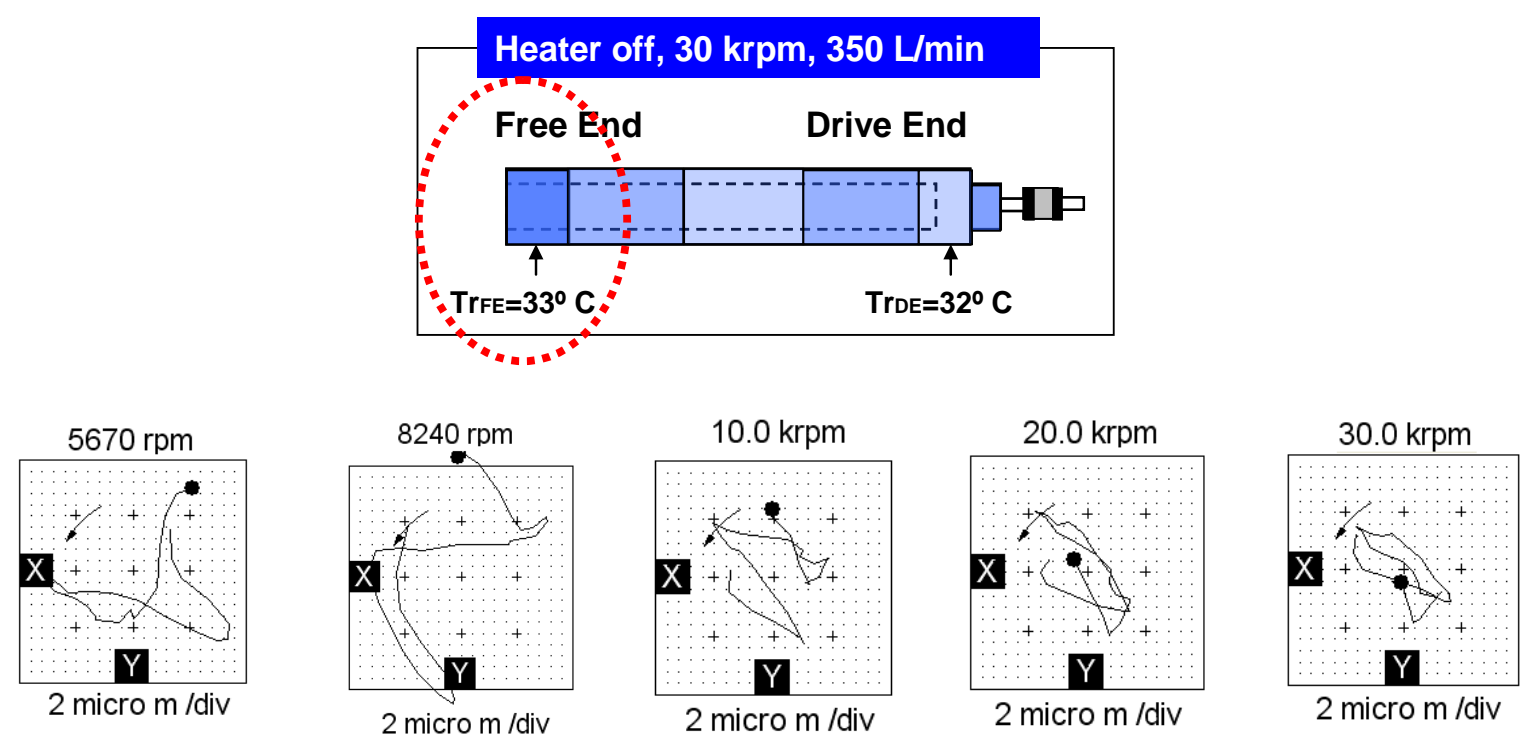

Speed down. Ramp rate $16.7 \mathrm{~Hz} / \mathrm{s}$

(a) Unfiltered rotor orbits
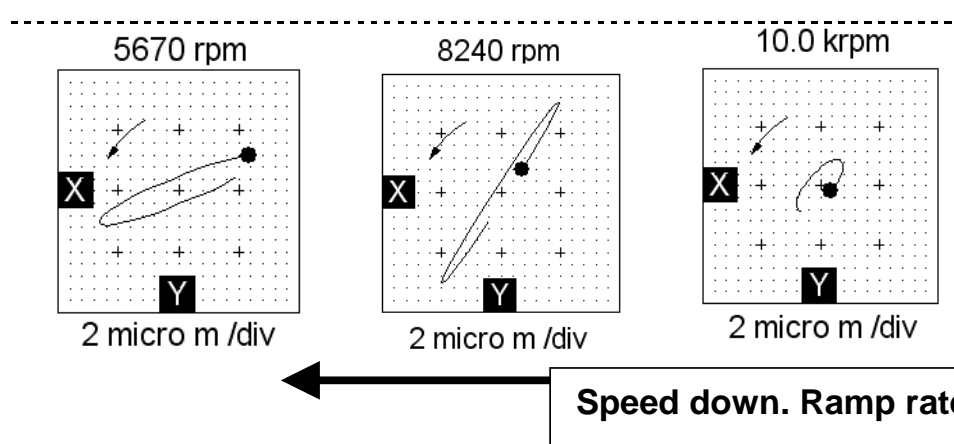

Speed down. Ramp rate $16.7 \mathrm{~Hz} / \mathrm{s}$

(b) Synchronous (1X) rotor orbits
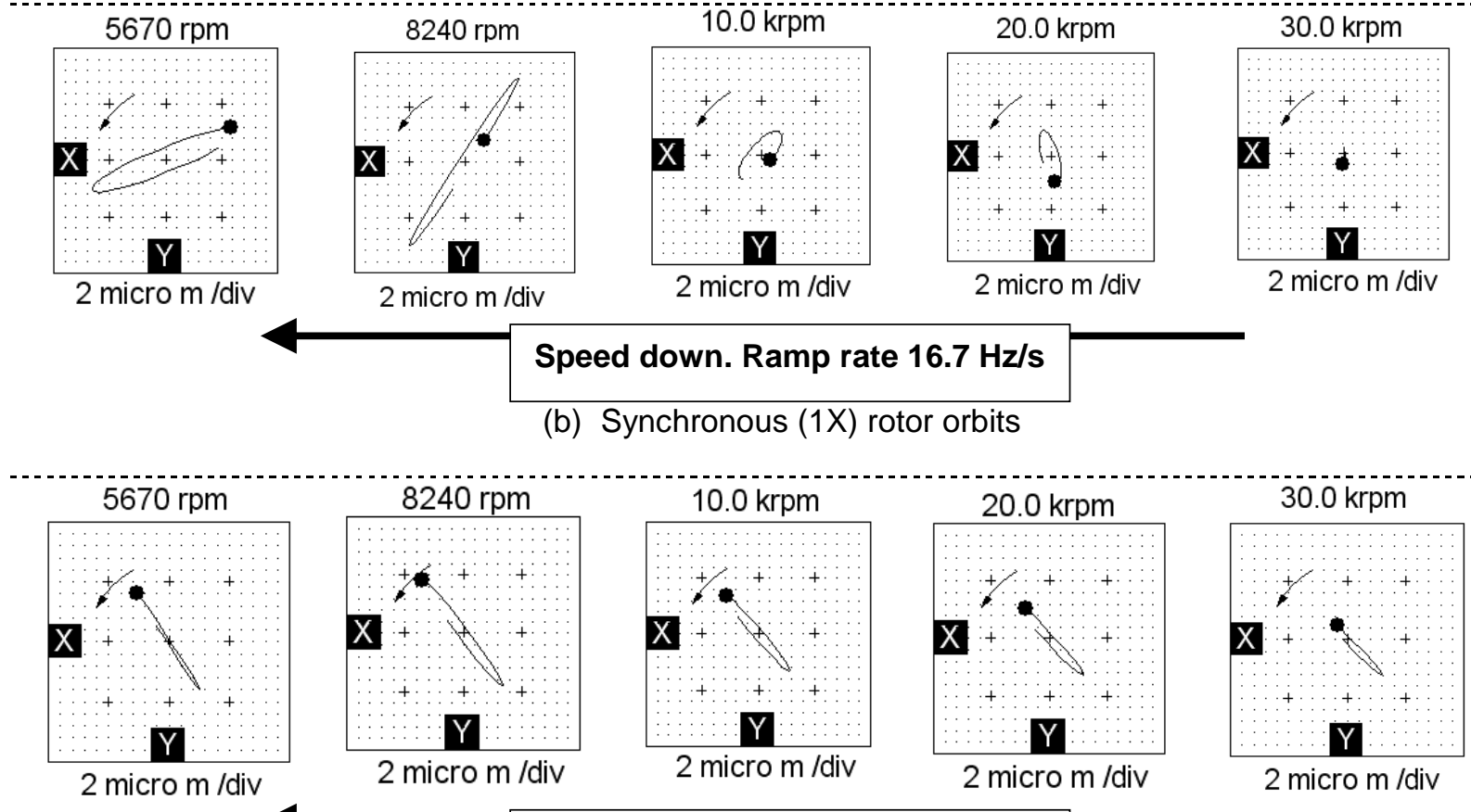

\section{Speed down. Ramp rate $16.7 \mathrm{~Hz} / \mathrm{s}$}

(c) $2 \mathrm{X}$ rotor orbits

Fig. L.2 Test case \#7. Free end rotor orbits. Heater off. Speed down from $30 \mathrm{krpm}$ to rest with ramp rate of $16.7 \mathrm{~Hz} / \mathrm{s}$. Cooling flow rate $\sim 350 \mathrm{~L} / \mathrm{min}$. No slow roll compensation. 

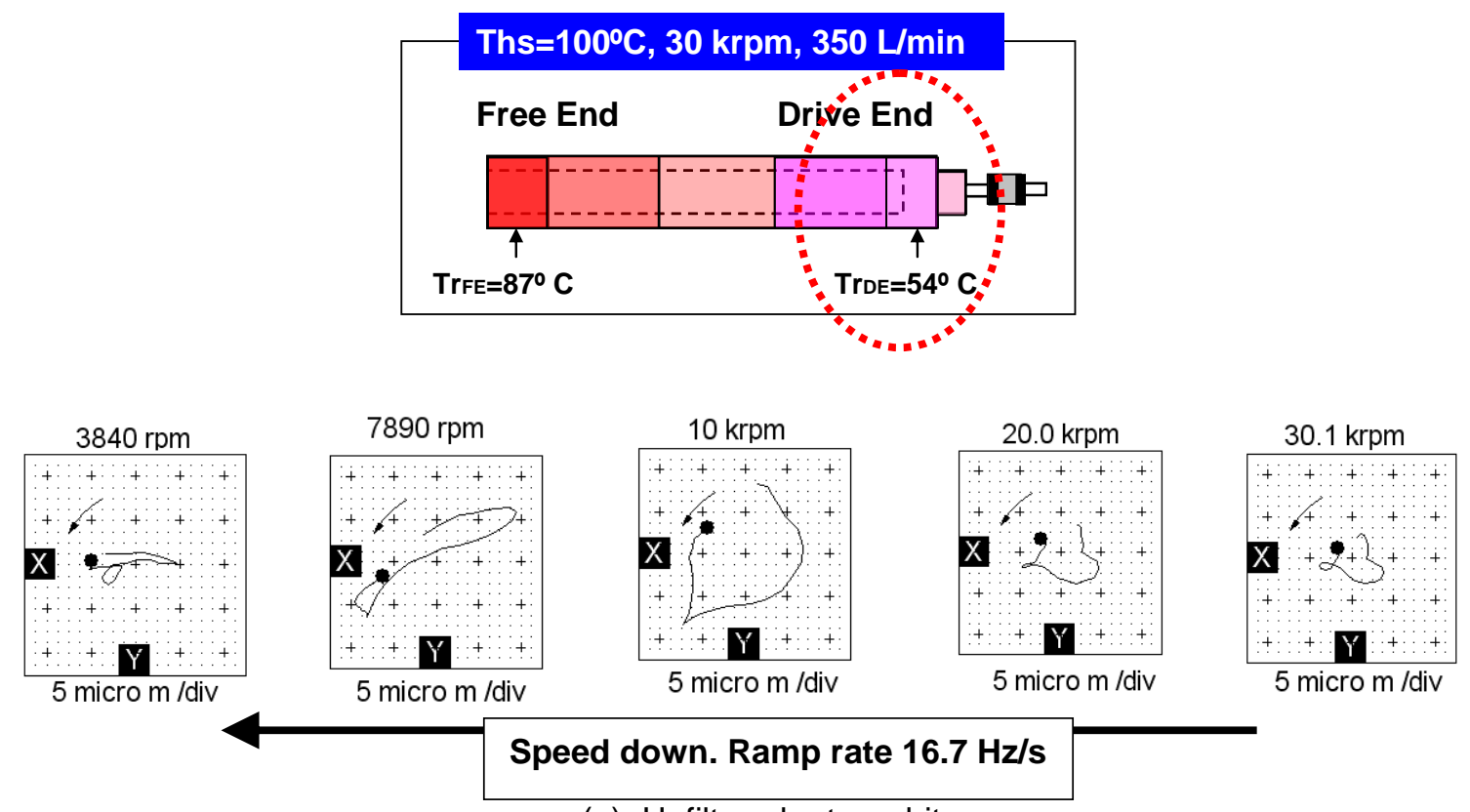

(a) Unfiltered rotor orbits

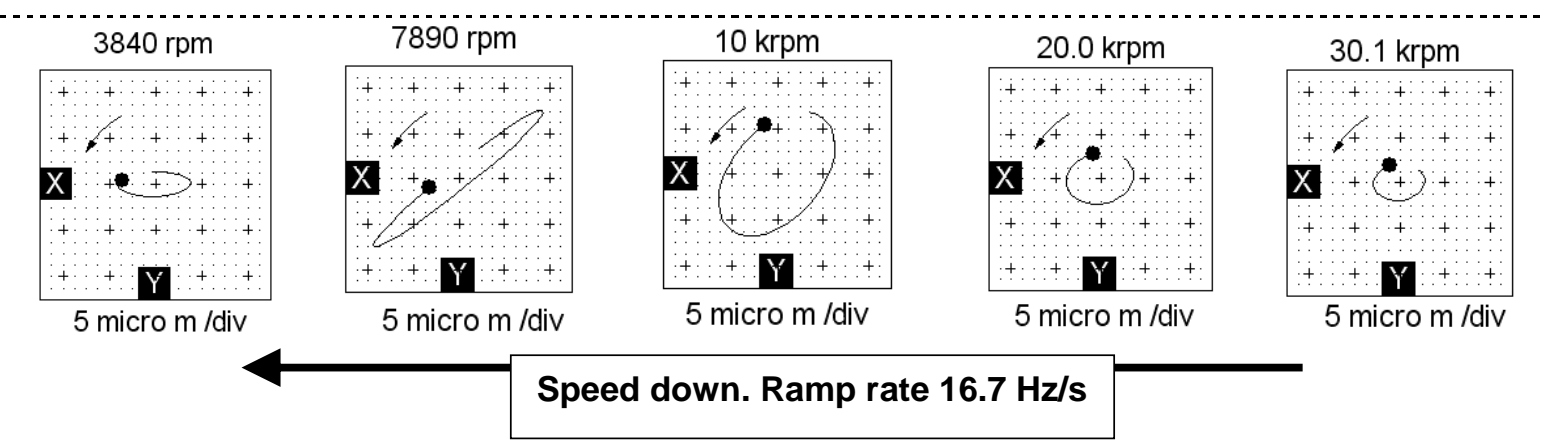

(b) Synchronous (1X) rotor orbits

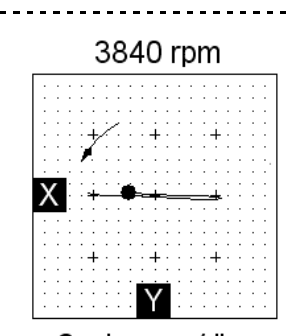

2 micro $\mathrm{m} / \mathrm{div}$

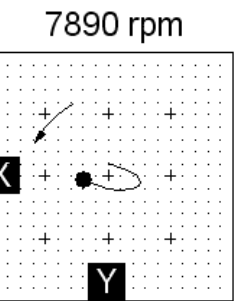

2 micro $\mathrm{m} / \mathrm{div}$

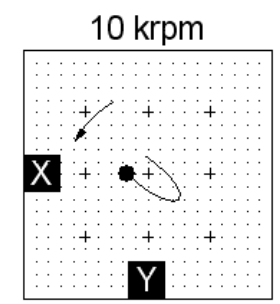

2 micro $\mathrm{m} / \mathrm{div}$

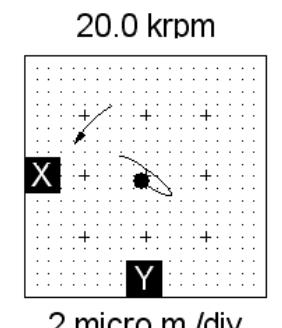

2 micro $\mathrm{m} / \mathrm{div}$
$30.1 \mathrm{krpm}$

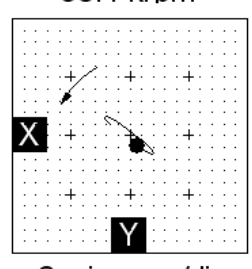

2 micro $\mathrm{m} / \mathrm{div}$

\section{Speed down. Ramp rate $16.7 \mathrm{~Hz} / \mathrm{s}$}

(c) $2 \mathrm{X}$ rotor orbits

Fig. L.3 Test case \#9. Drive end rotor orbits. $T_{h s}=100^{\circ} \mathrm{C}$. Speed down from $30 \mathrm{krpm}$ to rest with ramp rate of $16.7 \mathrm{~Hz} / \mathrm{s}$. Cooling flow rate $\sim 350 \mathrm{~L} / \mathrm{min}$. No slow roll compensation. Note different scale. 

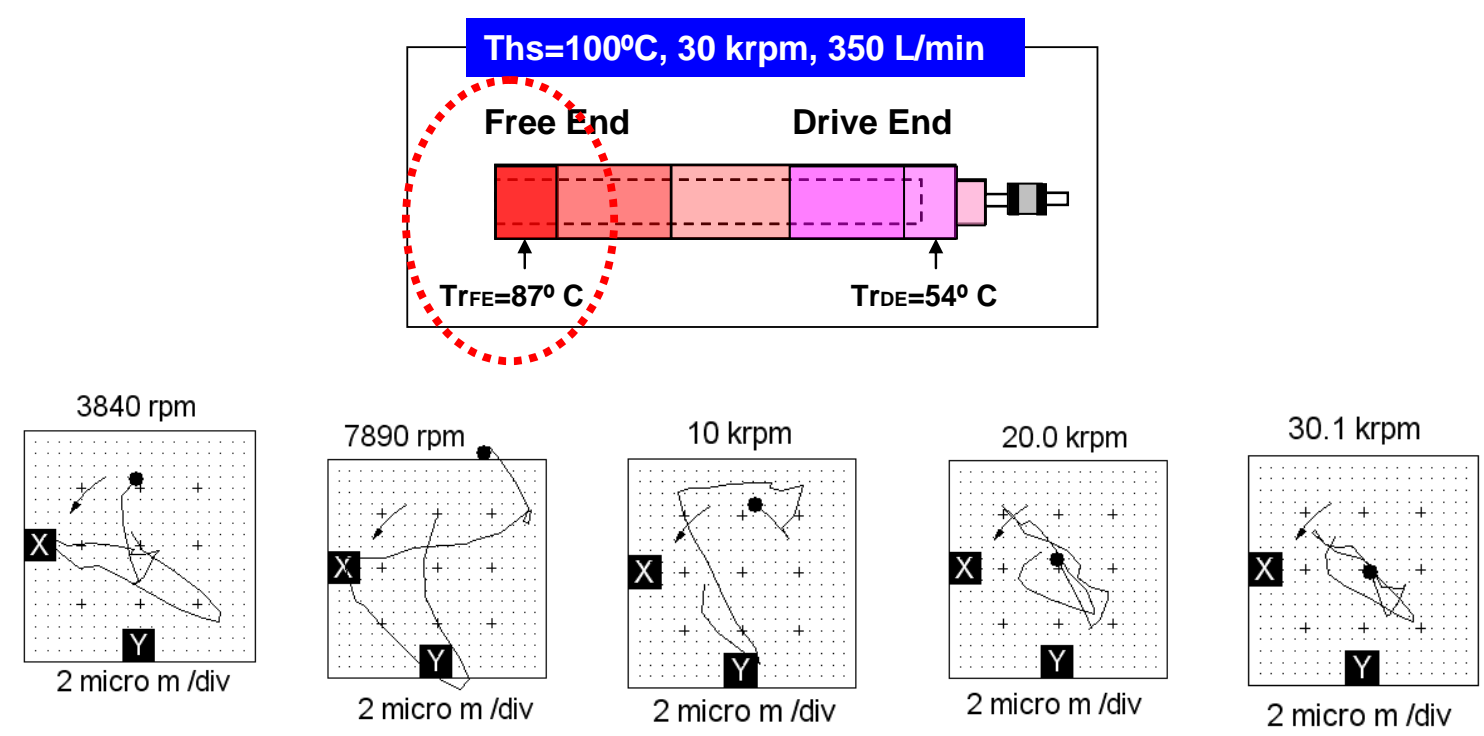

Speed down. Ramp rate $16.7 \mathrm{~Hz} / \mathrm{s}$

(a) Unfiltered rotor orbits
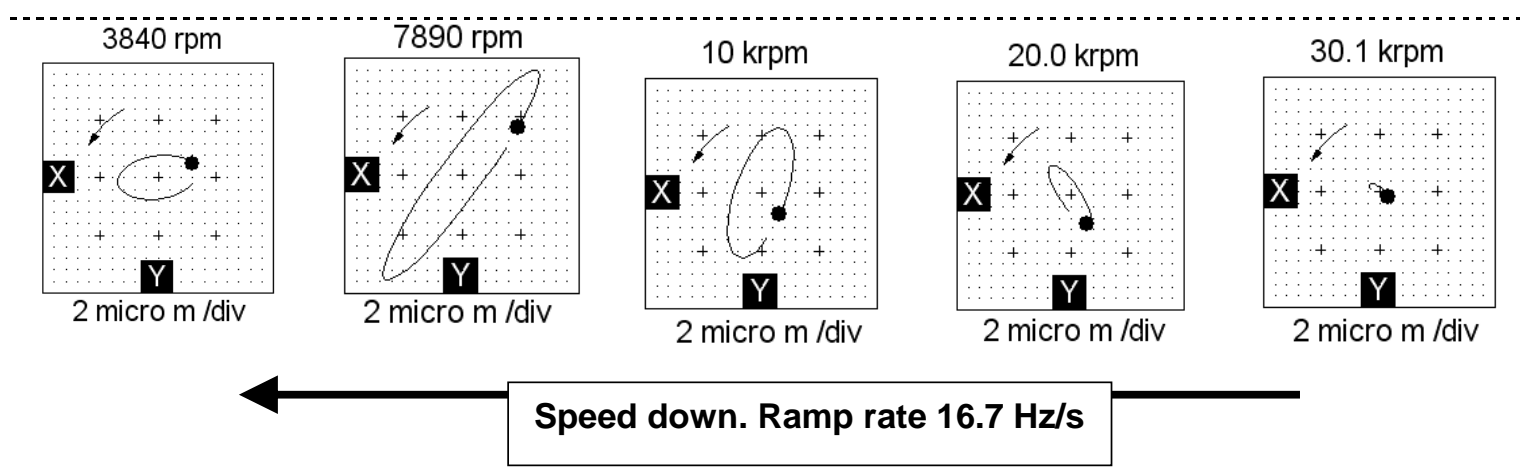

(b) Synchronous (1X) rotor orbits
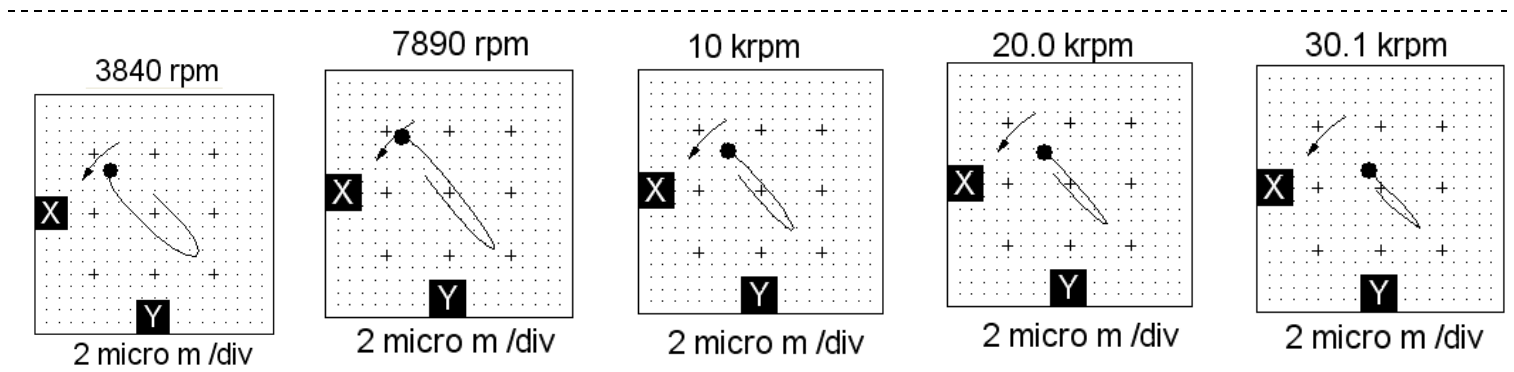

Speed down. Ramp rate $16.7 \mathrm{~Hz} / \mathrm{s}$

(c) $2 \mathrm{X}$ rotor orbits

Fig. L. 4 Test case \#9. Free end rotor orbits. $T_{h s}=100^{\circ} \mathrm{C}$. Speed down from $30 \mathrm{krpm}$ to rest with ramp rate of $16.7 \mathrm{~Hz} / \mathrm{s}$. Cooling flow rate $\sim 350 \mathrm{~L} / \mathrm{min}$. No slow roll compensation. 


\section{APPENDIX M}

\section{COMPLETE INPUT DATA FOR PREDICTION OF FOIL BEARING \\ PERFORMANCE AND PREDICTED TEMPERATURES AND}

STATIC LOAD PARAMETERS

Table M.1 Complete input parameters for GFB prediction

\begin{tabular}{|c|c|c|c|}
\hline \multicolumn{2}{|c|}{ Parameters } & Value & Unit \\
\hline \multirow{2}{*}{$\begin{array}{c}\text { Cooling stream gas } \\
\text { condition }\end{array}$} & Flow rate & See Tables M.2 and M.3 & $\mathrm{L} / \mathrm{min}$ \\
\hline & Temperature $\left(=T_{e}\right)$ & See Tables M.2 and M.3 & ${ }^{\circ} \mathrm{C}$ \\
\hline \multirow{3}{*}{ Operating condition } & Ambient pressure & 1.013 & bar \\
\hline & Ambient temperature $\left(=T_{a m b}\right)$ & See Tables M.2 and M.3 & ${ }^{\circ} \mathrm{C}$ \\
\hline & $\begin{array}{c}\text { (Constant) Shaft temperature: } \\
\text { (Material: Inconel 718) }\end{array}$ & See Tables M.2 and M.3 & ${ }^{\circ} \mathrm{C}$ \\
\hline $\begin{array}{l}\text { Thermal mixing } \\
\text { condition }\end{array}$ & Thermal mixing parameter & $0.65^{(4)}$ & - \\
\hline \multirow{7}{*}{$\begin{array}{c}\text { Bump geometry } \\
\text { (Material: Inconel } \\
\text { X-750) }\end{array}$} & Bump foil thickness & $1.20 \times 10^{-4}$ & $\mathrm{~mm}$ \\
\hline & Bump pitch & $4.35 \times 10^{-3}$ & $\mathrm{~mm}$ \\
\hline & Bump half length & $1.25 \times 10^{-3}$ & $\mathrm{~mm}$ \\
\hline & Bump height & $5 \times 10^{-4}$ & $\mathrm{~mm}$ \\
\hline & Friction coefficient, $\mu_{f}^{(1)}$ & 0.2 & - \\
\hline & Structural loss factor, $\gamma^{(2)}$ & 0.2 & - \\
\hline & Number of Bumps & 26 & - \\
\hline \multirow{5}{*}{$\begin{array}{c}\text { Top foil geometry and } \\
\text { properties } \\
\text { (Material: Inconel } \\
\text { X-750) }\end{array}$} & $\begin{array}{c}\text { Foil Arc Diameter } \\
\text { (= Rotor outer diameter) }\end{array}$ & $3.65 \times 10^{-2}$ & $\mathrm{~mm}$ \\
\hline & Foil Arc Length & 355 & degree \\
\hline & $\begin{array}{l}\text { Top foil width } \\
\text { (=Axial length) }\end{array}$ & $3.81 \times 10^{-2}$ & $\mathrm{~mm}$ \\
\hline & Foil thickness & $1.20 \times 10^{-4}$ & $\mathrm{~mm}$ \\
\hline & $\begin{array}{c}\text { Stiffening factor }{ }^{(3)} \\
\text { (circumferential direction) }\end{array}$ & 4 & - \\
\hline \multicolumn{2}{|c|}{ Nominal radial clearance } & $1 \times 10^{-4}$ & $\mathrm{~mm}$ \\
\hline
\end{tabular}

(1) Assumed as $\mu_{f} \approx \gamma$. In general, the experimentally identified friction coefficient has the same magnitude as the loss factor [10,39].

(2) Estimated from the area enclosed by the mechanical hysteresis loop in the static load versus FB deflection curves at room temperature (Fig. 14).

(3) Empirical parameter. A measure of the anisotropic elastic properties in a top foil.

(4) The thermal mixing ratio depends on the bearing configuration and applied cooling method. 
Table M. 2 Drive end GFB: Predicted bearing static parameters

\begin{tabular}{|c|c|c|c|c|c|c|c|c|c|c|c|c|c|c|c|c|}
\hline $\begin{array}{c}\text { Test } \\
\text { Case } \\
\#\end{array}$ & {$\left[\begin{array}{l}T_{h s} \\
{\left[{ }^{\circ} \mathrm{C}\right]}\end{array}\right]$} & $\begin{array}{l}\text { Rotor } \\
\text { speed } \\
{[\mathrm{krpm}]}\end{array}$ & $\begin{array}{c}\text { Cooling } \\
\text { flow } \\
\text { rate } \\
\text { (per } \\
\text { bearing) } \\
{[\mathrm{L} / \mathrm{min}]}\end{array}$ & $\begin{array}{c}\text { Cooling } \\
\text { flow } \\
\text { Temp } \\
\text {-erature } \\
T_{C o} \\
=T_{e} \\
{\left[{ }^{\circ} \mathrm{C}\right]^{(1)}}\end{array}$ & $\begin{array}{l}T_{a m b} \\
{\left[{ }^{\circ} \mathrm{C}\right]} \\
(1)\end{array}$ & $\begin{array}{c}\text { Rotor } \\
\mathrm{OD} \\
{\left[{ }^{\circ} \mathrm{C}\right]} \\
(1)(2)\end{array}$ & $\begin{array}{c}\text { Shaft } \\
\text { centri } \\
\text {-fugal } \\
\text { growth } \\
\underset{(3)}{[\mu \mathrm{m}]}\end{array}$ & $\begin{array}{c}\text { Net } \\
\text { Shaft } \\
\text {-bearing } \\
\text { thermal } \\
\text { expan } \\
\text {-sion }[\mu \mathrm{m}] \\
(3)\end{array}$ & $\begin{array}{c}\text { Axially } \\
\text { averaged } \\
\text { gas } \\
\text { film } \\
\text { temp- } \\
\text { erature } \\
{\left[{ }^{\circ} \mathrm{C}\right]}\end{array}$ & \begin{tabular}{|c} 
Peak \\
gas \\
film \\
temp- \\
erature \\
{$\left[{ }^{\circ} \mathrm{C}\right]$}
\end{tabular} & $\begin{array}{c}\text { Axially } \\
\text { averaged } \\
\text { bearing } \\
\text { sleeve } \\
\text { ID } \\
\text { temp- } \\
\text { erature } \\
{\left[{ }^{\circ} \mathrm{C}\right]} \\
\end{array}$ & \begin{tabular}{|c} 
Peak \\
bearing \\
sleeve \\
ID \\
temp- \\
erature. \\
{$\left[{ }^{\circ} \mathrm{C}\right]$}
\end{tabular} & $\left|\begin{array}{c}\text { Eccent } \\
\text {-ricity } \\
{[\mu \mathrm{m}]}\end{array}\right|$ & $\begin{array}{c}\text { Attitude } \\
\text { angle } \\
{\left[{ }^{\circ}\right]}\end{array}$ & $\left|\begin{array}{c}\text { Mini- } \\
\text { mum } \\
\text { film } \\
\text { Thick } \\
\text {-ness } \\
{[\mu \mathrm{m}]}\end{array}\right|$ & $\begin{array}{c}\text { Drag } \\
\text { torque } \\
{[\mathrm{N}} \\
-\mathrm{mm}]\end{array}$ \\
\hline 7 & Off & 10 & 175 & 25 & 23 & 33 & 0.08 & 1.72 & 28.8 & 31.6 & 25.6 & 26.9 & 91 & 25 & 10 & 0.72 \\
\hline 7 & Off & 20 & 175 & 25 & 23 & 33 & 0.34 & 1.59 & 28.6 & 33.2 & 25.5 & 27.6 & 83 & 32 & 18 & 1.07 \\
\hline 7 & Off & 30 & 175 & 25 & 23 & 33 & 0.76 & 1.49 & 28.4 & 34.4 & 25.4 & 28.2 & 76 & 38 & 25 & 1.35 \\
\hline 4,8 & 65 & 10 & 175 & 30 & 29 & 43 & 0.08 & 0.62 & 37.1 & 40.5 & 32.8 & 34.4 & 88 & 25 & 11 & 0.73 \\
\hline 4,8 & 65 & 20 & 175 & 32 & 29 & 50 & 0.34 & 1.00 & 40.5 & 46.3 & 34.5 & 37.3 & 79 & 34 & 19 & 1.08 \\
\hline 4,8 & 65 & 30 & 175 & 36 & 28 & 53 & 0.76 & 1.19 & 41.7 & 48.9 & 34.9 & 38.4 & 71 & 39 & 27 & 1.38 \\
\hline 5,9 & 100 & 10 & 175 & 28 & 22 & 49 & 0.08 & 4.55 & 37.5 & 42.3 & 28.2 & 31.4 & 94 & 24 & 11 & 0.73 \\
\hline 5,9 & 100 & 20 & 175 & 33 & 23 & 55 & 0.34 & 5.36 & 41.1 & 48.1 & 31.2 & 34.4 & 86 & 32 & 19 & \begin{tabular}{|l|}
1.07 \\
\end{tabular} \\
\hline 5,9 & 100 & 30 & 175 & 33 & 23 & 61 & 0.76 & 5.49 & 42.5 & 51.1 & 31.9 & 35.9 & 79 & 38 & 26 & 1.36 \\
\hline 6 & 150 & 10 & 175 & 37 & 26 & 70 & 0.08 & 7.83 & 51.6 & 58.5 & 37.9 & 41.1 & 97 & 24 & 11 & \begin{tabular}{|l|}
0.73 \\
\end{tabular} \\
\hline 4 & 65 & 10 & 125 & 31 & 29 & 45 & 0.08 & 0.53 & 40.2 & 44.4 & 37.7 & 41.0 & 90 & 25 & 11 & 0.73 \\
\hline 4 & 65 & 20 & 125 & 34 & 29 & 50 & 0.34 & 0.51 & 43.0 & 49.3 & 39.8 & 44.8 & 81 & 33 & 20 & 1.08 \\
\hline 4 & 65 & 30 & 125 & 38 & 28 & 57 & 0.76 & 0.46 & 46.3 & 54.4 & 42.3 & 48.6 & 73 & 39 & 27 & 1.38 \\
\hline 5 & 100 & 10 & 125 & 31 & 22 & 51 & 0.08 & 12.35 & 42.0 & 47.7 & 36.4 & 40.5 & 103 & 23 & 10 & \begin{tabular}{|l|}
0.70 \\
\end{tabular} \\
\hline 5 & 100 & 20 & 125 & 35 & 23 & 56 & 0.34 & 13.58 & 44.9 & 53.1 & 38.6 & 44.6 & 95 & 31 & 18 & 1.06 \\
\hline 5 & 100 & 30 & 125 & 40 & 23 & 64 & 0.76 & 15.68 & 48.9 & 58.7 & 41.5 & 48.5 & 89 & 35 & 25 & 1.35 \\
\hline 6 & 150 & 10 & 125 & 42 & 27 & 72 & 0.08 & 19.72 & 58.6 & 66.8 & 49.4 & 55.2 & 110 & 22 & 10 & 0.71 \\
\hline 4 & 65 & 10 & 75 & 34 & 28 & 46 & 0.08 & 0.63 & 41.2 & 45.5 & 38.3 & 41.7 & 90 & 25 & 11 & 0.73 \\
\hline 4 & 65 & 20 & 75 & 38 & 28 & 53 & 0.34 & 0.69 & 45.3 & 52.0 & 41.5 & 46.7 & 81 & 34 & 20 & 1.08 \\
\hline 4 & 65 & 30 & 75 & 36 & 28 & 49 & 0.76 & 0.43 & 41.8 & 49.1 & 38.7 & 44.4 & 73 & 39 & 26 & 1.37 \\
\hline 5 & 100 & 10 & 75 & 34 & 22 & 54 & 0.08 & 13.75 & 44.3 & 50.4 & 38.0 & 42.4 & 103 & 23 & 10 & 0.72 \\
\hline 5 & 100 & 20 & 75 & 40 & 23 & 60 & 0.34 & 15.66 & 48.2 & 57.0 & 41.0 & 47.2 & 97 & 30 & 18 & 1.06 \\
\hline 5 & 100 & 30 & 75 & 43 & 23 & 64 & 0.76 & 15.97 & 49.6 & 59.4 & 42.1 & 49.1 & 90 & 36 & 25 & 1.35 \\
\hline 6 & 150 & 10 & 75 & 48 & 27 & 75 & 0.08 & 20.92 & 61.2 & 69.5 & 51.3 & 57.2 & 110 & 23 & 11 & 0.73 \\
\hline 4 & 65 & 10 & 25 & 38 & 28 & 46 & 0.08 & 0.66 & 41.3 & 45.4 & 38.4 & 41.5 & 90 & 25 & 11 & 0.73 \\
\hline 4 & 65 & 20 & 25 & 37 & 29 & 44 & 0.34 & 0.50 & 39.8 & 45.2 & 37.5 & 41.6 & 81 & 33 & 19 & 1.08 \\
\hline 4 & 65 & 30 & 25 & 39 & 29 & 47 & 0.76 & 0.58 & 41.8 & 48.9 & 39.0 & 44.5 & 74 & 39 & 26 & 1.38 \\
\hline 5,10 & 100 & 10 & 25 & 40 & 23 & 50 & 0.08 & 12.26 & 42.4 & 47.6 & 36.9 & 40.5 & 102 & 23 & 10 & 0.73 \\
\hline 5,10 & 100 & 20 & 25 & 38 & 23 & 45 & 0.34 & 9.70 & 38.8 & 45.1 & 34.4 & 39.0 & 91 & 31 & 18 & 1.06 \\
\hline 5,10 & 100 & 30 & 25 & 41 & 24 & 45 & 0.76 & 9.64 & 39.6 & 47.2 & 35.3 & 40.8 & 84 & 36 & 25 & 1.35 \\
\hline 6 & 150 & 10 & 25 & 57 & 28 & 79 & 0.08 & 22.23 & 64.0 & 72.4 & 53.4 & 59.3 & 111 & 23 & 11 & 0.75 \\
\hline
\end{tabular}

(1) Obtained from the test data. Input parameters in the analytical model

(2) Represent rotor temperatures at the bearing locations. Estimated from a constant temperature gradient (linear temperature drop) from the recorded rotor FE and DE temperatures $\left(\operatorname{Tr}_{F E}\right.$ and $\left.\operatorname{Tr}_{D E}\right)$.

(3) Operating radial clearance $=$ nominal clearance - shaft centrifugal growth - net shaft-bearing thermal expansion). 
Table M.3 Free end GFB: Predicted bearing static parameters

\begin{tabular}{|c|c|c|c|c|c|c|c|c|c|c|c|c|c|c|c|c|}
\hline $\begin{array}{c}\text { Test } \\
\text { Case } \\
\#\end{array}$ & {$\left[\begin{array}{l}T_{h s} \\
{\left[{ }^{\circ} \mathrm{C}\right]}\end{array}\right]$} & $\begin{array}{l}\text { Rotor } \\
\text { speed } \\
{[\mathrm{krpm}]}\end{array}$ & $\begin{array}{c}\text { Cooling } \\
\text { flow } \\
\text { rate } \\
\text { (per } \\
\text { bearing) } \\
{[\mathrm{L} / \mathrm{min}]}\end{array}$ & $\begin{array}{c}\text { Cooling } \\
\text { flow } \\
\text { Temp } \\
\text {-erature } \\
T_{C o} \\
=T_{e} \\
{\left[{ }^{\circ} \mathrm{C}\right]^{(1)}}\end{array}$ & $\begin{array}{l}T_{a m b} \\
{\left[{ }^{\circ} \mathrm{C}\right]} \\
(1)\end{array}$ & $\begin{array}{c}\text { Rotor } \\
\mathrm{OD} \\
{\left[{ }^{\circ} \mathrm{C}\right]} \\
(1)(2)\end{array}$ & $\begin{array}{c}\text { Shaft } \\
\text { centri } \\
\text {-fugal } \\
\text { growth } \\
\underset{(3)}{[\mu \mathrm{m}]}\end{array}$ & $\begin{array}{c}\text { Net } \\
\text { Shaft } \\
\text {-bearing } \\
\text { thermal } \\
\text { expan } \\
\text {-sion }[\mu \mathrm{m}] \\
(3)\end{array}$ & $\begin{array}{c}\text { Axially } \\
\text { averaged } \\
\text { gas } \\
\text { film } \\
\text { temp- } \\
\text { erature } \\
{\left[{ }^{\circ} \mathrm{C}\right]}\end{array}$ & \begin{tabular}{|c} 
Peak \\
gas \\
film \\
temp- \\
erature \\
{$\left[{ }^{\circ} \mathrm{C}\right]$}
\end{tabular} & $\begin{array}{c}\text { Axially } \\
\text { averaged } \\
\text { bearing } \\
\text { sleeve } \\
\text { ID } \\
\text { temp- } \\
\text { erature } \\
{\left[{ }^{\circ} \mathrm{C}\right]} \\
\end{array}$ & $\begin{array}{c}\text { Peak } \\
\text { bearing } \\
\text { sleeve } \\
\text { ID } \\
\text { temp- } \\
\text { erature } \\
{\left[{ }^{\circ} \mathrm{C}\right]}\end{array}$ & $\left|\begin{array}{c}\text { Eccent } \\
\text {-ricity } \\
{[\mu \mathrm{m}]}\end{array}\right|$ & $\begin{array}{c}\text { Attitude } \\
\text { angle } \\
{\left[{ }^{\circ}\right]}\end{array}$ & $\left|\begin{array}{c}\text { Mini- } \\
\text { mum } \\
\text { film } \\
\text { Thick } \\
\text {-ness } \\
{[\mu \mathrm{m}]}\end{array}\right|$ & $\begin{array}{c}\text { Drag } \\
\text { torque } \\
{[\mathrm{N}} \\
-\mathrm{mm}]\end{array}$ \\
\hline 7 & Off & 10 & 175 & 25 & 23 & 33 & 0.08 & 1.70 & 28.8 & 31.3 & 25.6 & 26.8 & 89 & 27 & 12 & 0.66 \\
\hline 7 & Off & 20 & 175 & 25 & 23 & 33 & 0.34 & 1.58 & 28.5 & 32.4 & 25.5 & 27.2 & 80 & 36 & 22 & 0.98 \\
\hline 7 & Off & 30 & 175 & 25 & 23 & 33 & 0.76 & 1.48 & 28.3 & 33.2 & 25.4 & 27.6 & 72 & 41 & 29 & 1.25 \\
\hline 4,8 & 65 & 10 & 175 & 30 & 29 & 56 & 0.08 & 4.55 & 44.1 & 49.1 & 35.8 & 38.1 & 92 & 27 & 13 & 0.67 \\
\hline 4,8 & 65 & 20 & 175 & 32 & 29 & 63 & 0.34 & 5.03 & 46.6 & 53.1 & 37.0 & 40.0 & 82 & 36 & 23 & 0.98 \\
\hline 4,8 & 65 & 30 & 175 & 36 & 28 & 67 & 0.76 & 5.14 & 47.3 & 54.5 & 37.1 & 40.5 & 74 & 41 & 31 & \begin{tabular}{|l|}
1.26 \\
\end{tabular} \\
\hline 5,9 & 100 & 10 & 175 & 28 & 22 & 65 & 0.08 & 7.36 & 47.0 & 54.0 & 33.6 & 36.7 & 94 & 27 & 13 & 0.67 \\
\hline 5,9 & 100 & 20 & 175 & 33 & 23 & 74 & 0.34 & 7.85 & 50.2 & 58.5 & 35.4 & 39.3 & 85 & 35 & 23 & \begin{tabular}{|l|}
0.98 \\
\end{tabular} \\
\hline 5,9 & 100 & 30 & 175 & 33 & 23 & 80 & 0.76 & 7.39 & 50.7 & 59.7 & 35.7 & 39.9 & 76 & 41 & 31 & 1.26 \\
\hline 6 & 150 & 10 & 175 & 37 & 26 & 98 & 0.08 & 12.90 & 67.9 & 78.7 & 45.5 & 50.6 & 99 & 27 & 14 & \begin{tabular}{|l|}
0.67 \\
\end{tabular} \\
\hline 4 & 65 & 10 & 125 & 31 & 29 & 57 & 0.08 & 11.96 & 48.0 & 53.9 & 42.7 & 47.0 & 99 & 26 & 13 & 0.67 \\
\hline 4 & 65 & 20 & 125 & 34 & 29 & 63 & 0.34 & 12.76 & 49.9 & 57.2 & 44.0 & 49.3 & 90 & 34 & 22 & 0.98 \\
\hline 4 & 65 & 30 & 125 & 38 & 28 & 69 & 0.76 & 13.64 & 51.5 & 59.8 & 45.0 & 51.0 & 83 & 40 & 30 & 1.24 \\
\hline 5 & 100 & 10 & 125 & 31 & 22 & 67 & 0.08 & 19.23 & 53.3 & 61.7 & 44.5 & 50.5 & 107 & 25 & 12 & \begin{tabular}{|l|}
0.66 \\
\end{tabular} \\
\hline 5 & 100 & 20 & 125 & 35 & 23 & 75 & 0.34 & 19.92 & 55.9 & 65.8 & 46.5 & 53.6 & 98 & 33 & 22 & 0.98 \\
\hline 5 & 100 & 30 & 125 & 40 & 23 & 85 & 0.76 & 20.87 & 58.7 & 69.2 & 48.4 & 56.0 & 90 & 38 & 30 & 1.24 \\
\hline 6 & 150 & 10 & 125 & 42 & 27 & 103 & 0.08 & 32.19 & 79.5 & 92.7 & 64.0 & 73.3 & 119 & 24 & 13 & 0.67 \\
\hline 4 & 65 & 10 & 75 & 34 & 28 & 60 & 0.08 & 13.44 & 49.9 & 56.0 & 43.8 & 48.3 & 101 & 26 & 13 & 0.66 \\
\hline 4 & 65 & 20 & 75 & 38 & 28 & 66 & 0.34 & 14.53 & 52.2 & 59.9 & 45.5 & 51.0 & 92 & 34 & 22 & 0.98 \\
\hline 4 & 65 & 30 & 75 & 36 & 28 & 58 & 0.76 & 10.38 & 45.7 & 52.9 & 40.9 & 46.1 & 80 & 40 & 30 & 1.25 \\
\hline 5 & 100 & 10 & 75 & 34 & 22 & 70 & 0.08 & 20.64 & 55.7 & 64.3 & 46.1 & 52.2 & 108 & 25 & 12 & 0.67 \\
\hline 5 & 100 & 20 & 75 & 40 & 23 & 80 & 0.34 & 22.23 & 59.7 & 70.2 & 49.1 & 56.6 & 100 & 33 & 22 & 0.98 \\
\hline 5 & 100 & 30 & 75 & 43 & 23 & 83 & 0.76 & 20.94 & 59.0 & 69.4 & 48.7 & 56.2 & 90 & 38 & 30 & 1.24 \\
\hline 6 & 150 & 10 & 75 & 48 & 27 & 106 & 0.08 & 33.41 & 82.2 & 95.4 & 65.9 & 75.2 & 121 & 24 & 13 & 0.67 \\
\hline 4 & 65 & 10 & 25 & 38 & 28 & 59 & 0.08 & 13.26 & 49.6 & 55.3 & 43.6 & 47.7 & 101 & 26 & 13 & 0.67 \\
\hline 4 & 65 & 20 & 25 & 37 & 29 & 53 & 0.34 & 9.50 & 44.8 & 50.6 & 40.5 & 44.8 & 87 & 35 & 22 & 0.98 \\
\hline 4 & 65 & 30 & 25 & 39 & 29 & 56 & 0.76 & 10.04 & 46.0 & 52.8 & 41.4 & 46.3 & 79 & 40 & 30 & 1.25 \\
\hline 5,10 & 100 & 10 & 25 & 40 & 23 & 66 & 0.08 & 18.67 & 53.0 & 60.4 & 44.3 & 49.6 & 106 & 25 & 12 & 0.66 \\
\hline 5,10 & 100 & 20 & 25 & 38 & 23 & 57 & 0.34 & 13.78 & 45.8 & 52.8 & 39.4 & 44.5 & 92 & 34 & 22 & 0.97 \\
\hline 5,10 & 100 & 30 & 25 & 41 & 24 & 56 & 0.76 & 12.81 & 45.3 & 52.9 & 39.4 & 44.8 & 83 & 39 & 30 & 1.24 \\
\hline 6 & 150 & 10 & 25 & 57 & 28 & 110 & 0.08 & 34.89 & 85.5 & 98.8 & 68.2 & 77.5 & 119 & 24 & 13 & 0.67 \\
\hline
\end{tabular}

(1) Obtained from the test data. Input parameters in the analytical model

(2) Represent rotor temperatures at the bearing locations. Estimated from a constant temperature gradient (linear temperature drop) from the recorded rotor FE and DE temperatures $\left(\operatorname{Tr}_{F E}\right.$ and $\left.\operatorname{Tr}_{D E}\right)$.

(3) Operating radial clearance $=$ nominal clearance - shaft centrifugal growth - net shaft-bearing thermal expansion. 


\section{APPENDIX N}

PREDICTED TEMPERATURE FIELDS: TEST CASE \#5. 10 KRPM

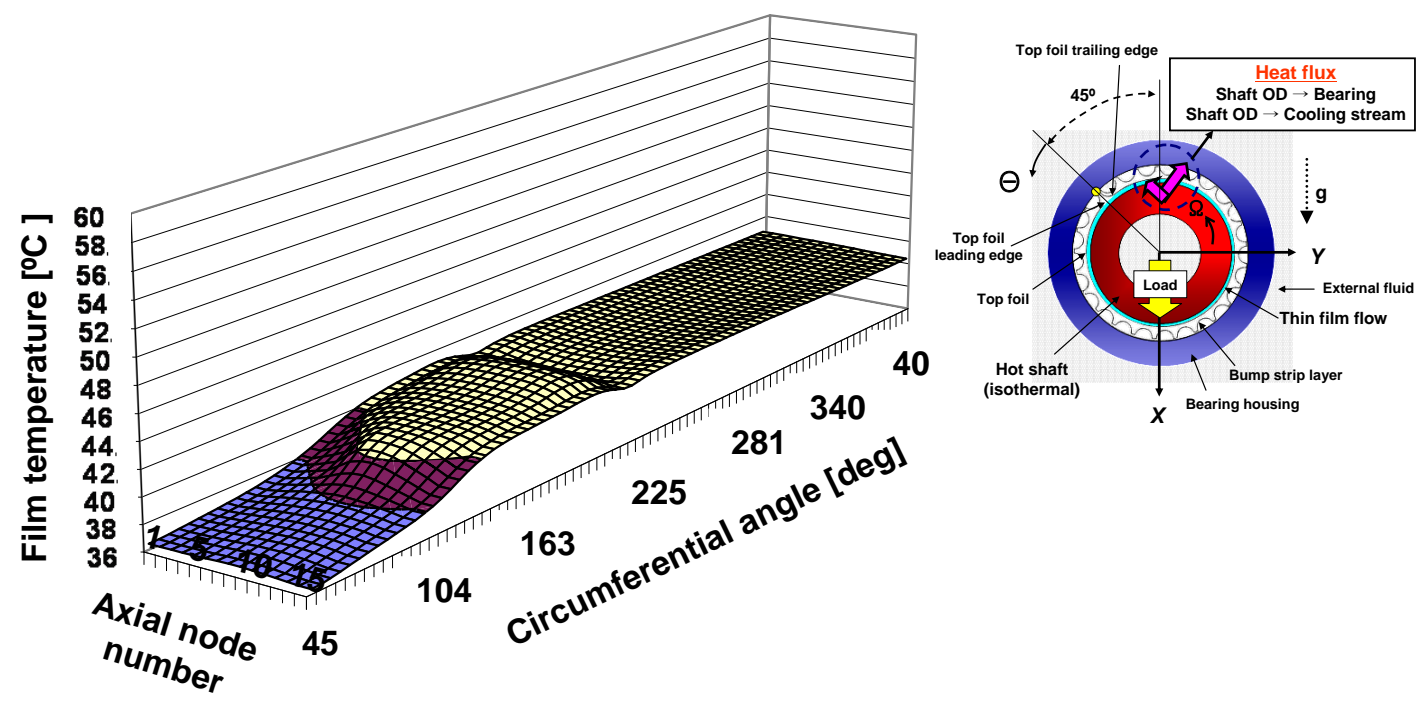

(a) Drive end bearing

(Cooling stream inlet temperature $=28^{\circ} \mathrm{C}$, uniform rotor $\mathrm{OD}$ temperature $=49^{\circ} \mathrm{C}, T_{a}=22^{\circ} \mathrm{C}$ )

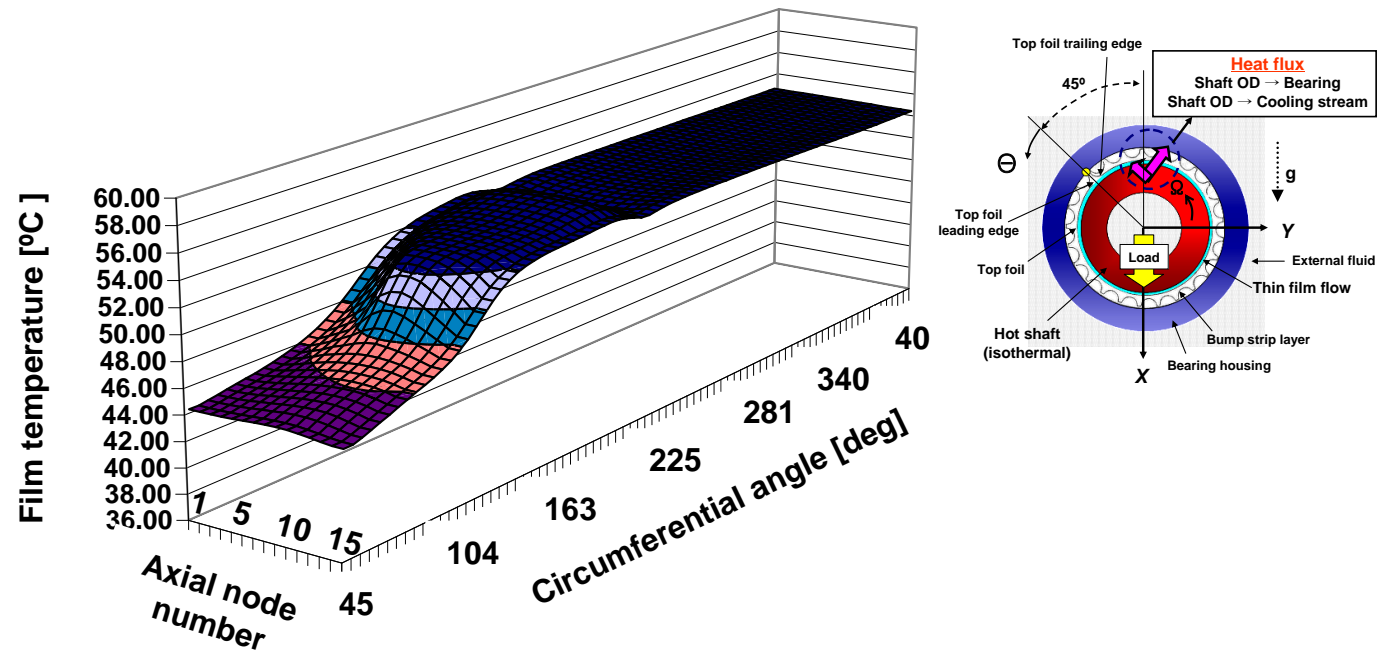

(b) Free end bearing

(Cooling stream inlet temperature $=28^{\circ} \mathrm{C}$, uniform rotor $\mathrm{OD}$ temperature $=65^{\circ} \mathrm{C}, T_{a}=22^{\circ} \mathrm{C}$ )

Fig. N.1 Prediction: Test case \#5. Thin film temperature fields in GFBs. $T_{h s}=100^{\circ} \mathrm{C}$, rotor speed at $10 \mathrm{krpm}$. Cooling flow rate per each bearing $175 \mathrm{~L} / \mathrm{min}$. Thermal mixing coefficient $\lambda=0.65$. 


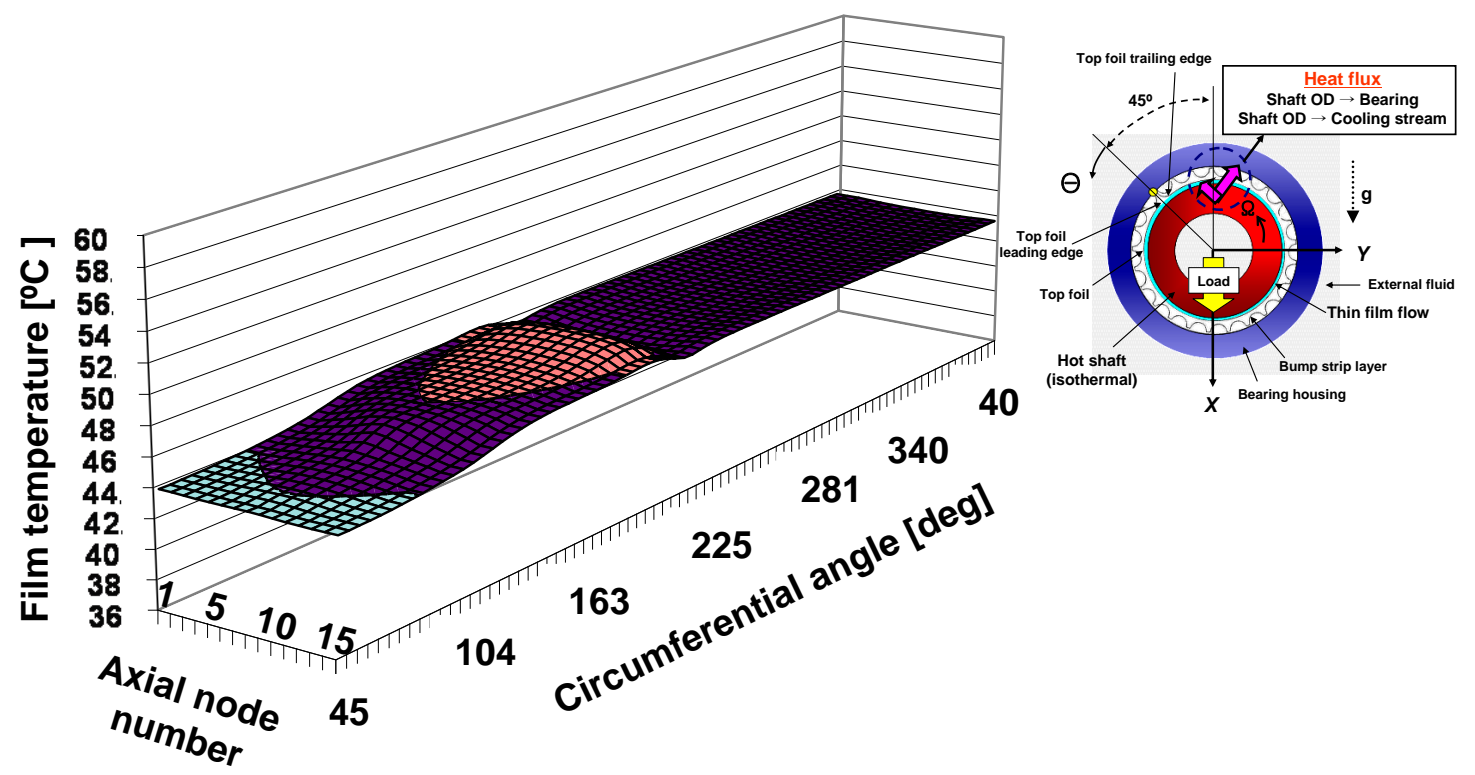

(a) Drive end bearing

(Cooling stream inlet temperature $=40^{\circ} \mathrm{C}$, uniform rotor $\mathrm{OD}$ temperature $=50^{\circ} \mathrm{C}, T_{a}=23^{\circ} \mathrm{C}$ )

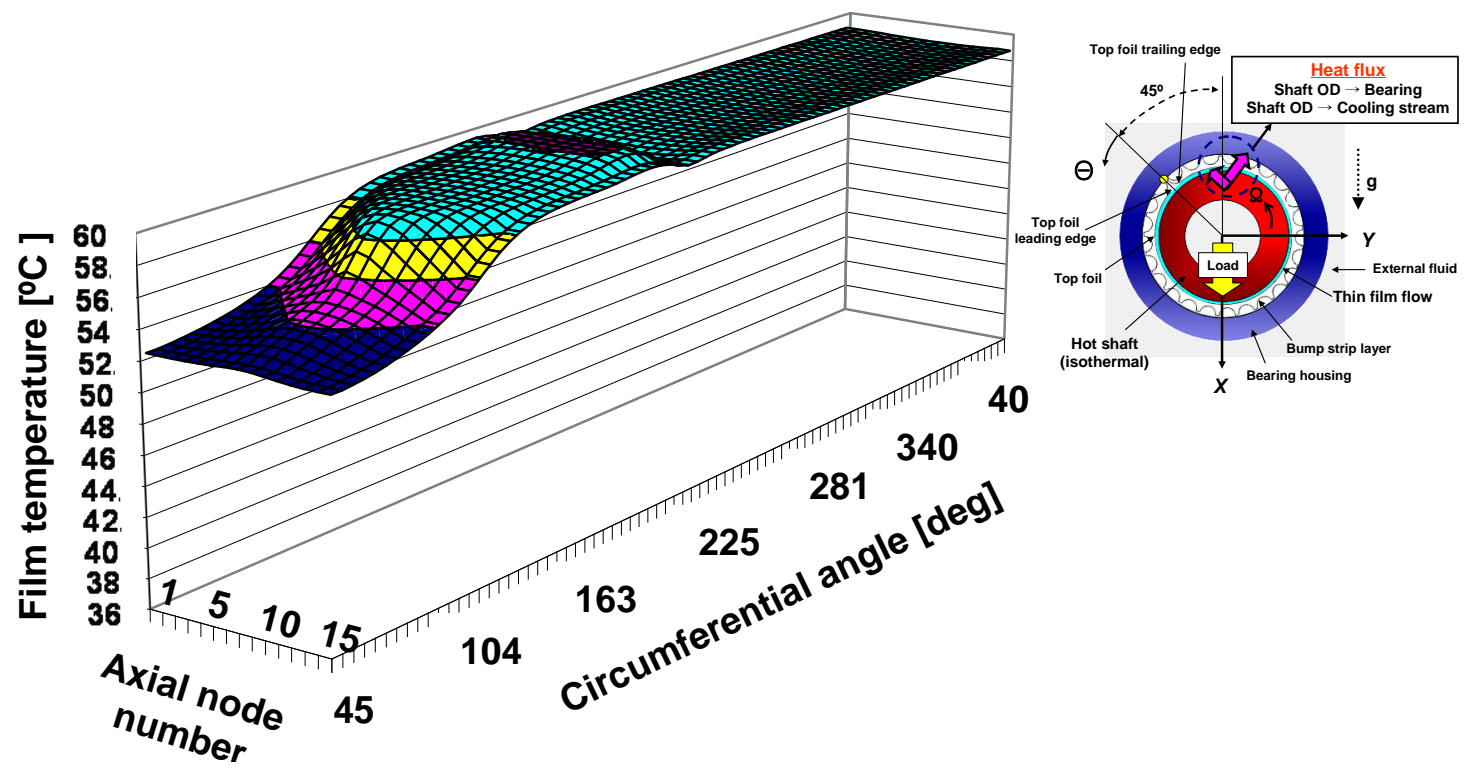

(b) Free end bearing

(Cooling stream inlet temperature $=40^{\circ} \mathrm{C}$, uniform rotor $\mathrm{OD}$ temperature $=66^{\circ} \mathrm{C}, T_{a}=23^{\circ} \mathrm{C}$ )

Fig. N.2 Prediction: Test case \#5. Thin film temperature fields in GFBs. $T_{h s}=100^{\circ} \mathrm{C}$, rotor speed at $10 \mathrm{krpm}$. Cooling flow rate per each bearing $25 \mathrm{~L} / \mathrm{min}$. Thermal mixing coefficient $\lambda=0.65$. 


\section{APPENDIX O \\ PREDICTED STIFFNESS AND DAMPING COEFFICIENTS:}

TEST CASES \#4 AND \#6

Figures 0.1 through 0.3 depict the predicted force coefficients calculated at synchronous frequency for test cases \#4 and \#6.

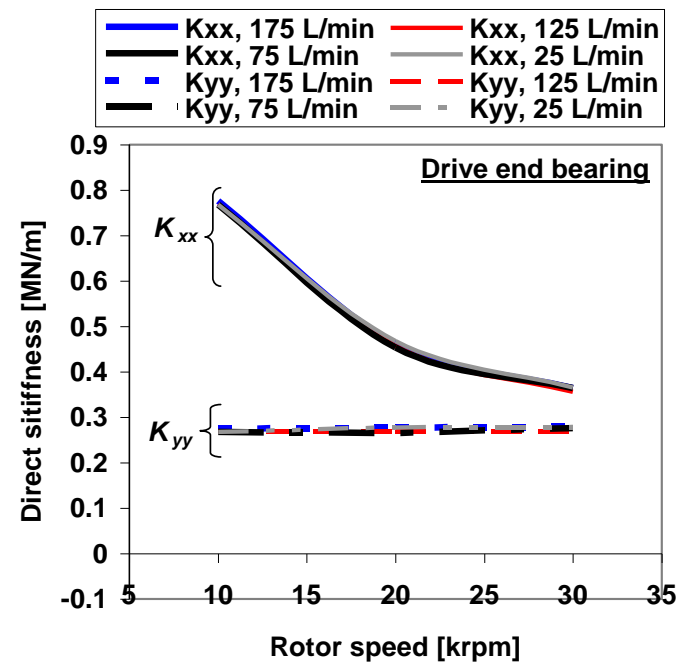

(a) Direct stiffness. Drive end bearing

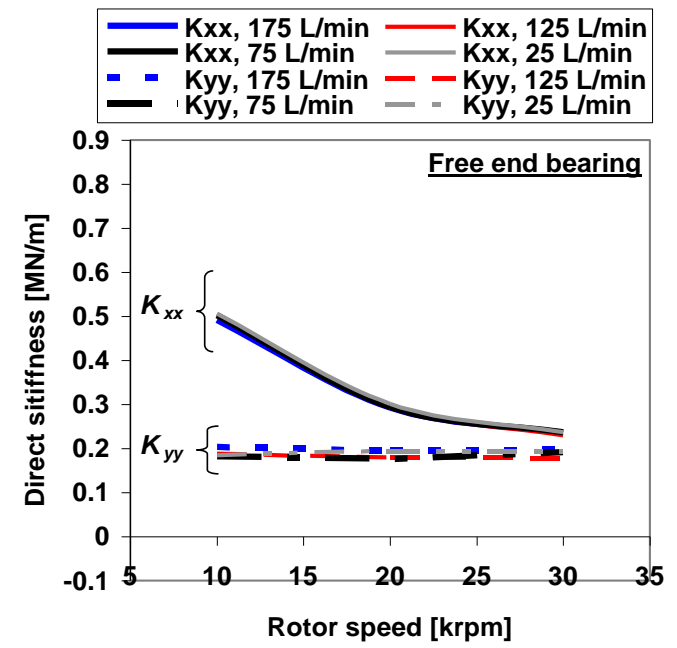

(c) Direct stiffness. Free end bearing

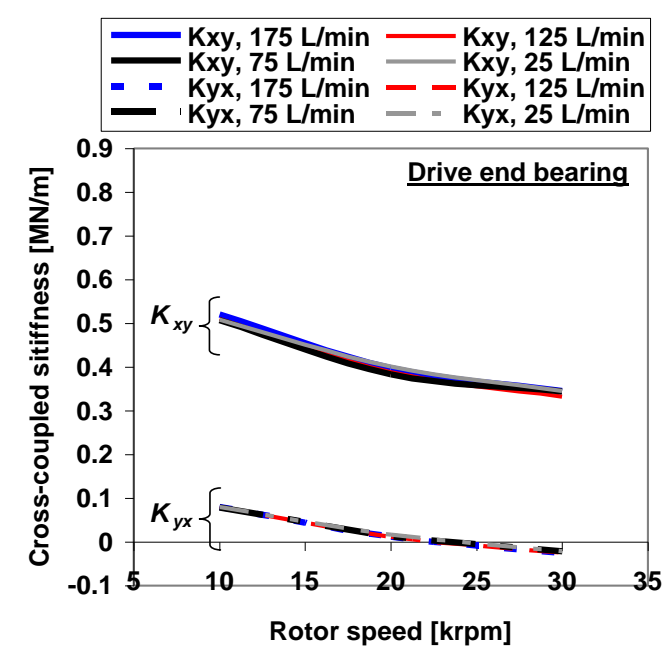

(b) Cross-coupled stiffness: Drive end bearing

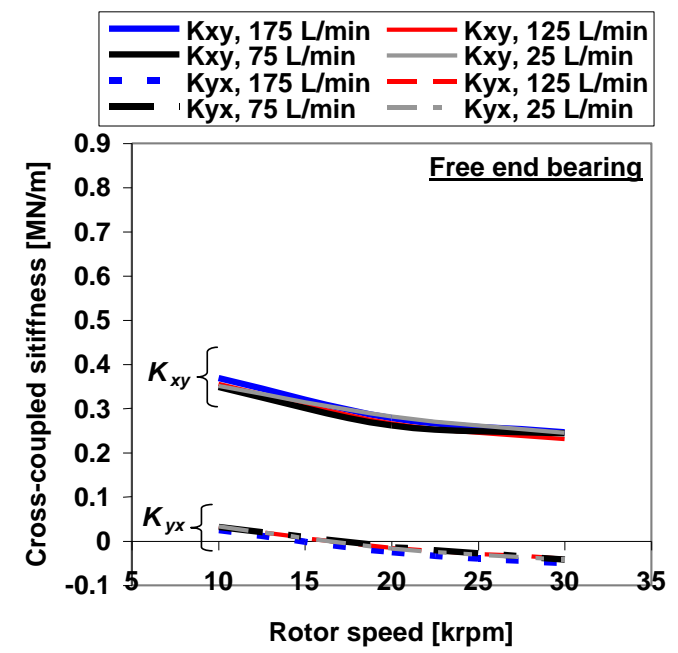

(d) Cross-coupled stiffness: Free end bearing

Fig. 0.1 Prediction: Test case \#4. $T_{h s}=65^{\circ} \mathrm{C}$. Drive end and free end foil bearing direct and cross-coupled stiffness versus rotor speed and increasing air cooling flow rates. 


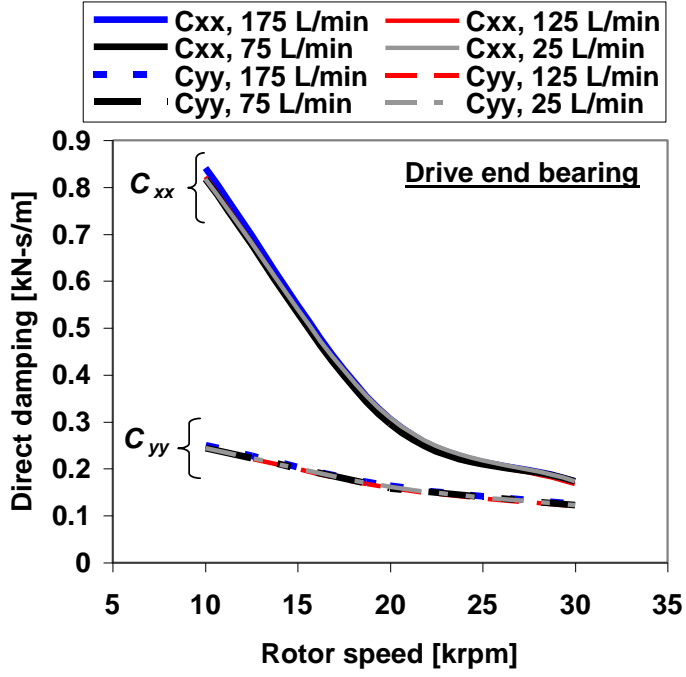

(a) Direct damping. Drive end bearing

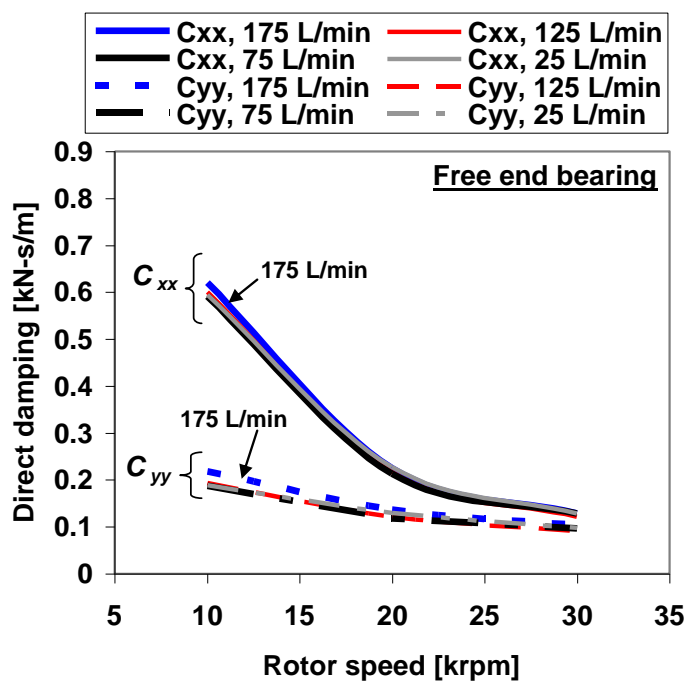

(c) Direct damping. Free end bearing

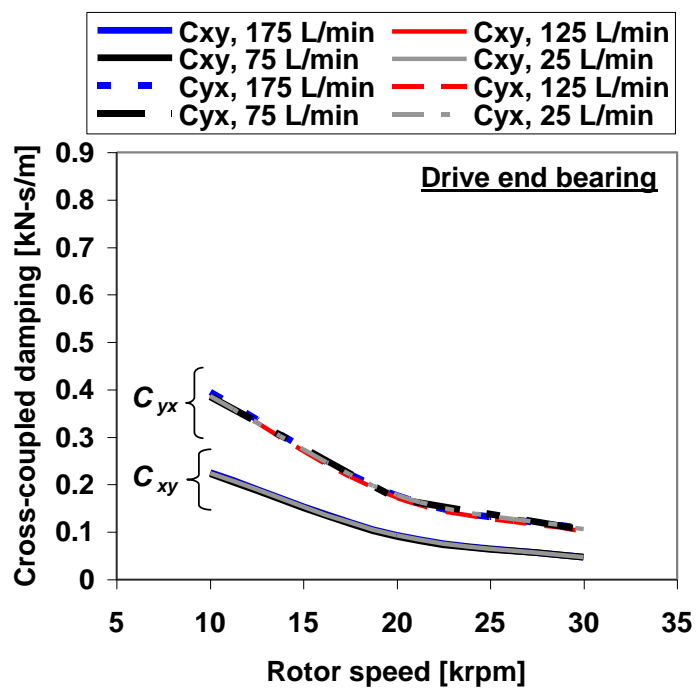

(b) Cross-coupled damping: Drive end bearing

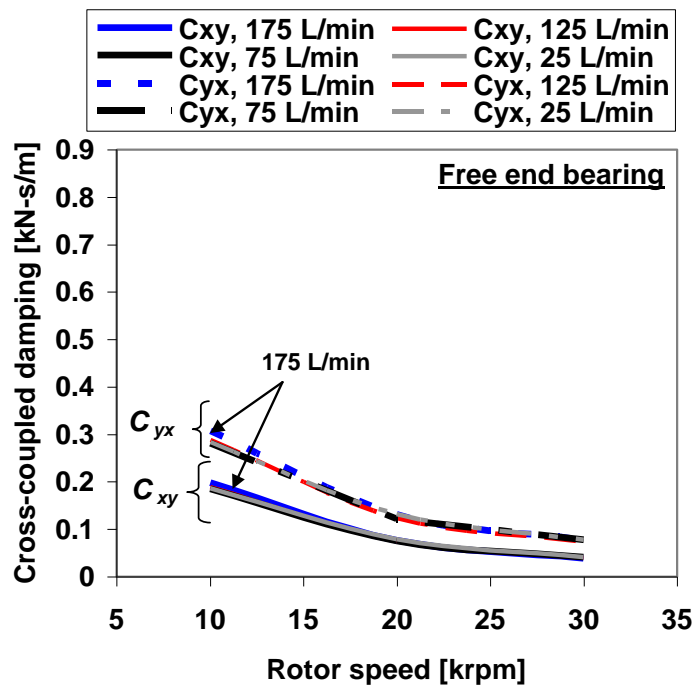

(d) Cross-coupled damping: Free end bearing

Fig. 0.2 Prediction: Test case \#4. $T_{h s}=65^{\circ} \mathrm{C}$ Drive end and free end foil bearing direct and cross-coupled damping coefficients versus rotor speed and increasing air cooling flow rates. 


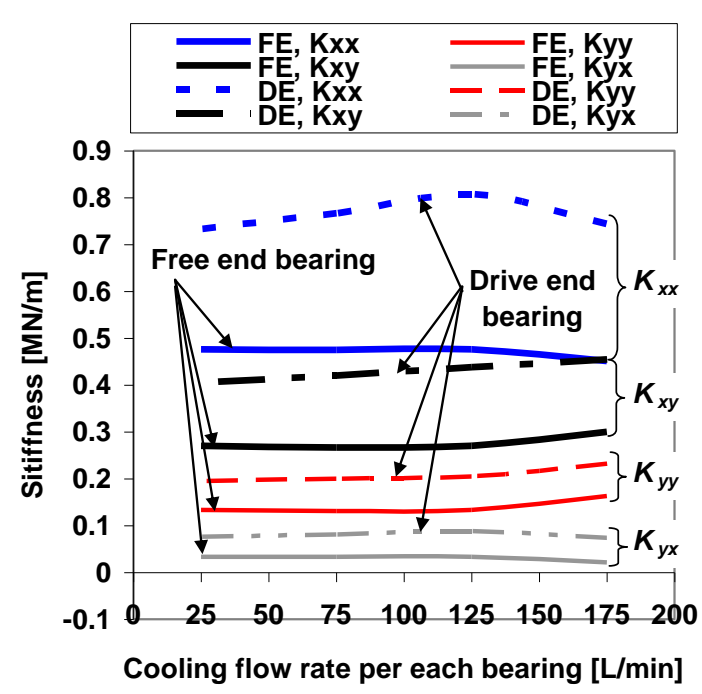

(a) Direct and cross-coupled stiffness

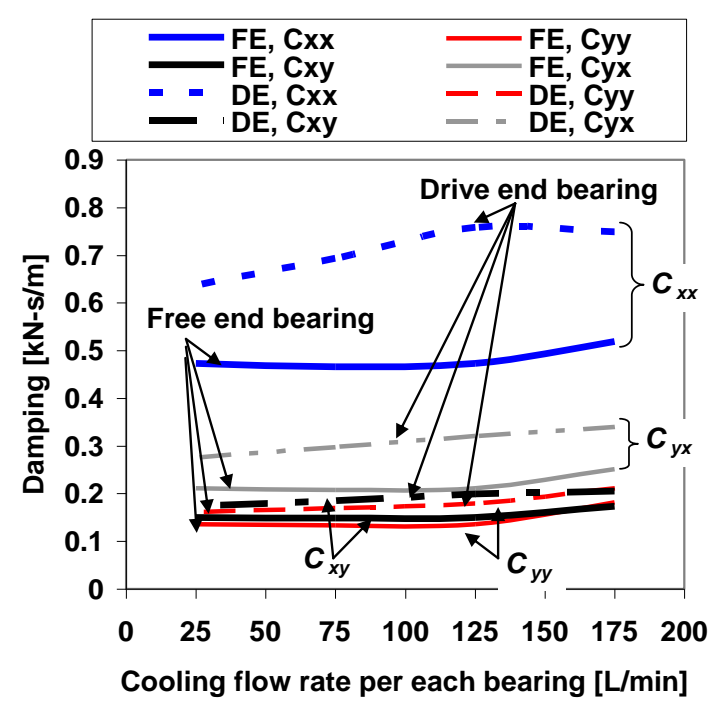

(b) Direct and cross-coupled damping

Fig. 0.3 Prediction: Test case \#6. $T_{h s}=150^{\circ} \mathrm{C}$. Drive end and free end foil bearing force coefficients versus air cooling flow rates for rotor speed $=10 \mathrm{krpm}$. 
VITA

Keun Ryu is a Senior Development Engineer in the Basic Development Team within Global Commercial Diesel Product Development at BorgWarner Turbo Systems in Asheville, NC. He received B.S. (2003) and M.S. (2005) degrees (Mechanical Engineering) from Hanyang University in Seoul, Korea as well as M.S (2007) and Ph.D (2011) degrees (Mechanical Engineering) from Texas A\&M University. He worked for two years (2003-2004) as a Graduated Studying Fellow at the Korea Institute of Science and Technology (KIST). He joined the Turbomachinery Laboratory at Texas A\&M University in 2005 and worked for five years (2005-2010) as a Graduate Research Assistant. Presently, at BorgWarner Turbo Systems, he focuses on the development of bearing and sealing system components with emphasis on oil-free bearing technology.

Keun Ryu has presented and published more than twenty technical papers and reports on gas bearings and rotordynamics. He also holds several patents for foil bearings and a micro gas turbine system. Since 2007, he has served the ASME Turbo Expo conference as a reviewer and technical session organizer/chair/co-chair. Presently, he is an invited technical paper reviewer for ASME Journal of Tribology, Elsevier Tribology International, and STLE Tribology Transactions.

Keun Ryu may be reached at BorgWarner Turbo Systems, 1849 Brevard Road, Arden, NC 28704. His email is keun.ryu@gmail.com. 